\title{
Techno-economic and Environmental Analysis of Bio-oil Production from Forest Residues via Non-catalytic and Catalytic Pyrolysis Processes
}

\author{
by \\ Dominique Lisa van Schalkwyk \\ Thesis presented in partial fulfilment \\ of the requirements for the Degree \\ of \\ MASTER OF ENGINEERING \\ (CHEMICAL ENGINEERING) \\ in the Faculty of Engineering \\ at Stellenbosch University
}

The financial assistance of the National Research Foundation (NRF) towards this research is hereby acknowledged. Opinions expressed and conclusions arrived at, are those of the author and are not necessarily to be attributed to the NRF.

Supervisor

Prof. Johann F. Görgens

Co-Supervisor

Dr. Mohsen Mandegari

December 2019 


\section{Declaration}

By submitting this thesis electronically, I declare that the entirety of the work contained therein is my own, original work, that I am the sole author thereof (save to the extent explicitly otherwise stated), that reproduction and publication thereof by Stellenbosch University will not infringe any third party rights and that I have not previously in its entirety or in part submitted it for obtaining any qualification.

Date: December 2019

Copyright (C) December 2019 Stellenbosch University

All rights reserved 


\section{Plagiarism Declaration}

1. Plagiarism is the use of ideas, material and other intellectual property of another's work and to present is as my own.

2. I agree that plagiarism is a punishable offence because it constitutes theft.

3. I also understand that direct translations are plagiarism.

4. Accordingly all quotations and contributions from any source whatsoever (including the internet) have been cited fully. I understand that the reproduction of text without quotation marks (even when the source is cited) is plagiarism.

5. I declare that the work contained in this assignment, except where otherwise stated, is my original work and that I have not previously (in its entirety or in part) submitted it for grading in this module/assignment or another module/assignment.

Student number:

Initials and surname: $\quad$ DL van Schalkwyk

Signature:

Date:

14 November 2019 


\section{Abstract}

Forest residues are a high fire risk and often disposed of by burning or sold as firewood; both contribute to air pollution, and the latter has low economic value. The 1.5 million dry metric tonnes of forest residues available in South Africa every year can instead be converted into liquid bio-oil and solid biochar through intermediate pyrolysis. However, bio-oil is acidic and has a low energy value as a result of its high oxygen content. Bio-oil can be upgraded to improve its oxygen content by introducing a $\mathrm{CaO}$ catalyst in situ to the pyrolysis process. Upgraded bio-oil can then be co-processed in a crude-oil refinery to produce bio-derived fuels. Therefore, the aim of this project was to determine whether or not the production of crude and upgraded bio-oils via non-catalytic and catalytic pyrolysis of forest residues for co-processing in an oil refinery is economically and environmentally feasible.

Process simulations were developed in Aspen Plus ${ }^{\mathrm{TM}}$ based on pilot plant data for non-catalytic and catalytic pyrolysis processes. All of the non-condensable gas and 21.5 wt. \% of the char (for non-catalytic pyrolysis biorefinery scenarios only) were combusted to meet the energy demands of the biorefinery scenarios. The net yield of non-catalytic pyrolysis products from Eucalyptus grandis forest residues (8.28 wt. \% moisture) was $22.6 \mathrm{wt}$. \% biochar and $19.8 \mathrm{wt}$. \% crude bio-oil, while the net yield of catalytic pyrolysis products was $16.5 \mathrm{wt}$ \% biochar and $18.4 \mathrm{wt}$ \% upgraded bio-oil.

There was a clear economy-of-scale benefit for non-catalytic and catalytic pyrolysis biorefinery scenarios as the biomass collection distance increased from a 100 to $300 \mathrm{~km}$ radius of the biorefinery. The Minimum Selling Price (MSP) of upgraded bio-oil (\$1.35/L) was significantly higher than the MSP of crude bio-oil $(\$ 0.75 / L)$ for a desired $22 \%$ Internal Rate of Return (IRR) at a $300 \mathrm{~km}$ radius of the biorefinery. However, the quality of upgraded bio-oil was superior to crude bio-oil for co-processing in an oil refinery. Co-processing crude bio-oil will likely produce bio-derived fuels with a significantly lower renewable carbon content and higher yield of undesirable $\mathrm{CO}, \mathrm{CO}_{2}$ and $\mathrm{H}_{2} \mathrm{O}$ gases.

The price premium for crude and upgraded bio-oils was substantiated by a significant environmental benefit. A Life Cycle Impact Assessment ( $L C I A)$ was conducted using the CML-IA baseline method in SimaPro ${ }^{\mathrm{TM}}$ to assess the environmental impact of producing $1 \mathrm{MJ}$ of crude or upgraded bio-oil, instead of crude-oil or diesel. The net Global Warming Potentials (GWPs) for crude bio-oil, upgraded bio-oil, crude-oil and diesel were $-0.30,-0.14,0.0052$ and $0.013 \mathrm{~kg} \mathrm{CO}$ eq/MJ of fuel, respectively. Biochar application to soils had a substantial influence on the GWP of bio-oil production through associated carbon sequestration.

Co-processing crude and upgraded bio-oils at pilot-scale was recommended to evaluate the relationship between blending ratio, distribution of oil refinery products and extent of deoxygenation reactions. Furthermore, the scope of this project should be expanded to include a techno-economic analysis for co-processing crude and upgraded bio-oils to further evaluate the economic feasibility of crude and upgraded bio-oil production. 


\section{Opsomming}

Bosbou residu is ' $n$ hoë brandrisiko en word dikwels weggemaak deur verbranding of te verkoop as vuurmaakhout; al twee dra by tot lugbesoedeling, en die laasgenoemde het lae ekonomiese waarde. Die 1.5 miljoen droë metrieke ton bosbou residu beskikbaar in Suid-Afrika elke jaar kan eerder omgeskakel word in vloeistof bio-olie en vastestof bioverkoolsel deur intermediêre pirolise. Bio-olie is egter suurvormend en het ' $n$ lae energiewaarde as gevolg van sy hoë suurstofinhoud. Bio-olie kan opgegradeer word om sy suurstofinhoud te verbeter deur'n CaO-katalisator in situ in die pirolise proses bekend te stel. Opgegradeerde bio-olie kan dan gekoprosesseer word in ' $n$ ru-olieraffinadery om bio-afgeleide brandstowwe te produseer. Daarom is die doel van hierdie projek om vas te stel of die produksie van ru- en opgegradeerde bio-olies via nie-katalitiese en katalitiese pirolise van bosbou residu vir koprosessering in'n olieraffinadery uitvoerbaar is vir die ekonomie en omgewing, of nie.

Prosessimulasies is ontwikkel in Aspen Plus ${ }^{\mathrm{TM}}$ gebaseer op loodsaanlegdata vir nie-katalitiese en katalitiese pirolise prosesse. Al die nie-kondenseerbare gasse en $21.5 \mathrm{wt}$. \% van die verkoolsel (slegs vir nie-katalitiese pirolise bioraffindery scenario's) is verbrand om aan die energievereistes van die bioraffinadery scenario's te voldoen. Die netto waarde van nie-katalitiese piroliese produkte uit Eucalyptus grandis bosbou residu (8.28 wt. \% vog) was 22.6 wt. \% bioverkoolsel en 19.8 wt. \% ru bio-olie, terwyl die netto opbrengs van katalitiese piroliese produkte $16.5 \mathrm{wt}$. \% bioverkoolsel en 18.4 wt. \% opgegradeerde bio-olie was.

Daar was 'n duidelike ekonomie-van-skaal-voordeel vir nie-katalitiese en katalitiese pirolise bioraffinadery scenario's soos wat die afstand van die biomassa versameling vergroot het van 100 tot $300 \mathrm{~km}$ radius van die bioraffinadery. Die Minimum Verkoopsprys (MSP) van opgegradeerde olie $(\$ 1.35 / L)$ was beduidend hoër as die MSP van ru bio-olie (\$0.75/L) vir ' $n$ verlangde $22 \%$ Interne Opbrengskoers (IRR) by 'n $300 \mathrm{~km}$ radius van die bioraffinadery. Die kwaliteit van opgegradeerde bio-olie was egter superieur teenoor ru bio-olie vir koprosessering in' $n$ olieraffinadery. Koprosessering van ru bio-olie sal waarskynlik bio-afgeleide brandstowwe met ' $n$ beduidende laer hernubare koolstofinhoud en hoër opbrengs van ongewensde $\mathrm{CO}, \mathrm{CO}_{2}$ en $\mathrm{H}_{2} \mathrm{O}$ produseer.

Die prys premie vir ru en opgegradeerde bio-olies is bevestig deur beduidende omgewingsvoordeel. ' $n$ Lewensiklusimpakassessering is gedoen deur die CML-IA basislyn metode in SimaPro ${ }^{\mathrm{TM}}$ te gebruik om die omgewingsimpak van die produsering van $1 \mathrm{MJ}$ van ru of opgegradeerde bio-olie, in plaas van ru-olie of diesel, te assesseer. Die netto Globale Verwarmingspotensiaal vir ru bio-olie, opgegradeerde bio-olie, ru-olie en diesel was $-0.30,-0.14,0.0052$ en $0.013 \mathrm{~kg} \mathrm{CO}_{2}$ eq/MJ van brandstof, onderskeidelik. Toepassing van bioverkoolsel op grond het ' $n$ substansiële invloed op die Globale Verwarmingspotensiaal van bio-olie produksie deur verwante koolstof sekwestrasie.

Koprosessering van ru en opgegradeerde bio-olies op loodsskaal is aanbeveel om die verhouding tussen vermengverhouding, distribusie van olieraffinadery produkte en omvang van 
reaksies van deoksigenering te evalueer. Verder moet die omvang van hierdie projek verbreed word om 'n tegno-ekonomiese analise vir koprosessering van ru en opgegradeerde bio-olies in te sluit om die ekonomiese uitvoerbaarheid van ru en opgegradeerde bio-olie produksie te evalueer. 


\section{Acknowledgements}

I acknowledge and am grateful to the Paper Manufacturers Association of South Africa (PAMSA), the Department of Science and Technology (DST) and the National Research Foundation (NRF) for financially supporting this project.

To my supervisor, Prof Görgens. Thank you for giving me the opportunity to be a part of this project and a leading Bioresource Technology research group; for your guidance throughout the project; and for your meaningful feedback on this thesis.

To my co-supervisor, Dr Mandegari. Thank you, Mohsen, for your patience, guidance and encouragement; for reading, reviewing and commenting on my work throughout the project; and for sparking ideas that helped me deepen the discussions in this thesis.

I also wish to acknowledge and thank, Dr Farzad for offering her time and expertise to help me develop the Life-Cycle Assessments for this project.

Thank you to my friends and colleagues at the department for their many words of encouragement and advice. I wish to specially thank Farai Chireshe for his perseverance in generating the pilot plant data for this thesis.

I wish to acknowledge and thank, Rachel for kindly driving me to and from the department every day.

Thank you, Irma and lain for welcoming me into your home; for your support and encouragement; and for the many "kospakkies" that sustained me during this project.

I am forever grateful to have parents that never let me use my vision impairment as an excuse not to set ambitious goals and achieve them. Thank you from the bottom of my heart, Mom (Enid) and Dad (Raymond) for the many sacrifices you both have made to build the foundations that brought me to this point.

To my dear husband, Helgard. I cannot thank you enough for being on this journey with me; for listening to me endlessly talk about pyrolysis and never complaining; for staying up with me while I worked until late at night; for your unfailing belief in me; and for your love. Your support in so many ways has carried me through this project. 


\section{List of Acronyms and Abbreviations}

\begin{tabular}{|c|c|}
\hline ADP: & Abiotic Depletion \\
\hline AP: & Acidification \\
\hline BFP: & Basic Fuel Price \\
\hline BFW: & Boiler Feed Water \\
\hline bpd: & barrels per day \\
\hline C-10: & catalytic pyrolysis scenario - capacity required to co-process $10 \mathrm{wt}$ \% bio-oil \\
\hline C-100: & catalytic pyrolysis scenario - biomass collection within $100 \mathrm{~km}$ radius \\
\hline C-200: & catalytic pyrolysis scenario - biomass collection within $200 \mathrm{~km}$ radius \\
\hline C-300: & catalytic pyrolysis scenario - biomass collection within 300 km radius \\
\hline C1-C4: & Condensers 1 to 4 in condenser train \\
\hline C2A: & Aqueous fraction of bio-oil produced from C2 \\
\hline C2O: & Organic fraction of bio-oil produced from C2 \\
\hline CEPCI: & Chemical Engineering Plant Cost Index \\
\hline COD: & Chemical Oxygen Demand \\
\hline COP: & Coefficient of Performance \\
\hline CPO: & Catalytic Pyrolysis Oil \\
\hline $\mathrm{db}:$ & dry basis \\
\hline DCFROR: & Discounted Cash Flow Rate of Return \\
\hline E. grandis: & Eucalyptus grandis \\
\hline EP: & Eutrophication \\
\hline ESP: & Electrostatic Precipitator \\
\hline FCC: & Fluid Catalytic Cracking \\
\hline $\mathrm{FCl}:$ & Fixed Capital Investment \\
\hline FPO: & Fast Pyrolysis Oil \\
\hline GC/MS: & Gas Chromatography-Mass Spectroscopy \\
\hline GGE: & Gasoline Gallon Equivalent \\
\hline GHG: & Greenhouse Gases \\
\hline $\mathrm{GWP}_{100}$ & Global Warming Potential over 100 years \\
\hline HCO: & Heavy Cycle Oil \\
\hline HDO: & Hydrodeoxygenation \\
\hline HHV: & Higher Heating Value \\
\hline$h_{P}:$ & Specific enthalpy of the pyrolysis reaction \\
\hline HPO: & Hydrotreated Pyrolysis Oil \\
\hline
\end{tabular}


IEA: International Energy Agency

INDC: Intended Nationally Determined Contribution

IRR: Internal Rate of Return

ISBL: Inside-Battery-Limits

LHV: $\quad$ Lower Heating Value

Lignin A: $\quad$ lignin-derived oligomeric compounds with $\beta-0-4$ bond

Lignin B: lignin-derived phenylcoumaran compounds

KZN: KwaZulu-Natal

LCA: Life Cycle Assessment

$\mathrm{LCl}: \quad$ Life Cycle Inventory

LCIA: Life Cycle Impact Assessment

LCO: $\quad$ Light Cycle Oil

LGE: Litre Gasoline Equivalent

LPG: $\quad$ Liquefied Petroleum Gas

MAT: Micro Activity Test

MSP: Minimum Selling Price

MW: Molecular Weight

NC-10: $\quad$ non-catalytic pyrolysis scenario - required capacity to co-process 5 wt. \% bio-oil

NC-100: $\quad$ non-catalytic pyrolysis scenario - biomass collection within $100 \mathrm{~km}$ radius

NC-200: $\quad$ non-catalytic pyrolysis scenario - biomass collection within $200 \mathrm{~km}$ radius

NC-300: $\quad$ non-catalytic pyrolysis scenario - biomass collection within $300 \mathrm{~km}$ radius

NPV: $\quad$ Net Present Value

ODP: $\quad$ Ozone Layer Depletion

$\mathrm{PAH}$ : Polycyclic Aromatic Hydrocarbon

PAMSA: $\quad$ Paper Manufacturers Association of South Africa

PV: $\quad$ Photovoltaic

RSR: $\quad$ Riser Simulator Reactor

T: $\quad$ Temperature

TCl: $\quad$ Total Capital Investment

TDC: $\quad$ Total Direct Cost

TEA: Techno-economic Analysis

TOC: $\quad$ Total Operating Cost

UNFCCC: $\quad$ United Nations Framework Convention on Climate Change

VGO: $\quad$ Vacuum Gas Oil 


\section{Table of Contents}

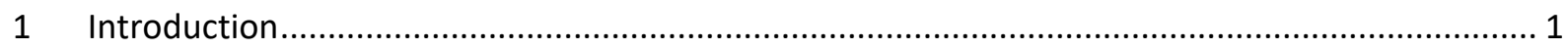

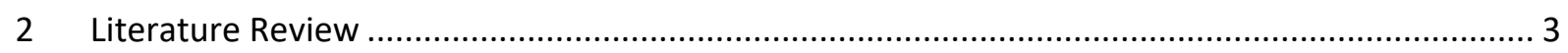

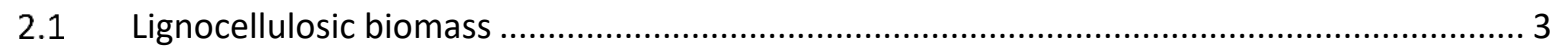

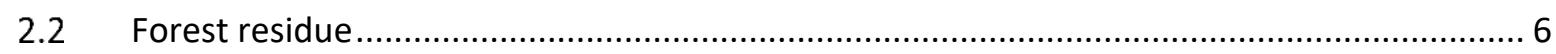

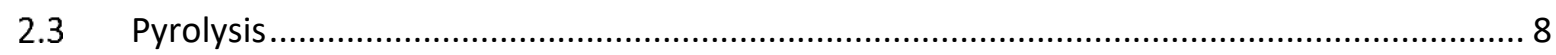

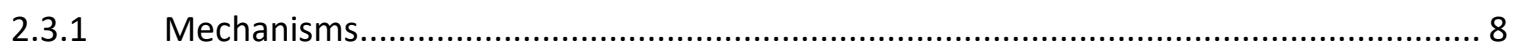

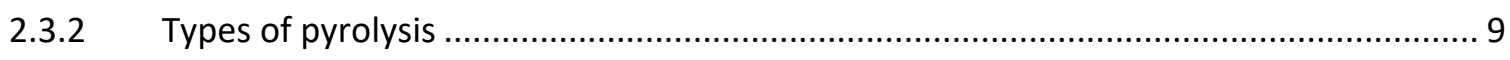

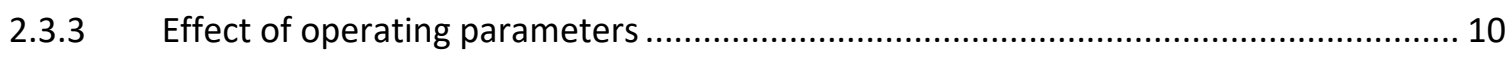

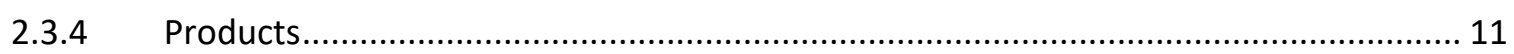

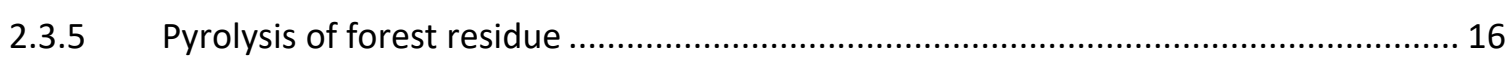

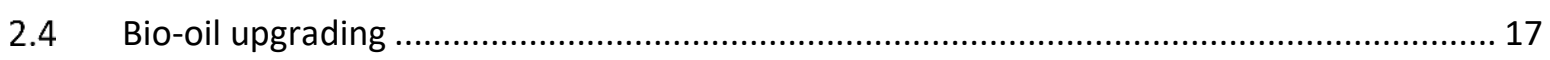

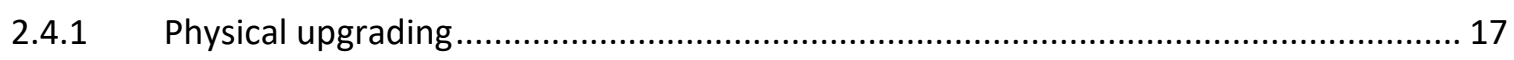

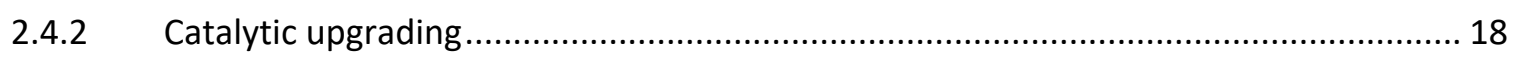

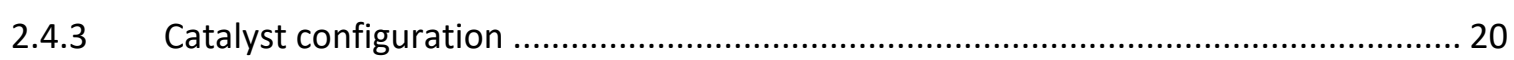

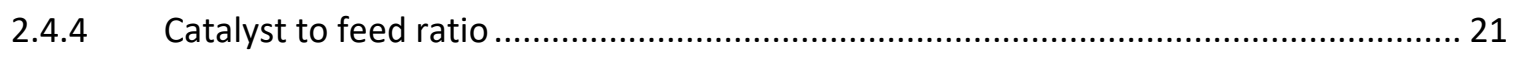

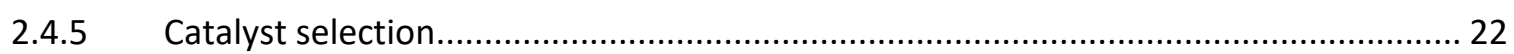

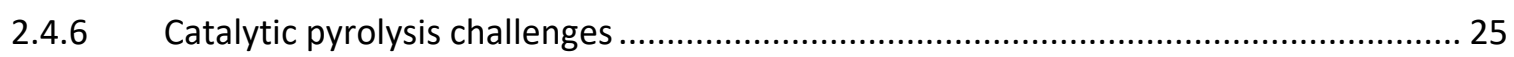

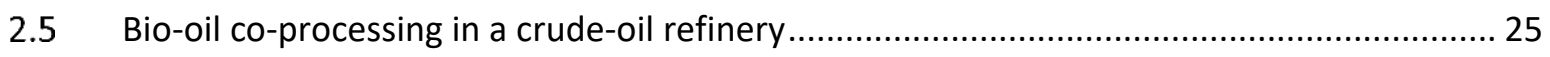

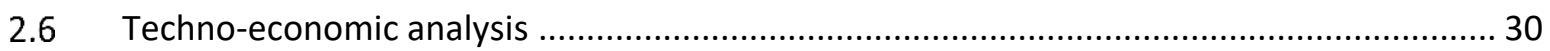

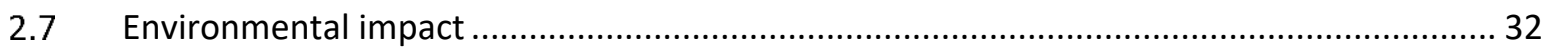

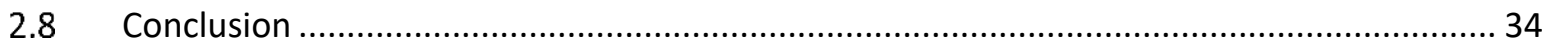

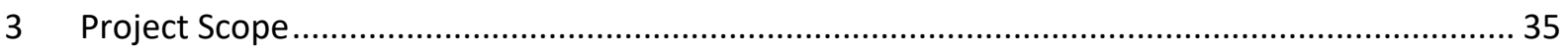

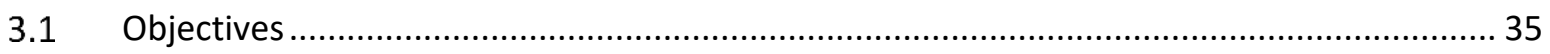

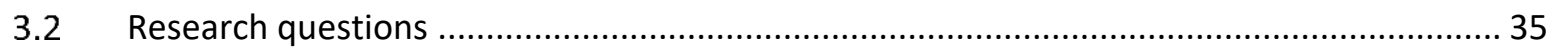

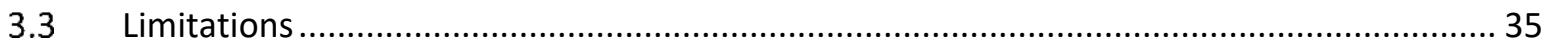

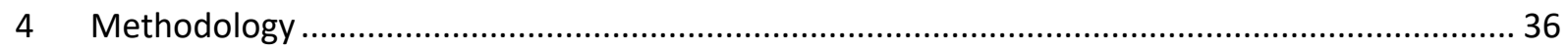

4.1 Estimation of forest residues available in South Africa.............................................. 38

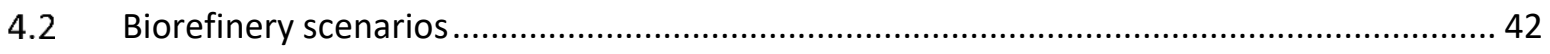

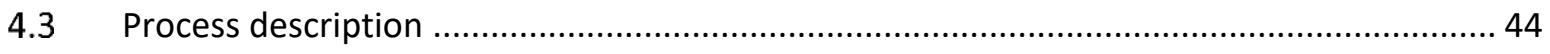

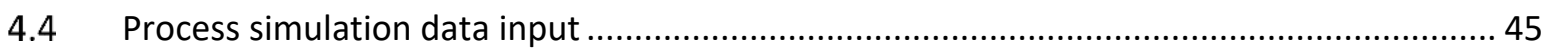

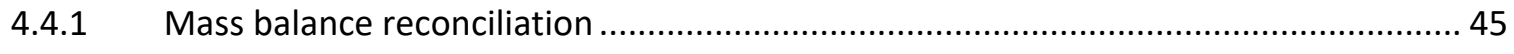

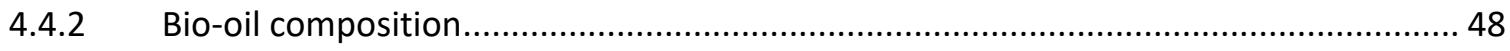

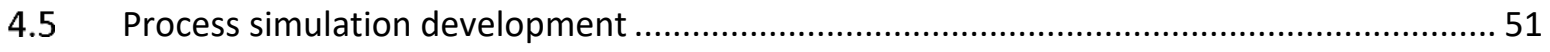

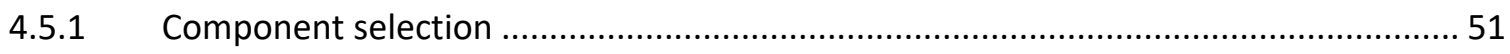

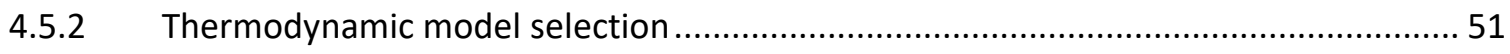


4.5.3 Non-catalytic and catalytic pyrolysis design basis........................................... 51

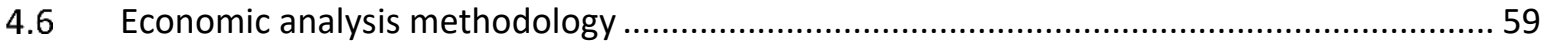

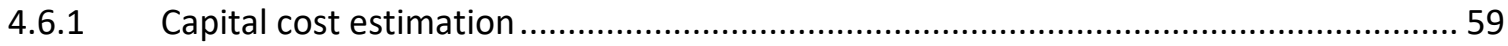

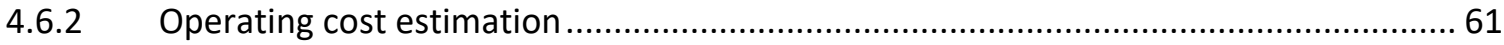

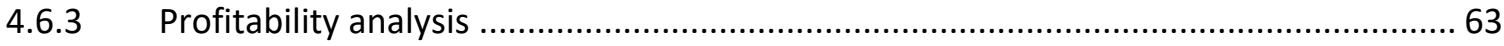

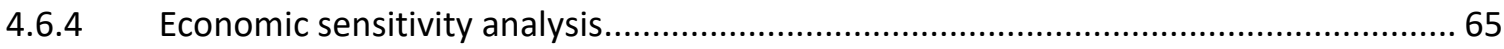

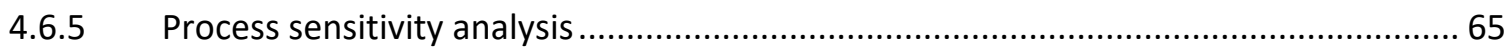

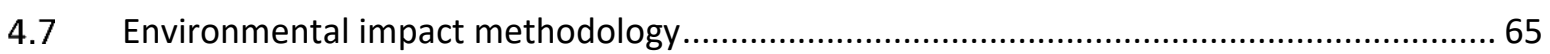

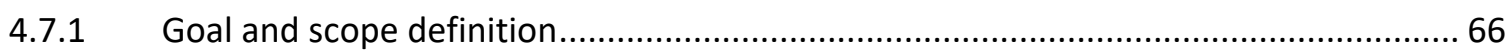

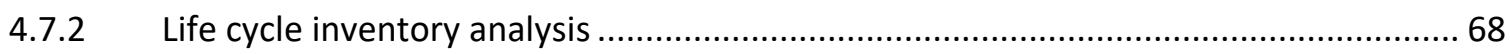

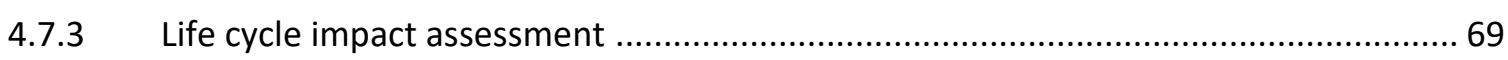

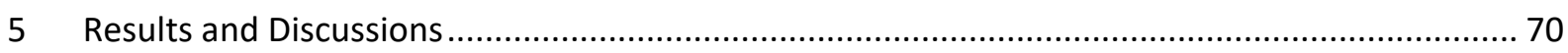

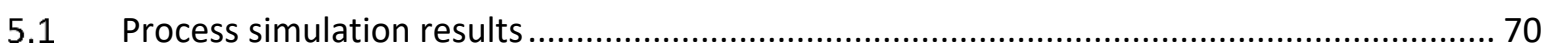

$5.1 .1 \quad$ Overall mass and energy balances ................................................................. 70

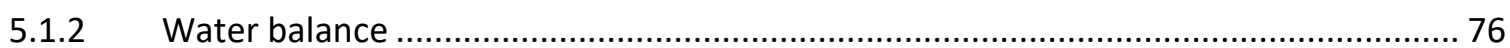

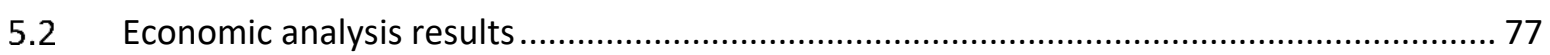

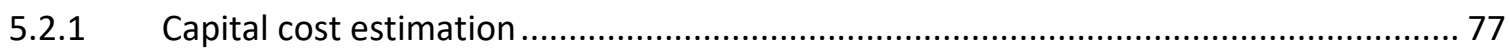

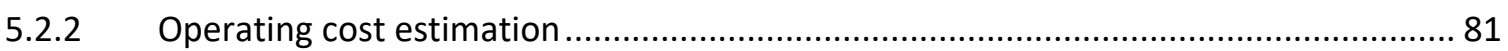

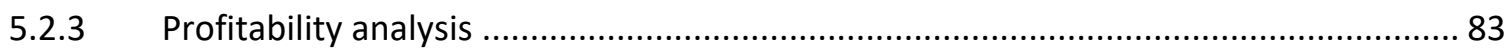

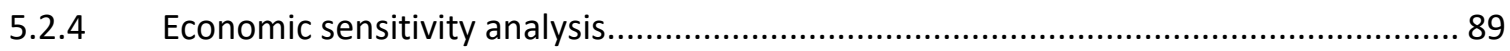

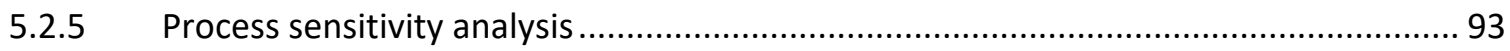

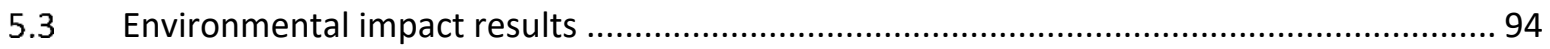

6 Conclusions and Recommendations ..................................................................... 101

6.1 Addressing the objectives ................................................................... 101

6.1.1 Develop process simulations in Aspen Plus ${ }^{\mathrm{TM}}$ for non-catalytic and catalytic pyrolysis biorefinery scenarios based on pilot plant data............................................................ 101

6.1.2 Develop economic analyses for non-catalytic and catalytic pyrolysis biorefinery scenarios based on process simulations

6.1.3 Measure and compare the environmental impact of producing crude and upgraded

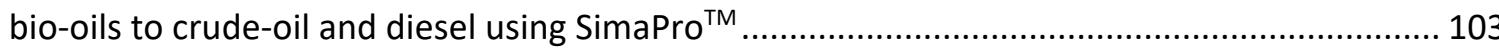

6.2 Recommendations for further research...................................................... 104

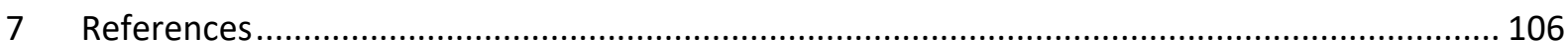

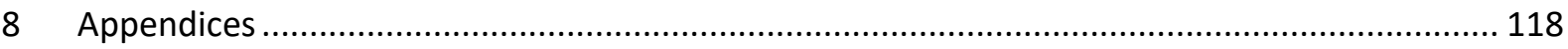

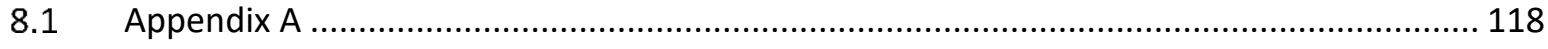

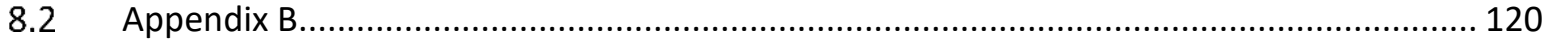

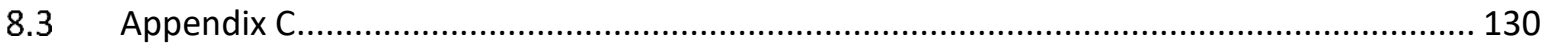

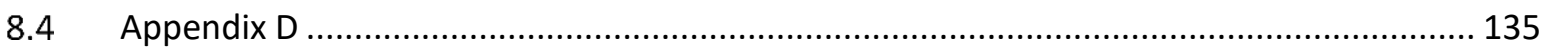




\section{CHAPTER 1}

\section{Introduction}

The main sources of global anthropogenic greenhouse gas (GHG) emissions are carbon dioxide emissions from fossil fuel combustion and industrial processes. These GHG emissions have been correlated with an increase in global mean temperature since the start of the industrial revolution (Shemfe, Gu \& Fidalgo, 2017). The current supply and use of energy is economically, environmentally and socially unsustainable, and if critical action is not taken, GHG emissions will be more than double by 2050 (IEA Renewable Energy Division, 2011).

There is an urgency to implement emission regulations and policies that will motivate the deployment of sustainable alternatives to fossil fuels, which is further motivated by depleting fossil fuel resources, and expected rises in global population and energy demand (Shemfe et al., 2017). Policies should incentivise and promote the production and use of bioenergy and biofuels, while ensuring that food security, biodiversity and social welfare are not compromised. This is achieved by including measures that promote low risk feedstocks, sustainable land use management and efficient processing technologies (IEA Renewable Energy Division, 2011).

The Paris Agreement was adopted at the $21^{\text {st }}$ United Nations Framework Convention on Climate Change (UNFCCC), and is a call for all countries to urgently address the negative impact of climate change by implementing policies to reduce GHG emissions. The goal of the Paris Agreement is to limit the increase in global mean temperature for this century to well below $2{ }^{\circ} \mathrm{C}$, with only a $1.5^{\circ} \mathrm{C}$ increase in global mean temperature as the target. South Africa is currently experiencing a severe drought brought on by the worst El Nino event in decades. Increased temperatures and reduced rainfall as a result of climate change in many parts of the world prompted South Africa and 195 other countries to sign the agreement (Department of Environmental Affairs, 2016). South Africa aims to honour the Paris Agreement and limit emissions through measures included in its Intended Nationally Determined Contribution (INDC), such as further investment into renewable power produced by the private sector, carbon taxing, carbon capture and storage, $20 \%$ hybrid-electric vehicles by 2030 , electric vehicles by 2050 and decarbonised electricity by 2050 (Department of Environmental Affairs, 2015).

Biofuels are important for reducing GHG emissions in the transport sector by limiting dependence on fossil fuels (IEA Renewable Energy Division, 2011). Today, biofuels only contribute to $2 \%$ of transportation fuels globally but ongoing technological developments suggest considerable potential for growth in the coming years. The International Energy Agency (IEA) proposes that bioenergy has the potential to supply up to $10 \%$ of the primary energy demand by 2035 , and biofuels 
have the potential to replace up to $27 \%$ of fossil fuels in the transport sector by 2050 (Wang, Dai, Yang \& Luo, 2017).

Forest residues are the woody biomass left behind in forests after felling and thinning trees, and as a high fire risk are often disposed of by burning or sold as firewood. Both of these contribute to air pollution and the latter has little economic value (Mitchell, Parker, Sharma \& Kaffka, 2015). Paper and pulp industries in South Africa are already using waste products such as bark, black liquor and paper sludge to generate at least $45 \%$ of the electricity and steam needed for the papermaking process (PAMSA, 2019), but the industry is looking for further bioenergy production by utilising forest residues to produce bio-derived transportation fuels, in an effort to reduce $\mathrm{CO}_{2}$ emissions produced by the combustion of fossil fuels during forest operations (Melendez, LeBel \& Stuart, 2013). Bioenergy and biofuel production from forest residue is considered an almost carbon neutral process (save for anthropogenic carbon emissions related to biomass transport and collection) since the biomass takes up $\mathrm{CO}_{2}$ from the atmosphere for photosynthesis, and releases $\mathrm{CO}_{2}$ again during combustion (Mohan, Pittman \& Steele, 2006).

Biomass such as forest residue can be converted into bioenergy and biofuel by biochemical, thermochemical or hybrid processes (Farzad, Mandegari, Guo, Haigh, Shah \& Görgens, 2017). The main biochemical processes are alcoholic fermentation and anaerobic digestion, and the main thermochemical processes are pyrolysis, gasification and combustion (Demirbas \& Balat, 2006). Pyrolysis is the conversion of biomass at elevated temperatures and in the absence of oxygen into solid char, liquid bio-oil and non-condensable gases (Collard \& Blin, 2014). Pyrolysis is one of the most suitable thermochemical processes, because it has the potential to produce high liquid yields that are more convenient for handling, storage and transport than gas (Wang, Dai, et al., 2017). However, the physiochemical properties of bio-oil are unlike fossil fuels, mostly due to its high oxygen and water content, though bio-oil can be upgraded to improve its quality for the purpose of co-processing in a crude-oil refinery to produce bio-derived transportation fuels (Czernik \& Bridgwater, 2004).

The aim of this project is to determine whether or not the production of crude and upgraded bio-oils via the pyrolysis of forest residues is economically and environmentally feasible for the purpose of co-processing in an oil refinery. This will be achieved through the development of process simulations in Aspen Plus ${ }^{\mathrm{TM}}$ that will generate the mass and energy balances needed to size and subsequently cost process equipment for the economic analyses. The environmental impact of producing crude and upgraded bio-oils will also be measured in SimaPro ${ }^{\mathrm{TM}}$ and compared to fossil fuels. 


\section{CHAPTER 2}

\section{$2 \quad$ Literature Review}

This chapter reviews and discusses literature that is relevant to the project. Section 2.1 and Section 2.2 focus on lignocellulosic biomass and forest residues, respectively. The mechanisms, operating conditions and products of pyrolysis processes are then described in Section 2.3. A review of bio-oil upgrading methods is given in Section 2.4. Section 2.5 outlines the advantages and limitations of coprocessing crude and upgraded bio-oils. Previous techno-economic analyses are discussed in Section 2.6 and finally, the environmental impact of the pyrolysis process is considered in Section 2.7.

\subsection{Lignocellulosic biomass}

Biomass includes all organic (living) matter that is renewable (Van de Velden, Baeyens, Brems, Janssens \& Dewil, 2010), and can be classified as woody, agricultural, aquatic, human and animal waste or industrial waste. Woody and agricultural biomasses are the most abundant type of biomass. Woody biomass includes the stems, branches, bark, leaves and off-cuts of trees, while agricultural biomass includes the stalks, straws, shells and other non-edible parts of agricultural crops. Aquatic biomass includes plants, microalgae and other microorganisms found in water. Human and animal waste biomass includes animal manure, food, paper and plastics. Industrial waste, such as black liquor produced by the paper industry, is separate from human and animal waste as it may contain toxic chemicals and harmful additives (Tripathi, Sahu \& Ganesan, 2016). The estimated distribution of biomass available in South Africa is shown in Figure 1. 


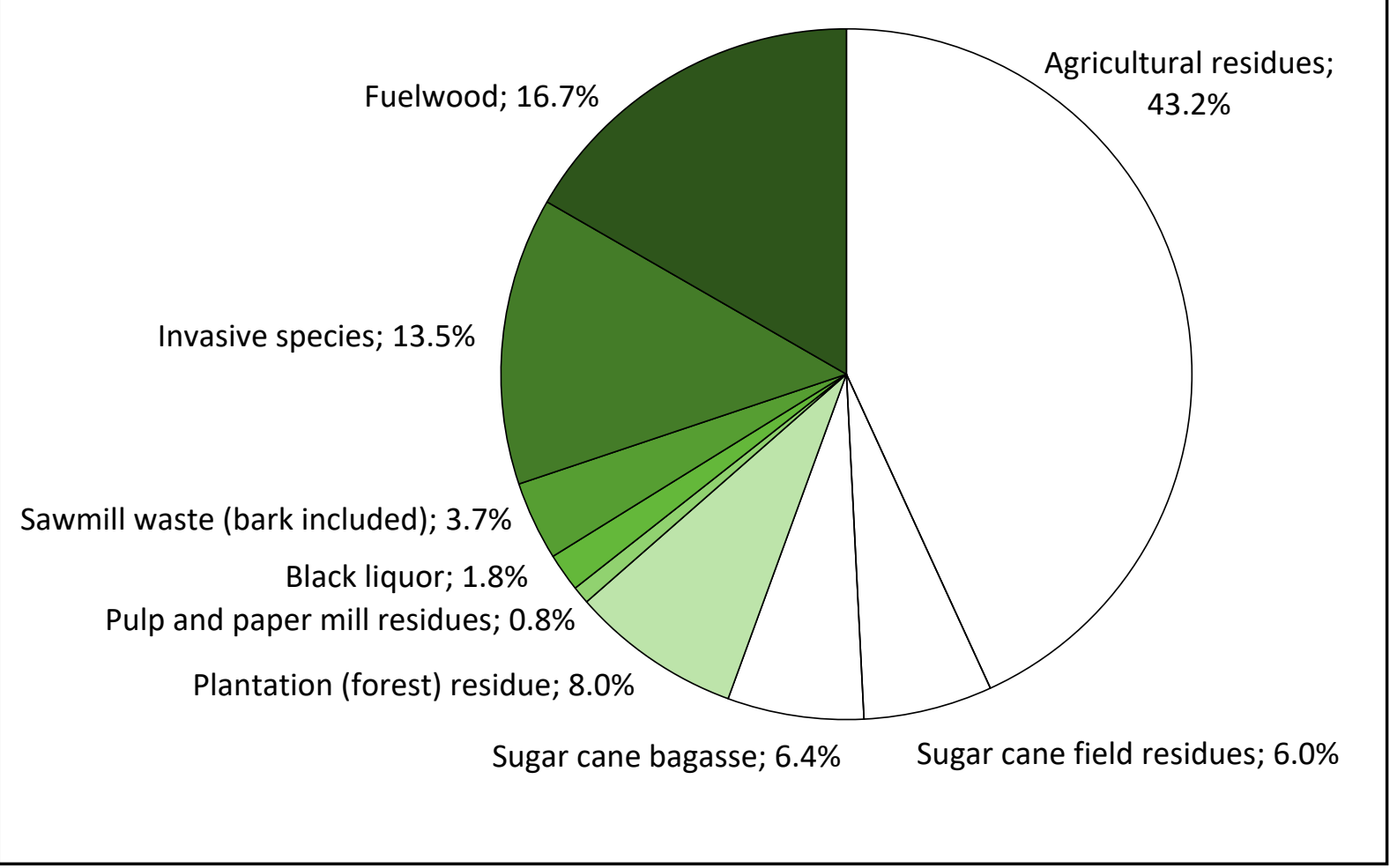

Figure 1: Estimated mass distribution of biomass available in South Africa (Hugo, 2016)

Woody and agricultural biomasses are classified as lignocellulosic biomasses. Lignocellulose is a three dimensional biopolymer largely composed of cellulose, hemicellulose and lignin, with small amounts of extractives and ash (Wang, Dai, et al., 2017). Typical biochemical compositions of lignocellulosic biomasses are given in Table 1.

Table 1: Biochemical composition of lignocellulosic biomasses (wt. \%)

\begin{tabular}{|lcccccc|}
\hline Biomass & Cellulose & Hemicellulose & Lignin & Extractives & Ash & Reference \\
\hline $\begin{array}{l}\text { Pine (softwood) } \\
\text { Beech (hardwood) }\end{array}$ & 46.9 & 20.3 & 27.3 & 5.1 & 0.3 & (Wang, Dai, et al., \\
$\begin{array}{l}\text { Corn stover } \\
26.9-42.7\end{array}$ & $13.3-23.2$ & $15.2-18.2$ & $9.8-22.0$ & $3.5-11.0$ & $\begin{array}{c}\text { (Wang, Dai, et al., } \\
\text { 2017) }\end{array}$ \\
$\begin{array}{l}\text { Sugarcane } \\
\text { bagasse }\end{array}$ & 40.6 & 22.8 & 25.5 & 7.5 & 3.6 & (Demirbas, 2016) \\
Rice straw & 37 & 16.5 & 13.6 & 13.1 & 19.8 & $\begin{array}{c}\text { (Qu, Guo, Shen, } \\
\text { Xiao \& Zhao, 2011) }\end{array}$ \\
\hline
\end{tabular}

Trees can be classified as softwood or hardwood: softwoods originate from gymnosperm (seeding) trees and hardwoods originate from angiosperms (flowering) trees. Softwoods generally grow faster but hardwoods are more dense (Wang, Dai, et al., 2017). Hardwoods are usually made up 
of more cellulose and hemicelluloses than softwoods, while softwoods contain more lignin. Hardwoods are made up of approximately 43-47 wt. \% cellulose, 25-35 wt. \% hemicelluloses, 16-24 wt. \% lignin and 2-8 wt. \% extractives, while softwoods contain approximately 40-44 wt. \% cellulose, 25-29 wt. \% hemicellulose, 25-31 wt. \% lignin and 1-5 wt. \% extractives (Balat, Balat, Kirtay \& Balat, 2009). The proportion of cellulose, hemicellulose and lignin biopolymers has a significant effect on the conversion of the biomass as a whole during the pyrolysis process (Wang, Dai, et al., 2017).

Cellulose is a linear polymer made up of glucose units connected by $\beta-1,4-$ glycoside bonds. Its linear structure allows strong hydrogen bonds to form between the long polymer chains, which gives cellulose its high crystallinity, high stability, strong chemical resistance and small surface area (SerranoRuiz \& Dumesic, 2012). Hemicellulose is made up of a heterogeneous mixture of glucose, galactose, mannose, xylose, arabinose and glucuronic acid. It surrounds cellulose and forms a link between cellulose and lignin polymers. Unlike cellulose, hemicellulose is amorphous, has a low molecular weight and poor physical strength (Dhyani \& Bhaskar, 2018; Mohan et al., 2006). Lignin is a three-dimensional, highly branched, cross-linked phenol polymer consisting of hydroxy-and methoxy- substituted phenylpropane monomers. These monomers can be classified as guaiacyl, syringyl and p-hydroxyl phenyl units. Lignin provides structural rigidity to the biomass by holding cellulose and hemicellulose polymers together, and also protects the biomass against microbial and fungal attack (Dhyani \& Bhaskar, 2018; Mohan et al., 2006; Serrano-Ruiz \& Dumesic, 2012). The arrangement of cellulose, hemicellulose and lignin in the lignocellulose biomass is shown simply in Figure 2.

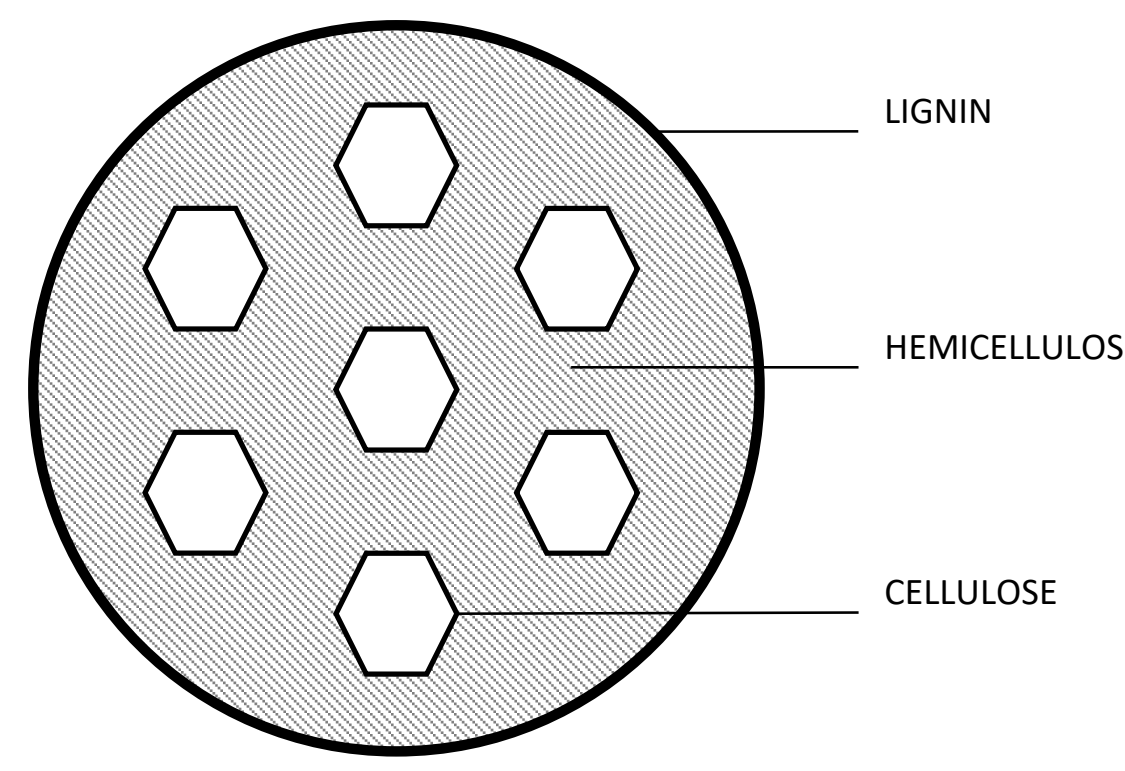

Figure 2: Arrangement of cellulose, hemicellulose and lignin in the lignocellulose biomass 
Extractives are non-structural components of the lignocellulosic biomass (Wang, Dai, et al., 2017) that can be extracted using solvents (Rowell, Pettersen, Han, Rowell \& Tshabalala, 2005). Extractives can be present as fats, waxes, proteins, simple sugars, pectin, essential oils and many other minor organic compounds (Dhyani \& Bhaskar, 2018; Mohan et al., 2006). Forest residues, specifically bark and needles, are high in extractives but the proportion and composition of the extractives are highly dependent on the wood species. Oasmaa and colleagues (2003) found that the extractives in forest residue can range from 5.4 to 10.5 wt. \% of the dry biomass (Oasmaa, Kuoppala, Gust \& Solantausta, 2003).

The inorganic content of wood is made up of a wide range of elements derived from mineral salts absorbed through the roots of trees, and is often referred to as ash. Ash is retained as a solid residue after biomass combustion. About $80 \mathrm{wt}$. \% of ash is made up of calcium, magnesium and potassium elements (Rowell et al., 2005; Wang, Dai, et al., 2017).

\subsection{Forest residue}

In 2016, $50 \%$ of the commercial timber plantation area in South Africa was made up of softwoods and the other $50 \%$ was made up of hardwoods. Pulpwood, sawlogs and mining timber production comprised of 57,38 and $2 \%$ of the plantation area, respectively with the remaining $3 \%$ of the plantation area allocated for other purposes (Forestry Economics Services, 2017). The distribution of pulpwood, sawlogs and mining timber products for softwoods and hardwoods is given in Table 2.

Table 2: Distribution (\% area) of Softwoods and Hardwoods (Forestry Economics Services, 2017)

\begin{tabular}{|lcc|}
\hline Product & Softwood & Hardwood \\
\hline Sawlogs & 73.5 & 2.9 \\
Pulpwood & 26.1 & 87.2 \\
Mining Timber & - & 4.6 \\
Other & 0.4 & 5.4 \\
\hline
\end{tabular}

Softwoods are mainly grown for sawlogs and hardwoods are mainly grown for pulpwood. Pinus patula (P. patula) is the main softwood species planted in South Africa and comprises of $50.4 \%$ of the total softwood area, while Eucalyptus grandis (E. grandis) is the main hardwood species planted in South Africa and comprises of $42.4 \%$ of the total hardwood area (Forestry Economics Services, 2017).

Forest residue is the woody biomass left behind in forests after felling or thinning operation, and typically includes treetops, small trees, stumps, branches, bark, twigs and leaves (Melendez et al., 2013). There are approximately 1.5 million dry tonnes of forest residues available in South Africa every year (Hugo, 2016). The paper and pulp industry has the largest share in South Africa's forest 
plantations, and inevitably produces the majority of these forest residues. Forest residues left behind in forests, however, are a high fire risk and often disposed of by burning or sold as firewood. Both of these contribute to air pollution and the latter has little economic value, therefore there is an opportunity for the paper and pulp industry to utilise the energy potential of forest residues in an environmentally friendly and profitable way (Mitchell et al., 2015).

Conversely, the removal of all forest residues has a negative effect on soil fertility. A $30 \%$ reduction in stem wood production was observed in the following harvest period when all forest residues were removed from E. grandis plantation areas (Gonçalves, Wichert, Gava, Masetto, Junior, Serrano \& Mello, 2007). The soil was left deficient of the important calcium and potassium nutrients.

The paper and pulp industry relies on soil productivity to maintain stem wood production therefore, forest litter (leaves and small twigs), stumps, root systems and a portion of branches should not be removed from plantations to preserve nutrients, prevent soil erosion and protect against compaction by heavy machinery (Wright, Eaton, Perlack \& Stokes, 2012; Yang, Li \& Zhang, 2016). Soil productivity in response to plantation management is highly site-specific (Nambiar \& Kallio, 2008), however, in the KwaZulu-Natal and Mpumalanga provinces of South Africa, where pulpwood production is concentrated (Forestry Economics Services, 2017), typically $80 \mathrm{wt}$. \% of branches are safe to remove for biofuel production ${ }^{1}$.

Forest residues are collected from forests either by one-pass or two-pass systems. The former occurs when round wood and forest residues are harvested simultaneously and forwarded to the primary landing, whereas the latter occurs when forest residues are recovered after the round wood is harvested. Two-pass systems are implemented when round wood is harvested by cut-to-length extraction and not full-tree extraction (Ackerman, Ham, Dovey, Toit, Wet, Kunneke \& Seifert, 2013; Röser, 2008).

Several factors influence the cost of harvesting forest residues for one and two-pass systems such as terrain and terrain accessibility, rate of recovery, chip quality and chip storage. Terrain accessibility is crucial for two-pass systems, and often determines the forwarding distance to landings and roadside due to the limited movability of harvesting and extraction equipment. In some cases, it will even be necessary to use the biomass as a brush mat to protect soft and sensitive soils against compaction and damage caused by heavy machinery, and as a result, the biomass will become contaminated. In two-pass systems, the biomass is allowed to dry in field, which decreases its recoverable volume per area but increases its energy value and allows time for nutrient transfer from the biomass back into the soil to take place. Chip quality is also improved when the biomass is allowed to dry in field. The moisture content of the biomass will decrease by $30-40 \%$ within the first two weeks

\footnotetext{
${ }^{1}$ Communication with Prof Ben du Toit, Department of Forest and Wood Science at Stellenbosch University
} 
after felling. The proper storage of chips is costly but also crucial to avoid physical and microbial degradation, and spontaneous combustion (Ackerman et al., 2013; Röser, 2008).

\subsection{Pyrolysis}

Pyrolysis is the thermochemical conversion of biomass at elevated temperatures and in the absence of oxygen into solid char, liquid bio-oil and non-condensable gas products (Collard \& Blin, 2014; Collard, Blin, Bensakhria \& Valette, 2012).

\subsubsection{Mechanisms}

The chemical bonds within the cellulose, hemicellulose and lignin biopolymers are broken as the biomass is heated. Volatile compounds are released and interact by means of rearrangement reactions (primary mechanisms) to form the primary pyrolysis products. Simultaneously, unstable volatile compounds undergo further conversion (secondary mechanisms) to form the secondary pyrolysis products (Collard \& Blin, 2014).

\subsubsection{Primary mechanisms}

The primary mechanisms of biomass conversion can be described by three pathways (i.e. char formation, depolymerisation and fragmentation) that are defined by the conditions under which the chemical bonds are broken (Collard \& Blin, 2014).

\section{a. Char formation}

The formation and combination of benzene rings in a polycyclic structure produces a solid residue known as char. Water vapour and non-condensable gases are typically released during these rearrangement reactions (Collard \& Blin, 2014; Pisupati \& Tchapda, 2015).

\section{b. Depolymerisation}

Depolymerisation occurs when covalent bonds between monomer units break, followed by stabilisation of the two new chain ends. Further depolymerisation results in shorter polymer chains, until volatile compounds are produced. These compounds are condensable at ambient temperature (Collard \& Blin, 2014). Lignin and hemicellulose have amorphous structures that depolymerise at lower temperatures than the crystalline structure of cellulose (Pisupati \& Tchapda, 2015).

\section{c. Fragmentation}

Fragmentation occurs when covalent bonds within monomer units break to form non-condensable gases and a range of volatile, low molecular weight compounds that are condensable at ambient temperature (Collard \& Blin, 2014; Collard et al., 2012). 


\subsubsection{Secondary mechanism}

Unstable volatile compounds can undergo cracking or recombination reactions. Cracking occurs when the intramolecular bonds within volatile compounds are broken to form lower molecular weight compounds. The products of the fragmentation and cracking pathways are often indistinguishable, making it difficult to determine which pathway is responsible. Recombination occurs when volatile compounds are recombined to form higher molecular weight compounds that can either be volatile or solid (secondary char) depending on the reaction conditions. Cracking and recombination reactions can be catalysed at the surface of the char, reactor or intentionally added catalyst. Catalyst deactivation during recombination reactions is also possible as secondary char can block pores on the catalytic surface (Collard \& Blin, 2014).

\subsubsection{Types of pyrolysis}

\subsubsection{Slow pyrolysis}

Slow pyrolysis is characterised by low heating rates and long vapour residence times. Slow pyrolysis of biomass occurs at temperatures ranging between 400 and $500{ }^{\circ} \mathrm{C}$ under heating rates from 0.1 to 1 ${ }^{\circ} \mathrm{C} / \mathrm{s}$ for vapour residence times between 300 and $550 \mathrm{~s}$. These long vapour residence times are optimal for secondary reactions to reach completion (Tripathi et al., 2016). The main product of slow pyrolysis is char, but typically $30 \mathrm{wt}$. \% bio-oil and $35 \mathrm{wt}$. \% non-condensable gas are also produced (Bridgwater, 2012a).

\subsubsection{Fast pyrolysis}

Fast pyrolysis is characterised by high heating rates and short vapour residence times. Fast pyrolysis of biomass occurs at temperatures ranging between 450 and $650{ }^{\circ} \mathrm{C}$ (Kan, Strezov \& Evans, 2016) under heating rates from 10 to $200{ }^{\circ} \mathrm{C} / \mathrm{s}$ for vapour residence times between 1 and $10 \mathrm{~s}$. These operating conditions are aimed at minimising char formation and secondary reactions therefore, fast pyrolysis typically produces 60 to 75 wt. \% bio-oil (Tripathi et al., 2016).

\subsubsection{Intermediate pyrolysis}

Intermediate pyrolysis takes place between slow and fast pyrolysis operating conditions. Intermediate pyrolysis occurs at temperatures ranging between 500 and $650{ }^{\circ} \mathrm{C}$ under heating rates from 1 to 10 ${ }^{\circ} \mathrm{C} / \mathrm{s}$ for vapour residence times between 0.5 and $20 \mathrm{~s}$. This type of pyrolysis with biomass typically produces 15 to $25 \mathrm{wt}$ \% char, 40 to $60 \mathrm{wt}$ \% bio-oil and 20 to $30 \mathrm{wt}$ \% non-condensable gas (Tripathi et al., 2016). 


\subsubsection{Vacuum pyrolysis}

Vacuum pyrolysis is operated at very low or vacuum pressures, unlike slow, fast and intermediate pyrolysis processes that are operated at atmospheric pressure. Vacuum pyrolysis occurs at temperatures ranging between 450 and $600{ }^{\circ} \mathrm{C}$ and pressures from 0.01 to $0.02 \mathrm{MPa}$. The heating rate is comparable to slow pyrolysis, but the vapour residence time is shorter than $1 \mathrm{~s}$. The low pressure/vacuum atmosphere results in the rapid removal of vapours, which considerably minimises secondary reactions to produce a high quality bio-oil. Vacuum pyrolysis typically produces 35 to $50 \mathrm{wt}$. \% bio-oil (Tripathi et al., 2016).

\subsubsection{Effect of operating parameters}

\subsubsection{Temperature}

Pyrolysis reaction temperature and heating rate have the most significant effect on product distribution (Isahak, Hisham, Yarmo \& Yun Hin, 2012). The biomass undergoes dehydration reactions below $300^{\circ} \mathrm{C}$ to produce mostly char, however, as temperature increases, depolymerisation takes over to produce condensable volatiles. Bio-oil production is maximised between 450 and $550{ }^{\circ} \mathrm{C}$ before fragmentation and secondary reactions take over. Meanwhile, char yield decreases from 300 to 600 ${ }^{\circ} \mathrm{C}$ but remains relatively stable as temperature increases above $600^{\circ} \mathrm{C}$. Finally, non-condensable gases are predominantly produced above $800^{\circ} \mathrm{C}$ (Neves, Thunman, Matos, Tarelho \& Gómez-Barea, 2011).

\subsubsection{Heating rate}

Heating rate determines the type of pyrolysis (i.e. slow, fast or intermediate), and the composition and nature of the pyrolysis products (Kan et al., 2016). Higher char yields are produced under lower heating rates, where secondary cracking reactions are reduced, whereas lower char yields are produced under higher heating rates, where primary fragmentation reactions are promoted and bio-oil and noncondensable gas yields are enhanced (Tripathi et al., 2016). Bio-oil oxygen content also decreases at higher heating rates, while oxygen containing non-condensable gas $\left(\mathrm{CO}_{2}\right.$ and $\left.\mathrm{CO}\right)$ yield increases (Akhtar \& Amin, 2012).

\subsubsection{Vapour residence time}

Vapour residence time is the amount of time volatiles spend in the reactor before separation into biooil and non-condensable gas. Higher char yields are associated with longer vapour residence times as sufficient time is allowed for secondary recombination reactions to reach completion. Conversely, higher bio-oil yields are associated with shorter vapour residence times. Vapour residence time not only effects the char yield but also the char composition, by stimulating the development of micro and macro pores (Tripathi et al., 2016). The effect of temperature and vapour residence time on the quality 
of pyrolysis products is still not completely understood (Akhtar \& Amin, 2012). Nevertheless, the effect of vapour residence time on pyrolysis products is overshadowed by the effects of temperature and heating rate (Tripathi et al., 2016).

\subsubsection{Particle size}

The primary and secondary mechanisms of pyrolysis are influenced by biomass particle size because biomass is a poor conductor of heat. The temperature gradient across the particle naturally increases with particle size, thereby impeding the rate of heat transfer and enhancing secondary reactions to produce char. Smaller particle sizes of $<1 \mathrm{~mm}$ are preferred for fast pyrolysis and bio-oil production but particle size reduction can be expensive and significantly impact the economics of biomass pyrolysis (Kan et al., 2016). Slow pyrolysis requires particle sizes ranging from 5 to $50 \mathrm{~mm}$, while intermediate pyrolysis requires particle sizes between 1 and $5 \mathrm{~mm}$ (Tripathi et al., 2016).

\subsubsection{Products}

The biochemical composition of the lignocellulosic biomass influences the distribution and quality of pyrolysis products. At lower pyrolysis temperatures, cellulose degrades into stable anhydrocellulose to produce char, while at higher pyrolysis temperatures, cellulose decomposes into volatile compounds to produce bio-oil and non-condensable gas. Hemicellulose also decomposes into volatiles, while lignin more readily yields char due to the fragmentation of its relatively weak bonds (Kan et al., 2016; Tripathi et al., 2016). Further detail about the pyrolysis products is provided in this section.

\subsubsection{Char}

Char (also referred to as biochar) is a solid product made up of unconverted organic solids, carbonaceous residues and inorganics (Kan et al., 2016). The proximate analysis, elemental analysis and higher heating value (HHV) for biochar produced from hardwood stem and hardwood bark under slow pyrolysis conditions at $500{ }^{\circ} \mathrm{C}$ are given in Table 3. The $H H V$ was calculated using the empirical correlations given in Equation 2-1.

$H H V=0.3491 C+1.1783 H+0.1005 S-0.1034 O-0.0151 N-0.0211 A$

Where, $C, H, O, N, S$ and $A$ represent carbon, hydrogen, oxygen, nitrogen, sulphur and ash, respectively, and are expressed in mass percentages on a dry basis (Channiwala \& Parikh, 2002). 
Table 3: Proximate and elemental analyses for biochar produced from hardwood (Lee, Park, Ryu, Gang, Yang, Park, Jung \& Hyun, 2013)

\begin{tabular}{|lccc|}
\hline Analysis & & Hardwood Stem & Hardwood Bark \\
\hline \multirow{2}{*}{ Proximate } & Moisture & 1.46 & 0.36 \\
(wt. \%, db) & Volatile Matter & 12.79 & 18.14 \\
& Fixed Carbon & 83.47 & 68.66 \\
& Ash & 2.28 & 12.84 \\
Elemental & Carbon & 89.31 & 84.84 \\
(wt. \%, db) & Hydrogen & 2.57 & 3.13 \\
& Oxygen & 7.34 & 10.20 \\
& Nitrogen & 0.78 & 1.83 \\
HHV (MJ/kg, db) & Sulphur & - & - \\
\hline
\end{tabular}

Lignocellulosic biomass, pyrolysis temperature and heating rate determines the physiochemical properties that makes biochar suitable for a wide range of applications. Biochar produced under low-temperature pyrolysis conditions is high in volatile matter that is made up of easily decomposable nutrient-rich substrates, which are suitable for soil applications. Alternatively, biochar produced under high-temperature pyrolysis conditions yields a large microscopic surface area and aromatic carbon content that is suitable for adsorption and carbon sequestration applications, respectively (Jindo, Mizumoto, Sawada, Sanchez-Monedero \& Sonoki, 2014). The applications of biochar related to its economic value are discussed in more detail below.

\section{a. Carbon sequestration}

Biochar can store carbon for thousands of years due to its strong resistance to biological decay (Lee et al., 2013). The economic value of biochar intended for carbon sequestration is dependent on its carbon content and the carbon tax rate set by government. Biochar with a carbon content of 89.31 wt. \% (given in Table 3) stores an equivalent 2.62 metric tonnes of carbon dioxide per metric tonne of biochar, assuming that 80 wt. \% of the carbon will be sequestered over a significant period of time (Han, Elgowainy, Dunn \& Wang, 2013). The carbon tax rate set by the South African government is R120/MT CO 2 eq (Republic of South Africa, 2019) therefore, biochar with a carbon content of 89.31 wt. \% is worth R314.66/MT ( \$23/MT).

\section{b. Charcoal}

Biochar with an HHV of $32.63 \mathrm{MJ} / \mathrm{kg}$ (included in Table 3 ) is similar to bituminous coal with an HHV of $31.00 \mathrm{MJ} / \mathrm{kg}$ therefore, it is traditionally used as fuel (charcoal) to produce heat for cooking 
(Channiwala \& Parikh, 2002; Lee et al., 2013). The economic value of charcoal in South Africa can range from R3 400/MT ( $\$ 243 / \mathrm{MT}$ ) to R4 800/MT ( $\$ 343 / \mathrm{MT}$ ) including VAT (Burger, 2018; Konz, Cohen \& van der Merwe, 2015; Wattle Wood Farm, 2019).

\section{c. Soil application}

Biochar increases the capacity for soil to hold water and nutrients, which reduces the need for fertilizers, and decreases the emission of greenhouse gases such as nitrous oxide and methane (Lee et al., 2013). Biochar also has the potential to increase crop productivity since inorganic minerals such as potassium, phosphorous, calcium and magnesium are present in high concentrations in the biochar, and are important for plant growth (Kim, Kim, Lee, Choi, Yeo, Choi \& Choi, 2013).

The capacity for biochar to replace fertilizer is not fully established because of the many parameters that influence its properties and application to the soil, such as: feedstock properties, pyrolysis conditions, soil properties and plant growth mechanisms (Lee et al., 2013). Based on the review by Agegnehu and colleagues (2017), a conservative assumption is to replace fertilizer with biochar in a 1:1 ratio (Agegnehu, Srivastava \& Bird, 2017). Biochar is comparable to Limestone Ammonium Nitrate (LAN) fertilizers, which were sold for between R5 000/MT ( \$357/MT) and R5 800/MT ( \$414/MT) in 2017 (Grain SA, 2019). Furthermore, biochar produced in South Africa by C Fert and Biogrow for soil application is sold for between R5 000/MT and R6 111/MT ( $\$ 437 / M T$ ).

\section{d. Activated carbon}

Biochar is similar to commercial activated carbon in activity but different in feedstock type, production and physiochemical properties. The surface of cellulose and hemicellulose biopolymers is made up of a wide range of functional groups that can be physically activated during pyrolysis or by further treatment with either steam or carbon dioxide. The resultant biochar has a high-degree of porosity, large microscopic surface area and strong affinity for non-polar substances, which makes it possible, for example, to adsorb organic and inorganic pollutants found in wastewater. Biochar was found to be more effective than commercial activated carbon in lead adsorption (Cao, Ma, Gao \& Harris, 2009; Lu, Zhang, Yang, Huang, Wang \& Qiu, 2012), and has shown to effectively adsorb other heavy metals such as cadmium, copper and nickel found in heavy metal contaminated soils (Kan et al., 2016; Lee et al., 2013; Qambrani, Rahman, Won, Shim \& Ra, 2017). Jindo and colleagues (2014) studied the effect of temperature on the volatile matter, surface area and carbon content of biochars produced via the pyrolysis of apple tree and oak tree wood chips. The authors found that biochars produced at higher temperatures $\left(600\right.$ to $800^{\circ} \mathrm{C}$ ) had lower volatile matter, larger surface area and higher carbon content than biochars produced at lower temperatures $\left(400\right.$ to $500{ }^{\circ} \mathrm{C}$ ) as shown in Table 4 (Jindo et al., 2014). 
Table 4: Volatile matter, surface area and carbon content of biochars produced at a range of temperatures (Jindo et al., 2014)

\begin{tabular}{|lcccc|}
\hline Feedstock & $\begin{array}{c}\text { Temperature } \\
\left({ }^{\mathbf{0}} \mathbf{C}\right)\end{array}$ & $\begin{array}{c}\text { Volatile Matter } \\
(\mathbf{w t .} \%)\end{array}$ & $\begin{array}{c}\text { Surface Area } \\
\left(\mathbf{m}^{\mathbf{2}} \mathbf{g} \mathbf{)}\right.\end{array}$ & $\begin{array}{c}\text { Carbon Content } \\
\text { (wt. } \%)\end{array}$ \\
\hline \multirow{3}{*}{ Apple tree wood chips } & 400 & 32.4 & 11.9 & 70.2 \\
& 500 & 18.3 & 58.6 & 79.1 \\
& 600 & 11.1 & 208.7 & 81.5 \\
& 700 & 7.7 & 418.7 & 82.3 \\
& 800 & 6.8 & 545.4 & 84.8 \\
Oak tree wood chips & 400 & 32.1 & 5.6 & 70.5 \\
& 500 & 19.4 & 103.2 & 77.6 \\
& 600 & 12.3 & 288.6 & 81.2 \\
& 700 & 8.3 & 335.6 & 83.2 \\
& 800 & 7.9 & 398.2 & 82.9 \\
\hline
\end{tabular}

The economic value of biochar intended for activated carbon applications falls within a wide range. Seal Water Tech sells activated carbon produced from coconut shells for R9 200/MT ( $\$ 657 / M T)$ including VAT (Seal Water Tech, 2019). Activated Carbon Innovations produces activated carbon (ranging from large granules to a fine powder) from macadamia nut shells that is sold for between R39 500/MT ( \$2 821/MT) and R49 500/MT ( $\$ 3$ 536/MT) excluding VAT (Activated Carbon Innovations, 2019). Rotocarb also produces activated carbon from macadamia nut shells, which is sold for R36 480/MT ( \$2 606/MT) including VAT (Burger, 2018).

\subsubsection{Gas}

The main non-condensable gases produced from biomass pyrolysis are carbon dioxide $\left(\mathrm{CO}_{2}\right)$, carbon monoxide (CO), hydrogen $\left(\mathrm{H}_{2}\right)$, methane $\left(\mathrm{CH}_{4}\right)$, ethane $\left(\mathrm{C}_{2} \mathrm{H}_{6}\right)$ and ethylene $\left(\mathrm{C}_{2} \mathrm{H}_{4}\right)$ (Kan et al., 2016). The amount of $\mathrm{CO}_{2}$ and $\mathrm{CO}$ produced is dependent on the thermal decomposition of hemicellulose and cellulose, respectively. The amount of $\mathrm{H}_{2}$ and $\mathrm{CH}_{4}$ is dependent on the thermal decomposition of lignin (Dhyani \& Bhaskar, 2018). Non-condensable gases can be combusted to generate heat for the process or recycled to the pyrolysis reactor as a fluidising gas (Dhyani \& Bhaskar, 2018; Kan et al., 2016).

\subsubsection{Bio-oil}

Bio-oil is a dark brown, free-flowing liquid composed of a complex mixture of oxygenated hydrocarbons, water and traces of char (Bridgwater, 2012b). It is produced by rapidly cooling the vapours leaving the pyrolysis reactor. Two phases are present in bio-oil due to its high water content, specifically the organic phase (also referred to as the organic fraction) and the aqueous phase (aqueous 
fraction). The organic phase has similar properties to a low-grade fuel and can be upgraded (as discussed in Section 2.4 below) to a high-grade fuel or useful chemicals, while the aqueous phase mostly consists of low-grade, oxygen-rich compounds such as acetic acid that cannot be used for fuel (Mirkouei, Haapala, Sessions \& Murthy, 2017; Zhang, Yan, Li \& Ren, 2005).

The organic compounds found in bio-oil can be categorised into chemical families such as acids, aldehydes, ketones, phenols, and sugars (Garcìa-Pérez, Chaala, Pakdel, Kretschmer \& Roy, 2007). Azeez and colleagues (2010) carried out fast pyrolysis experiments at approximately $470^{\circ} \mathrm{C}$ with beech and spruce wood feedstocks to identify and quantify the major chemical families found in the produced bio-oils. The gas chromatography-mass spectroscopy (GC/MS) analysis results for the biooils are given in Table 5. Acetic acid, hydroxyacetaldehyde and hydroxypropanone were present in the highest concentrations for both bio-oils. Furthermore, a portion of each bio-oil consisted of carbohydrate and lignin-derived compounds that are undetectable by GC/MS (Azeez, Meier, Odermatt \& Willner, 2010).

Table 5: Major chemical families (wt. \%, db) identified and quantified in beech and spruce wood bio-oils (Azeez et al., 2010)

\begin{tabular}{|lcc|}
\hline Chemical Families & Beech (Hardwood) & Spruce (Softwood) \\
\hline Acids & 8.2 & 2.6 \\
Aldehydes & 10.3 & 11.3 \\
Ketones & 5.1 & 4.2 \\
Sugars & 3.3 & 5.4 \\
Furans & 2.5 & 2.6 \\
Pyrans & 1.9 & 1.8 \\
Aromatics & 0.1 & 0.1 \\
Lignin-derived phenols & 0.3 & 0.5 \\
Guaiacols & 1.5 & 4.1 \\
Syringols & 3.1 & $<0.0$ \\
Undetectable by GC/MS & 63.7 & 67.3 \\
\hline
\end{tabular}

The properties of bio-oils are significantly different from conventional hydrocarbon fuels. Biooil has a high oxygen and water content, is highly acidic, mostly viscous, and undergoes undesirable secondary reactions during storage (aging). Table 6 summarises the typical properties of bio-oil produced from wood pyrolysis compared to heavy fuel oil. 
Table 6: Properties of bio-oil produced from wood and heavy fuel oil (Czernik \& Bridgwater, 2004)

\begin{tabular}{|lcc|}
\hline Physical Property & Bio-oil & Heavy Fuel Oil \\
\hline Moisture content (wt. \%) & $15-30$ & 0.1 \\
$\mathrm{pH}$ & 2.5 & - \\
Elemental composition (wt. \%, db) & & 85 \\
$\mathrm{C}$ & $54-58$ & 11 \\
$\mathrm{H}$ & $5.5-7.0$ & 1 \\
$\mathrm{O}$ & $35-40$ & 0.3 \\
$\mathrm{~N}$ & $0-0.2$ & 0.1 \\
Ash & $0-0.2$ & 40 \\
HHV & $16-19$ & 180 \\
Viscosity at $50^{\circ} \mathrm{C}(\mathrm{cP})$ & $40-100$ & \\
\hline
\end{tabular}

Oxygen (in the form of oxygenated hydrocarbons) lowers the heating value of bio-oil and gives bio-oil its polar nature, making it immiscible with conventional hydrocarbon fuels (Dhyani \& Bhaskar, 2018). Bio-oil contains about 35 to 40 wt. \% oxygen, which is distributed over 300 compounds (Czernik \& Bridgwater, 2004). Most of these compounds are present as carboxylic acids, hydroxyaldehydes, hydroxyketones, sugars and phenolics (Meier, Oasmaa \& Peacocke, 1997).

Water is derived from moisture in the feedstock and the dehydration reactions taking place during pyrolysis. Bio-oil contains about 15 to 30 wt. \% water, depending on the feedstock and its moisture content. Water affects the heating value, stability, aging and viscosity of bio-oil (Bridgwater, 2012b; Dhyani \& Bhaskar, 2018).

High quantities of organic acids (such as acetic and formic acids) lowers the $\mathrm{pH}$ of bio-oil to range between 2 and 3 . High acidity and moisture content at high operating temperatures makes biooil corrosive to process equipment, specifically process equipment in existing oil-refineries, where the bio-oil will eventually be co-processed with conventional hydrocarbon fuels (Bridgwater, 2012b).

The viscosity of bio-oil at $40{ }^{\circ} \mathrm{C}$ can vary between 35 and $1000 \mathrm{cP}$ depending on the nature of the feedstock, pyrolysis reaction conditions, separation efficiency of char, water content and storage time or aging. However, the viscosity of bio-oil produced from wood typically ranges from 40 to 100 CP (Czernik \& Bridgwater, 2004). The viscosity of bio-oil tends to increase during storage as secondary reactions between bio-oil compounds take place, which sometimes results in phase separation (Bridgwater, 2012b).

\subsubsection{Pyrolysis of forest residue}

Oasmaa and colleagues (2010) conducted fast pyrolysis with green forest residue ( $86 \mathrm{wt}$. \% spruce, 9 wt. \% pine and 5 wt. \% birch) and brown forest residue (80 wt. \% spruce, 10 wt. \% pine and 10 wt. \% 
birch) in a fluidising bed reactor operating between 480 and $520^{\circ} \mathrm{C}$. The bio-oil yields were 63.7 and 57.9 wt. \% for the green forest residue ( $8.1 \mathrm{wt}$. \% moisture) and brown forest residue ( $4.9 \mathrm{wt}$. \% moisture), respectively (Oasmaa, Solantausta, Arpiainen, Kuoppala \& Sipilä, 2010). The green forest residue (initially 55 wt. \% moisture) included about 63 wt. \% branches (37 wt. \% bark) and 37 wt. \% needles, whereas the brown forest residue (initially $35 \mathrm{wt}$. \% moisture) consisted of about $90 \mathrm{wt}$. \% branches (33 wt. \% bark) and 10 wt. \% needles (Oasmaa et al., 2003).

Puy and colleagues (2011) carried out pyrolysis in an auger reactor with softwood (pine) forest residues (6.21 wt. \% moisture) at a range of temperatures $\left(500\right.$ to $800{ }^{\circ} \mathrm{C}$ ) and solid residence times (1.5 to $5 \mathrm{~min}$ ). The highest bio-oil yield was $58.7 \mathrm{wt}$. \% at a temperature of $500^{\circ} \mathrm{C}$ and a solids residence time of $5 \mathrm{~min}$. The main compounds found in bio-oil (as identified by GC/MS) were oxygen-containing carboxylic acids, ketones, aldehydes, phenols and aromatics (Puy, Murillo, Navarro, López, Rieradevall, Fowler, Aranguren, García, Bartrolí \& Mastral, 2011).

Luo and colleagues (2017) conducted fast pyrolysis in an ablative reactor operating between 500 and $550^{\circ} \mathrm{C}$ with softwood (pine) forest residues (7.3 wt. \% moisture). The bio-oil yield was $60 \mathrm{wt}$. \% with an oxygen content of 54.05 wt. \% (Luo, Chandler, Anjos, Eng, Jia \& Resende, 2017).

Torri and colleagues (2016) investigated intermediate pyrolysis at $550^{\circ} \mathrm{C}$ and fast pyrolysis at $500{ }^{\circ} \mathrm{C}$ with hardwood (gum) and softwood (spruce) forest residues. The bio-oil yields were 49 and 69 wt. \% for intermediate and fast pyrolysis of hardwood forest residues (4.5 wt. \% moisture), and 50 and $70 \mathrm{wt}$. \% for intermediate and fast pyrolysis of softwood forest residues (6.3 wt. \% moisture), respectively. The authors then conducted catalytic pyrolysis experiments with softwood forest residues and a zeolite catalyst at $500{ }^{\circ} \mathrm{C}$ for a weight hourly space velocity of $4.3 \mathrm{~h}^{-1}$. The yield of biooil decreased from 70 to $62 \mathrm{wt}$. \%, while the quality of bio-oil in terms of oxygen content improved from 36.6 to 32.6 wt. \% (Torri, Paasikallio, Faccini, Huff, Caramão, Sacon, Oasmaa \& Zini, 2016).

Many researchers have found that forest residues are a suitable feedstock to produce bio-oil via pyrolysis, however, the high oxygen content of the produced bio-oil significantly limits its application as a fuel. Alternatively, bio-oil can be upgraded to improve its quality as discussed in Section 2.4 below.

\subsection{Bio-oil upgrading}

Bio-oil can be upgraded to improve its oxygen content, water content, and other physiochemical properties that make it unlike conventional hydrocarbon fuels. Several upgradation techniques have been studied, and can be classified as either physical or catalytic.

\subsubsection{Physical upgrading}

Bio-oil can be physically upgraded by filtration, solvent addition or emulsification. In the case of filtration, hot vapours leaving the pyrolysis reactor are filtered before condensation to reduce ash 
content in the bio-oil (Dhyani \& Bhaskar, 2018). Hot vapour filtration has been reported to reduce ash content in the bio-oil to $100 \mathrm{ppm}$ and alkali content to less than $10 \mathrm{ppm}$, which is a considerable improvement from conventional cyclone separation. Liquid filtration to remove ash content with low particle sizes (less than $5 \mu \mathrm{m}$ ) from the condensed bio-oil is challenging and requires high pressure drops and self-cleaning filters. Bio-oil mixed with polar solvents such as methanol has been reported to homogenise, reduce viscosity and improve aging. Finally, surfactant emulsifiers can improve the miscibility of bio-oil with conventional hydrocarbon fuels, however, this process is costly and energy intensive (Bridgwater, 2012a).

\subsubsection{Catalytic upgrading}

Bio-oil can be catalytically upgraded by ash, hydrodeoxygenation or catalyst vapour cracking. Active alkali metals such as potassium and sodium are naturally present in the biomass as ash, and through secondary vapour cracking can reduce bio-oil yield and quality. Ash vapour cracking can sometimes be more severe than char vapour cracking depending on the concentration of ash present in the biomass. Ash can be removed by washing the biomass in water or dilute acid but this method is not always viable as the cellulose and hemicellulose biopolymers can be hydrolysed, which reduces the bio-oil yield and quality inevitably, and the wet biomass still has to be dried before pyrolysis (Bridgwater, 2012a).

Hydrodeoxygenation (HDO) or hydrotreating involves the removal of oxygen from bio-oil by catalytic reaction with hydrogen to form water as shown in Figure 3. This process occurs separately from pyrolysis. HDO requires a high pressure of about $20 \mathrm{MPa}$, a moderate temperature of about 400 ${ }^{\circ} \mathrm{C}$ and a source of hydrogen (Bridgwater, 2012a; Dhyani \& Bhaskar, 2018). Catalysts that have been extensively studied are cobalt-molybdenum disulphide, nickel-molybdenum disulphide and transition metals such as platinum, palladium and ruthenium (Bu, Lei, Zacher, Wang, Ren, Liang, Wei, Liu, Tang, Zhang \& Ruan, 2012; Dhyani \& Bhaskar, 2018). This process upgrades the bio-oil to an energy dense, non-corrosive, naphtha-like product. The disadvantage is the high cost associated with hydrogen supply from a renewable resource and operating at intensive pressures (Dickerson \& Soria, 2013).

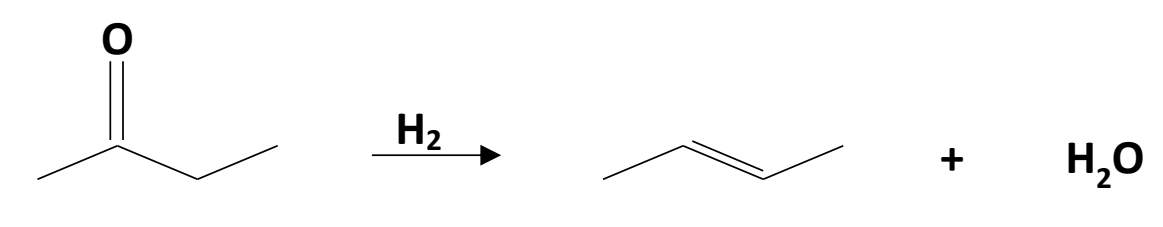

Figure 3: Hydrodeoxygenation reaction (Nolte \& Shanks, 2017) 
Hydrogen generation is a limitation of HDO. One of the methods to generate hydrogen involves bio-oil reforming, and another method involves biochar steam gasification. However, both of these methods are unfavourable for process economics as some of the product yield and inevitably revenue are expended. A third method involves natural gas steam reforming, which is favourable for process economics as natural gas is cheap, however, natural gas is produced from fossil fuel, which negatively impacts the environment. Moreover, the energy content of the natural gas can be as high as $20 \%$ of the energy content of the upgraded bio-oil. Hydrogen can also be generated through biomass steam gasification, however, diverting biomass to hydrogen production reduces the scale of bio-oil and biochar production. Finally, hydrogen produced from water electrolysis with renewable electricity (solar photovoltaic (PV) panels) is a clean and sustainable method that is better suited for processes where upgraded bio-oil and biochar are both revenue generating products. The downside of this method is the high capital cost and overall low efficiency (Carrasco, Gunukula, Boateng, Mullen, DeSisto \& Wheeler, 2017; Nikolaidis \& Poullikkas, 2017).

Catalytic cracking is an alternative method that deoxygenates bio-oil without using hydrogen. Bio-oil is usually processed over acidic zeolite catalysts at atmospheric pressure and moderate temperatures. The mechanism involves cracking pyrolysis vapours (breaking C-C bonds), hydrogen transfer, isomerisation, aromatic side chain scission, and deoxygenation reactions (Liu, Wang, Karim, Sun \& Wang, 2014). Oxygen is removed in the form of water, carbon dioxide and carbon monoxide via simultaneous dehydration, decarboxylation and decarbonylation reactions (Gollakota, Reddy, Subramanyam \& Kishore, 2016; Serrano-Ruiz \& Dumesic, 2012) as shown in Figure 4. 


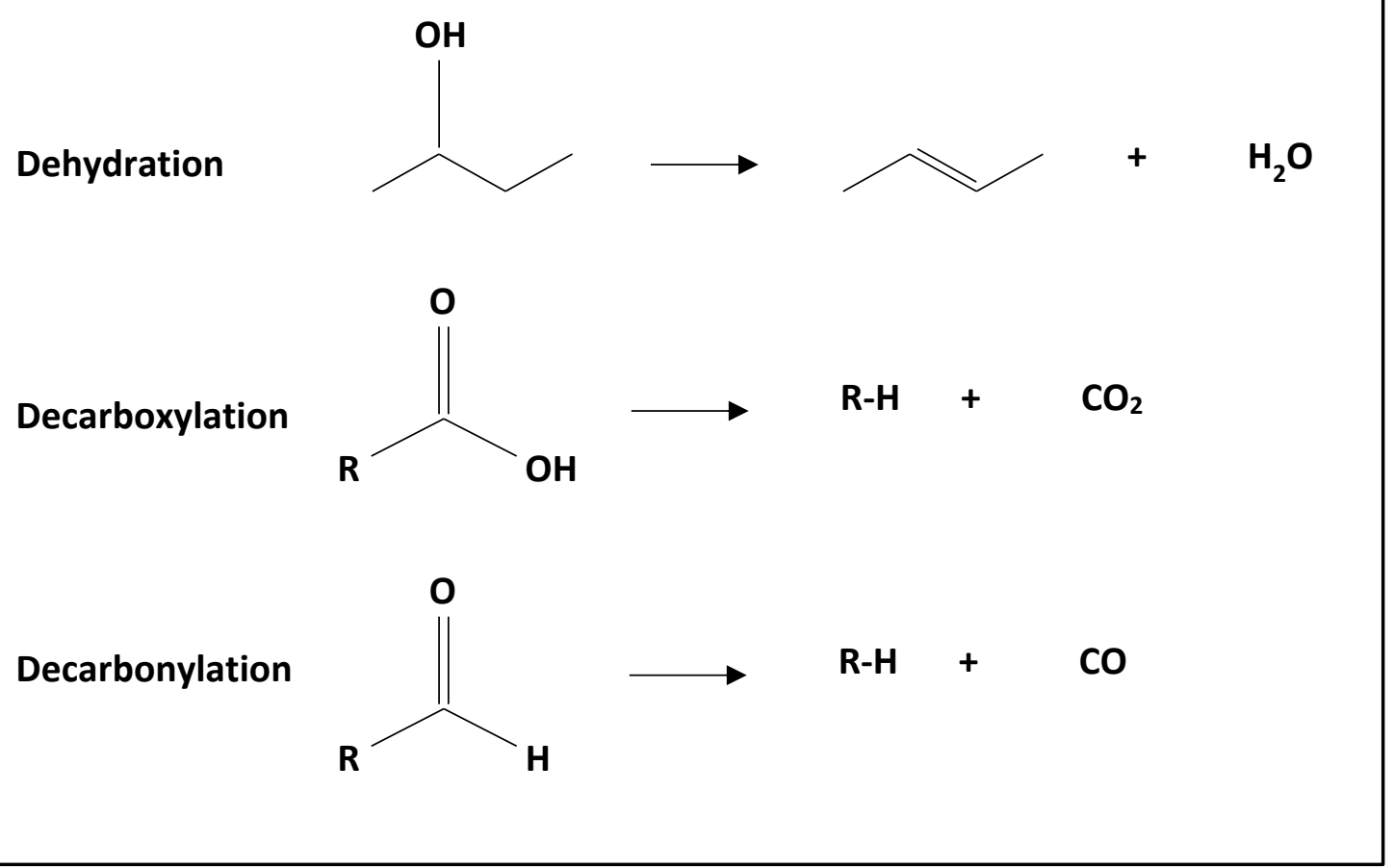

Figure 4: Catalytic cracking reactions (Nolte \& Shanks, 2017)

Catalytic cracking has significant technical and economic advantages over HDO. In catalyst cracking, hydrogen is not required and reactions take place at similar conditions to pyrolysis (atmospheric pressure and moderate temperatures), which allows both processes to be carried out in a single reactor (Serrano-Ruiz \& Dumesic, 2012).

\subsubsection{Catalyst configuration}

Upgrading bio-oil can be achieved via ex situ or in situ catalytic pyrolysis. For ex situ catalytic pyrolysis, the biomass is first pyrolysed, then the resulting vapours are passed over the catalyst in a second reactor, where deoxygenation takes place (Nolte \& Shanks, 2017). Pyrolysis and catalysis occur in separate reactors therefore, the operating conditions of both reactions can be optimised. Additionally, char can easily be separated from pyrolysis vapours prior to catalytic conversion to reduce catalyst deactivation (Wang, Dai, et al., 2017). The disadvantages are that the vapour residence time increases as the vapour stream travels to the ex situ reactor and eventually the condenser, and the second reactor adds to the capital cost of the process (Yildiz, Ronsse, Duren \& Prins, 2016).

For in situ catalytic pyrolysis, the biomass and catalyst are added to the pyrolysis reactor simultaneously, allowing the pyrolysis vapours to be deoxygenated as they are produced (Nolte \& Shanks, 2017), and reducing unfavourable recombination reactions. The disadvantages are that both pyrolysis and catalysis occur at the same temperature, which limits the opportunity to optimise both reactions, and char and ash may accumulate on the catalyst's surface, poisoning the catalyst (Wang, 
Dai, et al., 2017). Moreover, the catalyst is invariably entrained with the char, and is either discarded or recycled by combusting the char and separating the ash (Dayton, Carpenter, Kataria, Peters, Barbee, Mante \& Gupta, 2015). Both are unfavourable for process economics. Furthermore, higher catalyst loading is required for the in situ configuration to achieve the same quality of bio-oil produced from the ex situ configuration (Yildiz et al., 2016).

Li and colleagues (Li, Ou, Dang, Meyer, Jones, Brown \& Wright, 2015) compared ex situ and in situ catalytic pyrolysis processes, and found that the capital cost of the ex situ configuration is higher than the in situ configuration; the catalyst life span for the ex situ configuration is longer than the in situ configuration due to the reduced risk of deactivation, which also suggests that the ex situ configuration requires less maintenance; the catalyst in the ex situ configuration can be recycled more readily than the in situ configuration; and both configurations produce similar organic fraction yields but the in situ configuration produces significantly more aromatics and phenols (Li et al., 2015).

\subsubsection{Catalyst mixing}

The biomass and catalyst are combined for in situ catalytic pyrolysis by impregnation or dry mixing (Collard et al., 2012). Impregnation involves combining the biomass, catalyst and water to form a wellmixed slurry followed by drying to remove the water (Couhert, Commandre \& Salvador, 2009; Richardson, Blin, Volle, Motuzas \& Julbe, 2010). Uniform dispersion of the catalyst and intimate contact between the biomass and catalyst are achieved. Therefore, reactions taking place between volatiles and reactions taking place in the biomass matrix are both catalysed, which has a significant effect on the yield and composition of char and other products (Collard et al., 2012). Impregnation simultaneously washes the biomass particles and removes some of the inorganic content that would have formed part of the ash (Bru, Blin, Julbe \& Volle, 2007). Dry mixing involves mechanically combining the biomass and catalyst. This method does not achieve the same intimate contact between the biomass and catalyst as impregnation but it does not require additional energy for drying, which makes it a lot cheaper.

\subsubsection{Catalyst to feed ratio}

A high catalyst to feed ratio results in a lower bio-oil yield but a better bio-oil quality in terms of lower oxygen content and higher HHV (Dhyani \& Bhaskar, 2018; Paasikallio, Kalogiannis, Lappas, Lehto \& Lehtonen, 2017). The optimal catalyst to feed ratio is not only dependent on the type of catalyst and biomass but also on process specific factors such as reactor design and pyrolysis temperature. In general, high catalyst to feed ratios will enhance catalyst cracking (increasing bio-oil quality), and produce water, non-condensable gases and coke (decreasing bio-oil yield) (Paasikallio et al., 2017). Conversely, low catalyst to feed ratios (1:6 to $1: 8)$ will not necessarily be sufficient enough to significantly deoxygenate bio-oil because some vapours could leave the pyrolysis reactor without 
contacting the catalyst (Veses, Aznar, López, Callén, Murillo \& García, 2015; Yildiz et al., 2016) therefore, finding a balance is essential to producing the desired bio-oil quality. Veses and colleagues (2014) found that the optimal catalyst to feed ratio was 1:3 for CaO catalytic pyrolysis of pine wood chips at $450{ }^{\circ} \mathrm{C}$ since higher catalyst to feed ratios of $3: 1,1: 1$ and even $1: 2$ produced lower bio-oil yields (Veses, Aznar, Martinez, Martinez, Lopez, Navarro, Callen, Murillo \& Garcia, 2014).

Lin and colleagues (2010) conducted in situ catalytic pyrolysis at $520{ }^{\circ} \mathrm{C}$ with dry mixed white pine powder and $\mathrm{CaO}$ catalyst. The catalyst to feed ratio was 5:1 and silica sand was used as a heat carrier. CaO decreased oxygen content in the organic fraction from 39 wt. \% to 31 wt. \%. The researchers found that high catalyst to feed ratios were required to sufficiently deoxygenate the biooil as a result of the low contact achieved between the catalyst and biomass (Lin, Zhang, Zhang \& Zhang, 2010).

\subsubsection{Catalyst selection}

The ideal catalyst is highly active, selective towards specific compounds, resistant to deactivation, readily recyclable and effective at low catalyst to feed ratios (Veses et al., 2014). A catalyst is designed to make bio-oil less viscous by increasing cracking reactions and less corrosive by decreasing the formation of carboxylic acids. A catalyst is also designed to increase the heating value of bio-oil by enhancing the production of valuable hydrocarbons (Balat et al., 2009).

It is important to choose a catalyst that will select for desirable compounds. The following oxygen-containing functional groups (Oasmaa et al., 2003) are considered undesirable in bio-oil intended for co-processing in an existing oil refinery (Stefanidis, Kalogiannis, Iliopoulou, Lappas \& Pilavachi, 2011; Stefanidis, Karakoulia, Kalogiannis, Iliopoulou, Delimitis, Yiannoulakis, Zampetakis, Lappas \& Triantafyllidis, 2016):

- Ketones and aldehydes enhance aging reactions.

- Acids make bio-oil corrosive to materials of construction commonly found in an oil refinery. Acids also catalyse polymerisation reactions and reduce the stability of bio-oil.

- Esters and ethers reduce the heating value of bio-oil.

- Polycyclic aromatic hydrocarbons do not contain oxygen but are considered undesirable because of their carcinogenic properties that are hazardous for the environment, and polycyclic aromatic hydrocarbons also act as precursors for coke formation that can lead to catalyst deactivation.

The desired functional groups in bio-oil are aromatic and aliphatic hydrocarbons, and alcohols. Aliphatic and aromatic hydrocarbons have low oxygen and high energy content, which makes bio-oil more compatible with conventional hydrocarbon fuels (Wang, Dayton, Peters \& Mante, 2017). In addition, phenols and furans are high value-added chemicals that can make bio-oil production economically attractive (Stefanidis et al., 2011). 
Basic metal oxide catalysts such as $\mathrm{CaO}$ and $\mathrm{MgO}$ are covered in more detail as this type of catalyst was chosen for the pilot plant experiments conducted by Chireshe (2019) for this project. A review of traditional and promising catalysts for the catalytic pyrolysis of biomass is given below.

\subsubsection{Zeolites}

Zeolites are made up of alumina and silica units, linked by oxygen anions in a crystalline tetrahedral structure (Morris, 2011). Zeolites can have a variety of crystalline structures with open cavities that influence their selectivity. Naturally occurring zeolites such as chabazite and mordenite are not as vastly employed in industry as their synthetic counterparts (Galadima \& Muraza, 2015).

H-ZSM-5 is the most common zeolite catalyst employed in industry (Dickerson \& Soria, 2013). Zhang and colleagues (2014) reported that H-ZSM-5 catalytic pyrolysis of Aspen wood lignin (3:1 catalyst to feed ratio) reduced the oxygen content of the bio-oil from 28 to 4 wt. \%, increased the HHV from 30 to $46 \mathrm{MJ} / \mathrm{kg}$, and increased the yield of toluene (Zhang, Resende \& Moutsoglou, 2014). Unfortunately, zeolite catalysts undergo irreversible deactivation (de-aluminate) in the presence of bio-oil with a high water content (Serrano-Ruiz \& Dumesic, 2012).

\subsubsection{Acidic metal oxides}

Metal oxides have acid, base or combined properties due to lattice imperfections, such as electron holes and dislocations. Acid and base sites on the surface of metal oxides alter the composition of the bio-oil produced by promoting or preventing the formation of certain products (Wang, Dai, et al., 2017).

Acidic metal oxides such as $\mathrm{Al}_{2} \mathrm{O}_{3}$ and $\mathrm{SiO}_{2}$ deoxygenate bio-oil via cracking, dehydration and decarbonylation reactions (Wang, Dai, et al., 2017). Catalytic pyrolysis with $\mathrm{Al}_{2} \mathrm{O}_{3}$ produces more aromatic hydrocarbons and polycyclic aromatic hydrocarbons. Silicon dioxide catalysts with weak acidity and medium porosity are effective at removing acids, ketones and aldehydes and preventing coke and polycyclic aromatic hydrocarbon formation. Stefanidis and colleagues (2011) conducted in situ catalytic pyrolysis of beech wood at $500{ }^{\circ} \mathrm{C}$ with $\mathrm{Al}_{2} \mathrm{O}_{3}$ and $\mathrm{SiO}_{2}-\mathrm{Al}_{2} \mathrm{O}_{3}$ catalysts at a catalyst to feed ratio of $1: 2 . \mathrm{Al}_{2} \mathrm{O}_{3}$ and $\mathrm{SiO}_{2}-\mathrm{Al}_{2} \mathrm{O}_{3}$ both decreased oxygen content in the organic fraction of the biooil from 41.68 wt. \% to 24.00 and 30.45 wt. \%, respectively (Stefanidis et al., 2011).

\subsubsection{Basic metal oxides}

Basic metal oxides such as $\mathrm{MgO}$ and $\mathrm{CaO}$ deoxygenate pyrolysis vapours via ketonisation and aldol condensation of carboxylic acid and carbonyl compounds (Liu et al., 2014; Wang, Dai, et al., 2017). $\mathrm{MgO}$ decreases the bio-oil yield but improves its quality in terms of heating value, oxygen content and hydrocarbon distribution. CaO decreases selectivity towards phenols and sugars, removes acids and increases selectivity towards ketones. Catalytic pyrolysis with $\mathrm{CaO}$ also reacts with $\mathrm{CO}_{2}$-like compounds 
at temperatures above $400{ }^{\circ} \mathrm{C}$ to form $\mathrm{CaCO}_{3}$, which reduces $\mathrm{CO}_{2}$ emissions during pyrolysis (Carpenter, Westover, Czernik \& Jablonski, 2014; Shadangi \& Mohanty, 2014a; Veses et al., 2014).

Stefanidis and colleagues (2011) found that catalytic pyrolysis with MgO produced the lowest oxygen content and consequently the lowest organic fraction yield out of all the catalysts tested (such as $\mathrm{Al}_{2} \mathrm{O}_{3}, \mathrm{H}-\mathrm{ZSM}-5, \mathrm{SiO}_{2}-\mathrm{Al}_{2} \mathrm{O}_{3}$ and $\left.\mathrm{NiO}\right)$. $\mathrm{MgO}$ also produced relatively low amounts of aromatic hydrocarbons and polycyclic aromatic hydrocarbons, and relatively high amounts of phenols and ketones (Stefanidis et al., 2011).

A summary of catalytic pyrolysis results reported in literature is presented in Table 7. In each case (where data was available), the addition of a basic metal oxide catalyst decreased the oxygen content and increased the HHV of the organic fraction. The organic fraction yield generally decreased under catalytic pyrolysis conditions but Veses and colleagues (2014) observed an increase because better separation between the organic and aqueous fractions could be achieved due to an increase from 50 to $60 \mathrm{wt}$ \% in the water content of the aqueous fraction (Veses et al., 2014). Lin and colleagues (2010) reported that a high catalyst to feed ratio (5:1) was required to overcome the relatively low contact efficiency achieved in the fluidised bed reactor operating at a high superficial gas velocity (Lin et al., 2010).

Table 7: Effect of pyrolysis temperature (T) and catalyst to feed ratio (C:F) on organic fraction yield, oxygen content and HHV

\begin{tabular}{|c|c|c|c|c|c|c|c|c|c|c|}
\hline \multirow[b]{2}{*}{ Feed } & \multirow[b]{2}{*}{ Catalyst } & \multirow[b]{2}{*}{$\mathrm{T}\left({ }^{\circ} \mathrm{C}\right)$} & \multirow[b]{2}{*}{$C: F$} & \multicolumn{2}{|c|}{ Yield (wt. \%) } & \multicolumn{2}{|c|}{ Oxygen (wt. \%) } & \multicolumn{2}{|c|}{ HHV (MJ/kg) } & \multirow[b]{2}{*}{ Reference } \\
\hline & & & & $\frac{0}{\frac{0}{2}}$ & $\begin{array}{l}\frac{0}{0} \\
\frac{0}{0} \\
\frac{\pi}{00} \\
\frac{0}{2}\end{array}$ & $\frac{0}{\frac{0}{2}}$ & $\begin{array}{l}\frac{0}{d} \\
\frac{0}{0} \\
\frac{0}{00} \\
\frac{0}{2}\end{array}$ & $\frac{0}{\frac{0}{2}}$ & $\begin{array}{l}\frac{0}{d} \\
\frac{0}{0} \\
\frac{0}{00} \\
\frac{0}{2}\end{array}$ & \\
\hline Pine & $\mathrm{CaO}$ & 520 & $5: 1$ & 39.4 & 34.1 & 39.0 & 31.0 & - & - & (Lin et al., 2010) \\
\hline Beech & $\begin{array}{l}\mathrm{Al}_{2} \mathrm{O}_{3} \\
\mathrm{MgO}\end{array}$ & 500 & $1: 2$ & 37.4 & $\begin{array}{l}16.6 \\
15.0\end{array}$ & 41.7 & $\begin{array}{l}24.0 \\
21.9\end{array}$ & $\begin{array}{l}- \\
-\end{array}$ & $\begin{array}{l}- \\
-\end{array}$ & $\begin{array}{c}\text { (Stefanidis et } \\
\text { al., 2011) }\end{array}$ \\
\hline Pine & $\begin{array}{c}\mathrm{CaO}-\mathrm{MgO} \\
\mathrm{CaO}\end{array}$ & 450 & $1: 3$ & 27.0 & $\begin{array}{l}31.0 \\
34.0\end{array}$ & 31.5 & $\begin{array}{l}25.4 \\
24.2\end{array}$ & 22.4 & $\begin{array}{l}30.2 \\
29.6\end{array}$ & $\begin{array}{c}\text { (Veses et al., } \\
\text { 2014) }\end{array}$ \\
\hline $\begin{array}{l}\text { Karanja } \\
\text { seed }\end{array}$ & $\mathrm{CaO}$ & 550 & $1: 8$ & 33.0 & 31.3 & - & - & 22.5 & 23.0 & $\begin{array}{c}\text { (Shadangi \& } \\
\text { Mohanty, } \\
\text { 2014b) }\end{array}$ \\
\hline
\end{tabular}

\subsubsection{Low cost materials}

Low cost materials such as clay minerals (attapulgite, bentonite and sepiolite) and an industrial aluminium oxide residue known as red mud have shown promising results for catalytic pyrolysis. The 
advantage of selecting a low cost material such as $\mathrm{CaO}$ or $\mathrm{MgO}$ for the catalyst is that for in situ configurations, the catalyst does not have to be recovered or recycled at the end of the process (Veses et al., 2015). Thus, the cost associated with either separating the essential nutrients ( $\mathrm{Ca}$ or $\mathrm{Mg}$ ) from the char or combusting the char to recover the catalyst is avoided; instead the biochar and essential nutrients can be sold as a soil additive (Carpenter et al., 2014).

Natural $\mathrm{MgO}$, derived via thermal decomposition of magnesium carbonate $\left(\mathrm{MgCO}_{3}\right)$, is a promising cost effective and more environmentally friendly alternative to acidic synthetic zeolites. Basic oxide catalysts also have a greater tolerance against deactivation induced by alkali metals present in the ash than zeolites (Stefanidis et al., 2016).

\subsubsection{Catalytic pyrolysis challenges}

Coke is a product of catalysis, while char is a product of pyrolysis. Coke formation occurs when small biomass particles undergo catalytic polymerisation inside catalyst pores, whereas primary and secondary pyrolysis mechanisms contribute to char formation. Coke formation shortens the lifespan of the catalyst through catalyst deactivation, which can negatively impact process economics (Du, Valla \& Bollas, 2013). Carlson and colleagues (2009) reported that coke formation, however, can be reduced by applying high heating rates, maintaining high catalyst to feed ratios and selecting optimal catalysts (Carlson, Tompsett, Conner \& Huber, 2009). A thorough understanding of the mechanisms at play in the catalytic pyrolysis of biomass to produce upgraded bio-oil still remains a major research challenge (Lappas, Kalogiannis, Iliopoulou, Triantafyllidis \& Stefanidis, 2012).

\subsection{Bio-oil co-processing in a crude-oil refinery}

The highly oxygenated composition, physiochemical properties and instability under storage prevents bio-oil from being directly blended with petroleum fractions in crude-oil refineries. This is problematic for successful co-processing (blending) via hydrotreating but less so for co-processing via fluid catalytic cracking $(\mathrm{FCC})$, which can be accomplished without physically mixing the bio-oil and petroleum fractions (Bezergianni, Dimitriadis, Kikhtyanin \& Kubička, 2018). Fluid catalytic cracking is one of the main processes used in crude-oil refineries around the world to convert vacuum gas oil (VGO) or other heavy petroleum fractions into high-value products such as gasoline, liquefied petroleum gas (LPG), diesel-range light cycle oil (LCO) and heavy cycle oil (HCO) (Pinho, de Almeida, Mendes, Casavechia, Talmadge, Kinchin \& Chum, 2017). A possible route for co-processing bio-oil in an oil refinery is shown using a block flow diagram in Figure 5. Heavy petroleum fractions such as VGO are typically hydrotreated before conversion in the FCC unit to improve hydrogen-to-carbon ratios (Talmadge, Baldwin, Biddy, Mccormick, Beckham, Ferguson, Czernik, Magrini-bair, Foust, Metelski, Hetrick \& Nimlos, 2014). However, at a much lower concentration to VGO, crude or upgraded bio-oil can be 
directly injected into the FCC unit without prior hydrotreating. The FCC gasoline and LCO products are then hydrotreated to remove sulphur in compliance with fuel specifications (Pinho et al., 2017).

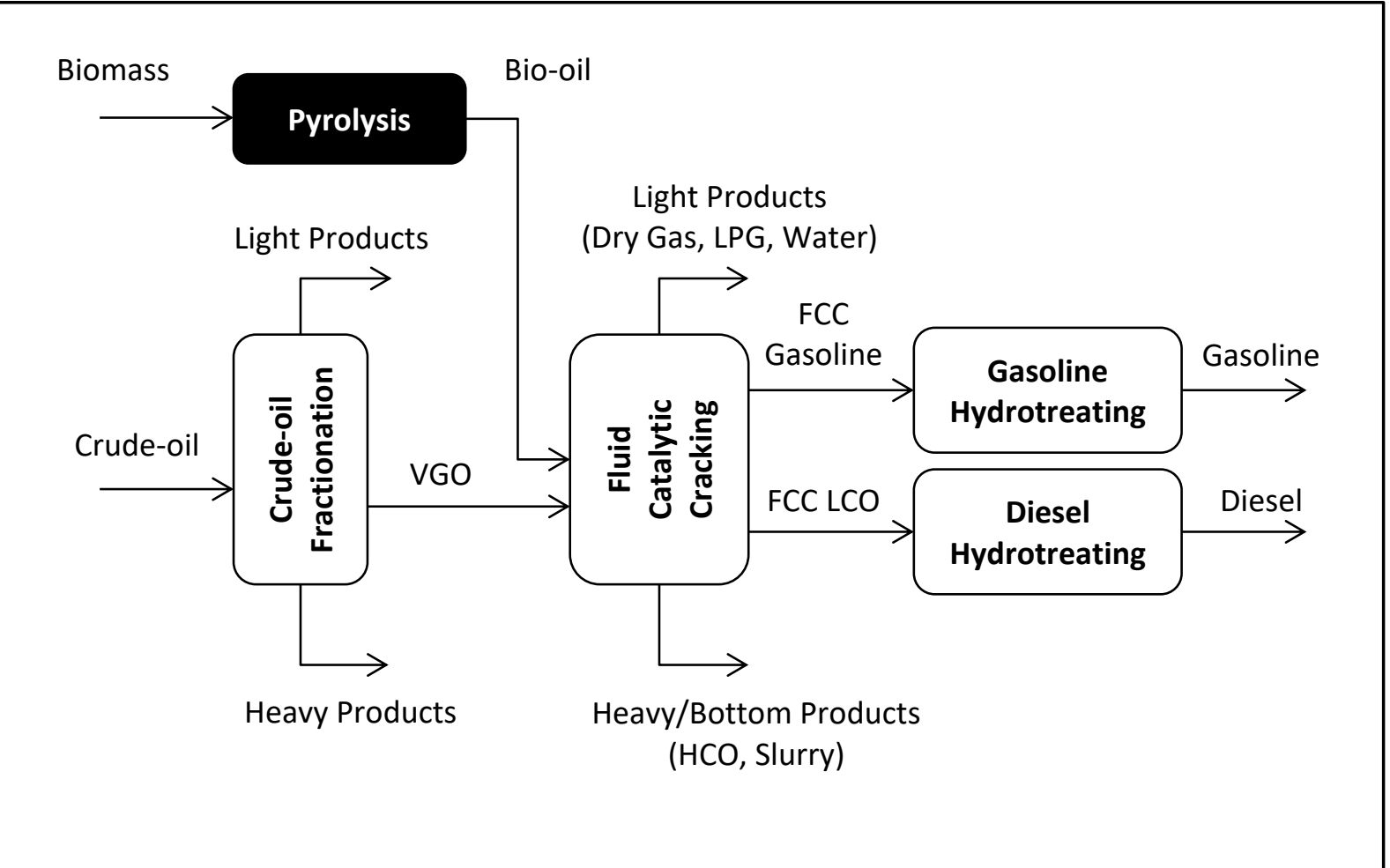

Figure 5: Co-processing bio-oil and VGO in an oil refinery (redrawn from Pinho et al. (2017))

A review of studies previously conducted on co-processing bio-oil with VGO is given below. Crude bio-oil refers to bio-oil produced via pyrolysis without further upgrading, and upgraded bio-oil refers to bio-oil produced via catalytic pyrolysis or pyrolysis with further upgrading (for example, hydrotreating). The blending ratio is defined as the mass percent of bio-oil present in the FCC feed.

Pinho and colleagues (2015) co-processed crude bio-oil produced via fast pyrolysis of pine wood chips with commercial VGO in a $150 \mathrm{~kg} / \mathrm{h}$ FCC demonstration-scale unit. Blends of 10 and 20 wt. $\%$ fast pyrolysis oil (FPO) were co-processed with VGO to produce high-value gasoline and diesel range products. An 8.2 wt. \% decrease in gasoline yield was observed when 20 wt. \% FPO was co-processed due to the dilution effect caused by the large amount of water present in the FPO. There was also a significant 19.6 wt. \% increase in coke yield with 20 wt. \% FPO but an insignificant increase with 10 wt. \% FPO. The first of its kind co-processing FCC demonstration-scale unit overcame the challenges experienced with blending FPO and VGO at lab-scale. Co-processing 20 wt. \% FPO was achieved with separate feed injection points into the FCC reactor. The authors concluded that up to $20 \mathrm{wt}$ \% FPO could be directly co-processed with VGO in an FCC unit without prior upgrading (Pinho, De Almeida, Mendes, Ximenes \& Casavechia, 2015). 
The same research group then co-processed blends of 5 and 10 wt. \% FPO with VGO in a 200 $\mathrm{kg} / \mathrm{h}$ FCC demonstration-scale unit. The researchers suggested that even though co-processing $20 \mathrm{wt}$. $\%$ crude bio-oil is technically feasible, co-processing $5 \mathrm{wt}$. \% bio-oil is a reasonable starting point for the current commercial supply of bio-oil relative to VGO. Approximately 84 and $89 \mathrm{wt}$. \% of the 50.7 wt. \% oxygen present in the crude bio-oil was converted into $\mathrm{CO}, \mathrm{H}_{2} \mathrm{O}$ and some $\mathrm{CO}_{2}$ when VGO was co-processed with 5 and $10 \mathrm{wt}$. \% FPO, respectively. Furthermore, the successful demonstration of coprocessing crude bio-oil suggests that it would also be feasible to co-process upgraded bio-oil (Pinho et al., 2017).

Lindfors and colleagues (2015) investigated the effect of upgrading crude bio-oil prior to coprocessing on coke and liquid product yields. Co-processing was conducted with dry thermal bio-oil (6.6 wt. \% moisture), catalytic pyrolysis oil (CPO) and hydrotreated pyrolysis oil (HPO) in a $20 \mathrm{~kg} / \mathrm{h}$ pilot-scale micro activity test (MAT) reactor. Co-processing $20 \mathrm{wt}$. \% bio-component resulted in higher liquid yields for the upgraded bio-oils compared to crude bio-oil, however, liquid yields were lower than catalytic cracking of pure VGO overall. Co-processing $20 \mathrm{wt}$. \% bio-component also produced more coke than catalytic cracking of pure VGO overall (Lindfors, Paasikallio, Kuoppala, Reinikainen, Oasmaa \& Solantausta, 2015).

Thegarid and colleagues (2014) are of the view that crude bio-oil cannot be co-processed without upgrading the bio-oil first, either by HDO or catalytic pyrolysis. The researchers compared coprocessing $10 \mathrm{wt}$ \% \% CPO with VGO to co-processing $10 \mathrm{wt}$. \% HDO-oil with VGO, and found that both blends produced similar liquid products in terms of distribution and quality therefore, bio-oil can be upgraded in a single step with a suitable catalyst instead of the additional and costly hydrogenation step after pyrolysis (Thegarid, Fogassy, Schuurman, Mirodatos, Stefanidis, Iliopoulou, Kalogiannis \& Lappas, 2014).

Ibarra, Veloso and colleagues (2016) studied two coke deposition pathways by co-processing 20 wt. \% FPO and VGO in a riser simulator reactor (RSR). Cracking FPO tends to form soluble and insoluble coke with high concentrations of hydrogen and oxygen, whereas cracking VGO results in the formation of coke with high concentrations of aromatics. The authors found that when these coke formation pathways interact (i.e. in co-processing), the result was a decrease in coke formation. The high water content from the FPO formed steam and inhibited the VGO coke deposition pathway, while the hydrocarbons from the VGO act as hydrogen donors for the FPO oxygenates and inhibited the FPO coke deactivation pathway (Ibarra, Veloso, Bilbao, Arandes \& Castaño, 2016).

Wang, Venderbosch and Fang (2018) investigated the co-processing of $10 \mathrm{wt}$. \% crude (Crude$\mathrm{PL})$, mildly hydrotreated (SPO-1) and severely hydrotreated (SPO-2) bio-oils with VGO in a pilot-scale FCC unit operated at four different catalyst to oil (C/O) ratios $(5.1,6.3,7.2$ and 8.7). The conversion of co-processed crude and upgraded bio-oils with VGO and pure VGO increased as the C/O ratio increased. The results for dry gas, gasoline, coke, and $\mathrm{CO}$ and $\mathrm{CO}_{2}$ yields for increasing conversion are 
given in Figure 6. For all co-processing tests, the dry gas yield decreased by approximately half compared to pure VGO catalytic cracking as a result of a decrease in hydrogen donors from the VGO needed for hydrogen transfer reactions to take place. Co-processing of upgraded bio-oils produced comparable or slightly higher gasoline yields than pure VGO catalytic cracking, while co-processing crude bio-oil produced significantly lower gasoline yields due to lower carbon and higher oxygen contents. Co-processing of upgraded bio-oils could effectively transform more carbon into gasoline than pure VGO catalytic cracking by suppressing over-cracking reactions and lowering LPG yields. In addition, significant amounts of $\mathrm{CO}$ and $\mathrm{CO}_{2}$ were produced via decarbonylation and decarboxylation reactions in co-processing tests due to the presence of oxygenated compounds in the bio-oils (Wang, Venderbosch \& Fang, 2018). Co-processing crude and (less so) upgraded bio-oils in existing FCC units at oil refineries may require modifications to account for pressure build-up and increased capacity (van Dyk, Su, McMillan \& Saddler, 2019). Bio-oils with high water contents may also damage FCC catalysts and effect downstream processes (Talmadge et al., 2014).

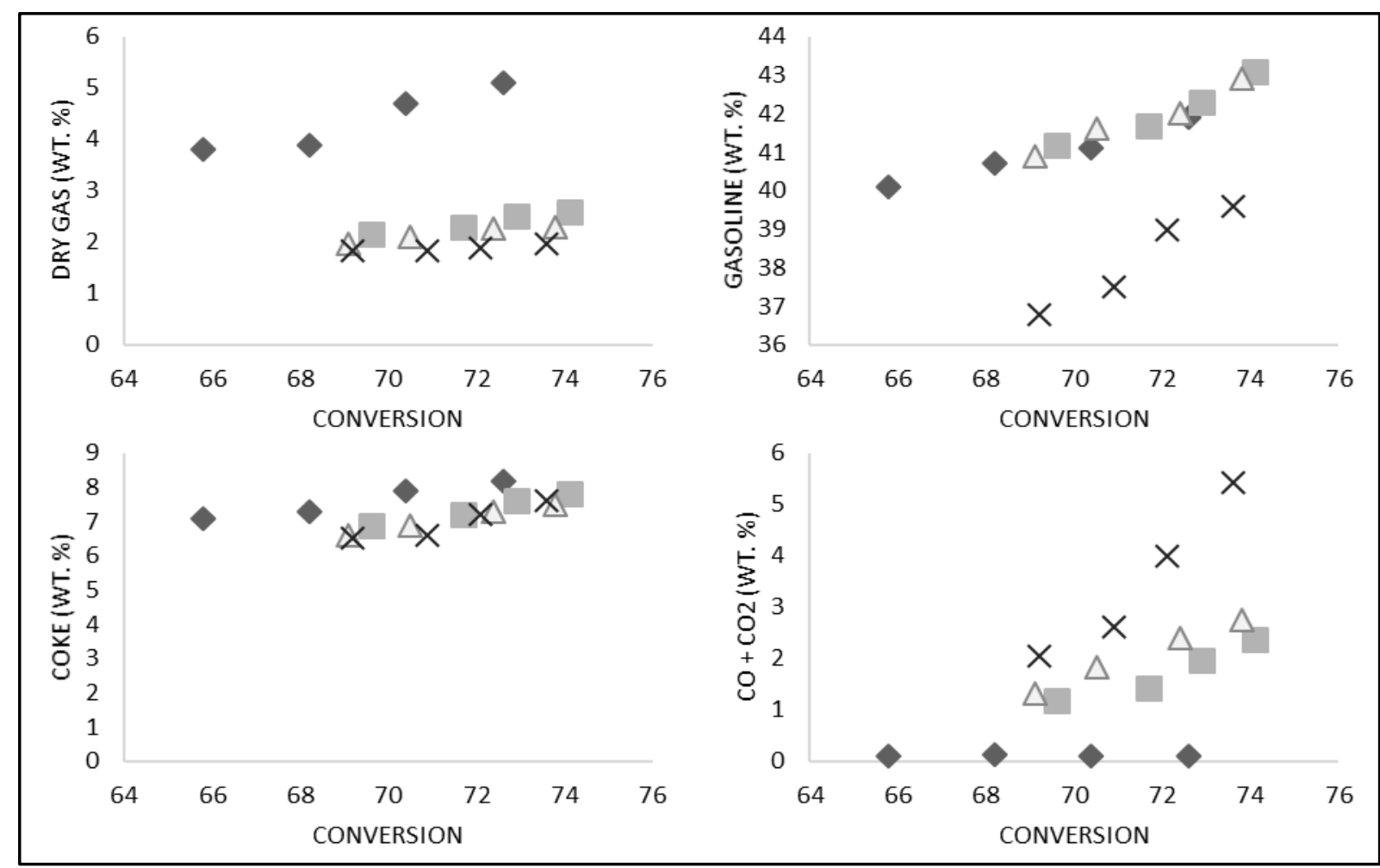

Figure 6: Dry gas, gasoline, coke, and $\mathrm{CO}$ and $\mathrm{CO}_{2}$ yields for increasing conversion of pure VGO catalytic cracking and co-processing crude and upgraded bio-oils (redrawn from Wang et al. (2018)) $-\checkmark$ VGO, $\square$ SPO-2, $\triangle$ SPO-1 and $X$ Crude-PL

Previous studies on co-processing crude and upgraded bio-oils with VGO are presented in Table 8. Co-processing $20 \mathrm{wt}$. \% crude and upgraded bio-oils generally increased coke yield. The interaction of the coke deposition pathways as described by Ibarra, Veloso and colleagues (2016) due 
to co-processing crude bio-oil with a high water content was the only exception (Ibarra et al., 2016). Co-processing 10 wt. \% crude and upgraded bio-oils resulted in a negligible change in coke yield at pilot and demonstration-scale, however, co-processing 10 wt. \% upgraded bio-oil produced more coke at lab-scale (de Miguel Mercader, Groeneveld, Kersten, Way, Schaverien \& Hogendoorn, 2010). Pinho and colleagues (2015) pointed out that co-processing on a larger scale can improve feed dispersion and catalyst contact that is problematic at lab-scale (Pinho et al., 2015). Co-processing 10 wt. \% upgraded bio-oil had negligible effect on total liquid yield (gasoline, LPG, LCO and bottoms), however, co-processing the same amount of crude bio-oil decreased total liquid yield. Co-processing 10 wt. \% upgraded bio-oil containing up to $28.8 \mathrm{wt}$. \% water at pilot-scale also had negligible effect on coke and total liquid yield (Wang, Li \& Fang, 2016). Furthermore, co-processing 5 wt. \% crude bio-oil decreased coke yield and had negligible effect on total liquid yield. Therefore, a maximum of 5 wt. \% crude biooil and a maximum of 10 wt. \% upgraded bio-oil will be considered for co-processing in this project.

Table 8: Co-processing crude and upgraded bio-oils with VGO in FCC units

\begin{tabular}{|c|c|c|c|c|c|c|c|c|c|}
\hline $\begin{array}{l}\text { Blend } \\
\text { (wt. \%) }\end{array}$ & $\frac{0}{\frac{0}{2}}$ & $\begin{array}{l}\text { xygen } \\
\%, \mathrm{db}\end{array}$ & $\begin{array}{l}\overline{\bar{o}} \\
\text { o } \\
\text { ำ }\end{array}$ & $\begin{array}{l}\text { Water } \\
\text { (wt. \%) }\end{array}$ & $\begin{array}{c}\text { HHV } \\
\text { (MJ/kg) }\end{array}$ & Coke & $\begin{array}{l}\text { Total } \\
\text { Liquid }\end{array}$ & Scale & Reference \\
\hline $\begin{array}{l}5 \\
10\end{array}$ & 50.7 & - & - & 31.9 & - & $\begin{array}{c}\downarrow \\
N / A\end{array}$ & $\begin{array}{l}\text { N/A } \\
\downarrow\end{array}$ & Demo & (Pinho et al., 2017) \\
\hline $\begin{array}{l}10 \\
20\end{array}$ & 51.15 & - & - & 25.5 & 21.46 & $\begin{array}{l}\text { N/A } \\
\uparrow\end{array}$ & $\begin{array}{l}\downarrow \\
\downarrow\end{array}$ & Demo & (Pinho et al., 2015) \\
\hline 20 & 37.8 & - & - & 46.5 & - & $\downarrow$ & $\downarrow$ & Lab & (Ibarra et al., 2016) \\
\hline 10 & - & 19.5 & - & 28.8 & - & $N / A$ & $N / A$ & Pilot & (Wang et al., 2016) \\
\hline 10 & - & $\begin{array}{l}27 \\
-\end{array}$ & $\begin{array}{l}- \\
21\end{array}$ & $\begin{array}{c}11 \\
3\end{array}$ & - & $\begin{array}{l}\uparrow \\
\uparrow\end{array}$ & $\begin{array}{l}N / A \\
N / A\end{array}$ & Lab & $\begin{array}{c}\text { (Thegarid et al., } \\
\text { 2014) }\end{array}$ \\
\hline 20 & $\begin{array}{c}36.5 \\
-\end{array}$ & $\begin{array}{l}- \\
22\end{array}$ & $\begin{array}{l}- \\
-\end{array}$ & $\begin{array}{l}6.7 \\
8.3\end{array}$ & $\begin{array}{l}22.1 \\
27.7\end{array}$ & $\begin{array}{l}\uparrow \\
\uparrow\end{array}$ & $\begin{array}{l}\downarrow \\
\downarrow\end{array}$ & Pilot & $\begin{array}{c}\text { (Lindfors et al., } \\
\text { 2015) }\end{array}$ \\
\hline 20 & - & - & 28 & 15.9 & 25.2 & $\uparrow$ & $\mathrm{N} / \mathrm{A}$ & Lab & $\begin{array}{c}\text { (de Miguel } \\
\text { Mercader et al., } \\
\text { 2010) }\end{array}$ \\
\hline 10 & $\begin{array}{c}50.97 \\
- \\
-\end{array}$ & $\begin{array}{l}- \\
- \\
-\end{array}$ & $\begin{array}{c}- \\
39.25 \\
27.43\end{array}$ & $\begin{array}{l}24.5 \\
12.5 \\
12.7\end{array}$ & - & $\begin{array}{l}\mathrm{N} / \mathrm{A} \\
\mathrm{N} / \mathrm{A} \\
\mathrm{N} / \mathrm{A}\end{array}$ & $\begin{array}{c}\downarrow \\
\text { N/A } \\
\text { N/A }\end{array}$ & Pilot & (Wang et al., 2018) \\
\hline
\end{tabular}


The feasibility of co-processing crude and upgraded bio-oils with VGO in an FCC unit is not only evaluated by reaction conditions and product yields but also by the amount of renewable carbon that is present in the total liquid product (Bezergianni et al., 2018). Wang, Venderbosch and Fang (2018) reported that co-processing upgraded bio-oils with VGO produced more than double the amount of renewable carbon in the total liquid product than co-processing crude bio-oil (Wang et al., 2018). Pinho and colleagues (2015) reported 2 and $5 \mathrm{wt}$. \% renewable carbon in the total liquid produced via coprocessing 10 and 20 wt. \% crude bio-oil with VGO, respectively. The carbon content in bio-oil was reduced from 42.35 wt. \% to approximately 30 wt. \% in the FCC unit primarily because of decarbonylation reactions taking place (Pinho et al., 2015). The same research group later coprocessed 5 wt. \% crude bio-oil with VGO and reported 1 wt. \% renewable carbon in the total liquid product (Pinho et al., 2017). Two more studies that both co-processed 10 wt. \% upgraded bio-oil with VGO reported 7 wt. \% (Wang et al., 2016) and 7.5 wt. \% (Fogassy, Thegarid, Schuurman \& Mirodatos, 2012) renewable carbon in the total liquid product. A summary of the renewable carbon content in the total liquid produced via co-processing crude and upgraded bio-oils with VGO is given in Table 9.

Table 9: Renewable carbon content of total liquid produced from co-processing crude and upgraded bio-oils with VGO

\begin{tabular}{|lccc|}
\hline Blend (wt. \%) & \multicolumn{2}{l}{ Renewable Carbon (wt. \%) } & Reference \\
& Crude & Upgraded & (Wang et al., 2018) \\
10 & 2.3 & 5.6 (SPO-1) & \\
5 & 1.0 & 6.4 (SPO-2) & (Pinho et al., 2017) \\
10 & 2.0 & - & (Pinho et al., 2015) \\
10 & 5.0 & - & (Wang et al., 2016) \\
10 & - & 7.0 & (Fogassy et al., 2012) \\
\hline
\end{tabular}

\subsection{Techno-economic analysis}

A techno-economic analysis (TEA) is used to evaluate the technical and economic performances of a new and innovative product design or to make existing product designs more competitive (Brown \& Brown, 2013; Do \& Lim, 2016). Ringer and colleagues (2006) conducted a TEA on the production of crude bio-oil via fast pyrolysis of wood chips at a production rate of $550 \mathrm{dry}$ MT/day. The internal rate of return (IRR) for the process and minimum selling price (MSP) of the bio-oil was $10 \%$ and \$7.62/GJ on a lower heating value (LHV) basis (\$0.16/L for an assumed $17 \mathrm{MJ} / \mathrm{kg} \mathrm{LHV}$ and $1200 \mathrm{~kg} / \mathrm{m}^{3} \mathrm{density)}$ ), respectively. The Total Capital Investment $(\mathrm{TCl})$ for the process was \$48.3 million (Ringer, Putsche \& Scahill, 2006). 
Wang and Jan (2018) conducted a TEA on the production of crude bio-oil via fast pyrolysis of rice husks at a biomass throughput ( 9 wt. \% moisture) of 1000 dry MT/day. The biochar co-product yield and carbon content were 27 and $20.4 \mathrm{wt}$. \%, respectively, and the biochar selling price was $\$ 100 / M T$. The MSP of bio-oil for a $10 \%$ IRR was $\$ 0.55 / L$, and the TCI for the process was $\$ 42.3$ million. The biochar contained almost 50 wt. \% silica sand, which hindered its value as a fertilizer therefore, biochar (as a credit) only represented $\$ 0.02 / L$ of bio-oil (Wang \& Jan, 2018).

There are several techno-economic analyses available in literature on upgraded bio-oils produced via fast pyrolysis or catalytic pyrolysis with zeolite catalysts, followed by hydrotreating (Anex, Aden, Kazi, Fortman, Swanson, Wright, Satrio, Brown, Daugaard, Platon, Kothandaraman, Hsu \& Dutta, 2010; Dutta, Sahir, Tan, Humbird, Snowden-swan, Meyer, Ross, Sexton, Yap \& Lukas, 2015; Jones, Meyer, Snowden-Swan, Asanga, Eric, Abhijit, Jacob \& Cafferty, 2013; Li et al., 2015; Thilakaratne, Brown, Li, Hu \& Brown, 2014; Wright, Satrio, Brown, Daugaard \& Hsu, 2010). Hydrogen is either produced onsite (usually biogenic) or purchased from an external source (usually anthropogenic). The latter is often cheaper but has a negative impact on the environment (Patel, Zhang \& Kumar, 2016). A summary of MSP and TCl for these studies is given in Table 10.

The MSP and TCl for the studies reported in Table 10 range from $\$ 0.53 / \mathrm{L}$ to $\$ 1.65 / \mathrm{L}$ and $\$ 200$ million to $\$ 700$ million, respectively. Feedstock cost is effected by feedstock production, collection, pre-treatment (e.g. chipping) and transportation distance (Roy \& Dias, 2017). The feedstock cost has a substantial impact (21.3\%) on MSP as reported by Carrasco and colleagues (2017). Onsite hydrogen production versus offsite procurement also has a significant impact on MSP. Hydrogen purchased from an external source gave the lowest MSP of $\$ 0.53 / \mathrm{L}$, while hydrogen produced onsite from purchased natural gas gave a high MSP of \$1.11/L. Wright and colleagues (2010) showed that hydrogen production onsite from a portion of the bio-oil gave a higher MSP of $\$ 0.82 / L$ than hydrogen purchased from an external source as the bio-oil yield in the former case decreased by $\sim 40$ vol. \% (Wright et al., 2010). The TCl estimate of $\$ 700$ million by Jones and colleagues (2013) is considerably higher than the other estimates as the authors estimated a total capital cost of $\$ 174$ million for the pyrolysis reactor (Jones et al., 2013), whereas Dutta and colleagues (2015) assumed a substantially lower total capital cost of $\$ 92.5$ million (Dutta et al., 2015). 
Table 10: MSP and TCl of upgraded bio-oil production via pyrolysis followed by hydrotreating (2000 dry MT/day capacity, 10\% IRR, FR: forest residue, CS: corn stover, NG: natural gas)

\begin{tabular}{|c|c|c|c|c|c|c|c|}
\hline Feedstock & $\begin{array}{c}\text { Feedstock } \\
\text { Cost } \\
\text { (\$/MT) }\end{array}$ & Pyrolysis & Hydrogen & $\begin{array}{l}\text { MSP } \\
(\$ / L)\end{array}$ & $\begin{array}{c}\mathrm{TCl} \\
(\$ \mathrm{~m})\end{array}$ & $\begin{array}{l}\text { Cost } \\
\text { Year }\end{array}$ & Reference \\
\hline CS & 75 & Fast & $\begin{array}{l}\text { Onsite } \\
\text { Offsite }\end{array}$ & $\begin{array}{l}0.79 \\
0.53\end{array}$ & $\begin{array}{l}280 \\
200\end{array}$ & 2010 & (Anex et al., 2010) \\
\hline CS & 83 & Fast & $\begin{array}{l}\text { Onsite } \\
\text { Offsite }\end{array}$ & $\begin{array}{l}0.82 \\
0.56\end{array}$ & $\begin{array}{l}287 \\
200\end{array}$ & 2010 & (Wright et al., 2010) \\
\hline Pine & 80 & $\begin{array}{l}\text { In situ } \\
\text { Ex situ }\end{array}$ & $\begin{array}{c}\text { Onsite (NG) } \\
-\end{array}$ & $\begin{array}{l}1.11 \\
1.13\end{array}$ & - & 2011 & (Li et al., 2015) \\
\hline Poplar & 97 & In situ & Onsite & 0.98 & 457 & 2011 & (Thilakaratne et al., 2014) \\
\hline Woody & 80 & $\begin{array}{l}\text { In situ } \\
\text { Ex situ }\end{array}$ & Onsite (NG) & $\begin{array}{l}0.91 \\
0.88\end{array}$ & $\begin{array}{l}546 \\
590\end{array}$ & 2011 & (Dutta et al., 2015) \\
\hline $\begin{array}{l}\text { Woody } \\
\text { (incl. FR) }\end{array}$ & 80 & Fast & Onsite (NG) & 0.90 & 700 & 2011 & (Jones et al., 2013) \\
\hline FR & 69 & Fast & Onsite & $1.65^{*}$ & 427 & 2015 & (Carrasco et al., 2017) \\
\hline
\end{tabular}

*15.3\% IRR

Techno-economic analyses on upgraded bio-oil production via catalytic pyrolysis with basic metal oxide catalysts such as $\mathrm{CaO}$ and $\mathrm{MgO}$, on the other hand, are scarce in literature. Moreover, to the best of the author's knowledge, there is currently no literature available in this regard that evaluates forest residues as a feedstock.

\subsection{Environmental impact}

Bio-oil production via pyrolysis produces air emissions, wastewater and solid waste during operations such as biomass harvesting, biomass transportation and bio-oil combustion. Therefore, it is important to consider the environmental impact of the process. The Life Cycle Assessment (LCA) is a comprehensive method that assesses environmental impact at each step of a product life cycle, from raw materials to product disposal or end use. This is termed the "cradle-to-grave" approach. In some cases, however, the end use of the product is excluded from the LCA, and termed the "cradle-to-gate" approach (Sharifzadeh, Sadeqzadeh, Guo, Borhani, Murthy, Cortada, Wang, Hallett \& Shah, 2019).

An environmental advantage of bio-oil production from sustainable forest products such as forest residue is the positive impact in mitigating long-term climate change. Trees take up $\mathrm{CO}_{2}$ from the atmosphere and store carbon in wood. The harvested wood then releases the carbon back into the atmosphere as $\mathrm{CO}_{2}$ during decomposition or combustion, completing the cycle. Therefore, with the 
exception of $\mathrm{CO}_{2}$ emissions related to forestry operations, forest residues are considered a carbon neutral source of energy. Fossil fuel, on the other hand, is not a carbon neutral source of energy as $\mathrm{CO}_{2}$ is released into the atmosphere during combustion but not taken up during formation (Mohan et al., 2006; Steele, Puettmann, Penmetsa \& Cooper, 2012). Furthermore, biochar production from forest residues has the potential to make a near carbon neutral process carbon negative through carbon sequestration (Lee et al., 2013).

One of the ways that the LCA quantifies environmental impact is through the Global Warming Potential (GWP) metric. The GWP metric relates the amount of heat a greenhouse gas (GHG) traps in the atmosphere to an equivalent amount of heat $\mathrm{CO}_{2}$ traps in the atmosphere, over a fixed period of time, commonly 20,100 or 500 years. For example, the GWP of methane over 20 years is 56 , which means that methane will trap 56 times more heat than an equivalent amount of $\mathrm{CO}_{2}$ over 20 years (Steele et al., 2012).

Steele and colleagues (2012) compared the environmental impact of producing crude bio-oil via fast pyrolysis of southern pine forest residue to residual fuel oil (RFO), a by-product of transportation fuel production in an oil refinery, using the "cradle-to-grave" approach. The GWP for bio-oil and RFO was $0.032 \mathrm{~kg} \mathrm{CO}_{2} / \mathrm{MJ}$ and $0.107 \mathrm{~kg} \mathrm{CO}_{2} / \mathrm{MJ}$, respectively, therefore substituting bio-oil for RFO resulted in a $69.8 \%$ reduction in GWP (Steele et al., 2012).

Iribarren, Peters and Dufour (2012) conducted an LCA on upgraded bio-oil gasoline and diesel fractions produced via fast pyrolysis of Poplar followed by hydrotreating using the "cradle-to-gate" approach. The GWP was -0.053 and $-0.048 \mathrm{~kg} \mathrm{CO}{ }_{2} \mathrm{eq} / \mathrm{MJ}$ for gasoline and diesel, respectively (Iribarren, Peters \& Dufour, 2012). The GWP reported for gasoline and diesel is negative because the end use (combustion) of the products was excluded.

Han and colleagues (2013) conducted an LCA using the "cradle-to-grave" approach to investigate the GWP of upgraded bio-oils produced via three pathways involving fast pyrolysis followed by hydrotreating: 1) hydrogen was produced via onsite natural gas reforming, 2) hydrogen was produced via onsite bio-oil reforming and electricity was produced via biochar combustion, and 3) hydrogen was produced via onsite bio-oil reforming and biochar was applied to the soil. The feedstock for the first pathway was forest residues, and the feedstock for the second and third pathways was corn stover. The GWPs for pathways 1, 2 and 3 were $0.037,0.011$ and $-0.012 \mathrm{~kg} \mathrm{CO}$ eq/MJ, respectively (Han et al., 2013). The environmental benefit was significant when biochar was applied to the soil instead of combusted for electricity production, even though biochar was produced as a by-product with unsurprisingly low yield (14.7 wt. \%) and carbon content (51.0 wt. \%) under fast pyrolysis conditions. In a recent state-of-the-art review, Sharifzadeh and colleagues (2019) pointed out the gap in research on the environmental benefit of biochar as a co-product of pyrolysis (Sharifzadeh et al., 2019). 


\subsection{Conclusion}

Forest residues are a high fire risk and are often disposed of by burning or sold as firewood, both of which eventually contribute to air pollution. There are approximately 1.5 million dry metric tonnes of forest residues available in South Africa every year therefore, there is an opportunity for the paper and pulp industry to utilise these forest residues in a more environmentally friendly and profitable way. Moreover, $\mathrm{CO}_{2}$ emissions associated with forestry operations can be reduced by replacing fossil fuels with bio-derived fuels.

Fast pyrolysis is associated with high bio-oil yields, whereas intermediate pyrolysis produces both bio-oil and biochar as primary products. Biochar has a wide range of applications, from carbon sequestration to wastewater treatment hence, biochar has the potential to contribute significantly to improving the profitability and reducing the environmental impact of the pyrolysis process.

Bio-oil can be upgraded to improve its oxygen and water content, and physiochemical properties that make it unlike conventional hydrocarbon fuel. Basic metal oxide catalysts such as $\mathrm{CaO}$ and $\mathrm{MgO}$ are both suitable for upgrading bio-oil via catalytic pyrolysis. There are several technoeconomic analyses available in literature on upgraded bio-oil production via fast pyrolysis or catalytic pyrolysis with zeolite catalysts followed by hydrotreating. On the other hand, techno-economic analyses on upgraded bio-oil production via catalytic pyrolysis with basic metal oxide catalysts such as $\mathrm{CaO}$ and $\mathrm{MgO}$ catalysts are scarce.

Co-processing a maximum of $5 \mathrm{wt}$ \% crude bio-oil and $10 \mathrm{wt}$. \% upgraded bio-oil at an oil refinery will be the benchmark for techno-economic analysis development of non-catalytic and catalyst pyrolysis biorefineries, respectively.

Bio-oil production from forest residues has a positive environmental impact since forest residues are considered a close to carbon neutral source of energy. Furthermore, biochar production from forest residues has the potential to make a near carbon neutral process carbon negative through carbon sequestration, however, there is a gap in research on the environmental benefit of biochar as a co-product of pyrolysis. 


\section{CHAPTER 3}

\section{Project Scope}

\subsection{Objectives}

The overall aim of this project is to determine whether or not the production of crude and upgraded bio-oils via non-catalytic and catalytic pyrolysis of forest residues for co-processing in an oil refinery is economically and environmentally feasible. This will be achieved through the following objectives:

1. Develop process simulations in Aspen Plus ${ }^{\mathrm{TM}}$ for non-catalytic and catalytic pyrolysis biorefinery scenarios based on pilot plant data.

2. Develop economic analyses for non-catalytic and catalytic pyrolysis biorefinery scenarios based on process simulations.

3. Measure and compare the environmental impact of producing crude and upgraded bio-oils to crude-oil and diesel using SimaPro ${ }^{\mathrm{TM}}$.

\subsection{Research questions}

The following research questions need to be answered to accomplish these objectives:

1. What is the energy demand for non-catalytic and catalytic pyrolysis processes, and how is it achieved?

2. Which pyrolysis process produces the lowest MSP of bio-oil?

3. How does the MSP of crude and upgraded bio-oils compare in terms of energy value?

4. How does the biorefinery capacity effect the MSP of crude and upgraded bio-oils?

5. Which economic parameters will be most sensitive to the MSP of crude and upgraded bio-oils?

6. Which pyrolysis process has the lowest environmental impact?

7. What is the estimated reduction in GWP of the FCC feed when crude or upgraded bio-oil is co-processed with VGO instead of pure VGO catalytic cracking?

\subsection{Limitations}

1. This project is based on the results of non-catalytic and catalytic pyrolysis pilot plant experiments conducted by Farai Chireshe (Chireshe, 2019), but some assumptions were made from literature, where experimental data was not available.

2. Process simulation for bio-oil co-processing in an FCC unit was not considered in this project.

3. Environmental impact for bio-oil co-processing in an FCC unit was also not considered in this project. However, the environmental burden of crude-oil and diesel production was taken from the SimaPro ${ }^{\mathrm{TM}}$ inventory for comparison. 


\section{CHAPTER 4}

\section{Methodology}

The overall research approach for this project is shown graphically in Figure 7. Non-catalytic and catalytic pyrolysis processes were simulated in Aspen Plus ${ }^{\mathrm{TM}}$ using literature and available pilot plant data, and sound technical assumptions to specify process units. The process simulations provided the mass and energy balances needed to size process equipment in preparation for the economic analyses. Profitability was measured by MSP, and the sensitivity thereof was evaluated against economic variables and model assumptions such as biomass cost and working capital. Finally, the environmental impact of crude and upgraded bio-oil production was measured in SimaPro ${ }^{\mathrm{TM}}$ and compared to fossil fuel production. 


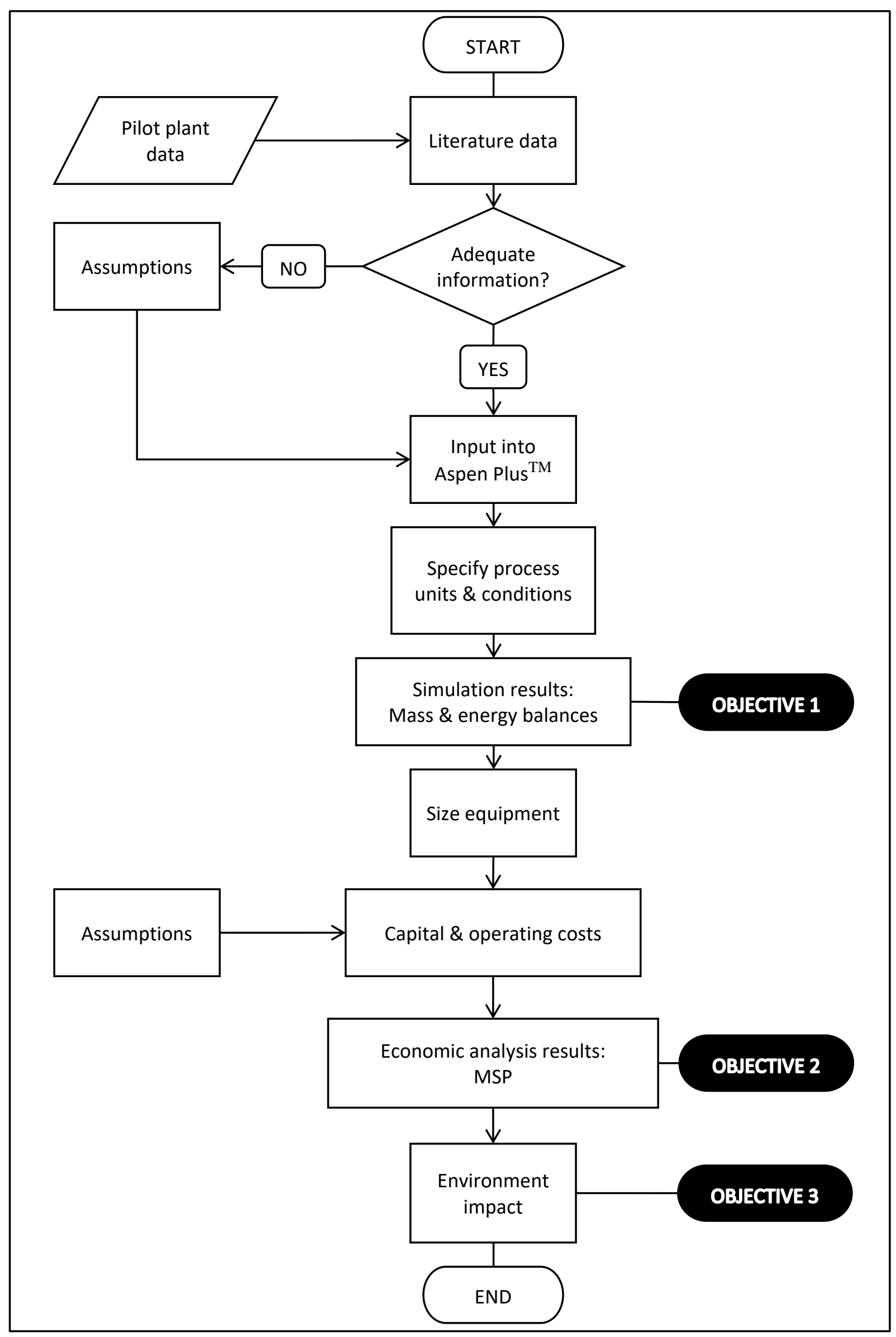

Figure 7: Research approach 


\subsection{Estimation of forest residues available in South Africa}

The amount of forest residues available in South Africa was estimated based on a method developed by Dovey (2009), where plantation timber volumes are converted into stem, bark and branch dry masses by experimentally determined multipliers (Dovey, 2009). The timber products sold from plantations around South Africa in 2016 was recently reported by the Forestry Economics Services, a division of the Department of Agriculture, Forestry and Fisheries (Forestry Economics Services, 2017). The total products sold from plantations according to species are provided in Table 11. The timber products published in units of mass were converted to units of volume using the multipliers in Table 12. The multipliers reported by Dovey (2009) and given in Table 13 were then used to convert timber volumes into the stem, bark and branch dry masses that are reported in Table 14. The following assumptions were made: 1) all 'softwoods' were taken as P. patula, 2) 'wattle' and 'other hardwoods' were taken as $A$. mearnsii, and 3) 'other gum' was taken as an average of E. dunnii, E. macarthurii, $E$. nitens and E. smithii. Finally, the total amount of forest residues (considering branches only) available in South Africa in 2016 was estimated to be just over 1.5 million dry metric tonnes.

Table 11: Timber products sold from plantations in 2016 (Forestry Economics Services, 2017)

\begin{tabular}{|c|c|c|c|c|c|c|}
\hline & $\begin{array}{c}\text { Sawlogs \& } \\
\text { Veneer Logs } \\
\left(\mathrm{m}^{3}\right)\end{array}$ & $\begin{array}{c}\text { Poles \& } \\
\text { Droppers } \\
\left(\mathrm{m}^{3}\right)\end{array}$ & $\begin{array}{c}\text { Mining } \\
\text { Timber } \\
\text { (MT) }\end{array}$ & $\begin{array}{l}\text { Pulpwood } \\
\text { (MT) }\end{array}$ & $\begin{array}{l}\text { Charcoal \& } \\
\text { Firewood } \\
\text { (MT) }\end{array}$ & $\begin{array}{c}\text { Other } \\
\text { Products } \\
\text { (MT) }\end{array}$ \\
\hline Total softwoods & 4227050 & 55877 & 0 & 2292485 & 27359 & 33889 \\
\hline Total E. grandis & 176632 & 216867 & 268061 & 3024702 & 66044 & 22025 \\
\hline Total other gum & 43661 & 28664 & 31127 & 2711823 & 12560 & 6851 \\
\hline Total wattle & 0 & 312 & 0 & 607220 & 91191 & 22077 \\
\hline Total other hardwoods & 0 & 25800 & 0 & 23922 & 231 & 2462 \\
\hline
\end{tabular}


Table 12: Multipliers to convert between volume and mass (Forestry Economics Services, 2017)

\begin{tabular}{|lcc|}
\hline Product & Species & Conversion ( $\mathbf{m}^{\mathbf{3}} \mathbf{\text { MT }}$ ) \\
\hline \multirow{3}{*}{ Sawlogs } & Softwood & 0.94 \\
& Eucalyptus grandis & 0.94 \\
Mining timber & Other eucalyptus species & 0.78 \\
& Eucalyptus grandis & 1.47 \\
& Other eucalyptus species & 1.25 \\
& Wattle & 1.19 \\
Pulpwood & Softwood & 1.00 \\
& Eucalyptus grandis & 1.47 \\
& Other eucalyptus species & 1.25 \\
Matchwood & Wattle & 1.19 \\
Firewood & Other hardwood species & 1.25 \\
Poles, laths, droppers etc. & - & 1.03 \\
Transmission poles & - & 1.25 \\
Cross arms & - & 1.56 \\
\hline
\end{tabular}

Table 13: Multipliers to convert timber volume to dry mass, timber dry mass to bark and timber dry mass to branches (Dovey, 2009)

\begin{tabular}{|c|c|c|c|}
\hline Species & Timber Dry Mass (MT/m³) & Bark (MT/ha) & Branches (MT/ha) \\
\hline A. mearnsii & 0.654 & 0.130 & 0.260 \\
\hline P. patula & 0.387 & 0.090 & 0.260 \\
\hline E. dunnii & 0.536 & 0.160 & 0.120 \\
\hline E. grandis & 0.450 & 0.120 & 0.120 \\
\hline E. macarthurii & 0.551 & 0.150 & 0.210 \\
\hline E. nitens & 0.526 & 0.120 & 0.340 \\
\hline E. smithii & 0.581 & 0.100 & 0.210 \\
\hline
\end{tabular}


Table 14: Total forest residue available in South Africa

\begin{tabular}{|lcccc|}
\hline & Total $\left(\mathbf{m}^{\mathbf{3}}\right)$ & $\begin{array}{c}\text { Stem } \\
\text { (dry MT) }\end{array}$ & $\begin{array}{c}\text { Bark } \\
\text { (dry MT) }\end{array}$ & $\begin{array}{c}\text { Branches } \\
\text { (dry MT) }\end{array}$ \\
\hline Total softwoods & 6651972 & 2574313 & 231688 & 669321 \\
Total E. grandis & 5343947 & 2404776 & 288573 & 288573 \\
Total other gum & 3525276 & 1933614 & 256204 & 425395 \\
Total wattle & 864489 & 565376 & 73499 & 146998 \\
Total other hardwoods & 59069 & 38631 & 5022 & 10044 \\
\hline
\end{tabular}

Collection and transport costs of forest residues are high because forest residues are often spread over extensive areas and transported over long distances to biorefineries (Brown, Rowe \& Wild, 2013). Polagye, Hodgson and Malte (2007) compared the cost of biofuel production via fast pyrolysis of forest thinnings at mobile and centralised (stationary) facilities to biomass transport distance. The authors found that industrial-scale and long-term biofuel production at a mobile facility was significantly more expensive than at a centralised facility. Biofuel production at a centralised facility was also increasingly more attractive for transport distances below $300 \mathrm{~km}$ (Polagye, Hodgson \& Malte, 2007). Similarly, Brown, Rowe and Wild (2016) reported that biomass transport to a centralised facility was more cost effective than to a mobile facility when transport distance was below 300 km (Brown et al., 2013).

The distribution of forest residues (considering branches only) available in South Africa in 2016 according to region is given in Table 15. The regions with the most forest residues were KwaZulu-Natal (KZN) Midlands (19.6 wt. \%), Mpumalanga South (18.4 wt. \%) and KZN South (13.5 wt. \%). The location of the centralised biorefinery is approximately $40 \mathrm{~km}$ west of Dundee (KZN Midlands), which was determined by drawing a circle with a $300 \mathrm{~km}$ radius around the regions with the most forest residues as shown in Figure 8. The total amount of forest residues available for collection and transportation from Mpumalanga South, KZN North, KZN Midlands, Zululand and KZN South to the biorefinery was then 1067210 dry metric tonnes. However, not all forest residues should be removed from the forest floor. Forest litter (leaves and small twigs), stumps, root systems and a portion of branches should be retained to maintain soil productivity by preserving nutrients, preventing soil erosion and protecting against compaction (Wright et al., 2012; Yang et al., 2016) therefore, only 853768 dry metric tonnes (equivalent to $80 \mathrm{wt}$. \%) of forest residues were available for collection. 
Table 15: Distribution of forest residues (branches) available in South Africa according to region

\begin{tabular}{|lc|}
\hline Region & Branches (wt. \%) \\
\hline Limpopo & 3.58 \\
Mpumalanga North & 10.59 \\
Central Districts & 3.36 \\
Mpumalanga South & 18.39 \\
Maputaland & 0.00 \\
Zululand & 11.18 \\
KZN Midlands & 19.55 \\
KZN North & 6.65 \\
KZN South & 13.51 \\
Eastern Cape & 7.98 \\
Southern Cape & 4.17 \\
Western Cape & 1.04 \\
\hline
\end{tabular}

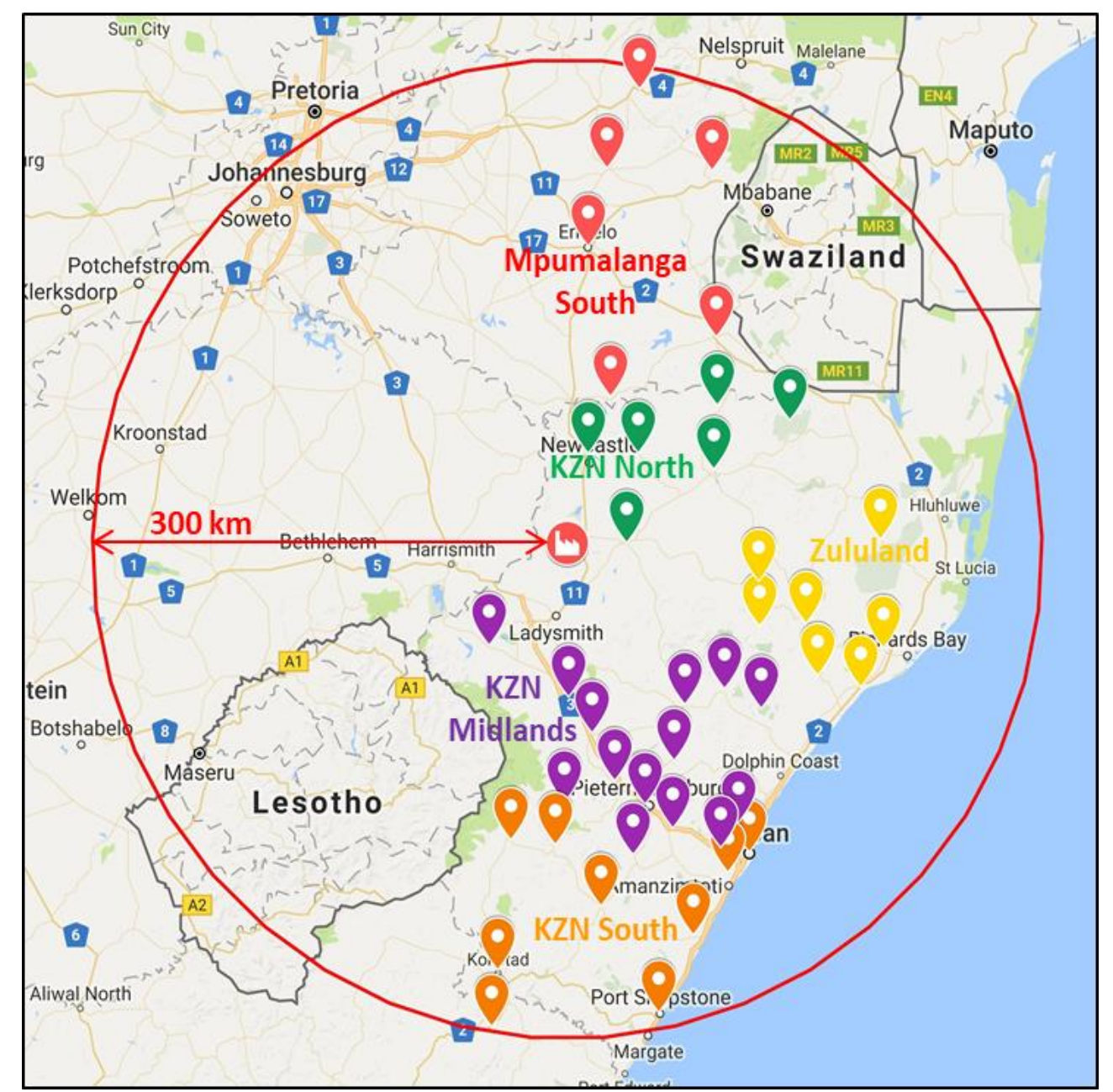

Figure 8: Location of the forest residue pyrolysis plant (biorefinery) - 9 Mpumalanga South 9 KZN North ${ }^{2}$ ululand 9 KZN Midlands 9 KZN South 


\subsection{Biorefinery scenarios}

South Africa has four crude-oil refineries, one coal-to-liquid refinery and one gas-to-liquid refinery. The location of the refinery, distance from the biorefinery, capacity (barrels per day or bpd) and production of VGO are summarised in Table 16.

Table 16: Locations and Capacities of refineries in South Africa

\begin{tabular}{|c|c|c|c|c|c|}
\hline Refinery & Location & Distance $(\mathbf{k m})^{\mathrm{b}}$ & Type & Capacity (bpd) & $\operatorname{VGO}\left(\mathrm{m}^{3} / \text { day }\right)^{\mathrm{c}}$ \\
\hline Chevref & Cape Town & 1247 & Crude-oil & 100000 & 3609 \\
\hline Enref & Durban & 224 & Crude-oil & 120000 & 4331 \\
\hline Natref & Sasolburg & 249 & Crude-oil & 108000 & 3898 \\
\hline Sapref & Durban & 228 & Crude-oil & 180000 & 6496 \\
\hline Sasol & Secunda & 196 & CTL & 150000 & 5413 \\
\hline PetroSA & Mossel Bay & 999 & GTL & 45000 & 1624 \\
\hline
\end{tabular}

a. (South African Petroleum Industry Association, 2017)

b. Straight-line distance measured from the refinery to the biorefinery

c. The conversion of crude-oil to VGO was taken as $22.7 \mathrm{vol}$. \% (Hill, 2011). The density of VGO was taken as $947.2 \mathrm{~kg} / \mathrm{m}^{3}$ (Pinho et al., 2015)

The total amount of forest residues available for bio-oil production within a $300 \mathrm{~km}$ radius of the biorefinery was assumed to stay constant at 853768 dry MT/year. Since biomass cost is proportional to biomass collection distance, the economic feasibility of crude and upgraded bio-oil production was evaluated for biomass collection within 100, 200 and $300 \mathrm{~km}$ radii of the pyrolysis biorefinery as shown in Figure 9 . The corresponding biorefinery capacities for biomass collection within 100, 200 and $300 \mathrm{~km}$ radii were 338, 1655 and 2549 dry MT/day, respectively. Considering the findings from literature, co-processing of up to $5 \mathrm{wt}$. \% crude bio-oil and $10 \mathrm{wt}$ \% upgraded bio-oil with VGO was investigated. Natref is a suitable refinery for co-processing because of its size and distance from the biorefinery, however, where the biorefinery capacity exceeds the maximum amount of bio-oil that can be co-processed at Natref, the remaining bio-oil can be sent to Enref or Sapref. The corresponding biorefinery capacities for co-processing $5 \mathrm{wt}$. \% crude bio-oil and $10 \mathrm{wt}$. \% upgraded bio-oil were 813 and $1710 \mathrm{dry} \mathrm{MT/day,} \mathrm{respectively.} \mathrm{A} \mathrm{summary} \mathrm{of} \mathrm{the} \mathrm{biorefinery} \mathrm{scenarios} \mathrm{that} \mathrm{were} \mathrm{considered} \mathrm{for}$ non-catalytic (NC-100, NC-5, NC-200 and NC-300) and catalytic (C-100, C-200, C-10 and C-300) pyrolysis is presented in Table 17. The average distance reported was calculated based on a weighted average: the amount of biomass available in each zone (indicated by the 9 location markers in Figure 9 ) within the considered radius multiplied by the straight-line distance between each zone and the biorefinery, 
divided by the total amount of biomass available within the considered radius. The amount of biomass available in each region was determined from the biomass distribution given in Table 15 and evenly distributed between the zones in each region (actual data for each zone is not publically available).

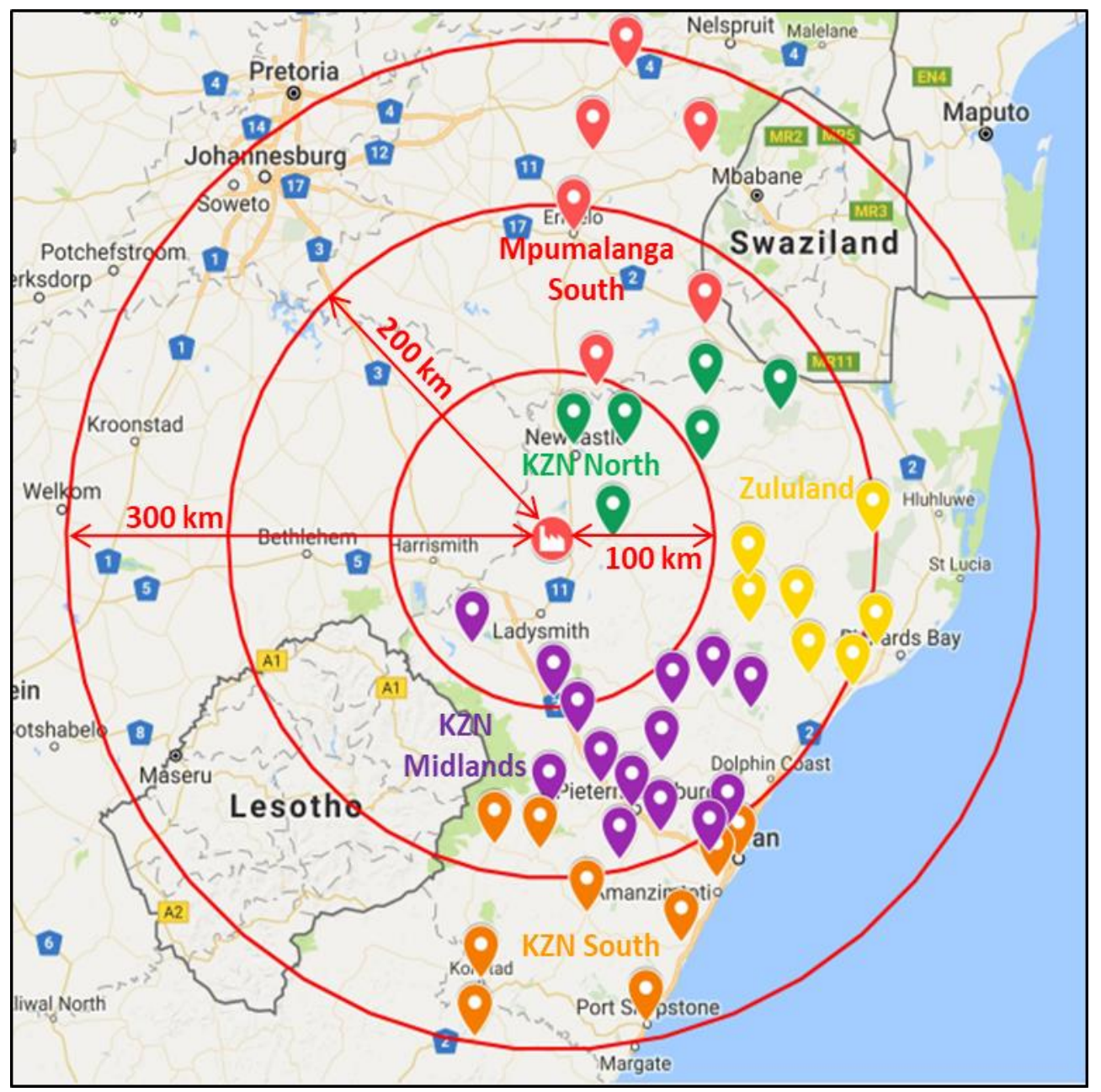

Figure 9: 100, 200 and $300 \mathrm{~km}$ radii from biorefinery for biomass collection - 9 Mpumalanga South $\vartheta_{\text {KZN North }}$ zululand 9 KZN Midlands 9 KZN South 
Table 17: Biorefinery scenarios for co-processing bio-oil produced via non-catalytic (NC) and catalytic (C) pyrolysis

\begin{tabular}{|lcccccc|}
\hline Scenario & $\begin{array}{c}\text { Radius } \\
(\mathbf{k m})\end{array}$ & $\begin{array}{c}\text { Average } \\
\text { Distance } \\
(\mathbf{k m})\end{array}$ & $\begin{array}{c}\text { Biorefinery } \\
\text { Capacity } \\
\text { (dry MT/day) }\end{array}$ & $\begin{array}{c}\text { Blend } \\
\text { (wt. \% bio-oil) } \\
\text { Natref }\end{array}$ & $\begin{array}{c}\text { Blend } \\
\text { (wt. \% bio-oil) } \\
\text { Enref }\end{array}$ & $\begin{array}{c}\text { Blend } \\
\text { (wt. \% bio-oil) } \\
\text { Sapref }\end{array}$ \\
\hline NC-100 & 100 & 80 & 338 & 2.08 & - & - \\
NC-5 & 157 & 113 & 813 & 5.00 & - & - \\
NC-200 & 200 & 143 & 1655 & 5.00 & 4.66 & - \\
NC-300 & 300 & 179 & 2549 & 5.00 & 5.00 & 3.07 \\
C-100 & 100 & 80 & 338 & 1.98 & - & - \\
C-200 & 200 & 143 & 1655 & 9.68 & - & - \\
C-10 & 224 & 153 & 1710 & 10.00 & - & - \\
C-300 & 300 & 179 & 2549 & 10.00 & 4.42 & - \\
\hline
\end{tabular}

a. Bio-oil yield was 22.86 wt. \% and 21.65 wt. \% for non-catalytic and catalytic pyrolysis, respectively. Biomass moisture content was 8.28 wt. \%. Biorefinery operates for 335 days per year.

\subsection{Process description}

An overview of the non-catalytic and catalytic pyrolysis experiments is given here. However, the detailed experimental methodology followed to generate non-catalytic and catalytic pyrolysis data for this project can be found in the corresponding thesis by Farai Chireshe (Chireshe, 2019). Non-catalytic and catalytic pyrolysis experiments were conducted with a $5 \mathrm{~kg} / \mathrm{h}$ pilot pant reactor. A diagram of the pilot plant setup is given in Figure 10. A dry-mixed mixture of E. grandis forest residues (8.28 wt. \% moisture) and $\mathrm{CaO}$ catalyst (in catalytic pyrolysis runs) was passed from the feed hopper to the pyrolysis reactor through the piston feeder system. The pyrolysis reactor at atmospheric pressure was heated to $500{ }^{\circ} \mathrm{C}$ and rotated at $25 \mathrm{~Hz}$. Pyrolysis vapours, char, $\mathrm{CaO}$ and $\mathrm{CaCO}_{3}\left(\mathrm{CaO}\right.$ captured $\mathrm{CO}_{2}$ ) then progressed from the pyrolysis reactor to the char pot, where the char, $\mathrm{CaO}$ and $\mathrm{CaCO}_{3}$ were separated from the vapours. The vapours continued on to the condenser train system, where four condensers separated the vapours into bio-oil and non-condensable gases. The water temperature of the condensers ranged from $80^{\circ} \mathrm{C}(\mathrm{C} 1)$ to approximately $12{ }^{\circ} \mathrm{C}(\mathrm{C} 4)$. Finally, the non-condensable gases leaving C4 were sampled, collected in the gas towers and measured (by volume) before leaving the process. The non-condensable gas samples were analysed by GC/MS. The bio-oil collected in the second condenser (C2) was further separated into an aqueous fraction (C2A) and an organic fraction (C2O). 


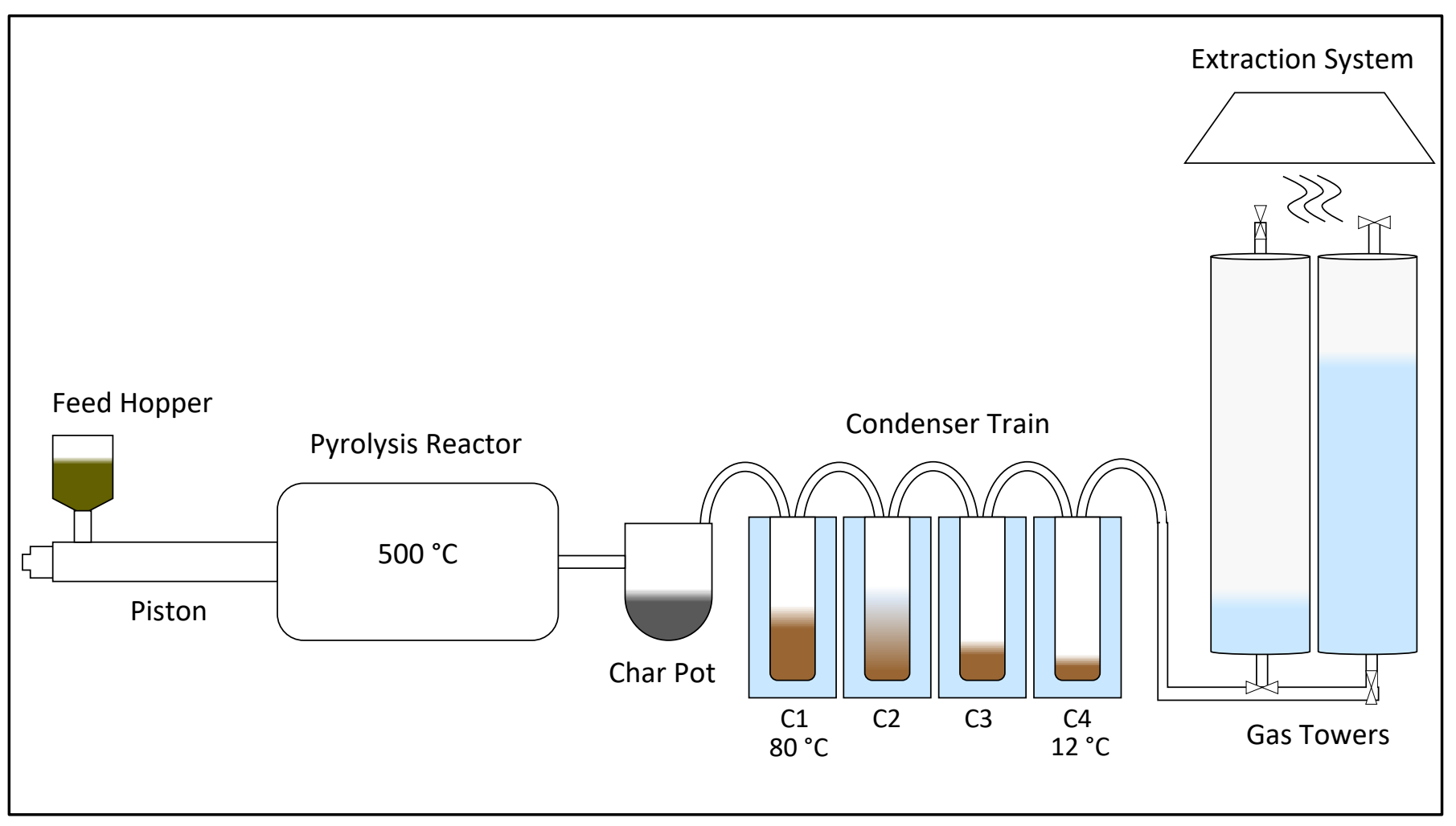

Figure 10: Pilot plant setup (redrawn from Chireshe (2019))

The biorefinery scenarios were simulated in Aspen Plus ${ }^{\mathrm{TM}}$ version 8.8 with the pilot plant data for non-catalytic and catalytic pyrolysis given in Appendix A. The simulated biorefinery scenarios include biomass pre-treatment (milling and drying), heat recovery, steam and power production and utility production (cooling and chilled water) in addition to pyrolysis and product recovery executed at the pilot plant.

\subsection{Process simulation data input}

\subsubsection{Mass balance reconciliation}

The total mass yield of non-catalytic and catalytic pyrolysis products from $E$. grandis forest residues (8.28 wt. \% moisture) was 89.10 and 89.06 wt. \%, respectively. The mass balance closure was agreeable with literature and considered acceptable by industrial experts for a pilot-scale pyrolysis process. Sandström and colleagues (2016) conducted fast pyrolysis of forest residues and other biomasses at pilot-scale, and reported an average mass balance closure of $90.5 \mathrm{wt}$ \% (Sandström, Johansson, Wiinikka, Öhrman \& Marklund, 2016). Other researchers reported mass balance closures of 81 (Mullen, Boateng, Goldberg, Lima, Laird \& Hicks, 2010) and 93 wt. \% (Dayton et al., 2015) for pilot-scale pyrolysis processes. 
The deficit in the mass balance was attributed to pyrolysis vapours (bio-oil and non-condensable gas components) escaping through the feed hopper, bio-oil components condensing between the char pot and $\mathrm{C} 1$, incomplete condensation of bio-oil components passing through the condenser train (Yang, Heaven, Venetsaneas, Banks \& Bridgwater, 2018), and measuring the non-condensable gas yield based on the assumption that the non-condensable gas density remained constant throughout the experimental run². However, mass and elemental balances have to be closed to avoid process simulation calculation errors in Aspen Plus ${ }^{\mathrm{TM}}$ therefore, the following assumptions were made:

1. All nitrogen, sulphur and ash (Onarheim, Solantausta \& Lehto, 2015) compounds found in the biomass reported to the char in both non-catalytic and catalytic pyrolysis runs. All $\mathrm{CaO}$ and $\mathrm{CaCO}_{3}$ also reported to the char in catalytic pyrolysis runs (Veses et al., 2014). Thereafter, the char yield and elemental composition were unchanged.

2. The missing products for non-catalytic and catalytic pyrolysis runs (after applying the first assumption) were evenly split between the bio-oil (organics and water) and non-condensable gas components. This conservative approach was chosen based on the rationale presented for the deficit in the mass balance and subsequently to minimise the uncertainty placed on either product: if the mass balance were closed with the non-condensable gas only, the yield of non-condensable gas would have significantly increased by 53 wt. \% for non-catalytic pyrolysis and 62 wt. \% for catalytic pyrolysis, whereas if the mass balance were closed with the bio-oil only, the yield of bio-oil would have significantly increased by 55 wt. \% for non-catalytic pyrolysis and 64 wt. \% for catalytic pyrolysis. The organic content and water content of the missing bio-oil was allocated as follows:

a. The organic content of the missing bio-oil was the same as the organic content of the measured bio-oil collected in C1. During the bench-scale experiments, where an electrostatic precipitator (ESP) was used to capture uncondensed vapours leaving the condenser train, Chireshe (2019) found that the composition of these organics closely resembled the composition of the organics collected in C1 (Chireshe, 2019).

b. The water content of the missing bio-oil was the same as the overall water content of the measured bio-oil.

3. The overall elemental balance for carbon, hydrogen and oxygen was finally closed for non-catalytic and catalytic pyrolysis runs by changing the chemical composition of the non-condensable gas. The HHV of the new gas composition was matched to the calculated HHV (using Equation 2-1) of the measured gas composition since the non-condensable gases were mostly combusted to generate heat for the pyrolysis reactor in the process simulation.

\footnotetext{
${ }^{2}$ Communication with Mr. Richard Bingham, Technotherm
} 
The reconciled pilot plant data for non-catalytic and catalytic pyrolysis are given in Table 18 and Table 19, respectively.

Table 18: Reconciled pilot plant data for non-catalytic pyrolysis

\begin{tabular}{|c|c|c|c|c|c|c|c|c|c|}
\hline & & Feed & Char & C1 & C2A & $\mathrm{C2O}$ & C3 & C4 & Gas \\
\hline $\begin{array}{l}\text { Yield } \\
\text { (wt. \%) }\end{array}$ & & & 28.75 & 11.06 & 22.33 & 5.03 & 4.28 & 2.49 & 26.05 \\
\hline \multirow{5}{*}{$\begin{array}{l}\text { Elemental } \\
\text { Analysis } \\
\text { (wt. \%, db) }\end{array}$} & C & 48.01 & 83.02 & 44.31 & 42.51 & 71.97 & 67.46 & 74.24 & \\
\hline & $\mathrm{H}$ & 6.36 & 3.39 & 8.02 & 4.98 & 6.69 & 8.74 & 6.91 & \\
\hline & $\mathrm{O}$ & 45.46 & 13.01 & 47.67 & 52.51 & 21.34 & 23.79 & 18.85 & \\
\hline & $\mathrm{N}$ & 0.12 & 0.39 & 0.00 & 0.00 & 0.00 & 0.00 & 0.00 & \\
\hline & $S$ & 0.06 & 0.19 & 0.00 & 0.00 & 0.00 & 0.00 & 0.00 & \\
\hline \multirow{4}{*}{$\begin{array}{l}\text { Proximate } \\
\text { analysis } \\
\text { (wt. \%) }\end{array}$} & Moisture & 8.28 & 0.00 & 7.48 & 88.54 & 20.01 & 28.63 & 23.62 & \\
\hline & Fixed carbon & 15.06 & 77.42 & & & & & & \\
\hline & Volatile matter & 75.70 & 19.27 & & & & & & \\
\hline & Ash & 0.95 & 3.32 & & & & & & \\
\hline $\begin{array}{l}\mathrm{HHV} \\
(\mathrm{MJ} / \mathrm{kg}, \mathrm{db})\end{array}$ & & 19.33 & & 22.10 & & 29.08 & 30.17 & 32.63 & \\
\hline $\begin{array}{l}\text { Density } \\
\left(\mathrm{kg} / \mathrm{m}^{3}, \mathrm{db}\right)\end{array}$ & & & & 1184 & 1288 & 1041 & 1117 & 1234 & \\
\hline \multirow{8}{*}{$\begin{array}{l}\text { Composition } \\
\text { (wt. \%) }\end{array}$} & $\mathrm{CO}_{2}$ & & & & & & & & 58.59 \\
\hline & $\mathrm{CO}$ & & & & & & & & 33.18 \\
\hline & $\mathrm{CH}_{4}$ & & & & & & & & 5.18 \\
\hline & $\mathrm{H}_{2}$ & & & & & & & & 1.47 \\
\hline & $\mathrm{C}_{2} \mathrm{H}_{6}$ & & & & & & & & 0.79 \\
\hline & $\mathrm{C}_{2} \mathrm{H}_{4}$ & & & & & & & & 0.56 \\
\hline & $\mathrm{C}_{3} \mathrm{H}_{8}$ & & & & & & & & 0.13 \\
\hline & $\mathrm{C}_{4} \mathrm{H}_{6}$ & & & & & & & & 0.13 \\
\hline
\end{tabular}


Table 19: Reconciled pilot plant data for catalytic pyrolysis

\begin{tabular}{|c|c|c|c|c|c|c|c|c|c|c|}
\hline & & Feed & Char & $\begin{array}{c}\mathrm{CO}_{2} \\
\left(\mathrm{CaCO}_{3}\right)\end{array}$ & C1 & C2A & C2O & C3 & C4 & Gas \\
\hline $\begin{array}{l}\text { Yield } \\
\text { (wt. \%) }\end{array}$ & & & 16.53 & 20.85 & 12.86 & 17.86 & 3.81 & 3.02 & 1.95 & 23.11 \\
\hline \multirow{5}{*}{$\begin{array}{l}\text { Elemental } \\
\text { analysis } \\
\text { (wt. \%, db) }\end{array}$} & C & 48.01 & 79.09 & & 80.02 & 29.30 & 80.68 & 61.10 & 82.29 & \\
\hline & $\mathrm{H}$ & 6.36 & 3.36 & & 7.14 & 6.55 & 6.09 & 6.20 & 7.31 & \\
\hline & 0 & 45.46 & 16.52 & & 12.83 & 64.15 & 13.23 & 32.70 & 10.41 & \\
\hline & $\mathrm{N}$ & 0.12 & 0.69 & & 0.00 & 0.00 & 0.00 & 0.00 & 0.00 & \\
\hline & $S$ & 0.06 & 0.34 & & 0.00 & 0.00 & 0.00 & 0.00 & 0.00 & \\
\hline \multirow{4}{*}{$\begin{array}{l}\text { Proximate } \\
\text { analysis } \\
\text { (wt. \%) }\end{array}$} & Moisture & 8.28 & 0.00 & & 20.56 & 88.38 & 15.70 & 62.73 & 19.25 & \\
\hline & Fixed carbon & 15.06 & 56.25 & & & & & & & \\
\hline & Volatile matter & 75.70 & 37.98 & & & & & & & \\
\hline & Ash & 0.95 & 5.77 & & & & & & & \\
\hline $\begin{array}{l}\text { HHV } \\
(\mathrm{MJ} / \mathrm{kg}, \mathrm{db})\end{array}$ & & 19.33 & & & 35.37 & & 34.61 & 25.93 & 37.84 & \\
\hline $\begin{array}{l}\text { Density } \\
\left(\mathrm{kg} / \mathrm{m}^{3}, \mathrm{db}\right)\end{array}$ & & & & & 1152 & 1198 & 1040 & 1031 & 1042 & \\
\hline \multirow{8}{*}{$\begin{array}{l}\text { Composition } \\
\text { (wt. \%) }\end{array}$} & $\mathrm{CO}_{2}$ & & & & & & & & & 48.07 \\
\hline & $\mathrm{CO}$ & & & & & & & & & 2.23 \\
\hline & $\mathrm{CH}_{4}$ & & & & & & & & & 1.01 \\
\hline & $\mathrm{H}_{2}$ & & & & & & & & & 17.76 \\
\hline & $\mathrm{C}_{2} \mathrm{H}_{6}$ & & & & & & & & & 3.50 \\
\hline & $\mathrm{C}_{2} \mathrm{H}_{4}$ & & & & & & & & & 0.90 \\
\hline & $\mathrm{C}_{3} \mathrm{H}_{8}$ & & & & & & & & & 25.30 \\
\hline & $\mathrm{C}_{4} \mathrm{H}_{6}$ & & & & & & & & & 1.23 \\
\hline
\end{tabular}

\subsubsection{Bio-oil composition}

Bio-oil is made up of water and hundreds of organic compounds, while only 25 to $40 \mathrm{wt}$. \% of these compounds are detectable by GC/MS (Mullen, Strahan \& Boateng, 2009). Lignin and carbohydrate derived compounds are not volatile enough to be detected, which makes it difficult to determine the chemical composition of the organic content of bio-oil.

A method employed to estimate the chemical composition of the organic content of bio-oil for the purpose of process simulation involves matching the measured elemental analysis $(\mathrm{C}, \mathrm{H}$ and $\mathrm{O}$ ), HHV and density to known organic compounds found in bio-oil. Jones and colleagues (2013) and Carrasco and colleagues (2017) both estimated the chemical composition of the organic content of 
bio-oil using this method, and chose organic compounds from the main chemical families found in wood-derived bio-oils such as: acids, alcohols, aldehydes, ketones, phenols and sugars, as well as extractive and lignin-derived compounds (Carrasco et al., 2017; Jones et al., 2013). The organic compounds chosen by these researchers were combined to estimate the chemical composition of the organic content of crude and upgraded bio-oils in this project.

A list of the organic compounds chosen according to compound group is given in Table 20. The organic compositions of crude and upgraded bio-oils were determined by matching the corresponding elemental analysis, HHV and density results for non-catalytic and catalytic pyrolysis given in

Table 18 and Table 19 to the compounds listed in Table 20. This multi-objective-specification problem was solved using the Microsoft Excel add-in program Solver, and the solving method was set to the Generalized Reduced Gradient Nonlinear method. In some instances, a 100 wt. \% match in C, H and $O$ elements between the elemental analysis and chemical composition could not be found therefore, a balancing component (made up of elements $\mathrm{C}, \mathrm{H}$ and $\mathrm{O}$ ) was added to the composition to close the elemental balance. The share of the balancing component in the composition, however, was limited to a maximum of $2 \mathrm{wt}$. \%. The subsequent chemical composition of the organic content recovered from each condenser and overall are given in Table 20 for crude and upgraded bio-oils produced via non-catalytic and catalytic pyrolysis, respectively. Furthermore, it is worth mentioning that the estimated chemical composition of the organic content of crude and upgraded bio-oils has negligible impact on the subsequent economic analysis because bio-oil as a whole was the focus of the study, and not the individual bio-chemicals. 
Table 20: Composition of the organic content recovered from each condenser and overall for non-catalytic and catalytic pyrolysis

\begin{tabular}{|c|c|c|c|c|c|c|c|c|c|c|c|c|c|c|}
\hline \multirow{3}{*}{ Group } & \multirow{3}{*}{ Compound } & \multirow{3}{*}{ Formula } & \multicolumn{12}{|c|}{ Organic content composition (wt. \%) } \\
\hline & & & \multicolumn{6}{|c|}{ Non-catalytic pyrolysis } & \multicolumn{6}{|c|}{ Catalytic pyrolysis } \\
\hline & & & $\mathrm{C} 1$ & $\mathrm{C} 2 \mathrm{~A}$ & $\mathrm{C} 2 \mathrm{O}$ & $\mathrm{C} 3$ & C4 & Overall & $\mathrm{C} 1$ & $\mathrm{C} 2 \mathrm{~A}$ & $\mathrm{C} 2 \mathrm{O}$ & C3 & $\mathrm{C} 4$ & Overall \\
\hline \multirow{3}{*}{ Acids } & Acetic acid & $\mathrm{C} 2 \mathrm{H} 4 \mathrm{O} 2$ & 33.50 & - & - & - & - & 15.83 & - & 1.65 & - & 20.58 & - & 1.52 \\
\hline & Crotonic acid & $\mathrm{C} 4 \mathrm{H} 6 \mathrm{O} 2$ & 5.04 & - & 4.22 & - & - & 3.15 & - & - & 5.13 & 4.49 & 5.41 & 1.68 \\
\hline & Formic acid & $\mathrm{CH} 2 \mathrm{O} 2$ & 1.08 & 39.21 & - & - & - & 5.26 & - & 83.74 & - & 5.78 & - & 9.90 \\
\hline Alcohols & 1, 4 Benzenediol & $\mathrm{C} 6 \mathrm{H} 6 \mathrm{O} 2$ & - & - & 25.11 & - & - & 4.65 & 2.21 & - & - & - & - & 1.24 \\
\hline Aldehydes & $\begin{array}{l}\text { 3-Methoxy-4- } \\
\text { Hydroxybenzaldehyde }\end{array}$ & $\mathrm{C} 8 \mathrm{H} 8 \mathrm{O} 3$ & 2.20 & - & - & - & - & 1.11 & - & - & 5.82 & - & - & 1.32 \\
\hline \multirow{3}{*}{ Aromatics } & Benzene & $\mathrm{C} 6 \mathrm{H} 6$ & - & - & - & - & 36.95 & 3.26 & - & - & - & 6.11 & 73.78 & 6.75 \\
\hline & Phenol & $\mathrm{C} 6 \mathrm{H} 6 \mathrm{O}$ & - & - & - & - & 32.80 & 2.92 & 2.29 & - & - & - & - & 1.28 \\
\hline & Toluene & $\mathrm{C} 7 \mathrm{H} 8$ & - & - & 1.06 & 5.81 & - & 1.01 & 27.42 & - & 22.58 & - & - & 19.38 \\
\hline Esters & Propyl benzoate & $\mathrm{C} 10 \mathrm{H} 12 \mathrm{O} 2$ & - & - & 3.42 & 4.29 & - & 1.23 & 2.70 & - & - & - & - & 1.51 \\
\hline Extractives & Dehydroabietic acid & $\mathrm{C} 2 \mathrm{OH} 28 \mathrm{O} 2$ & - & - & - & 26.43 & - & 3.76 & 3.16 & - & - & - & - & 1.77 \\
\hline Furans & Furfural & $\mathrm{C} 5 \mathrm{H} 4 \mathrm{O} 2$ & - & 19.79 & - & - & - & 2.41 & 1.03 & - & - & 12.04 & - & 1.32 \\
\hline \multirow{2}{*}{ Guaiacols } & Isoeugenol & $\mathrm{C} 10 \mathrm{H} 12 \mathrm{O} 2$ & - & - & 6.51 & - & - & 1.21 & 2.05 & - & 1.88 & 20.58 & - & 2.75 \\
\hline & Guaiacol & $\mathrm{C} 7 \mathrm{H} 8 \mathrm{O} 2$ & - & - & - & 7.02 & - & 1.04 & 2.05 & - & - & - & - & 1.15 \\
\hline Ketones & Hydroxyacetone & $\mathrm{C} 3 \mathrm{H} 6 \mathrm{O} 2$ & 33.60 & - & - & 20.45 & - & 18.72 & - & 2.67 & 5.21 & - & - & 1.47 \\
\hline \multirow{4}{*}{ Lignin-derived } & Dibenzofuran & $\mathrm{C} 12 \mathrm{H} 8 \mathrm{O}$ & - & 5.39 & 36.95 & - & - & 7.50 & 12.24 & - & 53.26 & 9.86 & 4.36 & 17.26 \\
\hline & Dimethoxy stilbene & $\mathrm{C} 16 \mathrm{H} 16 \mathrm{O} 2$ & - & - & 1.71 & 19.61 & - & 3.08 & 34.83 & 3.00 & 2.00 & - & - & 20.25 \\
\hline & $\begin{array}{l}\text { Oligomeric compounds } \\
\text { with } \beta-0-4 \text { bond }\end{array}$ & $\mathrm{C} 2 \mathrm{OH} 26 \mathrm{O} 8$ & - & - & 9.11 & - & - & 1.68 & 2.22 & - & - & - & - & 1.25 \\
\hline & $\begin{array}{c}\text { Phenylcoumaran } \\
\text { compounds }\end{array}$ & $\mathrm{C} 21 \mathrm{H} 2608$ & - & - & - & 5.15 & 10.21 & 1.67 & 2.83 & - & - & - & - & 1.59 \\
\hline \multirow{2}{*}{ Sugars } & Cellobiose & $\mathrm{C} 12 \mathrm{H} 22 \mathrm{O} 11$ & 17.04 & 6.51 & - & 10.25 & 19.18 & 11.96 & 2.34 & - & - & - & 4.15 & 1.77 \\
\hline & Levoglucosan & $\mathrm{C} 6 \mathrm{H} 1005$ & 6.54 & 27.89 & - & - & - & 6.43 & 1.06 & 6.14 & 3.12 & - & 11.85 & 2.87 \\
\hline Syringols & Syringol & $\mathrm{C} 8 \mathrm{H} 10 \mathrm{O} 3$ & - & - & 6.51 & - & - & 1.21 & - & - & - & 19.56 & - & 1.27 \\
\hline
\end{tabular}




\subsection{Process simulation development}

\subsubsection{Component selection}

Biomass and char were specified as nonconventional components in Aspen Plus ${ }^{\mathrm{TM}}$. Nonconventional components are not defined by a molecular formula found in the Aspen Plus ${ }^{\mathrm{TM}}$ databanks. Instead, these components are specified by their elemental and proximate analyses to estimate through empirical models enthalpy and density properties (Onarheim et al., 2015). Specifically, the HCOALGEN and the DCOALIGT models were used to estimate the enthalpy and density of biomass and char components (AspenTech, 2013). Isoeugenol, lignin-derived oligomeric compounds with $\beta-0-4$ bond ('Lignin A'), lignin-derived phenylcoumaran compounds ('Lignin B'), cellobiose and levoglucosan are user-defined compounds. Jones and colleagues (2013) provided the molecular structure and thermodynamic data for these compounds to be defined in Aspen Plus ${ }^{\mathrm{TM}}$ (Jones et al., 2013). The remaining bio-oil and non-condensable gas compounds were specified as conventional components, which had thermodynamic properties readily available in the Aspen Plus ${ }^{\mathrm{TM}}$ databanks.

\subsubsection{Thermodynamic model selection}

An activity coefficient thermodynamic model was selected for process simulations over an equation-of-state thermodynamic model because of the non-ideal nature of the organic compounds present in the bio-oil, and the complicated component interactions taking place during pyrolysis. More specifically, the UNIQUAC thermodynamic model was selected (Onarheim et al., 2015).

\subsubsection{Non-catalytic and catalytic pyrolysis design basis}

An overview of the mass and energy flows between the sections of the biorefinery for non-catalytic and catalytic pyrolysis scenarios is given in Figure 11. 


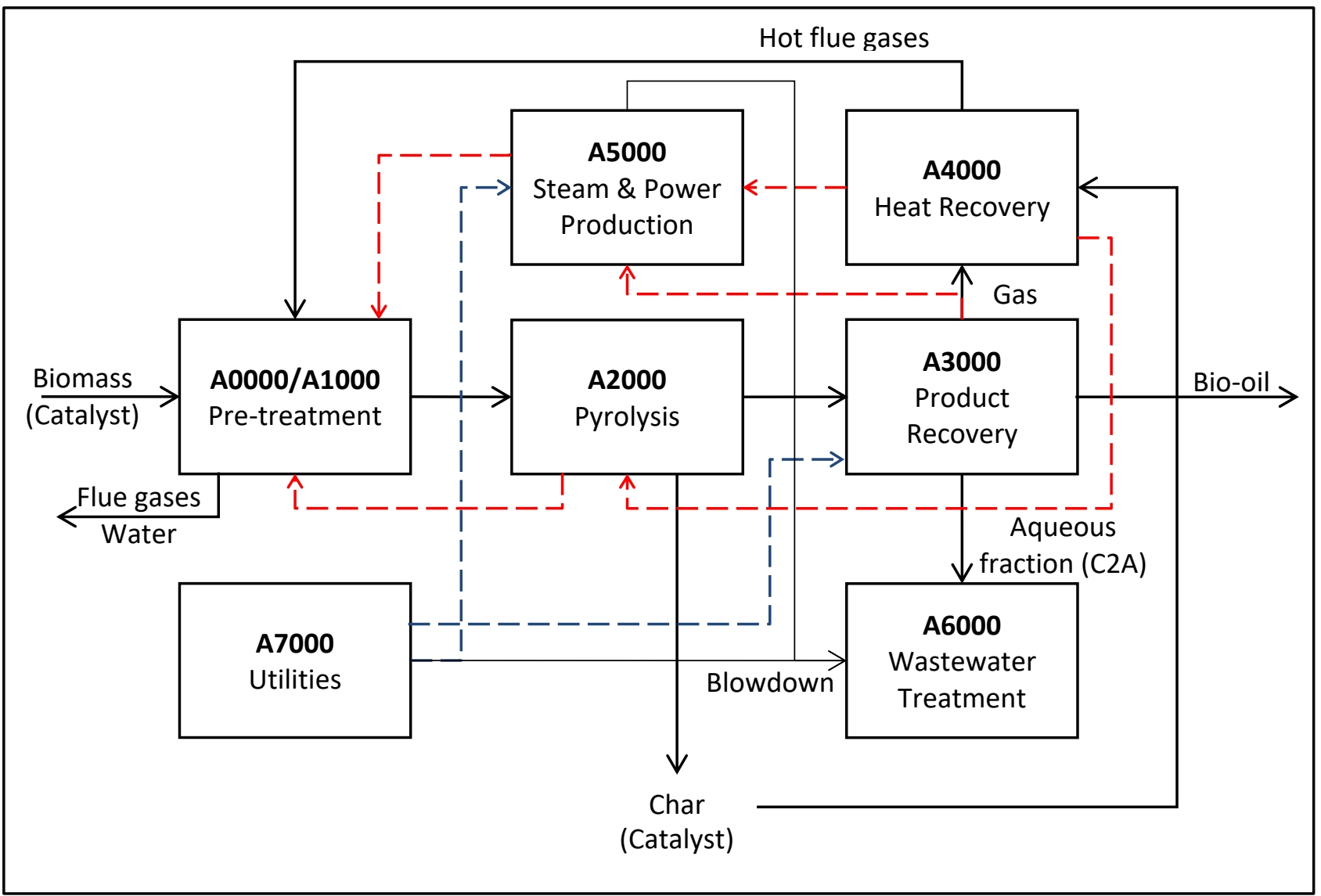

Figure 11: Overview of biorefinery mass flows (-) and energy flows (- -) for non-catalytic and (catalytic) pyrolysis scenarios

\subsubsection{Section A1000 (pre-treatment)}

Pre-treatment is modelled in Sections A1000 as shown in the screenshot of the Aspen Plus ${ }^{\mathrm{TM}}$ model given in Figure 12. The biomass (1001) with 40 wt. \% moisture (1002) was ground down from $2 \mathrm{~cm}$ to approximately $2 \mathrm{~mm}$ in size. The grinder (MILL) was not modelled but the power required for grinding was taken as $14 \mathrm{kWh} / g r e e n$ MT (Carrasco et al., 2017) and included in the process utilities.

The biomass was partially dried with the flue gases produced in Section A4000 therefore, to avoid creating a loop that would have slowed down process calculations in Aspen Plus ${ }^{\mathrm{TM}}$, the drying process shown in Figure 13 was modelled simply as a separator (S1001) and heater (H1001) to achieve the same moisture content ( $8.28 \mathrm{wt}$. \%) and temperature of the biomass leaving the real drying process. The real drying process is shown in the screenshot of the Aspen Plus ${ }^{\mathrm{TM}}$ model given in Figure 13. It was necessary to simulate this process in order to more accurately estimate the energy demand and cost of the process units involved.

The ground biomass stream (1003) was duplicated to feed into the real drying process (0001), where it was first preheated ( $\mathrm{HX0001)}$ up to $100{ }^{\circ} \mathrm{C}$ by indirect contact with the hot char produced in Section A2000, followed by direct contact drying (DR0001) with the flue gases (0003) leaving Section A4000 at $130{ }^{\circ} \mathrm{C}$. The remaining moisture in the biomass was finally decreased to 8.28 wt. \% by indirect 
contact drying (HX0002/DR0002) at $100{ }^{\circ} \mathrm{C}$ with the steam produced in Section A5000 at 4.5 bar and $170{ }^{\circ} \mathrm{C}$. In the catalytic pyrolysis scenarios, the dried biomass (1008) and catalyst (1009) were dry mixed (MIX1001) before entering the pyrolysis reactor in Section A2000.

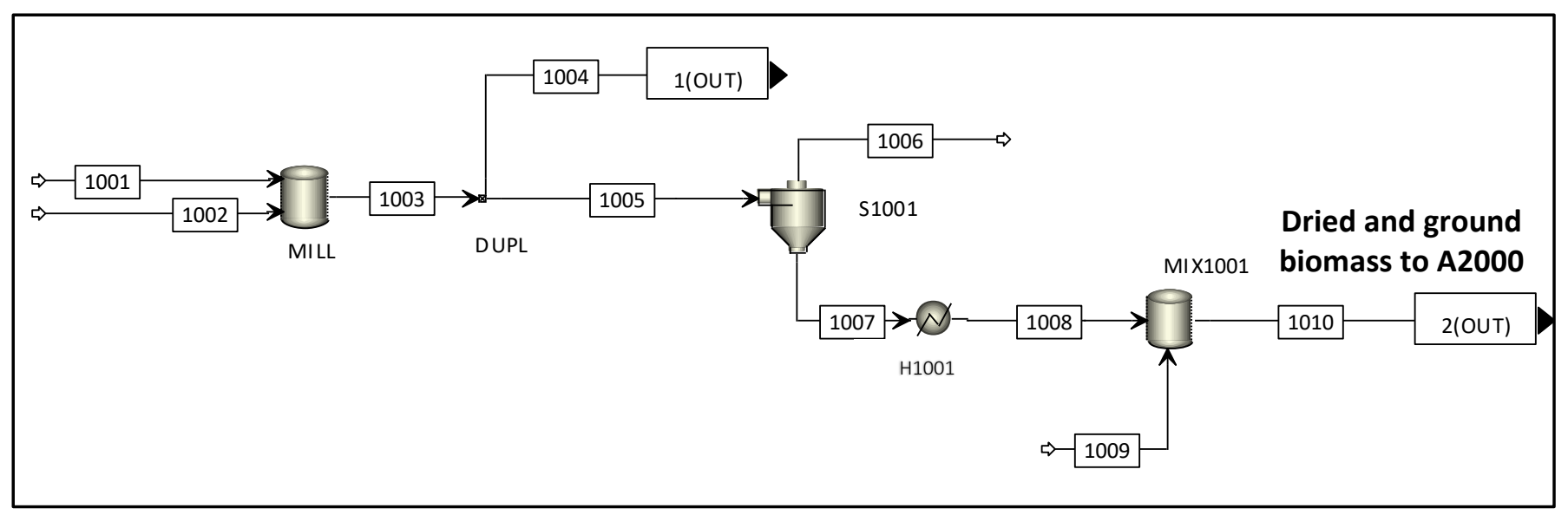

Figure 12: Pre-treatment

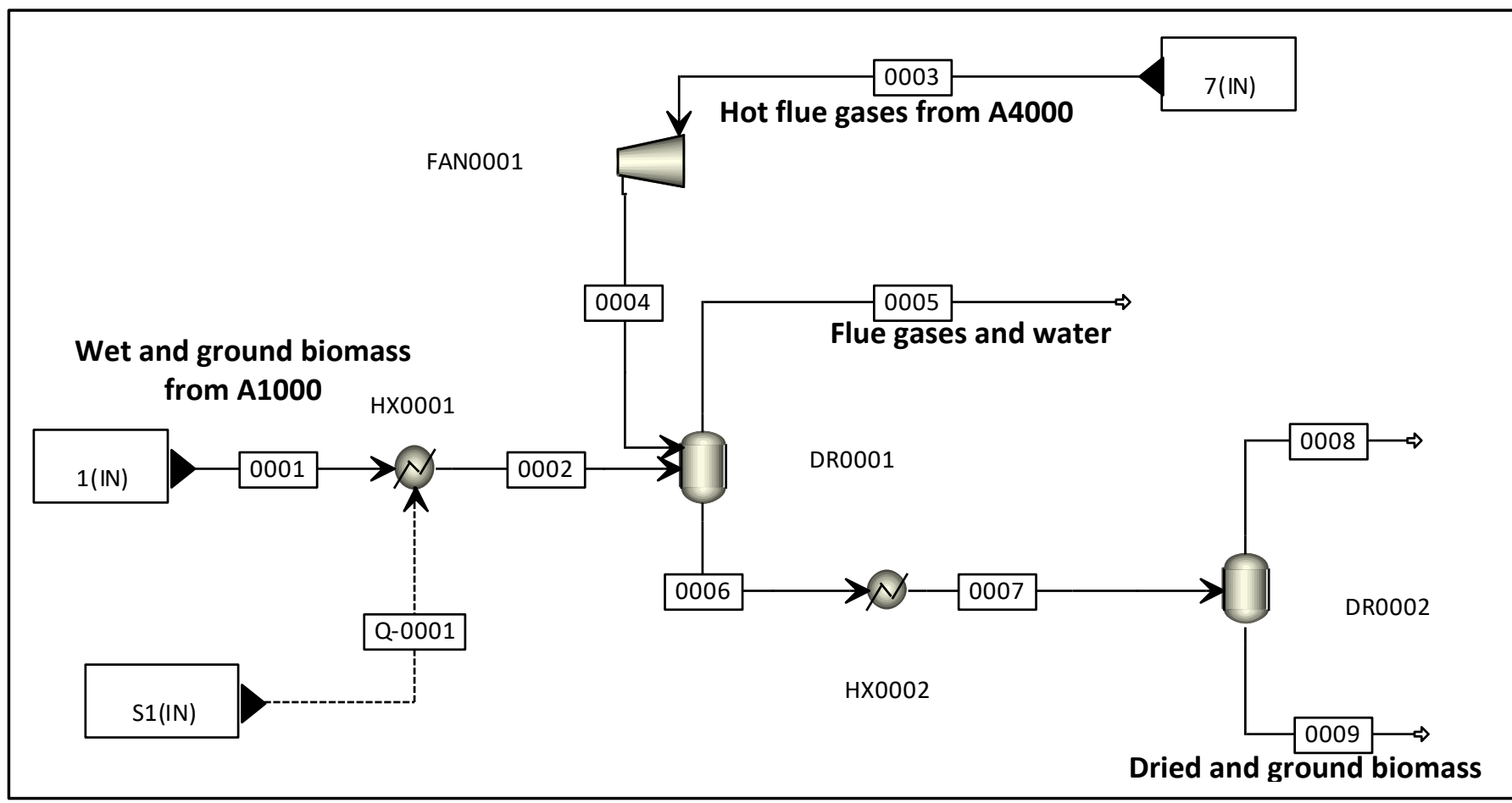

Figure 13: Pre-treatment (real drying process)

\subsubsection{Section A2000 (pyrolysis)}

Pyrolysis is modelled in Section A2000 as shown in the screenshot of the Aspen Plus ${ }^{\mathrm{TM}}$ model given in Figure 14. The dried biomass (2001) and catalyst (in catalytic pyrolysis scenarios) were sent to the pyrolysis reactor (PYRO), which was modelled using the RYield block. The yields of char, bio-oil components (determined in Section 4.4.2) and non-condensable gas components, and pyrolysis temperature $\left(500^{\circ} \mathrm{C}\right)$ and pressure $(1.01325 \mathrm{bar})$ were the only inputs required. In catalytic pyrolysis 
scenarios, the $\mathrm{CaO}$ catalyst reacts during pyrolysis with some of the $\mathrm{CO}_{2}$ produced to form solid $\mathrm{CaCO}_{3}$, which was modelled using the RStoic block (CAT). This reaction is exothermic $\left(\Delta H_{298 K}^{0}=-179 \mathrm{~kJ} / \mathrm{mol}\right.$ (Veses et al., 2014)) therefore, less heat is expected for catalytic pyrolysis than non-catalytic pyrolysis. Heat will be generated for the pyrolysis reactor (Q-2004) in Section A4000 by combusting all of the non-condensable gases produced and if necessary, some of the char produced. HX2001 represents the wall separating the pyrolysis reaction from the hot flue gases. The volatiles and char (containing $\mathrm{CaO}$ and $\mathrm{CaCO}_{3}$ in catalytic pyrolysis scenarios) leaving the pyrolysis reactor were immediately separated by a cyclone (CY2001). The volatiles (2005) were sent to Section A3000 to recover bio-oil and noncondensable gases. A portion of the char (2007) was sent to Section A4000 for combustion (as described above) and the remaining char (2008) was cooled down to $150{ }^{\circ} \mathrm{C}$ in the biomass preheater in Section A0000.

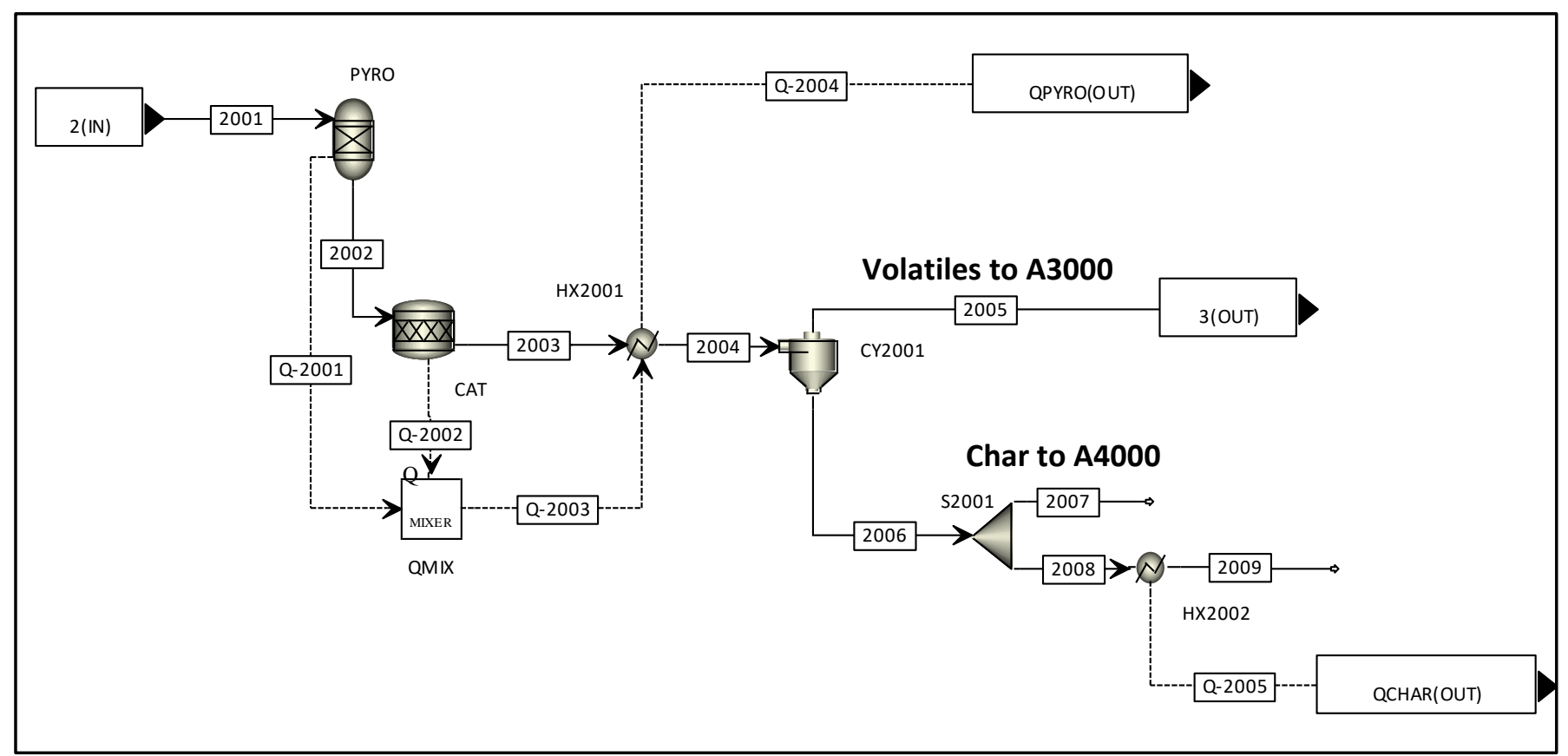

Figure 14: Pyrolysis

\subsubsection{Section $A 3000$ (product recovery)}

Product recovery is modelled in Section A3000 as shown in the screenshot of the Aspen Plus ${ }^{\mathrm{TM}}$ model given in Figure 15. The pyrolysis vapours (3001) leaving Section A2000 at $500{ }^{\circ} \mathrm{C}$ were first cooled to $260{ }^{\circ} \mathrm{C}(\mathrm{HX} 3001)$ and then $210{ }^{\circ} \mathrm{C}$ to recover some heat for steam and power production in Section A5000 before bio-oil recovery, which was modelled based on the condenser train implemented at the pilot plant. Each condenser (C1-C4) was modelled using heat exchanger and separator blocks as specified in Table 21. The condenser train similar to the pyrolysis reactor, operated at atmospheric pressure. The bio-oil recovered from C2 was further separated (S3002B) into organic (3009) and aqueous (3010) fractions. The aqueous fraction was sent for wastewater treatment in Section A6000. 
The non-condensable gases leaving C4 were sent to Section A4000 for combustion, while the recovered bio-oils and organic fraction were pumped (P3001) into a storage tank (T3001).

Table 21: Process simulation condenser train specifications

\begin{tabular}{|lccc|}
\hline Condenser & Blocks & Temperature $\left({ }^{\circ} \mathrm{C}\right)$ & Utility \\
\hline C1 & CON3001, S3001 & 80 & Cooling Water \\
C2 & CON3002, S3002A & 60 & Cooling Water \\
C3 & CON3003, S3003 & 40 & Chilled Water \\
C4 & CON3004, S3004 & 20 & Chilled Water \\
\hline
\end{tabular}

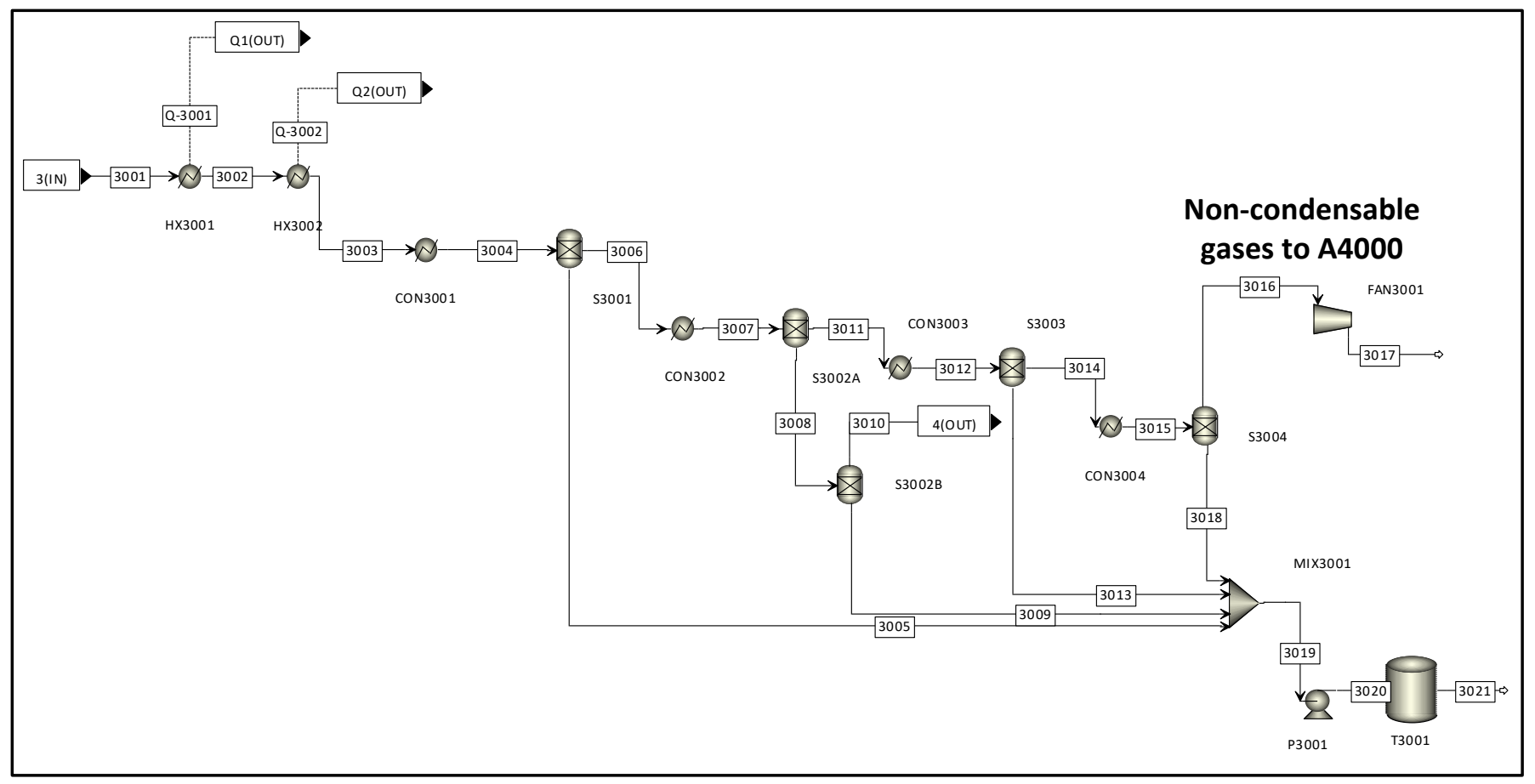

Figure 15: Product recovery

\subsubsection{Section A4000 (heat recovery)}

Heat recovery is modelled in Section A4000 as shown in the screenshot of the Aspen Plus ${ }^{\mathrm{TM}}$ model given in Figure 16. The RStoic block was used to model the combustor $(\mathrm{H} 4001)$ that provides heat for the pyrolysis reactor and dryer. Nonconventional components such as char cannot undergo combustion in the RStoic block without first converting the elemental analysis into conventional components with known stoichiometry (AspenTech, 2013). Instead, char was represented by an equivalent amount of solid carbon (4001) in energy value. The real yield and composition of noncondensable gases (4002) was used instead of the reconciled yield and composition to avoid underestimating the amount of char required to meet the energy needs of the process because char is a high-value product. Ambient air (4003) was preheated (HX4002) by flue gases (4008) before 
entering the combustor. Excess air kept the combustor outlet temperature below $1100{ }^{\circ} \mathrm{C}$ (Wright et al., 2010) without exceeding 10 vol. \% oxygen content in the flue gas (Jones et al., 2013) to avoid spontaneous combustion of the biomass in the dryer (DR0001). Hot flue gases leaving the combustor (4006) were cooled to $800{ }^{\circ} \mathrm{C}(\mathrm{HX} 4003)$ and then $300{ }^{\circ} \mathrm{C}(\mathrm{HX} 4001)$ to recover heat for steam and power production in Section $\mathrm{A} 5000$, followed by further cooling to $130^{\circ} \mathrm{C}$ in the air preheater. Finally, the flue gases were passed through a cyclone (CY4001) before biomass drying in Section A0000 to recover any ash (4011) that would have been produced if the actual char was combusted.

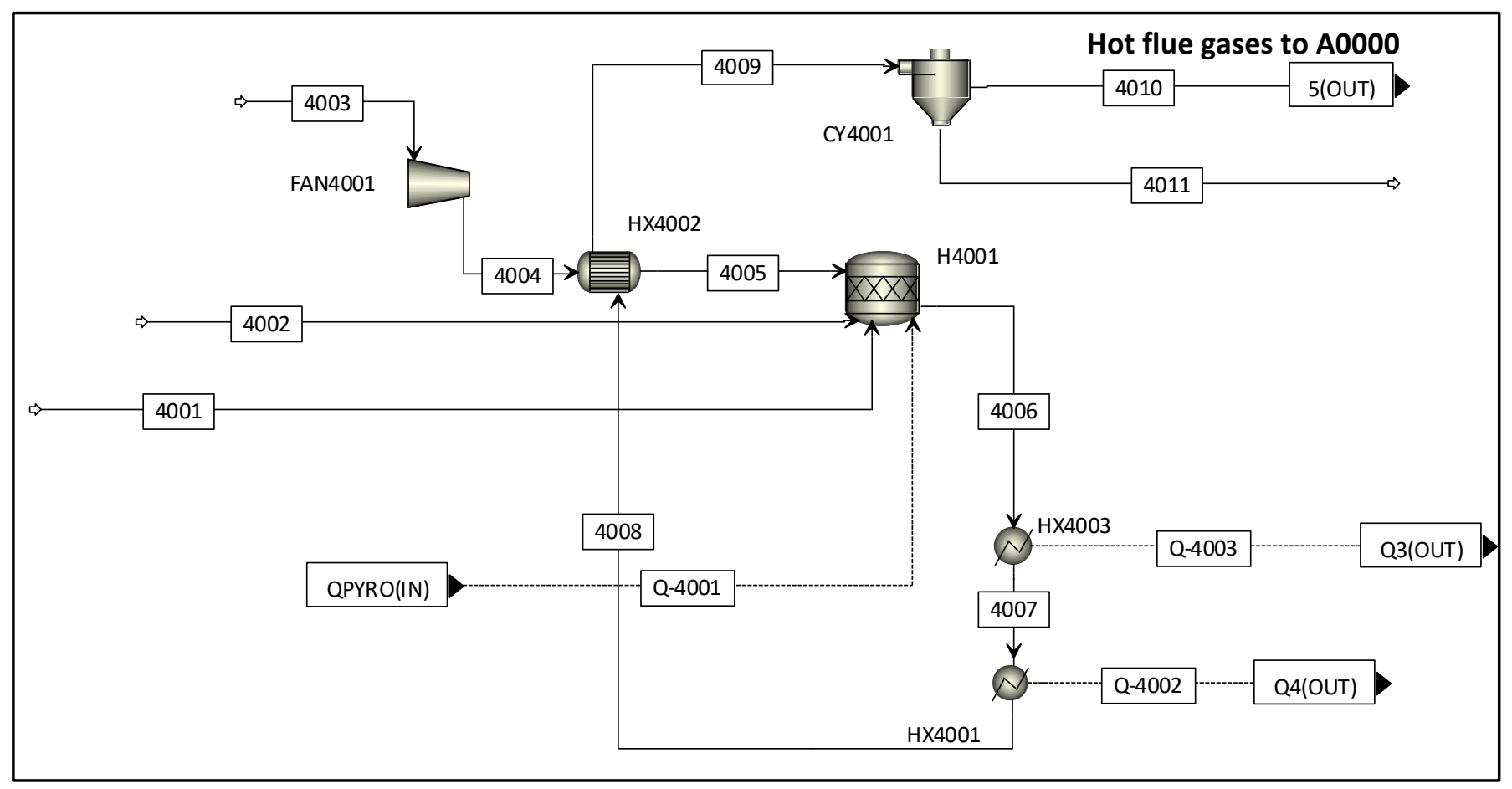

Figure 16: Heat recovery

\subsubsection{Section $A 5000$ (steam and power production)}

Steam and power production are modelled in Section A5000 as shown in the screenshot of the Aspen Plus $^{\mathrm{TM}}$ model given in Figure 17. Boiler feed water or BFW (5001) was pumped (P5001) to 30 bar and passed through a series of three process heat exchanges (HX5001/HX3002, HX5002/HX3001 and

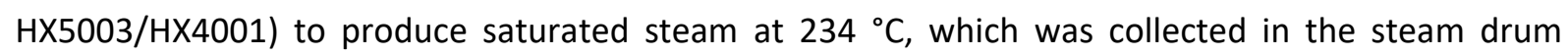
(STEAM). Water was periodically discharged (5007) from the steam drum (also referred to as blowdown) to prevent the build-up of solids (Dutta et al., 2015). The steam drum blowdown was taken as $3 \mathrm{wt}$. \% of the saturated steam (Ringer et al., 2006) and sent for wastewater treatment in Section A6000. The saturated steam was then superheated to about $360^{\circ} \mathrm{C}$ by another process heat exchanger (HX5005/HX4003) before it reached the steam turbines. The superheated steam was discharged to low pressure steam at 4.5 bar and $170{ }^{\circ} \mathrm{C}$ from the first turbine (C5001), and split (S5001) to supply steam (5014) for the indirect dryer (HX0002/DR0002) (De Kam, Morey \& Tiffany, 2009) and steam (5011) for 
additional electricity production in the second turbine (C5002). The turbines operated at $85 \%$ isentropic efficiency and 96 \% mechanical efficiency (Ali Mandegari, Farzad \& Görgens, 2017). Low pressure steam (5011) was discharged to saturated steam at 0.2 bar from the second turbine and condensed (CON5001) to $50^{\circ} \mathrm{C}$ before joining the condensed steam at $110^{\circ} \mathrm{C}(5015)$ from the indirect dryer in the condensate collection tank (S5002). The condensate was then treated in hot condensate polishing and deaerator process units not modelled in Aspen Plus ${ }^{\mathrm{TM}}$ but included in the economic analyses (Dutta et al., 2015). Treated BFW makeup water (5018) was added to the treated condensate (MIX5001) and pumped (P5001) to 30 bar at the beginning of the steam cycle.

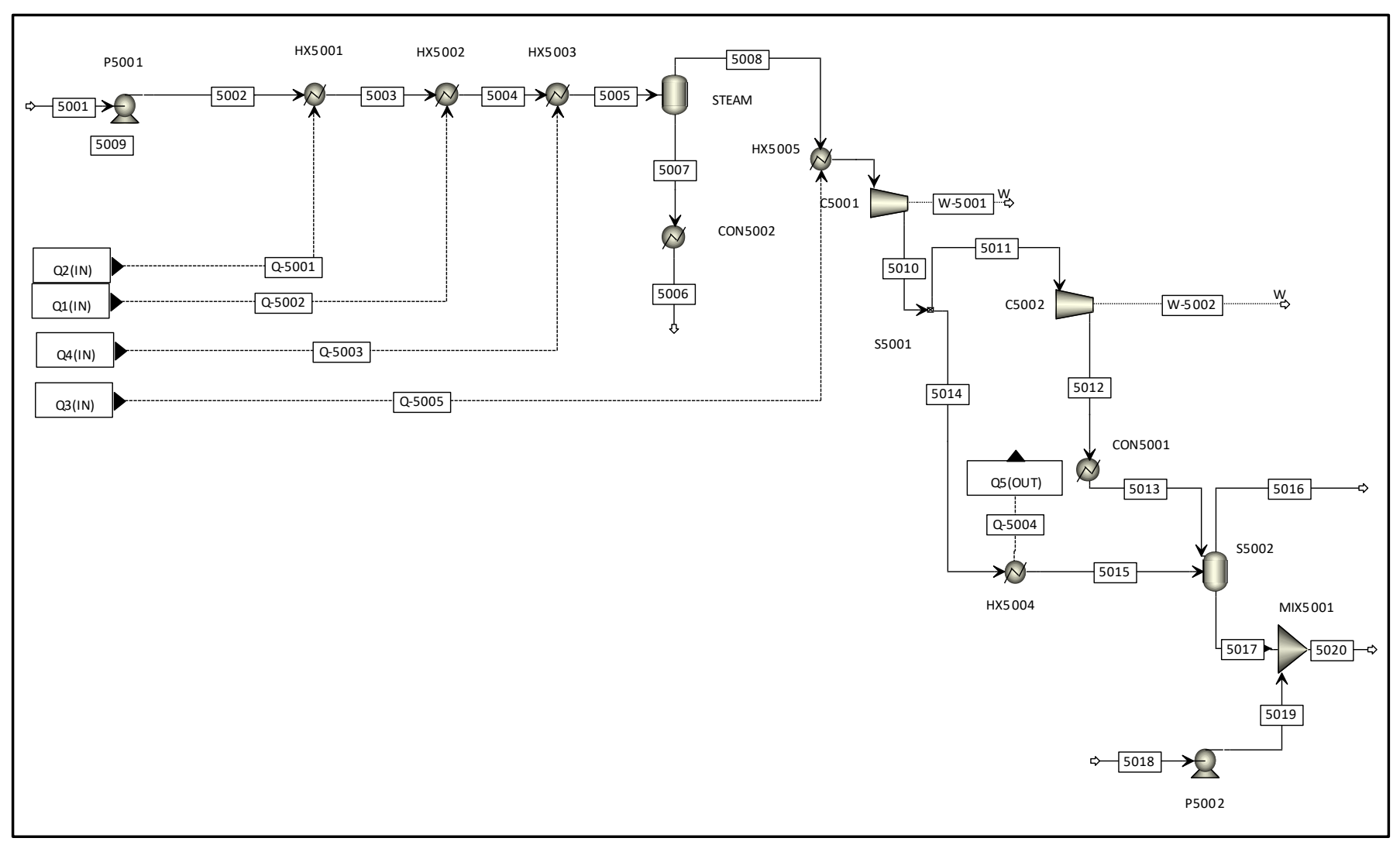

Figure 17: Steam and power production

\subsubsection{Section $A 6000$ (wastewater treatment)}

Wastewater for both non-catalytic and catalytic pyrolysis processes was made up of the aqueous fraction of bio-oil recovered from the second condenser (3010), steam drum blowdown (5007) and cooling tower blowdown. The chemical oxygen demand (COD) of the aqueous fraction was approximately $11 \mathrm{~g} / \mathrm{L}$ (estimated by Aspen Plus ${ }^{\top \mathrm{M}}$ ), which was considered low enough ( $<51 \mathrm{~g} / \mathrm{L}$ ) to be treated by aerobic digestion followed by discharge to municipal wastewater treatment (Jones et al., 2013). Aerobic digestion was not modelled in Aspen Plus ${ }^{\mathrm{TM}}$ but included in the economic analyses. 


\subsubsection{Section A7000 (utilities)}

The cooling tower was modelled based on the principle of evaporative cooling. Makeup water was added to the cooling tower to account for water losses attributed to evaporation, drift and blowdown (Turton, Bailie, Whiting \& Shaeiwitz, 2009), which is expressed mathematically in Equation 4-1.

$W_{M}=W_{E}+W_{D}+W_{B}$

Equation 4-1

Where, $W_{M}\left[\mathrm{~m}^{3} / \mathrm{h}\right]$ is makeup water, and $W_{E}, W_{D}$ and $W_{B}$ are evaporation, drift and blowdown water losses $\left[\mathrm{m}^{3} / \mathrm{h}\right]$, respectively. The evaporation water loss was calculated using Equation 4-2 (Perry, Green \& Maloney, 1997).

$W_{E}=0.00085 \times W_{C} \times\left(T_{\text {in }}-T_{\text {out }}\right) \times 1.8$ Equation 4-2

Where, $W_{C}\left[\mathrm{~m}^{3} / \mathrm{h}\right]$ is the combined flow rate of the cooling water required by the process $\left(W_{C W \text { req }}\right)$ and $W_{M}$ given in Equation $4-3, T_{\text {in }}\left[{ }^{\circ} \mathrm{C}\right]$ is the returned cooling water temperature and $T_{\text {out }}$ $\left[{ }^{\circ} \mathrm{C}\right]$ is the supplied cooling water temperature.

$W_{C}=W_{M}+W_{C W r e q}$

Equation 4-3

Equation 4-1, Equation 4-2 and Equation 4-3 are then combined in Equation 4-4 and rearranged in Equation 4-5 to give an expression to calculate $W_{C}$, which was required to model the cooling tower in Aspen Plus ${ }^{\mathrm{TM}}$. Drift and blowdown water losses were taken as 0.3 and 3 vol. \% of $W_{C}$, respectively (Walas, 1990).

$W_{C}=\left(0.00085 \times\left(T_{\text {in }}-T_{\text {out }}\right) \times 1.8+0.003+0.03\right) \times W_{C}+W_{C W \text { req }}$

Equation 4-4

$W_{C}=\frac{W_{C W r e q}}{1-\left(0.00085 \times\left(T_{\text {in }}-T_{\text {out }}\right) \times 1.8+0.003+0.03\right)}$

Equation 4-5

The cooling tower was modelled in Aspen Plus ${ }^{\mathrm{TM}}$ by specifying the outlet temperature and evaporative water loss of a flash drum. Cooling water was supplied to the process at $28^{\circ} \mathrm{C}$ and returned to the cooling tower at $37^{\circ} \mathrm{C}$ (Ali Mandegari et al., 2017). The power $P$ [W] required for the pumps and fans that operate the cooling tower was calculated by dividing the heat duty $Q[\mathrm{~W}]$ of the cooling tower by its coefficient of performance (COP) as shown in Equation 4-6. The COP for the cooling tower was taken as 7 (Bergsten, 2009). Cooling water was supplied to CON3001, CON3002 and CON5001. 
$P=\frac{Q}{C O P}$

Chilled water was supplied to the process at $4{ }^{\circ} \mathrm{C}$ and 2 atm, and returned to the chilled water system at $15^{\circ} \mathrm{C}$ and $1 \mathrm{~atm}$ (Ali Mandegari et al., 2017). The power consumption for the chilled water system compressor was estimated at $0.56 \mathrm{~kW} /$ ton of refrigeration. The chilled water system required cooling water to condense the refrigerant. The amount of cooling water required was calculated by assuming that the amount of heat removed from the refrigerant was equal to the amount of heat removed from the process (Humbird, Davis, Tao, Kinchin, Hsu, Aden, Schoen, Lukas, Olthof, Worley, Sexton \& Dudgeon, 2011). Chilled water was supplied to CON3003, CON3004 and CON5002.

\subsection{Economic analysis methodology}

The economic analysis followed after mass and energy balances were generated from the process simulation for each biorefinery scenario in Aspen Plus ${ }^{\mathrm{TM}}$. The mass and energy balances were used to size and cost process equipment, and calculate variable operating costs based on feedstock, chemicals, wastewater and solid waste disposal flowrates for the capital and operating cost estimates (Ali Mandegari et al., 2017). The economic feasibility of each biorefinery scenario was then evaluated through a profitability analysis, and the effect of a change in economic parameter on profitability was assessed through a sensitivity analysis.

\subsubsection{Capital cost estimation}

Capital costs are costs incurred during the construction of the biorefinery, leading up to its operation. The Fixed Capital Investment $(\mathrm{FCl})$ included capital cost estimates for purchased and installed equipment, and direct and indirect costs (Vlysidis, Binns, Webb \& Theodoropoulos, 2011). The Total Capital Investment ( $\mathrm{TCl}$ ) was then calculated as the sum of the $\mathrm{FCl}$, land cost and working capital (Turton et al., 2009). The capital cost estimate provided is only a preliminary estimate with an accuracy range of $\pm 30 \%$ (Woods, 2007).

\subsubsection{Fixed capital investment}

Purchased equipment costs $\left(C_{P}^{0}\right)$ were either found in literature (Carrasco et al., 2017; Dutta et al., 2015; Humbird et al., 2011; Jones et al., 2013; Woods, 2007), quoted by the manufacturer (i.e. the pyrolysis reactor) or estimated by Aspen Plus ${ }^{\mathrm{TM}}$. The installed equipment cost $\left(C_{P}\right)$ was calculated using Equation 4-7 for the referenced capacity, and relates the purchased equipment cost to operating pressure and materials of construction by means of an installation factor $(F)$ that can be found in 
literature. However, Aspen Plus ${ }^{T M}$ calculates installed equipment costs based on predefined installation factors.

$\mathrm{C}_{\mathrm{P}}=\mathrm{C}_{\mathrm{P}}^{0} \mathrm{~F}$

Equation 4-7

The installed equipment cost was then adjusted using Equation 4-8 and Equation 4-9 to the required capacity and relevant year of study, respectively.

$\frac{C_{a}}{C_{b}}=\left(\frac{A_{a}}{A_{b}}\right)^{n}$

Equation 4-8

$C_{1}=C_{2}\left(\frac{C E P C I_{2}}{C E P C I_{1}}\right)$

Equation 4-9

Where $A_{a}, A_{b}$ and $n$ represent the capacity for the referenced installed equipment cost, the capacity for the required installed equipment cost and the scaling exponent, respectively. The adjusted installed equipment cost was then scaled to reflect the relevant year of study using the Chemical Engineering Plant Cost Index (CEPCI). The chosen year and CEPCI for this project were 2017 and 567.5 , respectively.

Direct costs are costs incurred for new plant installation such as warehouse, site development and additional installation such as piping. These costs were calculated based on a percentage of the inside-battery-limits (ISBL) installed equipment cost, which is the sum of installed equipment costs for Sections A1000/A0000, A2000, A3000 and A4000 of the biorefinery. The total direct cost (TDC) was then calculated as the sum of the installed equipment costs and direct costs. Indirect costs include prorateable costs, field expenses, home office and construction fees, project contingency and other costs such as start-up and commissioning costs. These costs were calculated based on a percentage of the TDC. The FCl was finally calculated as the sum of the TDC and total indirect costs (Humbird et al., 2011). The guidelines for calculating direct and indirect costs are given in Table 22. 
Table 22: Guidelines for calculating direct and indirect costs (Humbird et al., 2011)

\begin{tabular}{|lc|}
\hline Cost & Factor \\
\hline Warehouse & $4 \%$ of ISBL \\
Site development & $9 \%$ of ISBL \\
Additional piping & $4.5 \%$ of ISBL \\
Prorateable costs & $10 \%$ of TDC \\
Field expenses & $10 \%$ of TDC \\
Home office and construction fees & $20 \%$ of TDC \\
Project contingency & $10 \%$ of TDC \\
Other costs & $10 \%$ of TDC \\
\hline
\end{tabular}

\subsubsection{Operating cost estimation}

Operating costs are incurred during the operation of the biorefinery, and can be categorised as either fixed or variable. Fixed operating costs such as employee salaries and benefits, general overheads, maintenance, taxes and insurance are not dependent on the operating capacity of the biorefinery. Variable operating costs such as forest residues and catalysts, utilities and waste treatment are dependent on the operating capacity of the biorefinery (Brown \& Brown, 2013; Turton et al., 2009).

Table 23 lists the expected number of employees and their salaries for a 2000 dry MT/day pyrolysis biorefinery in the United States (Jones et al., 2013). Salaries for South Africa are expected to be lower (Gorgens, Mandegari, Farzad, Daful \& Haigh, 2016) therefore, the effect of salaries on profitability will be explored through a sensitivity analysis. The number of employees required for each biorefinery scenario was adjusted to the scale of the biorefinery. Employee salaries were adjusted to the relevant year of study using a labour cost index of 24.29 for 2017 and 21.45 for 2011 (U.S. Bureau of Labor Statistics, 2019). Benefits and overheads (90\% of salaries) were included in the fixed operating cost estimate along with insurance and taxes $(0.7 \%$ of $\mathrm{FCl})$, and general maintenance $(3 \%$ of $\mathrm{FCl})$ (Jones et al., 2013). 
Table 23: Employee salaries (Jones et al., 2013)

\begin{tabular}{|lccc|}
\hline Position & Amount & Number of & Amount \\
& $\mathbf{( 2 0 1 1} \mathbf{\$ )}$ & Employees & $\mathbf{( 2 0 1 7 \$ )}$ \\
\hline Plant Manager & 161400 & 1 & 182770 \\
Plant Engineer & 76800 & 1 & 86968 \\
Maintenance Supervisor & 62600 & 1 & 70888 \\
Lab Manager & 61500 & 1 & 69643 \\
Shift Supervisor & 52700 & 5 & 298388 \\
Lab Technician & 43900 & 3 & 149137 \\
Maintenance Technician & 43900 & 16 & 695974 \\
Shift Operators & 52700 & 40 & 2029036 \\
Yard Employees & 30700 & 12 & 347647 \\
\hline Clerks and Secretaries & 39500 & 3 & 134190 \\
\hline
\end{tabular}

Forest residues are collected after round wood harvesting (two-pass system) and forwarded to the roadside with tractor-trailers. The biomass is then chipped at the roadside directly into truck trailers. Ackerman and colleagues (2013) calculated the roadside cost of collected and chipped forest residues using the South African Harvesting and Transport System Costing Model. The roadside cost was adjusted from R112.25/MT (\$12.90/MT for a 2012 R8.70/\$ exchange rate) in 2012 (Ackerman et al. , 2013) to R146.83/MT (\$10.49/MT for a 2017 R14.00/\$ exchange rate) in 2017 using the Producer's Price Index (Statistics South Africa, 2019).

Ackerman and colleagues (2013) suggested that the best truck configuration for biomass transport from the roadside to the biorefinery is a self-unloading system with side and back tippers (Ackerman et al., 2013). The estimated transport cost (including capital) for this type of vehicle with a payload of 33 metric tonnes was R17.11/km in 2017 (Department of Agriculture Forestry and Fisheries, 2018). The average one-way distance from the roadside to the biorefinery within a $300 \mathrm{~km}$ radius of the biorefinery is $179 \mathrm{~km}$ therefore, the transport cost for a round trip (assuming the transport cost of R17.11/km remains the same regardless of a full or empty load) was R185.66/MT (\$13.26/MT). The transport cost for biomass collection within a 200 and $100 \mathrm{~km}$ radius of the biorefinery was calculated in a similar way and reported in Table 24 . The total biomass cost was calculated by adding the roadside cost and transport cost. 
Table 24: Transport cost and total cost of forest residues

\begin{tabular}{|lccccc|}
\hline $\begin{array}{l}\text { Radius } \\
\mathbf{( k m )}\end{array}$ & $\begin{array}{c}\text { Roadside Cost } \\
\mathbf{( R / M T )}\end{array}$ & $\begin{array}{c}\text { Average Distance } \\
\mathbf{( k m )}\end{array}$ & $\begin{array}{c}\text { Transport Cost } \\
\mathbf{( R / M T )}\end{array}$ & $\begin{array}{c}\text { Total Cost } \\
\mathbf{( R / M T )}\end{array}$ & $\begin{array}{c}\text { Total Cost } \\
\text { (\$\$MT) }\end{array}$ \\
\hline 300 & 146.83 & 179 & 185.66 & 332.49 & 23.75 \\
200 & 146.83 & 143 & 148.17 & 295.00 & 21.07 \\
100 & 146.83 & 80 & 82.66 & 229.49 & 16.39 \\
\hline
\end{tabular}

Other variable operating costs such as catalyst cost and wastewater treatment cost are given in Table 25. Variable operating costs were adjusted to the relevant year of study using a chemical cost index (Federal Reserve Economic Data, 2019). The total operating cost is finally the sum of the total fixed and variable operating costs.

Table 25: Variable operating costs

\begin{tabular}{|lccccc|}
\hline Variable cost & Value & $\begin{array}{c}\text { Cost } \\
\text { Year }\end{array}$ & Unit & $\begin{array}{c}\text { Value } \\
\text { (2017\$) }\end{array}$ & Reference \\
\hline Catalyst (CaO) & 150.00 & 2017 & $\$ / \mathrm{MT}$ & 150.00 & www.alibaba.com \\
\hline Ash disposal & 31.81 & 2007 & $\$ / \mathrm{MT}$ & 41.59 & (Humbird et al., 2011) \\
Wastewater & 0.73 & 2011 & $\$ / 100 \mathrm{~m}^{3}$ & 0.75 & (Jones et al., 2013) \\
Process water & 0.22 & 2001 & $\$ / \mathrm{MT}$ & 0.41 & \\
Cooling tower chemicals & 7.70 & 2014 & $\$ /$ year/kW & 7.70 & (Dutta et al., 2015) \\
BFW chemicals & 0.17 & 2014 & $\$ / \mathrm{MT}$ blowdown & 0.17 & \\
50 wt. \% caustic & 0.18 & 2010 & $\$ / \mathrm{kg}$ & 0.20 & \\
\hline
\end{tabular}

\subsubsection{Profitability analysis}

The profitability or economic feasibility of each biorefinery scenario was measured after the capital and operating cost estimates were complete. The discounted cash flow rate of return (DCFROR) analysis was used to measure the minimum selling price (MSP) profitability metric, which is defined as the lowest market price capable of yielding a net present value (NPV) of zero at a nominal or desired internal rate of return (IRR). The nominal IRR (discount rate) was $10 \%$, whereas the desired IRR (to attract private investors to the Greenfields project) was $22 \%$. The MSP profitability metric is useful for comparison between a product and its competitor (Brown \& Brown, 2013). The assumptions required for the DCFROR analysis are presented in Table 26.

The bulk selling price for electricity in South Africa in 2017 was \$0.06/kWh (Motiang \& Nembahe, 2017). Agri-lime is used in agricultural applications to increase soil pH and improve crop productivity. The catalytic pyrolysis biorefinery scenarios produced a mixture of approximately 25 wt. $\% \mathrm{CaO}$ and 75 wt. \% $\mathrm{CaCO}_{3}$, which is similar to the chemical composition of agri-lime. Therefore, the 
selling price of this mixture was assumed to be the same as agri-lime. Agri-lime is sold from Kalkor for R163.00/MT (\$11.64/MT) in South Africa (Kalkor, 2019). The conservative selling price of R5 000/MT $(\$ 357.14 / \mathrm{MT})$ for biochar as a soil additive was chosen based on the literature review given in Section 2.3.4.1. The pyrolysis temperature was too low at $500{ }^{\circ} \mathrm{C}$ to produce biochar with a large enough surface area for activated carbon applications but suitable to produce biochar with enough volatile matter for soil applications, and still gain the environmental benefit of carbon sequestration.

Table 26: Profitability analysis assumptions

\begin{tabular}{|c|c|c|}
\hline Parameter & Value & Reference \\
\hline Project life (years) & 25 & (Ali Mandegari et al., 2017) \\
\hline Exchange rate $(\mathrm{R} / \$)$ & 14 & - \\
\hline Income tax rate (\%) & 28 & (Ali Mandegari et al., 2017) \\
\hline Annual operating hours & 8040 & - \\
\hline Loan (\% of $\mathrm{FCl})$ & 0 & (Nieder-Heitmann, Haigh \& Görgens, 2018) \\
\hline Working capital (\% of FCl) & 5 & (Ali Mandegari et al., 2017) \\
\hline Depreciation period (years) & 5 & \\
\hline Depreciation method & Straight Line & (Nieder-Heitmann et al., 2018) \\
\hline Salvage value & 0 & \\
\hline Construction period (years) & 2 & \multirow{4}{*}{ (Nieder-Heitmann et al., 2018) } \\
\hline$\%$ Spent in -2 & 10 & \\
\hline \% Spent in -1 & 60 & \\
\hline$\%$ Spent in 0 & 30 & \\
\hline Start-up time (years) & 0.5 & \multirow{4}{*}{ (Dutta et al., 2015) } \\
\hline Production during start-up (\%) & 50 & \\
\hline Variable costs during start up (\%) & 75 & \\
\hline Fixed costs during start-up (\%) & 100 & \\
\hline Biochar selling price $(\$ / M T)$ & 357.14 & - \\
\hline Agri-lime selling price (\$/MT) & 11.64 & (Kalkor, 2019) \\
\hline Electricity selling price $(\$ / k W h)$ & 0.06 & (Motiang \& Nembahe, 2017) \\
\hline Nominal IRR (\%) & 10 & - \\
\hline Desired IRR (\%) & 22 & - \\
\hline Cost year & 2017 & - \\
\hline CEPCI & 567.5 & - \\
\hline
\end{tabular}




\subsubsection{Economic sensitivity analysis}

The DCFROR analyses for non-catalytic and catalytic biorefinery scenarios were based on several economic parameter assumptions that need to be evaluated against profitability. The economic sensitivity analysis quantifies the effect a change in model parameter (e.g. biomass cost price) has on the MSP profitability metric. The sensitivity of the MSP was evaluated for a $25 \%$ change (increase and decrease) in the model parameters given in Table 27. The baseline values for total operating cost (TOC) and $\mathrm{FCl}$ will be determined from the capital and operating cost estimates for non-catalytic and catalytic pyrolysis biorefinery scenarios.

Table 27: Sensitivity analysis parameters

\begin{tabular}{|lcccc|}
\hline Parameter & Unit & $\mathbf{- 2 5 \%}$ & Baseline & $\mathbf{+ 2 5 \%}$ \\
\hline Electricity selling price & $\$ / \mathrm{kWh}$ & 0.04 & 0.06 & 0.07 \\
Agri-lime selling price & $\$ / \mathrm{MT}$ & 8.73 & 11.64 & 14.55 \\
Working capital & $\% \mathrm{FCl}$ & 3.75 & 5.00 & 6.25 \\
Biomass cost price & $\$ / \mathrm{MT}$ & 15.80 & 21.07 & 26.34 \\
Income tax rate & $\%$ & 21.00 & 28.00 & 35.00 \\
Biochar selling price & $\$ / \mathrm{MT}$ & 267.86 & 357.14 & 446.43 \\
Catalyst cost price & $\$ / \mathrm{MT}$ & 112.50 & 150.00 & 187.50 \\
TOC & $\$ /$ year & - & variable & - \\
FCl & $\$$ & - & variable & - \\
\hline
\end{tabular}

\subsubsection{Process sensitivity analysis}

Approximately $89 \mathrm{wt}$. \% of the biomass was recovered as pyrolysis products during pilot plant experiments therefore, several assumptions were made to close the mass balance for process simulation development as discussed in Section 4.4.1. The MSP of bio-oil was conservatively estimated based on the unreconciled bio-oil yields for non-catalytic and catalytic pyrolysis processes. However, more efficient product recovery and longer operation at industrial-scale may improve these yields: depositions on the surfaces of process equipment occur at the start of operation, while thereafter these depositions build-up at a slower rate (Sandström et al., 2016). Therefore, the sensitivity of the MSP was also evaluated for a change in bio-oil yield correlated to an 89.0, 94.5 and 100.0 wt. \% mass balance closure.

\subsection{Environmental impact methodology}

The LCA method was selected to assess the environmental impact of bio-oil production via noncatalytic and catalytic pyrolysis processes based on the developed process simulation. The four phases of the LCA are 1) goal and scope definition, 2) Life Cycle Inventory (LCI), 3) Life Cycle Impact Assessment 
(LCIA) and 4) interpretation. Phase 4 takes place throughout Phases 1 to 3 , as shown in Figure 18, and will be discussed in Section 5.3.

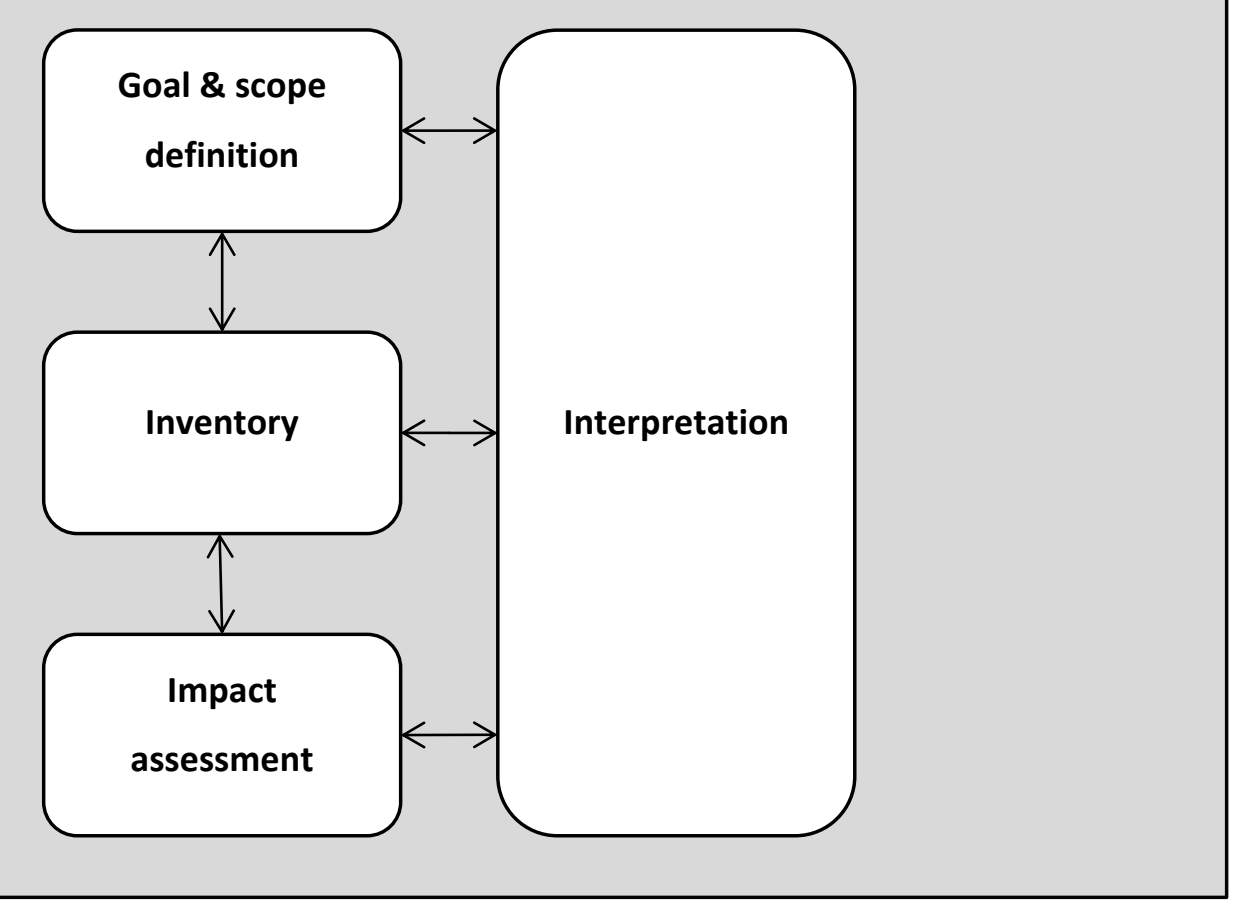

Figure 18: Interaction between the four phases of the LCA

\subsubsection{Goal and scope definition}

The intended application of the product, system boundary and functional unit are fundamental modelling elements of the LCA described in Phase 1 (Sharifzadeh et al., 2019).

\subsubsection{Description of LCA scenarios}

Two LCA scenarios were considered for this project. The first scenario evaluated the environmental impact of valorising forest residues by producing bio-oil via non-catalytic or catalytic pyrolysis instead of disposing of forest residues by in-field burning. The second scenario evaluated the environmental impact of bio-oil production via non-catalytic or catalytic pyrolysis instead of crude-oil and diesel production.

\subsubsection{System boundary}

A "cradle-to-gate" approach for bio-oil production was employed for both scenarios. The activities related to cultivation, thinning and felling of trees to produce forest residues were not included in the LCA because these processes are essential to the production of merchantable wood products (Steele et al., 2012). Therefore, the "cradle" in both scenarios was forest residue collection. The products of pyrolysis were biochar, bio-oil, agri-lime (in the case of catalytic pyrolysis) and a small amount of 
electricity. In the first scenario, the end point of the LCA was the biorefinery gate therefore, the applications of bio-oil and biochar were not considered. In the second scenario, the biochar was transported to an agricultural area and applied to the soil, and the bio-oil was transported to the oil refinery gate, which was the end point of the LCA. The system boundary for bio-oil production via catalytic pyrolysis in the second scenario is given in Figure 19.

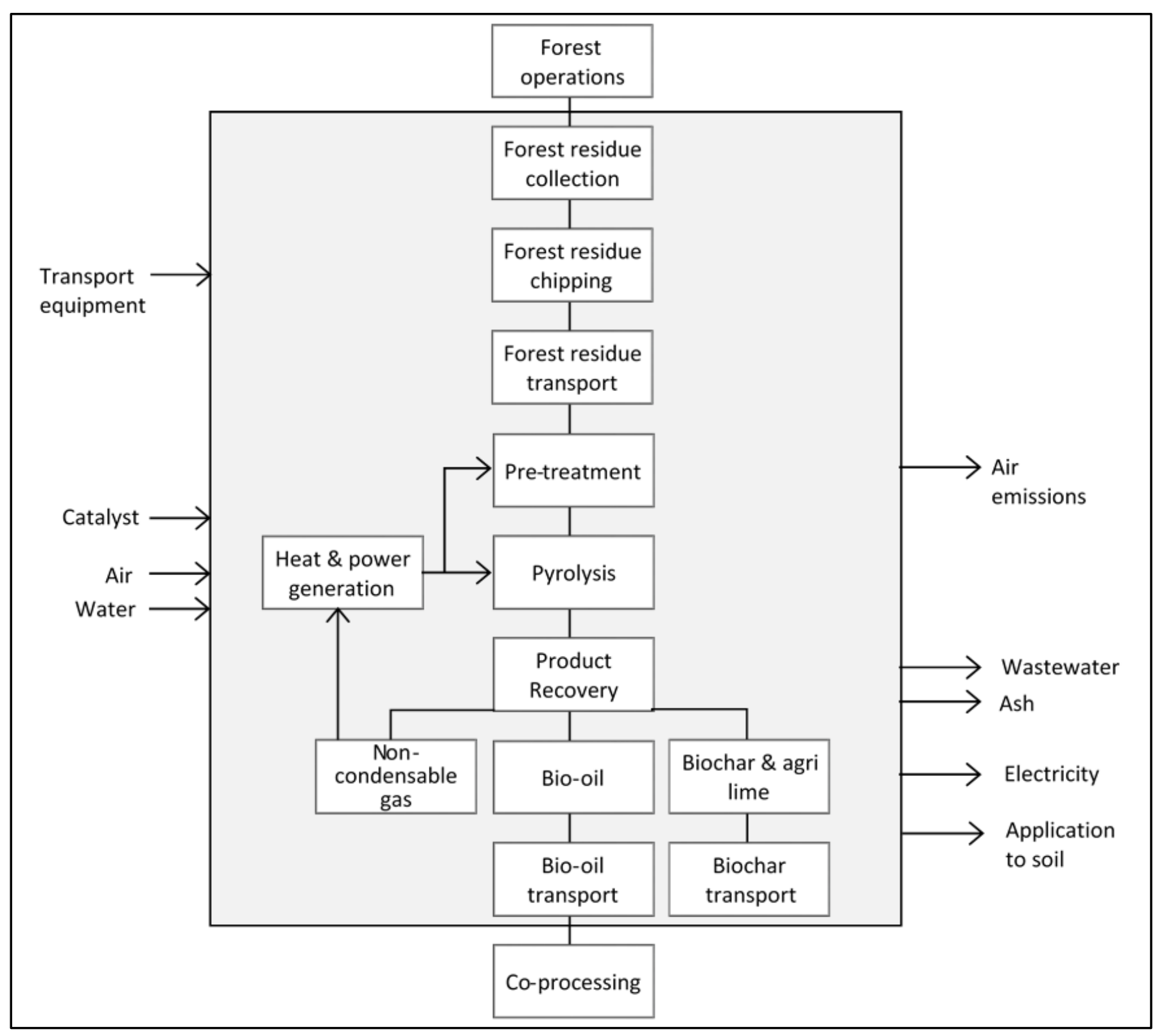

Figure 19: System boundary for bio-oil production in the second scenario via catalytic pyrolysis

\subsubsection{Functional unit}

Researchers have previously chosen functional units such as calorific value of products (Iribarren et al., 2012), mass of feedstock (Roberts, Gloy, Joseph, Scott \& Lehmann, 2010), distance travelled (Hsu, 2012) and area of land cultivated (Kauffman, Hayes \& Brown, 2011) based on their system boundary. 
However, distance travelled and area of land cultivated are less common functional units (Patel et al., 2016). In this study, the functional unit for the first scenario was $1 \mathrm{~kg}$ of dry forest residues since the valorisation of forest residues was compared to its disposal, and the functional unit for the second scenario was $1 \mathrm{MJ}$ of energy produced since bio-oil production was compared to fossil fuel production.

\subsubsection{Allocation procedure}

The main methodologies of the LCA such as allocation procedure are also defined in Phase 1 . There are three main allocation procedures to divide the environmental impacts of a process between its products. The first is allocation by a physical relation such as mass or energy, the second is allocation by economic value, and the third is system boundary expansion (Sharifzadeh et al., 2019). The system boundary expansion method is used when a co-product of the investigated process displaces a conventional product (i.e. the environmental impact of the conventional process is avoided and credited to the investigated process) but may not be appropriate if the yield of the co-product is comparable to the yield of the intended product as the co-product credit may disproportionately overshadow the environmental impact of the intended product (Han et al., 2013).

Allocation by mass was chosen for both scenarios. Biochar has a significant economic value as a co-product, which is not suitable for allocation by economic value when bio-oil is the main product (Lu \& El Hanandeh, 2019). Furthermore, the economic value of bio-oil is not fixed but determined through the profitability analysis, where several assumptions were made. Bio-oil and biochar are similar in calorific value, whereas agri-lime is not a fuel but still a significant co-product of catalytic pyrolysis therefore, neither allocation by energy value nor allocation by system boundary expansion were appropriate.

\subsubsection{Life cycle inventory analysis}

Inventory data related to all inputs and outputs across the system boundary are collected for each unit operation in the second phase of the LCA (Sharifzadeh et al., 2019). The inventory data for both scenarios are given in Appendix D, and were entered into SimaPro ${ }^{\mathrm{TM}}$ version 8.5 .0 to compare the environmental impact of each scenario in the third phase of the LCA. The following assumptions were made regarding the inventory data:

1. Carbon dioxide taken up by the biomass was included but activities directly related to stem wood production such as land use, water use, nutrient replenishment and forest operations were excluded.

2. Capital goods were included for all transport-related inventory.

3. Biochar was transported to the agricultural areas around Durban (KZN), $300 \mathrm{~km}$ away from the biorefinery. 
4. $20 \mathrm{wt}$. \% of biochar carbon content was released to the atmosphere as carbon dioxide over 100 years of carbon sequestration (Han et al., 2013).

5. Biochar nitrogen content was equivalent to conventional $N$ fertilizer (Han et al., 2013).

6. The environmental impact of biochar beyond carbon sequestration and conventional $\mathrm{N}$ fertilizer was not considered (Han et al., 2013).

7. Calcium carbonate was an avoided product since it was applied to the soil with biochar, and replaced conventional $\mathrm{pH}$ raising agents.

8. Carbon dioxide was released when calcium carbonate was applied to the soil with biochar.

9. Calcium oxide also replaced conventional pH raising agents when it was applied to the soil with biochar: $1 \mathrm{~kg}$ of calcium oxide is equivalent to $1.79 \mathrm{~kg}$ of calcium carbonate (Carey, Ketterings \& Hunter, 2006).

10. Electricity was assigned an energy value of $29.0 \mathrm{MJ} / \mathrm{kg}$ for the purpose of mass allocation.

\subsubsection{Life cycle impact assessment}

There are two main methodologies for LCIA in the third phase of the LCA: the environmental problem-oriented (midpoint) approach and the damage-oriented (endpoint) approach (Farzad, Mandegari \& Görgens, 2017). The Institute of Environmental Sciences (CML) at Leiden University developed a midpoint method (CML-IA baseline), which has previously been applied to characterise the environmental impact of pyrolysis processes (Iribarren et al., 2012; Peters, Iribarren \& Dufour, 2015). Therefore, CML-IA baseline was chosen as the default characterisation method for the LCIA in this study. Furthermore, abiotic depletion (ADP) of fossil fuels, acidification (AP), eutrophication (EP), global warming potential over 100 years (GWP ${ }_{100}$ ), and ozone layer depletion (ODP) impact categories were evaluated. 


\section{CHAPTER 5}

\section{$5 \quad$ Results and Discussions}

In this chapter, the mass and energy balance results of process simulations developed in Aspen Plus ${ }^{\mathrm{TM}}$ for non-catalytic and catalytic pyrolysis biorefinery scenarios are discussed in Section 5.1 to address Objective 1. The outcome of Objective 1 was integral to the development of economic analyses for the biorefinery scenarios. The results of capital and operating cost estimates, and subsequent profitability and sensitivity analyses are discussed in Section 5.2 to address Objective 2. Finally, the results for the LCIA developed in SimaPro ${ }^{\mathrm{TM}}$ to evaluate the environmental impact of non-catalytic and catalytic pyrolysis processes are discussed in Section 5.3 to address Objective 3 .

\subsection{Process simulation results}

The mass and energy balance results for the non-catalytic and catalytic pyrolysis biorefinery scenarios are presented and discussed below. Stream tables for the process simulations developed in Aspen Plus $^{\mathrm{TM}}$ are given in Appendix B.

\subsubsection{Overall mass and energy balances}

The overall mass and energy balance represents the main contributors to the material and energy flows through the process, and provides meaningful insight into the overall process performance. The overall mass and energy balances for the biorefinery scenarios are given in Table 28 . The mass balance over the pilot plant was closed for process simulation development in Aspen Plus ${ }^{\mathrm{TM}}$ as discussed in Section 4.4.1, but the bio-oil and non-condensable gas masses reported in Table 28 are based on the unreconciled yields to prevent overestimating profitability for the economic analyses and energy resources available to meet the heating, cooling and power demands of the biorefinery scenarios, respectively. 
Table 28: Overall mass and energy balances for the biorefinery scenarios

\begin{tabular}{|c|c|c|c|c|c|c|c|c|c|}
\hline Scenariot & & NC-100 & NC-5 & NC-200 & NC-300 & C-100 & C-200 & C-10 & C-300 \\
\hline \multicolumn{10}{|l|}{ Input } \\
\hline Forest residues & MT/day & 338 & 813 & 1655 & 2549 & 338 & 1655 & 1710 & 2549 \\
\hline Catalyst & MT/day & - & - & - & - & 158 & 773 & 799 & 1190 \\
\hline \multicolumn{10}{|l|}{ Net output } \\
\hline Char & MT/day & 83 & 200 & 407 & 627 & 61 & 298 & 308 & 459 \\
\hline Agri-lime & MT/day & - & - & - & - & 234 & 1148 & 1186 & 1768 \\
\hline $\mathrm{CO}_{2}\left(\right.$ of $\mathrm{CaCO}_{3}$ ) & MT/day & - & - & - & - & 77 & 375 & 388 & 578 \\
\hline Bio-oil* & MT/day & 73 & 176 & 358 & 551 & 68 & 332 & 343 & 511 \\
\hline Aqueous fraction* & MT/day & 72 & 173 & 352 & 541 & 56 & 274 & 283 & 422 \\
\hline Surplus electricity & $\mathrm{MW}$ & 0.42 & 1.03 & 2.10 & 3.24 & 1.62 & 7.95 & 8.22 & 12.25 \\
\hline \multicolumn{10}{|l|}{ Energy demand } \\
\hline Heating & MW & 17.1 & 41.2 & 83.8 & 129.0 & 17.0 & 83.3 & 86.0 & 128.2 \\
\hline Cooling & MW & 4.14 & 9.95 & 20.24 & 31.17 & 7.72 & 37.79 & 39.03 & 58.18 \\
\hline Power & MW & 0.65 & 1.56 & 3.17 & 4.88 & 0.84 & 4.09 & 4.23 & 6.29 \\
\hline \multicolumn{10}{|l|}{ Energy resources } \\
\hline \multirow{2}{*}{ Char } & MT/day & 23 & 55 & 112 & 172 & - & - & - & - \\
\hline & MW & 8 & 19 & 39 & 61 & - & - & - & - \\
\hline \multirow{2}{*}{ Non-condensable gas* } & MT/day & 76 & 183 & 372 & 573 & 65 & 318 & 329 & 490 \\
\hline & MW & 11 & 26 & 53 & 82 & 20 & 96 & 99 & 147 \\
\hline
\end{tabular}

†Non-catalytic (NC) and catalytic (C) pyrolysis for biomass collection within a 100, 200 and $300 \mathrm{~km}$ radius of the biorefinery, and NC and $\mathrm{C}$ at the required biorefinery capacity to co-process 5 and $10 \mathrm{wt}$. \% bio-oil, respectively

‡Dry basis (8.28 wt. \% moisture)

*Based on unreconciled mass balance yield

The total energy recovered in bio-oil and biochar products based on a mass basis of forest residues is 10.97 and $9.39 \mathrm{MJ} / \mathrm{kg}$ (61.9 and $53.0 \%$ of biomass $\mathrm{HHV}$ ) for non-catalytic and catalytic pyrolysis biorefinery scenarios, respectively. All of the non-condensable gases and $21.5 \mathrm{wt}$. \% of the char yield (in the non-catalytic pyrolysis biorefinery scenarios) were combusted to provide heat for the pyrolysis reactor, and to produce steam for the dryer and power for the biorefinery. The total energy supplied on a mass basis of forest residues is 4.43 and $4.58 \mathrm{MJ} / \mathrm{kg}$ ( 25.0 and $25.9 \%$ of biomass HHV) for non-catalytic and catalytic pyrolysis biorefinery scenarios, respectively.

The total heating demand on a mass basis of forest residues is approximately $4 \mathrm{MJ} / \mathrm{kg}$ (about $22.6 \%$ of the biomass HHV). The total heating demand of all biorefinery scenarios is almost the same 
but the heating demand distribution is significantly different for non-catalytic and catalytic pyrolysis biorefinery scenarios as shown in Figure 20.

The pyrolysis reactor is one of the key energy consumers in the biorefinery. The pyrolysis reactor heating demand is the summation of the heat required to increase the temperature of the feed to $500^{\circ} \mathrm{C}$ and the heat required for the pyrolysis reaction itself. The specific enthalpy of the pyrolysis reaction (denoted as $h_{P}$ ) was $1.41 \mathrm{MJ} / \mathrm{kg}$ and $0.12 \mathrm{MJ} / \mathrm{kg}$ for non-catalytic and catalytic pyrolysis, respectively. The result for non-catalytic pyrolysis is in good agreement with previous studies. Daugaard and Brown (2003) estimated $h_{P}$ for fast pyrolysis conducted in a pilot-scale reactor at 500 ${ }^{\circ} \mathrm{C}$ with oak wood chips (8 wt. \% moisture) as $1.61 \mathrm{MJ} / \mathrm{kg}$ (Daugaard \& Brown, 2003). Onarheim, Solantausta and Lehto (2015) reported $h_{P}$ for fast pyrolysis simulated in Aspen Plus ${ }^{\mathrm{TM}}$ at $500{ }^{\circ} \mathrm{C}$ with pine wood chips ( $8 \mathrm{wt}$. \% moisture) as $1.78 \mathrm{MJ} / \mathrm{kg}$ (Onarheim et al., 2015). Yang and colleagues (2013) investigated pyrolysis at $500{ }^{\circ} \mathrm{C}$ with cedar wood chips for variable heating rates $\left(0.5\right.$ to $\left.5.3^{\circ} \mathrm{C} / \mathrm{s}\right)$ from slow to intermediate pyrolysis conditions. The authors found that $h_{P}$ (on a dry basis) increased with heating rate from $1.1 \mathrm{MJ} / \mathrm{kg}$ at $0.5{ }^{\circ} \mathrm{C} / \mathrm{s}$ to $1.2 \mathrm{MJ} / \mathrm{kg}$ at $5.3^{\circ} \mathrm{C} / \mathrm{s}$ (Yang, Kudo, Kuo, Norinaga, Mori, Ondrej \& Hayashi, 2013). On the other hand, $h_{P}$ was far less for catalytic pyrolysis compared to noncatalytic pyrolysis because of the exothermic reaction taking place between the $\mathrm{CaO}$ catalyst and carbon dioxide inside the pyrolysis reactor (Veses et al., 2014; Zhao, Zhang, Chen, Sun, Si \& Chen, 2014).

In the catalytic pyrolysis biorefinery scenarios, the heating demand for the pyrolysis reactor, dryer and power for the biorefinery could have been met by only burning a portion of the noncondensable gas produced, however, this would have a negative effect on the environmental impact of the biorefinery as the non-condensable gas contained high concentrations of carbon monoxide and methane gases therefore, all of the non-condensable gas produced was combusted to produce surplus electricity that was sold to the grid. Thus, the heating demand for power generation in catalytic pyrolysis was greater than non-catalytic pyrolysis.

The biomass was dried from 40 to $8.28 \mathrm{wt}$. \% moisture in two stages: the first stage involved drying the biomass by direct contact with hot flue gases, and the second stage involved drying the biomass by indirect contact with steam. The first stage of drying reduced the biomass moisture content by $28.1 \mathrm{wt}$. \% for catalytic pyrolysis as opposed to $12.8 \mathrm{wt}$. \% for non-catalytic pyrolysis. The significant difference in drying efficiency is directly related to the amount of flue gases produced. Catalytic pyrolysis produced more flue gases than non-catalytic pyrolysis because 85 vol. \% excess air was required to keep the outlet temperature of the combustor below $1100{ }^{\circ} \mathrm{C}$ compared to 20 vol. \% for non-catalytic pyrolysis. Therefore, the heating demand for the indirect dryer was higher for the noncatalytic pyrolysis biorefinery scenarios than the catalytic pyrolysis biorefinery scenarios. 


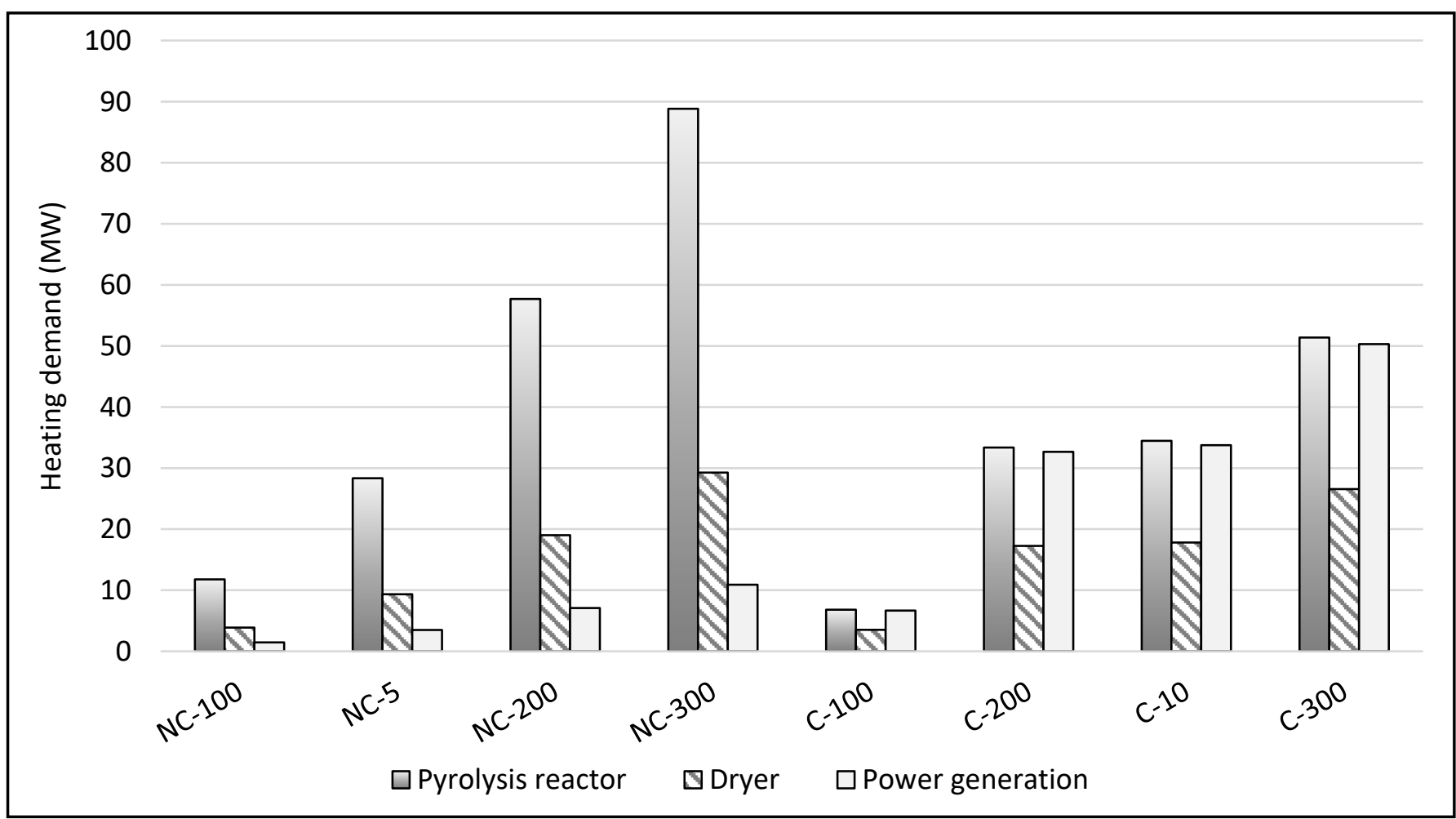

Figure 20: Heating demand distribution for each biorefinery scenario

The total cooling demand on a mass basis of forest residues is approximately 0.97 and 1.81 $\mathrm{MJ} / \mathrm{kg}$ for non-catalytic and catalytic pyrolysis biorefinery scenarios, respectively. The cooling demand distribution is depicted in Figure 21. The cooling demand for the condenser train, in particular C1 and C2, was lower for catalytic than non-catalytic pyrolysis because catalytic pyrolysis produced less biooil than non-catalytic pyrolysis. Furthermore, the absorption of $\mathrm{CO}_{2}$ by the $\mathrm{CaO}$ catalyst in the pyrolysis reactor upstream from the condenser train resulted in an even lower cooling demand for catalytic pyrolysis. Catalytic pyrolysis also produced more steam for power generation than non-catalytic pyrolysis therefore, the cooling demand to condense the low pressure steam discharged from the second turbine was higher.

The total cooling demand is met by about 95.0 and $95.8 \%$ cooling water with the remainder chilled water for non-catalytic and catalytic pyrolysis biorefinery scenarios, respectively. A similar study by Dutta and colleagues (2015) fulfilled a small portion of the cooling demand for a catalytic pyrolysis biorefinery with cooling water $(0.64 \mathrm{MJ} / \mathrm{kg}$ feedstock with 10 wt. \% moisture) and chilled water (0.27 $\mathrm{MJ} / \mathrm{kg}$ ) but the majority of the cooling demand was met by air-cooling (5.95 MJ/kg) (Dutta et al., 2015). In brief, air-coolers require more capital cost than water coolers but air-coolers reduce operating cost by eliminating water lost and wastewater generated through cooling tower evaporation and blowdown (Mandegari, Farzad \& Gorgens, 2016). The total cooling demand for catalytic pyrolysis in the compared study $(6.86 \mathrm{MJ} / \mathrm{kg})$ is considerably higher than this study $(1.81 \mathrm{MJ} / \mathrm{kg})$ because almost 
three times more power was produced (Dutta et al., 2015). Therefore, the cooling demand to condense the low pressure steam discharged from the second turbine was much greater.

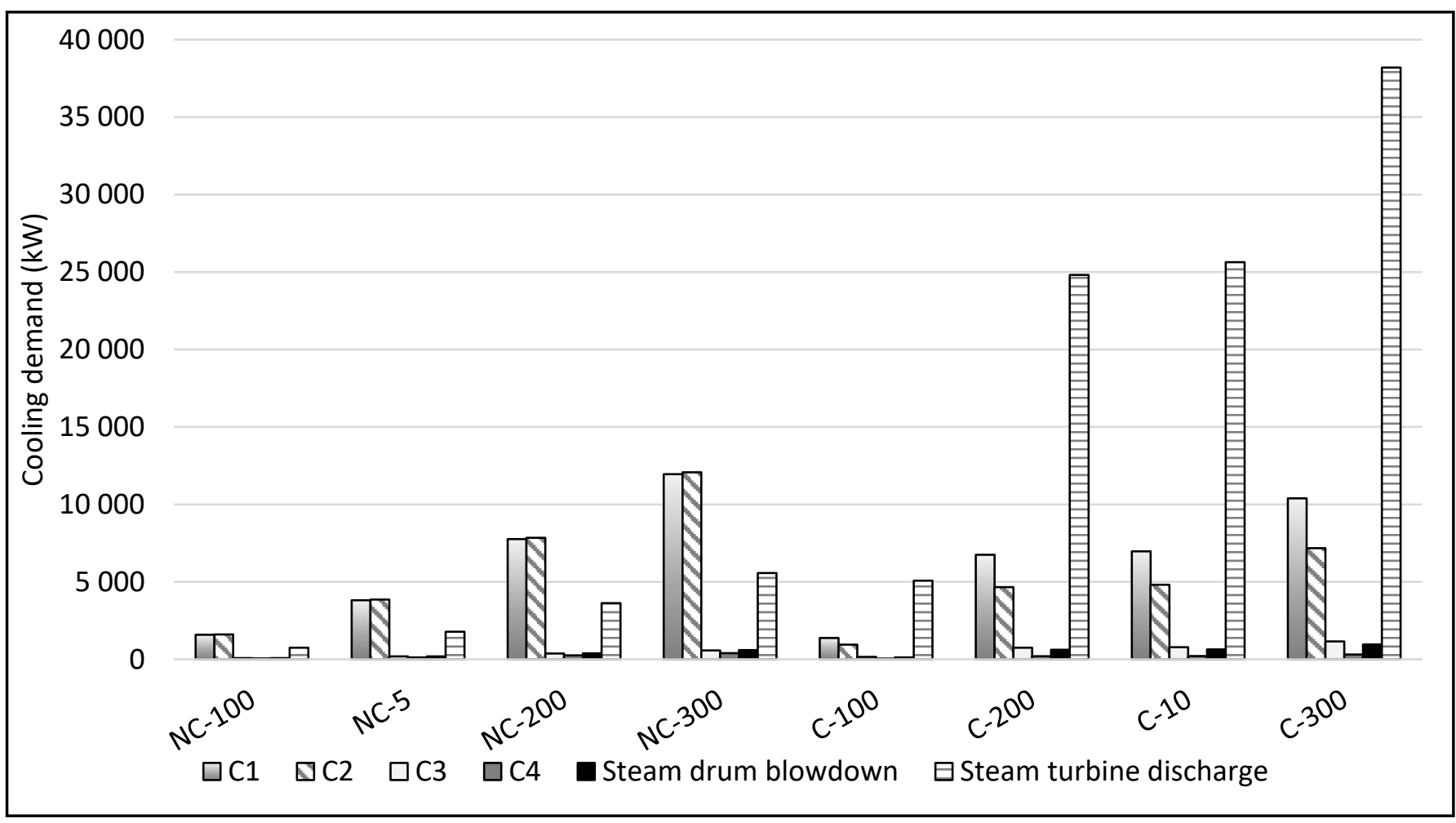

Figure 21: Cooling demand distribution for each biorefinery scenario

The total power demand on a mass basis of forest residues is approximately 0.15 and 0.20 $\mathrm{MJ} / \mathrm{kg}$ for non-catalytic and catalytic pyrolysis biorefinery scenarios, respectively. The power demand distribution is given in Figure 22. The grinder consumed the most power in each biorefinery scenario, contributing to about 51 and $39 \%$ of the total power demand for non-catalytic and catalytic pyrolysis, respectively. Grinding has previously been reported as an energy-intensive process (Bridgwater, Toft \& Brammer, 2002; Wright et al., 2010). The total power demand for catalytic pyrolysis was higher than non-catalytic pyrolysis because the cooling demand was greater, and 85 vol. \% excess air was required to keep the outlet temperature of the combustor below $1100{ }^{\circ} \mathrm{C}$ for catalytic pyrolysis versus 20 vol. $\%$ for non-catalytic pyrolysis. Therefore, more power was consumed by the fans driving the air and flue gases through the combustor and direct dryer.

Finally, the overall heating, cooling and power demand per litre of bio-oil produced $(\mathrm{kW} / \mathrm{L})$ from non-catalytic and catalytic pyrolysis biorefinery scenarios are compared in Figure 23. Heating and power demands for non-catalytic and catalytic pyrolysis biorefinery scenarios were comparable overall, while catalytic pyrolysis required more cooling per litre of bio-oil produced than non-catalytic pyrolysis. 
Process heat was recovered to satisfy the heating (steam for the indirect dryer) and power demands of the biorefinery, which characterized the process as entirely energy self-sufficient. The excess electricity produced was minimised as far as possible and sold to the grid at Eskom's bulk electricity selling price (R0.81/kWh or $\$ 0.06 / \mathrm{kWh}$ (Motiang \& Nembahe, 2017)), and not at the higher renewable electricity selling price $(\mathrm{R} 2.22 / \mathrm{kWh}$ or $\$ 0.16 / \mathrm{L}$ (Eskom, 2019)) since the excess electricity produced was not a main product of the biorefinery.

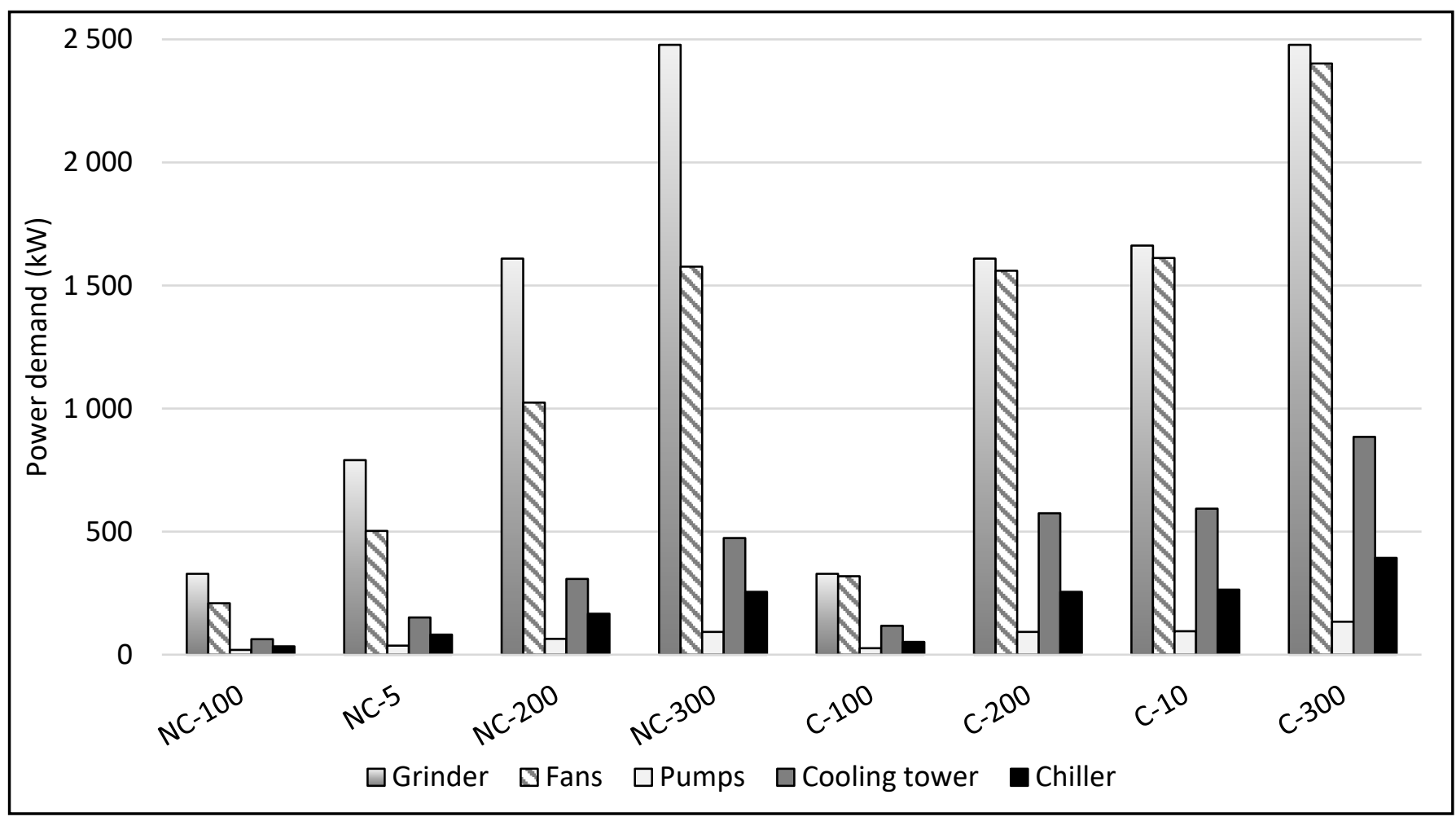

Figure 22: Power demand distribution for each biorefinery scenarios 
8.0

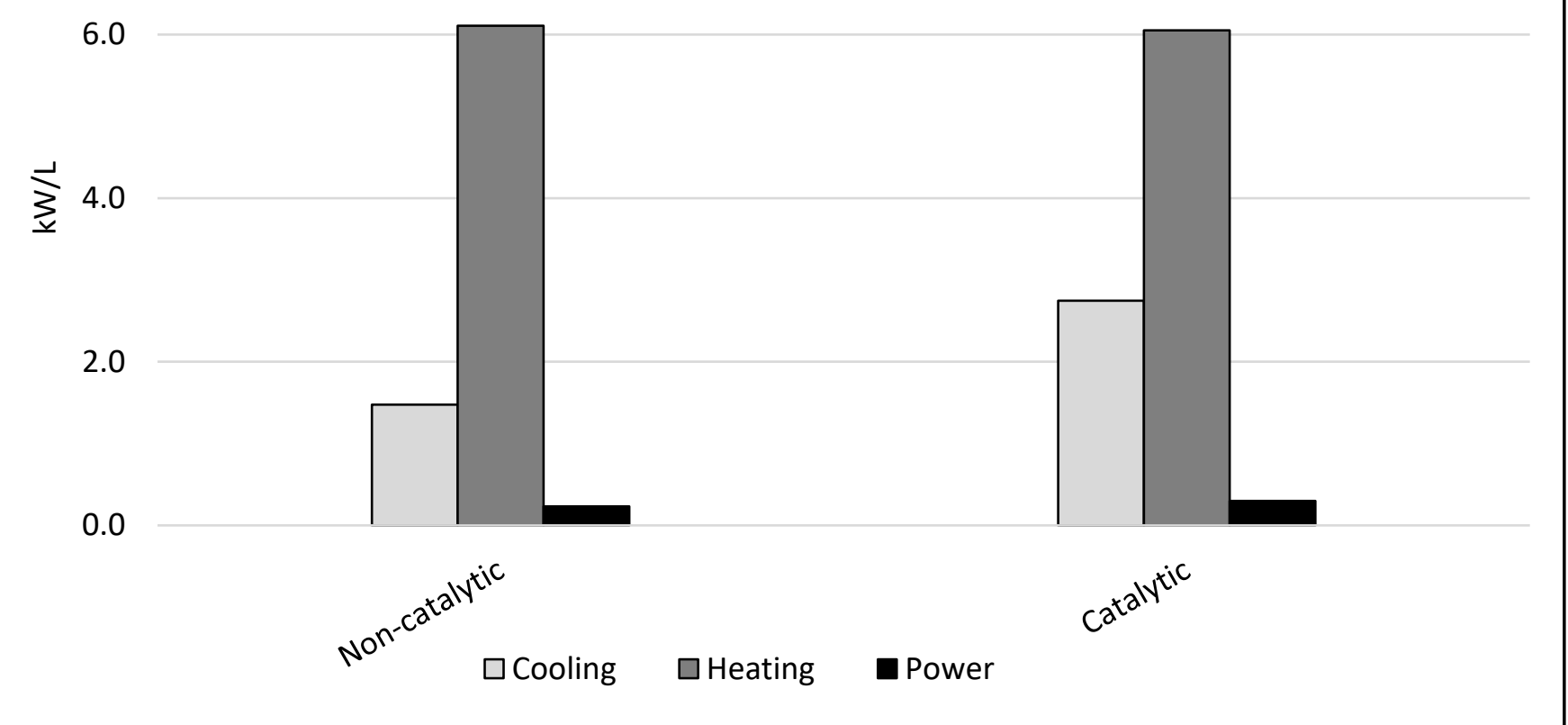

Figure 23: Overall heating, cooling and power demand per litre of bio-oil produced

\subsubsection{Water balance}

It is also important to consider water consumption in the overall performance evaluation of the biorefinery scenarios due to the limited water resources in South Africa. A summary of the process water and wastewater required and generated for each biorefinery scenario is given in Table 29. The total wastewater generated was 1.05 and $1.72 \mathrm{~kg} / \mathrm{kg}$ forest residues (8.28 wt. \% moisture) for non-catalytic and catalytic pyrolysis biorefinery scenarios, respectively, and was mostly made up of the cooling tower blowdown. The wastewater generated by the catalytic pyrolysis biorefinery in a similar study by Dutta and colleagues (2015) was predictably lower at $0.43 \mathrm{~kg} / \mathrm{kg}$ feedstock ( $10 \mathrm{wt}$. \% moisture) than the wastewater generated by the catalytic pyrolysis biorefinery scenarios in this study because the former mostly made use of air-cooling rather than water-cooling to meet the cooling demands of the biorefinery (Dutta et al., 2015). 
Table 29: Water balance (MT/day) for each biorefinery scenario

\begin{tabular}{|c|c|c|c|c|c|c|c|c|c|}
\hline Scenariot & & NC-100 & NC-5 & NC-200 & NC-300 & $C-100$ & C-200 & C-10 & C-300 \\
\hline \multirow{2}{*}{$\begin{array}{l}\text { Process } \\
\text { water }\end{array}$} & BFW makeup & 7 & 16 & 33 & 51 & 11 & 53 & 55 & 82 \\
\hline & $\begin{array}{c}\text { Cooling water } \\
\text { makeup }\end{array}$ & 468 & 1123 & 2284 & 3517 & 871 & 4263 & 4404 & 6564 \\
\hline \multirow{3}{*}{ Wastewater } & $\begin{array}{l}\text { Steam drum } \\
\text { blowdown }\end{array}$ & 7 & 16 & 33 & 51 & 11 & 53 & 55 & 82 \\
\hline & $\begin{array}{l}\text { Cooling tower } \\
\text { blowdown }\end{array}$ & 300 & 720 & 1465 & 2256 & 559 & 2734 & 2825 & 4210 \\
\hline & Aqueous fraction & 82 & 198 & 403 & 620 & 66 & 321 & 332 & 495 \\
\hline
\end{tabular}

+Non-catalytic (NC) and catalytic (C) pyrolysis for biomass collection within a 100, 200 and $300 \mathrm{~km}$ radius of the biorefinery, and NC and $\mathrm{C}$ at the required biorefinery capacity to co-process 5 and 10 wt. \% bio-oil, respectively.

\subsection{Economic analysis results}

The economic analysis was developed based on the mass and energy balance results, and involved estimating capital and operating costs for the profitability and sensitivity analyses. The economic analysis results for non-catalytic and catalytic pyrolysis biorefinery scenarios are presented and discussed below.

\subsubsection{Capital cost estimation}

The mass and energy balance results were used to size and subsequently cost process equipment for each biorefinery scenario. The total installed equipment cost, direct cost, indirect cost, Fixed Capital Investment ( $\mathrm{FCl}$ ) and Total Capital Investment ( $\mathrm{TCl}$ ) for each biorefinery scenario is given in Table 30 . A summary of the purchased equipment costs, installation factors and scaling factors used to determine the installed equipment costs is given Table C1 in Appendix C. Further details on the calculation of $\mathrm{FCl}$ and $\mathrm{TCl}$ for each biorefinery scenario are given in Table $\mathrm{C} 2$ in Appendix $\mathrm{C}$. The assumed cost of land was R952 141/ha ( $\$ 68000 /$ ha) based on the average cost of land in the area surrounding the biorefinery. The area of land required was calculated based on a $2000 \mathrm{dry} \mathrm{MT/day}$ biorefinery requiring approximately 463 ha of land (Dutta et al., 2015). 
Table 30: Summary of total installed equipment cost, direct cost, indirect cost, $\mathrm{FCl}$ and $\mathrm{TCl}$ (Million \$) for each biorefinery scenario

\begin{tabular}{|lcccccccc|}
\hline Scenariot & NC-100 & NC-5 & NC-200 & NC-300 & C-100 & C-200 & C-10 & C-300 \\
\hline Total Installed Equipment Cost & 54.7 & 99.2 & 161.8 & 218.5 & 64.3 & 194.5 & 199.0 & 264.3 \\
Total direct cost & 61.8 & 112.4 & 183.7 & 248.3 & 72.5 & 220.1 & 225.2 & 299.4 \\
Total indirect cost & 37.1 & 67.5 & 110.2 & 149.0 & 43.5 & 132.1 & 135.1 & 179.7 \\
Fixed Capital Investment & 98.9 & 179.9 & 294.0 & 397.2 & 116.0 & 352.2 & 360.4 & 479.1 \\
Total Capital Investment & $\mathbf{1 0 4 . 4}$ & $\mathbf{1 9 0 . 2}$ & $\mathbf{3 1 1 . 3}$ & $\mathbf{4 2 1 . 1}$ & $\mathbf{1 2 2 . 3}$ & $\mathbf{3 7 2 . 4}$ & $\mathbf{3 8 1 . 1}$ & $\mathbf{5 0 7 . 0}$ \\
\hline
\end{tabular}

†Non-catalytic (NC) and catalytic (C) pyrolysis for biomass collection within a 100, 200 and $300 \mathrm{~km}$ radius of the biorefinery, and NC and C at the required biorefinery capacity to co-process 5 and $10 \mathrm{wt}$. \% biooil, respectively.

The $\mathrm{TCl}$ for each biorefinery scenario in this study is compared to the $\mathrm{TCl}$ for similar studies against biorefinery capacity in Figure 24. The TCl for catalytic pyrolysis is higher than non-catalytic pyrolysis at the same biorefinery capacity mostly because of the extra processing capacity required for the catalyst. The $\mathrm{TCl}$ reported for catalytic pyrolysis in this study is significantly lower than the TCI reported for catalytic pyrolysis by Dutta and colleagues (2015) because hydrotreating process units were added after catalytic pyrolysis to further upgrade bio-oil into gasoline and diesel-quality fuels (Dutta et al., 2015). Jones and colleagues (2013) conducted a techno-economic analysis (TEA) to produce gasoline and diesel-quality fuels via fast pyrolysis followed by hydrotreating (Jones et al., 2013). The TCl reported was higher than both non-catalytic and catalytic pyrolysis biorefinery scenarios in this study. Co-processing crude or upgraded bio-oil in an oil refinery to produce gasoline and dieselquality fuels instead of a costly hydrotreating step is advantageous for the economic feasibility of the biorefinery scenarios in this study.

The $\mathrm{TCl}$ reported for non-catalytic pyrolysis in this study is significantly higher than the TCI reported in similar studies (Nsaful, Görgens \& Knoetze, 2013; Ringer et al., 2006). The compared studies excluded installed equipment costs for wastewater treatment and reported lower installed equipment costs for the pyrolysis section of the biorefinery as presented in Table 31. The pyrolysis reactors were costed based on individual pieces of equipment (Ringer et al., 2006) and literature (Nsaful et al., 2013), whereas the pyrolysis reactor in this study was costed based on a vendor quote. The installed equipment cost of the catalytic pyrolysis reactor in this study is agreeable with the study by Dutta and colleagues (2015), which also costed the catalytic pyrolysis reactor based on a vendor quote (Dutta et al., 2015). Furthermore, the only difference between the installed equipment cost of the non-catalytic and catalytic pyrolysis reactors in this study is the capacity required for the catalyst therefore, the $\mathrm{TCl}$ for non-catalytic pyrolysis is reasonable. 


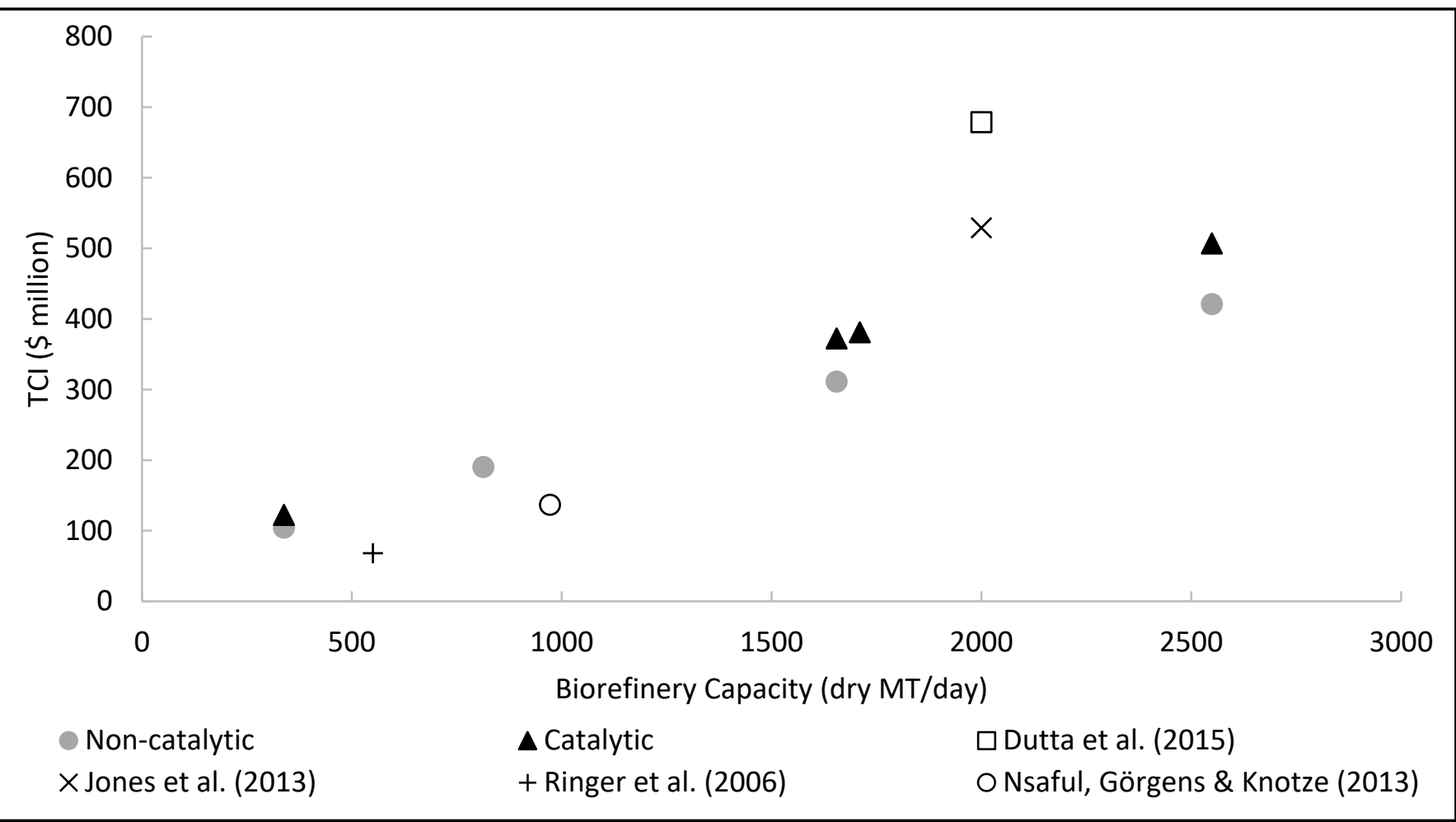

Figure 24: Comparison between TCl for non-catalytic and catalytic biorefinery scenarios in this study and similar studies (adjusted to $2017 \$$ )

Table 31: Installed equipment cost for the pyrolysis section of the biorefinery

\begin{tabular}{|lcc|}
\hline Reference & $\begin{array}{c}\text { Biorefinery Capacity } \\
\text { (dry MT/day) }\end{array}$ & $\begin{array}{c}\text { Installed Cost } \\
\text { (2017\$) }\end{array}$ \\
\hline (Ringer et al., 2006) & 550 & 5533831 \\
(Nsaful et al., 2013) & 972 & 7106087 \\
(Dutta et al., 2015) & 2000 & 89625662 \\
This study (non-catalytic) & 2549 & 90457375 \\
This study (catalytic) & 2549 & 116364134 \\
\hline
\end{tabular}

The installed equipment costs per section of the catalytic pyrolysis biorefinery in this study were compared and verified with the study by Dutta and colleagues (2015) as shown in Table 32 . Less electricity was produced in this study (12.0 and 18.5 MW for 1655 and 2549 dry MT/day biorefinery capacities, respectively) than in the compared study (43.2 MW) therefore, the installed equipment cost for steam and power production was significantly more for the latter. The installed equipment cost for wastewater treatment in the compared study was also higher, due to the additional wastewater produced during hydrotreating. Hydrotreating contributed to $34.7 \%$ of the overall $\mathrm{TCl}$ for the compared study, which is a significant saving for the biorefinery scenarios in this study as bio-oil can be co-processed in an existing oil refinery without a dedicated hydrotreating unit. 
Table 32: Installed equipment costs (Million 2017\$) per section of the catalytic pyrolysis biorefinery

\begin{tabular}{|lccc|}
\hline Reference & (Dutta et al., 2015) & \multicolumn{2}{c|}{ This study } \\
Biorefinery capacity (dry MT/day) & 2000 & 1655 & 2549 \\
TCI (Million 2017\$) & 678.8 & 372.4 & 507.0 \\
\hline Pre-treatment & $0.5^{*}$ & 38.0 & 56.0 \\
In situ catalytic pyrolysis & 89.6 & 86.0 & 116.0 \\
Product recovery & 21.7 & 18.0 & 22.0 \\
Hydrotreating & 31.5 & - & - \\
Hydrogen plant & 68.4 & - & - \\
Heat recovery & - & 4.0 & 6.0 \\
Steam and power production & 50.8 & 14.0 & 19.0 \\
Wastewater treatment & 16.7 & 8.0 & 11.0 \\
Utilities & 9.1 & 5.0 & 7.0 \\
Storage & - & 20.0 & 27.0 \\
\hline
\end{tabular}

*Installed equipment costs were mostly included in biomass cost price

The total installed equipment cost per section of the biorefinery based on the total volume of bio-oil produced per year for non-catalytic and catalytic pyrolysis biorefinery scenarios are compared in Figure 25 to demonstrate the significant economy-of-scale benefit, and predict hotspots that will influence the economic feasibility of the biorefinery scenarios. Section A2000 (pyrolysis) contributed the most to the total installed equipment cost of all biorefinery scenarios. Catalytic pyrolysis resulted in higher installed equipment costs for Section A2000 than non-catalytic pyrolysis because of the increased pyrolysis reactor capacity required for the catalyst. Section A1000 (pre-treatment) also contributed significantly to the total installed equipment cost of all biorefinery scenarios. Similarly, catalytic pyrolysis produced higher installed equipment costs for Section A1000 than non-catalytic pyrolysis because of the additional biomass/catalyst mixer and the increased biomass preheater capacity required to remove heat from the $\mathrm{CaO}$ and $\mathrm{CaCO}_{3}$ present in the char. On the other hand, noncatalytic pyrolysis generated higher installed equipment costs for Section A3000 (product recovery) than catalytic pyrolysis since non-catalytic pyrolysis produced more bio-oil and non-condensable gas (19.8 and 20.6 wt. \%) than catalytic pyrolysis (18.4 and 17.6 wt. \%). Finally, catalytic pyrolysis resulted in higher installed equipment costs for Section A5000 (steam and power production) than non-catalytic pyrolysis as catalytic pyrolysis produced more electricity than non-catalytic pyrolysis. 


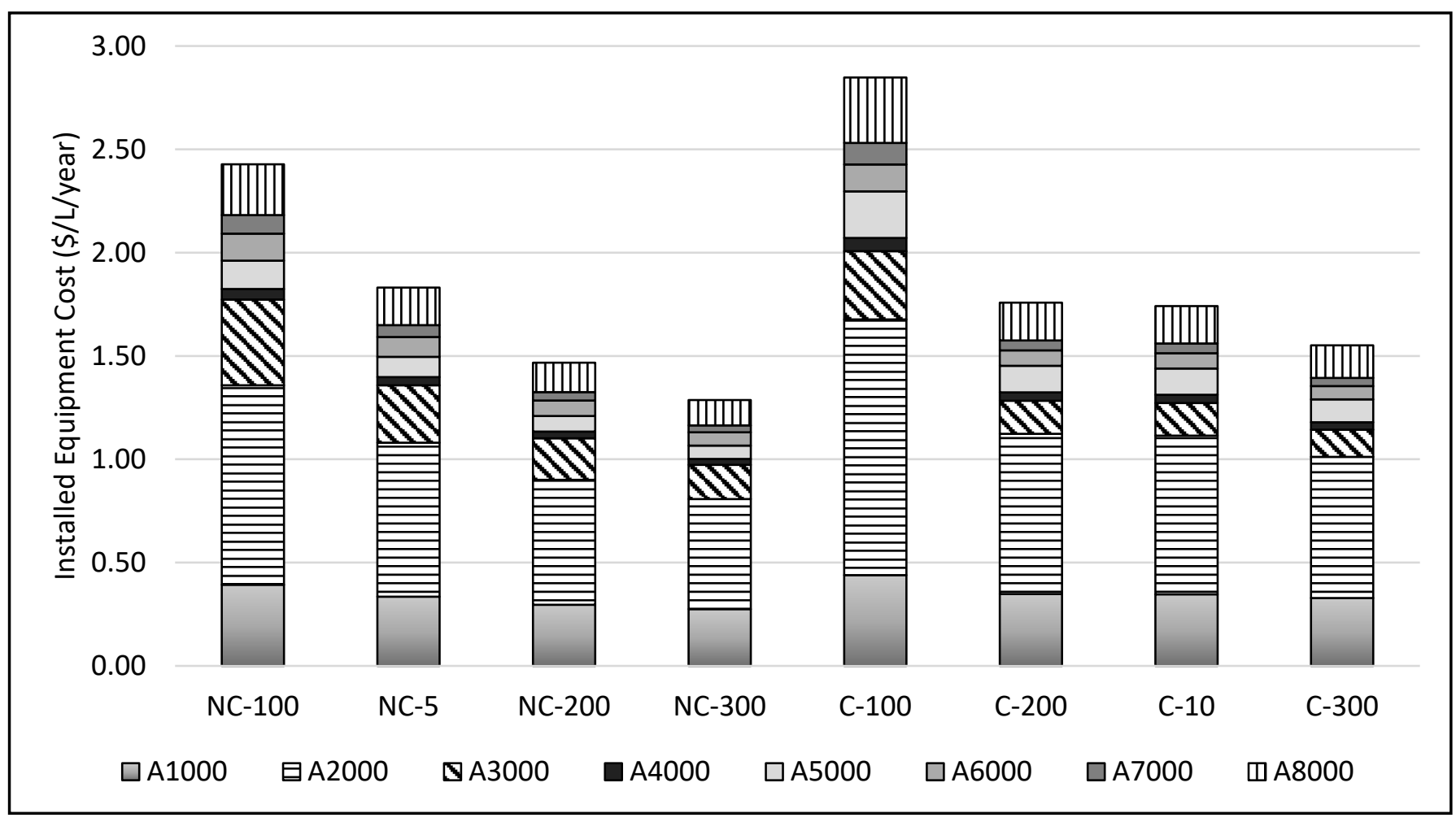

Figure 25: Breakdown of installed equipment costs per section for each biorefinery scenario - Sections A1000 (pre-treatment), A2000 (pyrolysis), A3000 (product recovery), A4000 (heat recovery), A5000 (steam and power production), A6000 (wastewater treatment), A7000 (utilities) and A8000 (storage) - Non-catalytic (NC) and catalytic (C) pyrolysis for biomass collection within a 100, 200 and $300 \mathrm{~km}$ radius of the biorefinery, and NC and C at the required biorefinery capacity to co-process 5 and $10 \mathrm{wt}$. \% bio-oil, respectively

\subsubsection{Operating cost estimation}

Operating costs are estimated on a per annum basis and categorised as either fixed or variable operating costs. The total fixed operating cost for each biorefinery scenario consists of employee salaries, benefits and overheads, maintenance, and insurance and taxes. The total variable operating cost for each biorefinery scenario is made up of feedstock, process water, auxiliary chemicals, wastewater and ash disposal costs. In addition, catalytic pyrolysis biorefinery scenarios also have the catalyst as a variable operating cost. The total fixed and variable operating costs for each biorefinery scenario are given in Table 33. Details for the calculation of total fixed and variable operating costs for each biorefinery scenario are given in Table C3 in Appendix C.

The \$20.20 million/year total operating cost for the 813 dry MT/day biorefinery capacity (Scenario NC-5) in this study was significantly lower than the $\$ 47.27$ million/year total operating cost for a 1000 dry MT/day biorefinery capacity in a similar study (Wang \& Jan, 2018) because natural gas (for heating) and electricity were bought in, and the rice husk biomass was more expensive at \$30/MT. The total fixed operating cost for the catalytic pyrolysis biorefinery scenarios in this study was agreeable with a similar study (Dutta et al., 2015), but the total variable operating cost for this study 
was once again lower than the compared study due to a higher biomass cost of $\$ 80 / \mathrm{MT}$ (including \$24.67/MT for grinding and drying (Jacobson, Roni, Lamers \& Cafferty, 2014)). Biomass cost in South Africa and other developing countries is considerably lower than the United States and Europe (IEA Renewable Energy Division, 2010). This will have a significant impact on the economic feasibility of the biorefinery scenarios in this study, and possibly attract foreign investors to the country.

Table 33: Fixed, variable and total operating costs (Million \$) for each biorefinery scenario

\begin{tabular}{|lcccccccc|}
\hline Scenariot & NC-100 & NC-5 & NC-200 & NC-300 & C-100 & C-200 & C-10 & C-300 \\
\hline Total fixed operating costs & 6.0 & 11.1 & 18.6 & 26.6 & 6.6 & 20.8 & 21.2 & 29.6 \\
Total variable operating costs & 3.3 & 9.2 & 20.7 & 35.7 & 11.4 & 60.2 & 62.9 & 96.6 \\
Total operating costs & 9.4 & 20.2 & 39.3 & 62.3 & 18.1 & 81.0 & 84.2 & 126.2 \\
\hline
\end{tabular}

†Non-catalytic (NC) and catalytic (C) pyrolysis for biomass collection within a 100, 200 and 300 km radius of the biorefinery, and $\mathrm{NC}$ and $\mathrm{C}$ at the required biorefinery capacity to co-process 5 and 10 wt. $\%$ bio-oil, respectively.

The total fixed operating cost for catalytic pyrolysis biorefinery scenarios is slightly higher than non-catalytic pyrolysis biorefinery scenarios because maintenance, and insurance and taxes were costed based on the $\mathrm{FCl}$. The total variable operating cost for catalytic pyrolysis, on the other hand, is significantly higher than non-catalytic pyrolysis due to the added cost of the catalyst. The contribution of fixed and variable operating costs to the total operating cost based on the total volume of bio-oil produced per year is shown in Figure 26. The individual contributions of process water, auxiliary chemicals, wastewater and ash disposal costs to the total operating cost of each biorefinery scenario were minor therefore, these costs were combined under the legend other variable costs. Feedstock, catalyst (in catalytic pyrolysis biorefinery scenarios) and maintenance costs contributed the most to the total operating cost for each biorefinery scenario. Feedstock cost increased with biomass transport distance from the biorefinery, which cancelled out the economy-of-scale benefit for the total operating cost beyond a $200 \mathrm{~km}$ radius of the biorefinery. However, the economy-of-scale benefit is far greater for the capital cost estimate up to a $300 \mathrm{~km}$ radius of the biorefinery, which will influence the economic feasibility of the biorefinery scenarios more significantly than the operating cost estimate. 


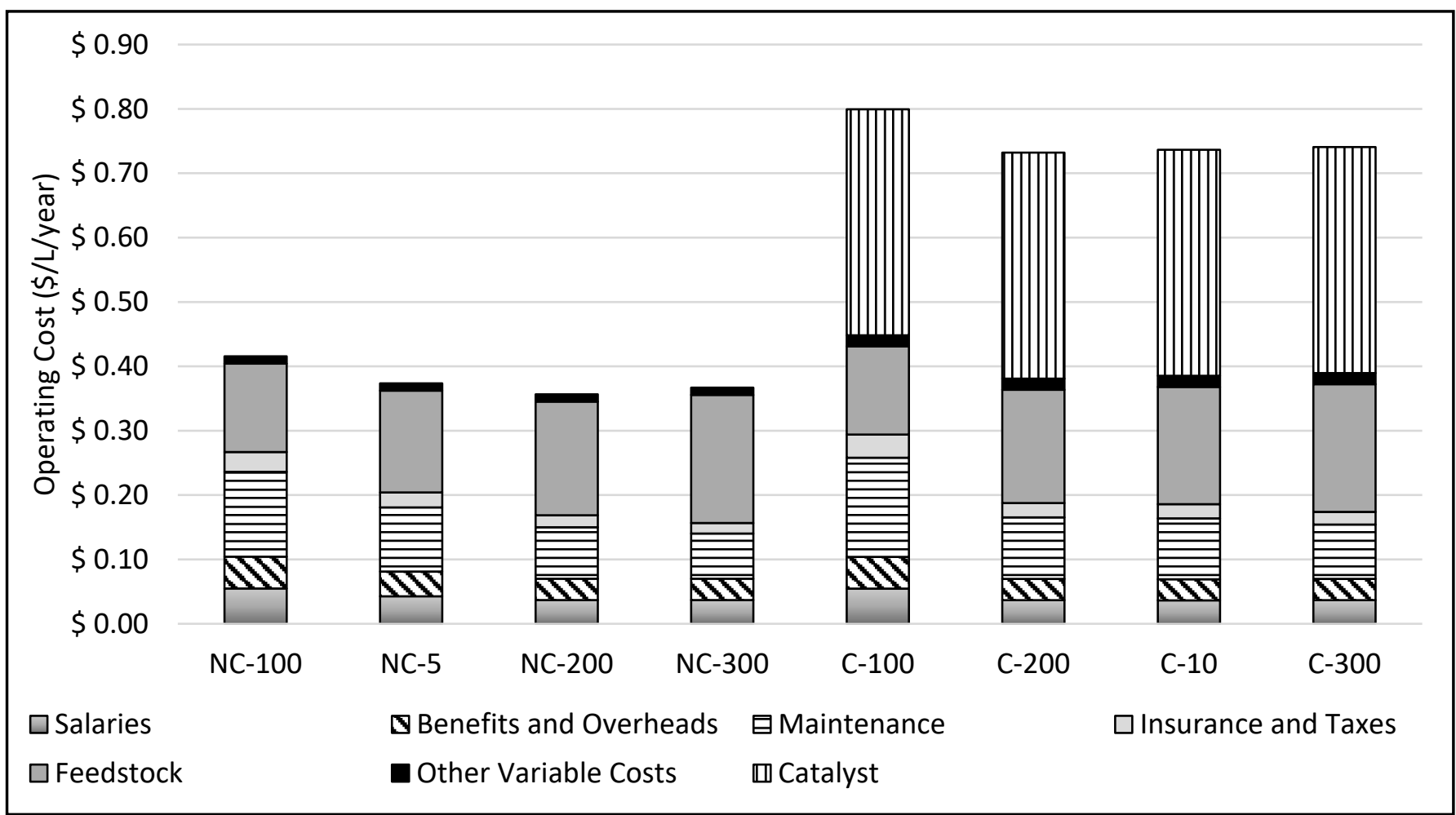

Figure 26: Fixed and variable operating costs contribution to total operating cost for each biorefinery scenario Sections A1000 (pre-treatment), A2000 (pyrolysis), A3000 (product recovery), A4000 (heat recovery), A5000 (steam and power production), A6000 (wastewater treatment), A7000 (utilities) and A8000 (storage) - Non-catalytic (NC) and catalytic (C) pyrolysis for biomass collection within a 100, 200 and $300 \mathrm{~km}$ radius of the biorefinery, and NC and $\mathrm{C}$ at the required biorefinery capacity to co-process 5 and $10 \mathrm{wt}$. \% bio-oil, respectively

\subsubsection{Profitability analysis}

The capital and operating cost estimates were used to perform a Discounted Cash Flow Rate of Return (DCFROR) analysis to determine the profitability of the biorefinery scenarios. The Minimum Selling Price (MSP) of bio-oil for each biorefinery scenario is reported in Table 34 based on the unreconciled bio-oil yield previously reported in Table 28, while the MSP of bio-oil based on the reconciled bio-oil yield will be evaluated through a sensitivity analysis in Section 5.2.5. The non-catalytic and catalytic pyrolysis biorefinery capacities reported in Table 34 were chosen based on the biomass collection distance from the biorefinery, and the amount of crude and upgraded bio-oil required to co-process 5 and 10 wt. \% at the Natref oil refinery, respectively. 
Table 34: MSP (\$/L) of bio-oil for each biorefinery scenario

\begin{tabular}{|lccc|}
\hline Scenario & \multicolumn{1}{c}{$\begin{array}{c}\text { Biorefinery } \\
\text { Capacity (dry MT/day) }\end{array}$} & IRR $=10 \%$ & IRR $=22 \%$ \\
\hline NC-100 & 338 & 0.62 & 1.51 \\
NC-5 & 813 & 0.42 & 1.09 \\
NC-200 & 1655 & 0.31 & 0.85 \\
NC-300 & 2549 & 0.27 & 0.75 \\
C-100 & 338 & 1.18 & 2.21 \\
C-200 & 1655 & 0.82 & 1.47 \\
C-10 & 1710 & 0.82 & 1.46 \\
C-300 & 2549 & 0.77 & 1.35 \\
\hline
\end{tabular}

†Non-catalytic (NC) and catalytic (C) pyrolysis for biomass collection within a 100, 200 and $300 \mathrm{~km}$ radius of the biorefinery, and $\mathrm{NC}$ and $\mathrm{C}$ at the required biorefinery capacity to co-process 5 and 10 wt. \% bio-oil, respectively.

Crude and upgraded bio-oils can be co-processed with vacuum gas oil (VGO) in an FCC unit to produce bio-derived transportation fuels. VGO is an intermediate product between crude-oil distillation, and gasoline and diesel production therefore, VGO does not have an available market price that can be used as a benchmark for the selling price of bio-oil. A market price can be estimated though based on the crude-oil price and the Basic Fuel Price (BFP) set by the government. Brent Crude is considered the benchmark for crude-oil prices in South Africa (Motiang \& Nembahe, 2017), and sold for an average value of $\$ 54.71 / \mathrm{bbl}$ in 2017 (Macrotrends, 2019). Additionally, the average value for the BFP in 2017 was $\$ 65.19 /$ bbl (Department of Energy, 2019). The market price of VGO lies between these two values, and is estimated based on a percentage of the total production cost for the oil refinery. Li and colleagues (2013) reported the average production cost for oil refineries in China per section of the oil refinery (Li, Fu, Ma, Liu, Li \& Dai, 2013). Crude-oil distillation accounted for approximately $13.81 \%$ of the production cost less the crude-oil price therefore, the market price of VGO in 2017 was estimated as $\$ 56.16 / \mathrm{bb}$ or $\$ 0.35 / \mathrm{L}$. The MSP of crude and upgraded bio-oils for biomass collection within a 100, 200 and $300 \mathrm{~km}$ radius of the biorefinery is compared to the estimated market price of VGO in Figure 27.

There is a significant decrease in MSP overall from a 100 to $200 \mathrm{~km}$ radius of the biorefinery relating to an increase in biorefinery capacity from 338 to 1655 dry MT/day. Thereafter, the MSP slightly decreases again from a 200 to $300 \mathrm{~km}$ radius of the biorefinery relating to an increase in biorefinery capacity from 1655 to 2549 dry MT/day. There is a clear economy-of-scale benefit up to a $300 \mathrm{~km}$ radius of the biorefinery for both non-catalytic and catalytic pyrolysis processes. However, the MSP of upgraded bio-oil (as expected from the capital and operating cost estimates) is higher than the 
MSP of crude bio-oil for the same Internal Rate of Return (IRR). The MSP of crude bio-oil at a nominal $10 \%$ IRR fell below the estimated market price of VGO at $\$ 0.31 / L$ and $\$ 0.27 / L$ corresponding to a 200 and $300 \mathrm{~km}$ radius of the biorefinery. However, the MSP of both crude and upgraded bio-oils at a more desirable $22 \%$ IRR was at least $\$ 0.39 / \mathrm{L}$ and $\$ 0.99 / \mathrm{L}$ above the estimated market price of VGO, respectively. The price premium of crude and upgraded bio-oils though can be substantiated by their environmental benefit over fossil-derived VGO, which will be evaluated in Section 5.3.

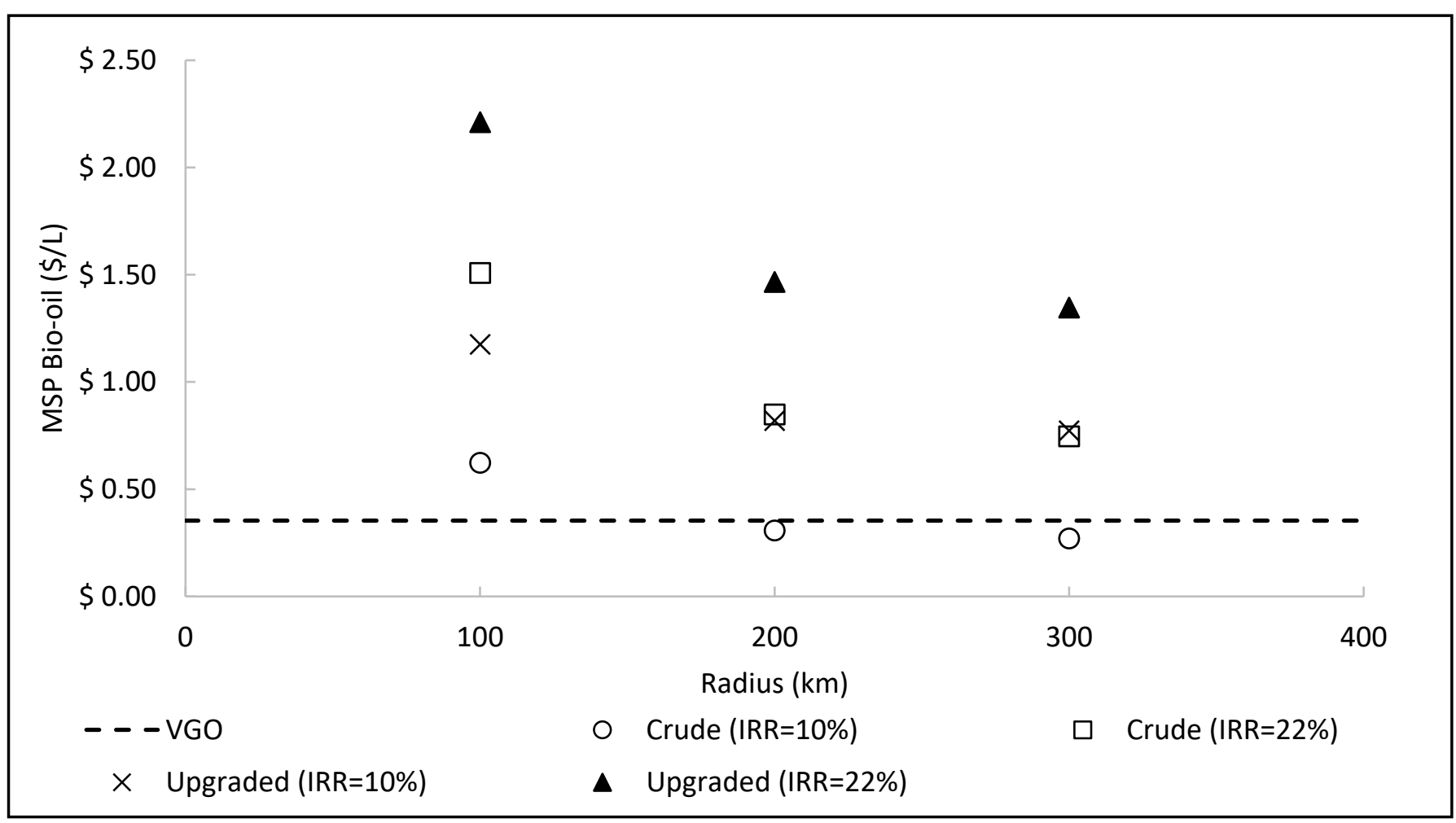

Figure 27: MSP (\$/L) of crude and upgraded bio-oils for biomass collection within a 100, 200 and $300 \mathrm{~km}$ radius of the biorefinery

The water content, oxygen content, LHV and HHV of crude and upgraded bio-oils produced via non-catalytic and catalytic pyrolysis compared to VGO are given in Table 35. Upgraded bio-oil more closely resembles VGO in energy value than crude bio-oil. Therefore, it is important to also compare the MSP of crude and upgraded bio-oils on a gasoline gallon equivalent (GGE) basis. The MSP was converted to a GGE basis using the LHV of crude and upgraded bio-oils. A litre of crude bio-oil is equivalent to 0.65 litres of gasoline, and a litre of upgraded bio-oil is equivalent to 0.77 litres of gasoline. The MSP of crude and upgraded bio-oils on a GGE basis for biomass collection within a 100, 200 and $300 \mathrm{~km}$ radius of the biorefinery is compared to the estimated market price of VGO in Figure 28. The MSP of crude bio-oil remains lower than the MSP of upgraded bio-oil overall. However, the MSP of upgraded bio-oil is slightly closer to the MSP of crude bio-oil at a desired $22 \%$ IRR, which indicates that upgraded bio-oil is actually more competitive with crude bio-oil. Furthermore, a litre of 
VGO is equivalent to 1.26 litres of gasoline therefore, the MSP of crude bio-oil at the nominal $10 \%$ IRR rose above the market value of VGO for biomass collection within a $300 \mathrm{~km}$ radius of the biorefinery.

Table 35: Properties of bio-oils produced via non-catalytic and catalytic pyrolysis compared to VGO

\begin{tabular}{|lccc|}
\hline & Non-catalytic & Catalytic & VGO \\
\hline Water (wt. \%) & 16.1 & 25.6 & $0.6^{\mathrm{a}}$ \\
Oxygen (wt. \%, db) & 35.8 & 14.0 & $0.3^{\mathrm{a}}$ \\
LHV (MJ/kg, db) & 23.0 & 33.2 & $43.0^{\mathrm{b}}$ \\
HHV (MJ/kg, db) & 24.5 & 34.7 & $45.0^{\mathrm{b}}$ \\
\hline
\end{tabular}

a. (Lindfors et al., 2015)

b. (Jechura, 2016)

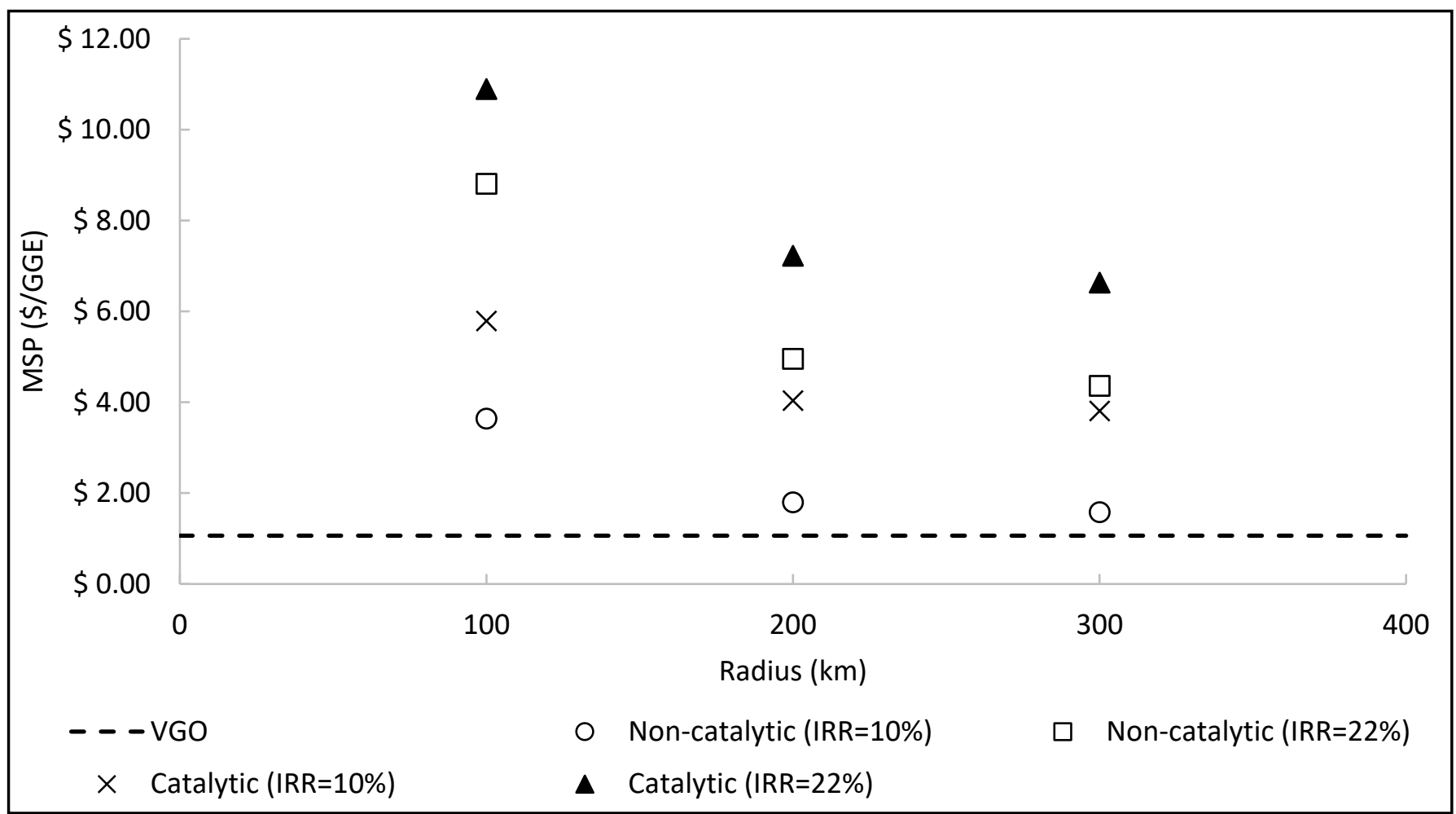

Figure 28: MSP (\$/GGE) of crude and upgraded bio-oils for biomass collection within a 100, 200 and $300 \mathrm{~km}$ radius of the biorefinery

The higher MSP of upgraded bio-oil can be justified over the lower MSP of crude bio-oil by its superior quality and suitability for co-processing. The impact on product yield and quality are unknown for co-processing bio-oil in an industrial-scale FCC unit but can be likened to co-processing bio-oil in a pilot-scale FCC unit. Co-processing 10 wt. \% upgraded bio-oil at pilot-scale had little effect on gasoline yield, while co-processing the same amount of crude bio-oil decreased gasoline yield from $41.1 \mathrm{wt}$. \% (pure VGO catalytic cracking) to 37.5 wt. \% (Wang et al., 2018). Co-processing 5 wt. \% crude bio-oil had 
negligible effect on gasoline yield but the renewable carbon content of the total liquid produced was substantially lower at $1.0 \mathrm{wt}$. \% (Pinho et al., 2017) than the 5.6 to $7.0 \mathrm{wt}$. \% renewable carbon content achieved when 10 wt. \% upgraded bio-oil was co-processed (Wang et al., 2016, 2018). Oil refineries in South Africa will be looking to offset their anthropogenic carbon emissions with the implementation of the Carbon Tax Act on 1 June 2019 (Republic of South Africa, 2019), which could make co-processing upgraded bio-oil more attractive than crude bio-oil if the carbon tax saving outweighs the difference in MSP.

Co-processing crude and (to a lesser extent) upgraded bio-oils at pilot-scale produces $\mathrm{CO}_{2}, \mathrm{CO}$ and $\mathrm{H}_{2} \mathrm{O}$ gaseous products as a result of deoxygenation reactions (Wang et al., 2018). Modifications related to pressure build-up and increased capacity for existing FCC units at oil refineries may be required to accommodate these gaseous products (van Dyk et al., 2019). Bio-oil with a high water content may also damage FCC catalysts and impact downstream processing. Furthermore, the construction materials of most existing FCC units at oil refineries may be susceptible to the corrosivity of bio-oil (Talmadge et al., 2014). The additional costs that the oil refinery may incur due to crude biooil co-processing are mostly unknown but based on the observations made by other researchers, it is reasonable to suggest that these costs will be less for upgraded bio-oil co-processing.

An oil refinery such as Natref could co-process 5 wt. \% crude bio-oil for $\$ 1.09 / \mathrm{L}$ or $10 \mathrm{wt}$. \% upgraded bio-oil for $\$ 1.46 / \mathrm{L}$ at the desired $22 \%$ IRR. Alternatively, oil refineries such as Enref and Sapref could collaborate with Natref to benefit from economy-of-scale by co-processing crude and upgraded bio-oils at the lowest price of $\$ 0.75 / \mathrm{L}$ and $\$ 1.35 / \mathrm{L}$ for a desired $22 \%$ IRR, respectively. The MSP of crude bio-oil for a nominal $10 \%$ IRR is at best $\$ 0.27 / \mathrm{L}$, which falls below the average BFP of $\$ 0.41 / L$ in 2017 (Department of Energy, 2019), while the MSP of upgraded bio-oil for a nominal $10 \%$ IRR is almost double the BFP at $\$ 0.77 / \mathrm{L}$. However, investors are looking for higher returns for innovative projects associated with high financial risk therefore, in addition to carbon tax rebates, oil refineries would require government subsidisation to make co-processing crude and upgraded bio-oils economically viable.

The MSP (\$/L) of crude and upgraded bio-oils produced via non-catalytic and catalytic pyrolysis in this study are compared to the MSP of bio-oils produced in similar studies against biorefinery capacity in Figure 29. The crude bio-oil MSP of $\$ 0.42 / \mathrm{L}$ for a 813 dry MT/day biorefinery capacity (Scenario NC-5) in this study is significantly lower than the MSP of $\$ 0.56 / \mathrm{L}$ for a $1000 \mathrm{dry}$ MT/day biorefinery capacity in the compared study (Wang \& Jan, 2018), because of the differences in biochar selling price $(\$ 357 / \mathrm{MT}$ versus $\$ 100 / \mathrm{MT})$ and biomass cost price ( $\$ 19 / \mathrm{MT}$ versus $\$ 30 / \mathrm{MT})$. The biochar in the compared study had a low carbon content of $20.4 \mathrm{wt}$. \% as a result of fast pyrolysis conditions, which limited its selling price. The production of high quality biochar in addition to bio-oil is an advantage of the intermediate pyrolysis conditions in this study. Alternatively, Ringer and colleagues (2006) reported lower installed equipment costs for a 550 dry MT/day biorefinery capacity than the 
338 dry MT/day biorefinery capacity (Scenario NC-100) in this study therefore, the reported MSP of \$0.21/L for crude bio-oil was unsurprisingly lower (Ringer et al., 2006).

The MSP of $\$ 0.82 / L$ and $\$ 0.77 / L$ for upgraded bio-oil production corresponding to a 1655 and 2549 dry MT/day biorefinery capacity (Scenarios C-200 and C-300) in this study falls within the range reported in literature $(\$ 0.57 / \mathrm{L}$ to $\$ 1.11 / \mathrm{L})$ corresponding to a 2000 dry MT/day biorefinery capacity. However, the MSP of $\$ 0.57 /$ L (Anex et al., 2010) and $\$ 0.60 / L$ (Wright et al., 2010) was reported for upgraded bio-oil production via hydrotreating with hydrogen purchased (anthropogenic) instead of produced onsite (usually biogenic), which is cheaper but has a negative impact on the environment. Most of the reported studies supplemented the hydrogen produced from the pyrolysis process with a small amount of hydrogen produced from steam reforming natural gas (Dutta et al., 2015; Jones et al., 2013; Li et al., 2015), while the remaining study (Thilakaratne et al., 2014) was satisfied by the hydrogen produced from the pyrolysis process alone. Before hydrotreating bio-oil, some of the reported studies (Dutta et al., 2015; Li et al., 2015; Thilakaratne et al., 2014) upgraded bio-oil via in situ catalytic pyrolysis with zeolite catalysts instead of fast pyrolysis. Zeolite catalysts are more expensive than basic metal oxide catalysts such as CaO (Stefanidis et al., 2016), which (in addition to the process equipment required to produce hydrogen onsite) can explain the difference in MSP between this study and the reported studies.

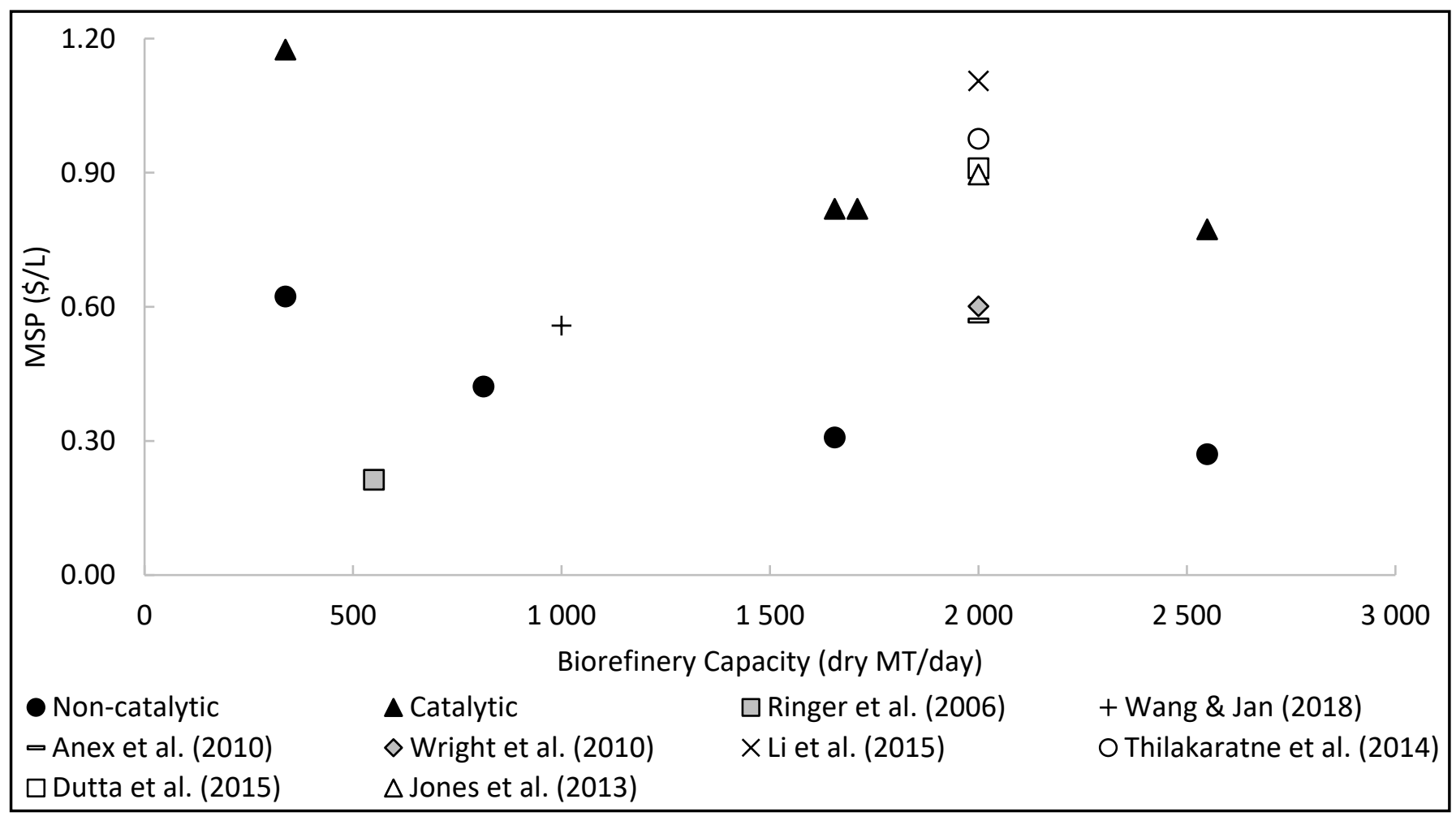

Figure 29: Comparison between the MSP (\$/L) of bio-oils produced via non-catalytic and catalytic pyrolysis in this study and similar studies (adjusted to 2017\$) for a $10 \%$ IRR 
The MSP (\$/GGE) of crude and upgraded bio-oils produced via non-catalytic and catalytic pyrolysis in this study are compared to the MSP of bio-oils produced in similar studies against biorefinery capacity in Figure 30. The MSP of upgraded bio-oils in this study compared to the MSP of upgraded bio-oils in the reported studies on an energy basis (Figure 30) is significantly different to the same comparison but on a volume basis (Figure 27). The MSP of \$4.04/GGE and \$3.81/GGE for upgraded bio-oil production corresponding to a 1655 and 2549 dry MT/day biorefinery capacity (Scenarios C-200 and C-300) in this study is greater than the MSP between \$3.52/GGE and \$3.38/GGE for upgraded bio-oil production corresponding to a 2000 dry MT/day biorefinery capacity in the reported studies (Dutta et al., 2015; Jones et al., 2013; Thilakaratne et al., 2014). Therefore, the upgraded bio-oils in the reported studies are closer in energy value to gasoline than the upgraded biooils in this study. There is also an obvious trade-off between production cost and product quality, however, lower production costs are still not competitive with fossil fuels at a desirable IRR.

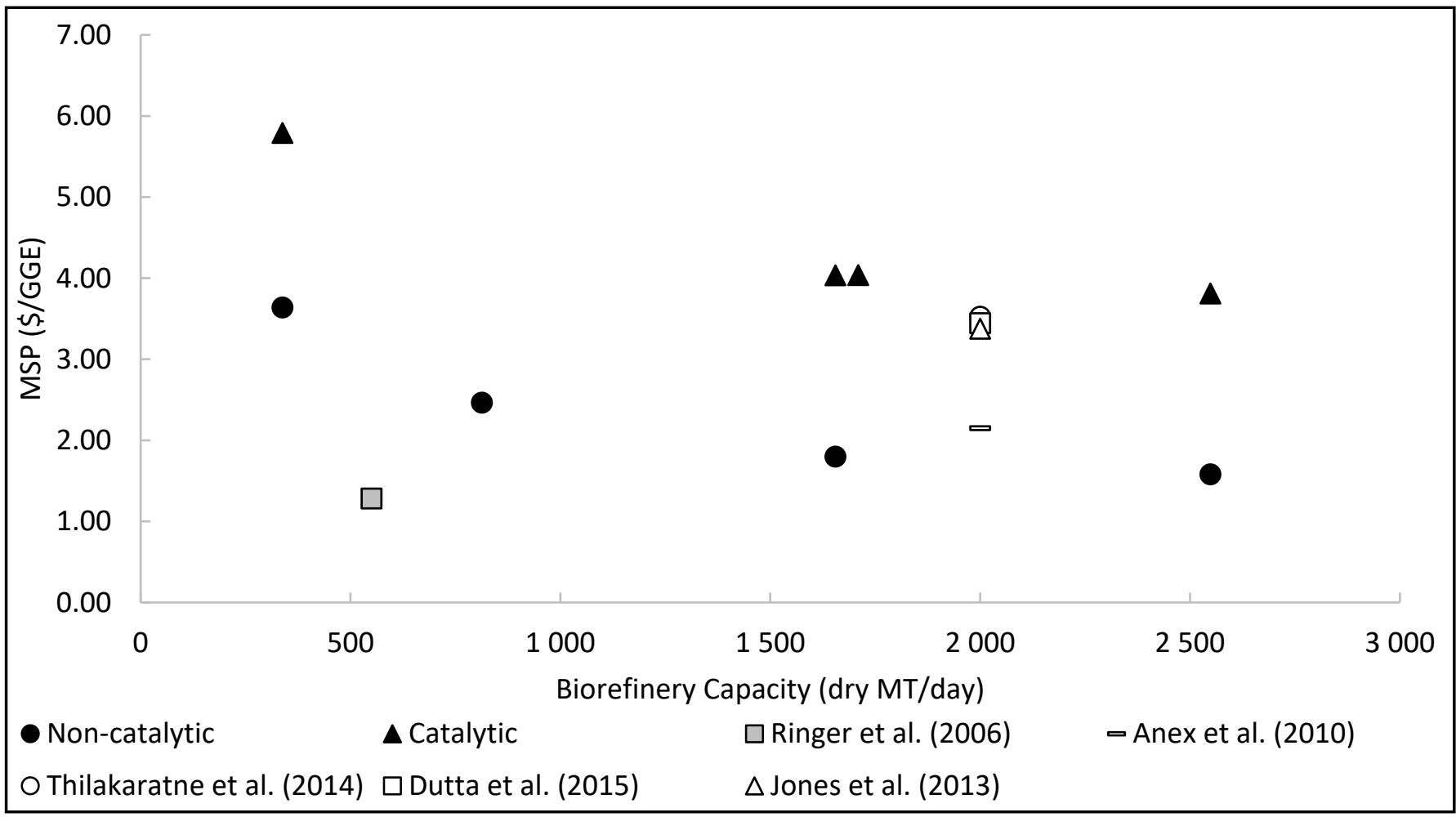

Figure 30: Comparison between the MSP (\$/GGE) of bio-oils produced via non-catalytic and catalytic pyrolysis in this study and similar studies (adjusted to 2017\$) for a $10 \%$ IRR

\subsubsection{Economic sensitivity analysis}

The DCFROR analyses for non-catalytic and catalytic pyrolysis biorefinery scenarios were based on some economic parameter assumptions to estimate the MSP of bio-oil. Therefore, an economic sensitivity analysis was conducted to assess how the MSP of bio-oil reacts to a $25 \%$ change (increase and decrease) in these parameters. The NC-200 and C-200 biorefinery scenarios at a desired $22 \%$ IRR 
were chosen for the economic sensitivity analysis over the more profitable NC-300 and C-300 biorefinery scenarios based on the economic risk associated with larger biorefineries (Yildiz et al., 2016). Moreover, the MSP of bio-oil for the chosen scenarios performed average overall out of the studied range.

The sensitivity analyses for the NC-200 and C-200 biorefinery scenarios (MSP in $\$ / L$ ) are given in Figure 31 and Figure 32, respectively. The MSP of crude bio-oil for the NC-200 biorefinery scenario was most sensitive to changes in $\mathrm{FCl}$, biochar selling price and total operating cost, while the MSP of upgraded bio-oil for the C-200 biorefinery scenario was most sensitive to changes in $\mathrm{FCl}$, total operating cost and catalyst cost (also included in the total operating cost). The MSP of crude bio-oil for the NC-200 biorefinery scenario was least sensitive to changes in electricity selling price and working capital, while the MSP of upgraded bio-oil for the C-200 biorefinery scenario was least sensitive to changes in electricity selling price, agri-lime selling price and working capital. Thilakaratne and colleagues (2014) also found that the MSP of bio-oil was least sensitivity to changes in electricity selling price (Thilakaratne et al., 2014). Surplus electricity contributed to about 40 and $66 \%$ of the total electricity produced for non-catalytic and catalytic pyrolysis, respectively. Therefore, sufficient electricity can be diverted back to the biorefinery to satisfy additional power demand without significantly impacting profitability.

A $25 \%$ increase in biochar selling price prompted the MSP of bio-oil for the NC-200 and C-200 biorefinery scenarios to decrease by 13.0 and $5.5 \%$, respectively. The biochar selling price influenced the MSP of bio-oil for the NC-200 biorefinery scenario more than the C-200 biorefinery scenario because more biochar was produced and sold. Furthermore, the more optimistic MSP of bio-oil may be achieved if biochar is sold to an international market instead of in South Africa, where the biochar market is still developing and biochar selling prices are more conservative (Konz et al., 2015).

For a $25 \%$ decrease in FCl, the MSP of bio-oil for the NC-200 and C-200 biorefinery scenarios responded with a 30.1 and $20.8 \%$ decrease, respectively. Similarly, for a $25 \%$ decrease in total operating cost, the MSP of bio-oil for the NC-200 and C-200 biorefinery scenarios decreased by 10.9 and $12.9 \%$, respectively. These optimistic scenarios may be possible with further technological development of pyrolysis processes (Sharifzadeh et al., 2019).

The sensitivity analyses for the NC-200 and C-200 biorefinery scenarios (MSP in \$/GGE) are given in Figure 33 and Figure 34, respectively. The MSP of bio-oil for the NC-200 and C-200 biorefinery scenarios was still sensitive to changes in $\mathrm{FCl}$ and total operating cost, however the MSP of bio-oil was more comparable on an energy basis than on a volume basis. The difference in MSP of bio-oil (\$/L) for the NC-200 and C-200 biorefinery scenarios for a $25 \%$ decrease in $\mathrm{FCl}$ and total operating cost was 60.4 and $75.9 \%$, respectively. Alternatively, the difference in MSP of bio-oil (\$/GGE) for the NC-200 and C-200 biorefinery scenarios for a $25 \%$ decrease in $\mathrm{FCl}$ and total operating cost was 35.3 and 48.3 $\%$, respectively. 
Fixed Capital Investment

Biochar Selling Price

Total Operating Cost

Income Tax Rate

Biomass Cost Price

Working Capital

Electricity Selling Price

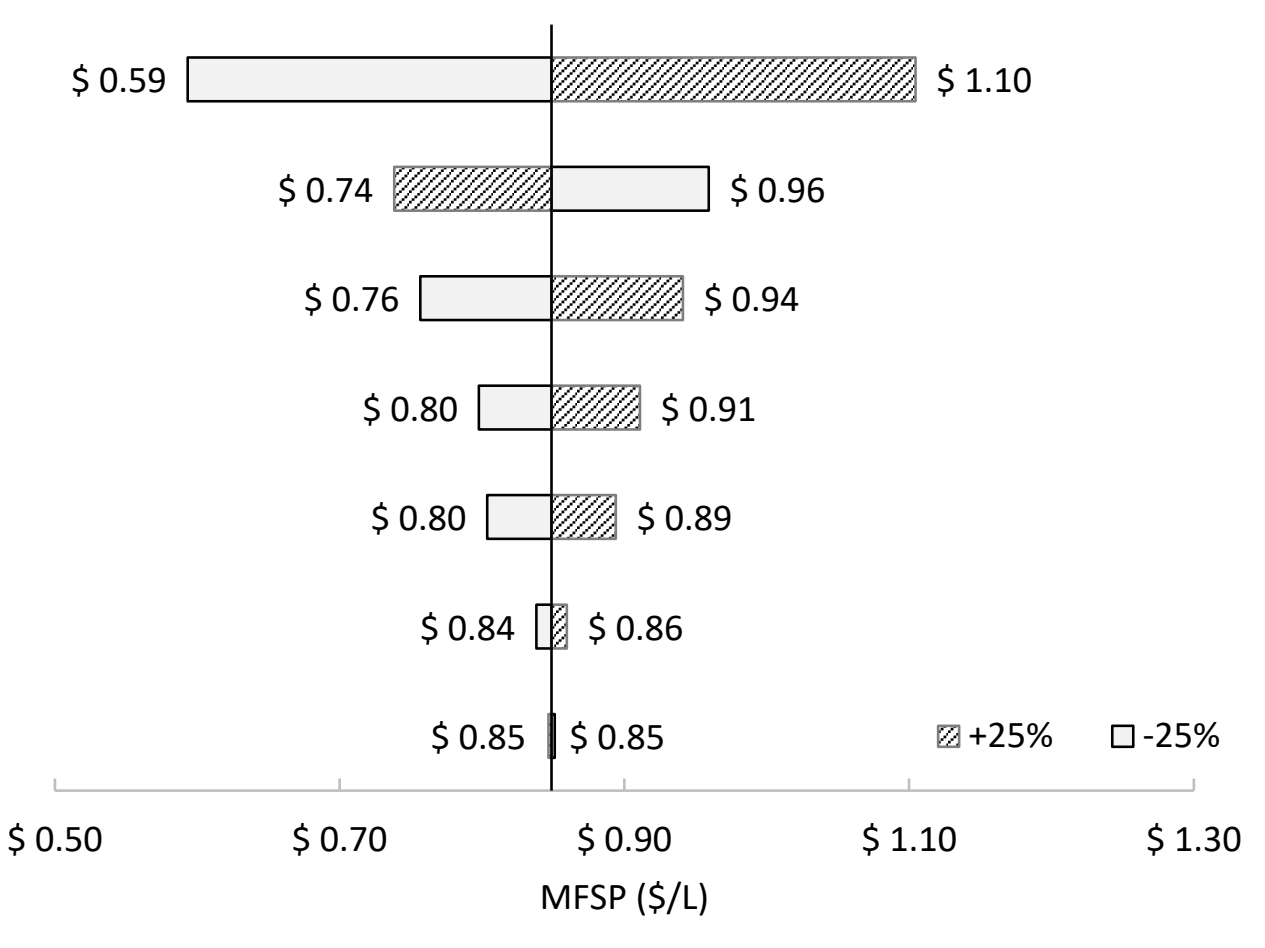

Figure 31: Sensitivity analysis (MSP in $\$ / L$ ) for biorefinery scenario NC-200
Fixed Capital Investment

Total Operating Cost

Catalyst cost price

Biochar selling price Income tax rate

Biomass cost price

Working capital

Agri-lime selling price

Electricity selling price

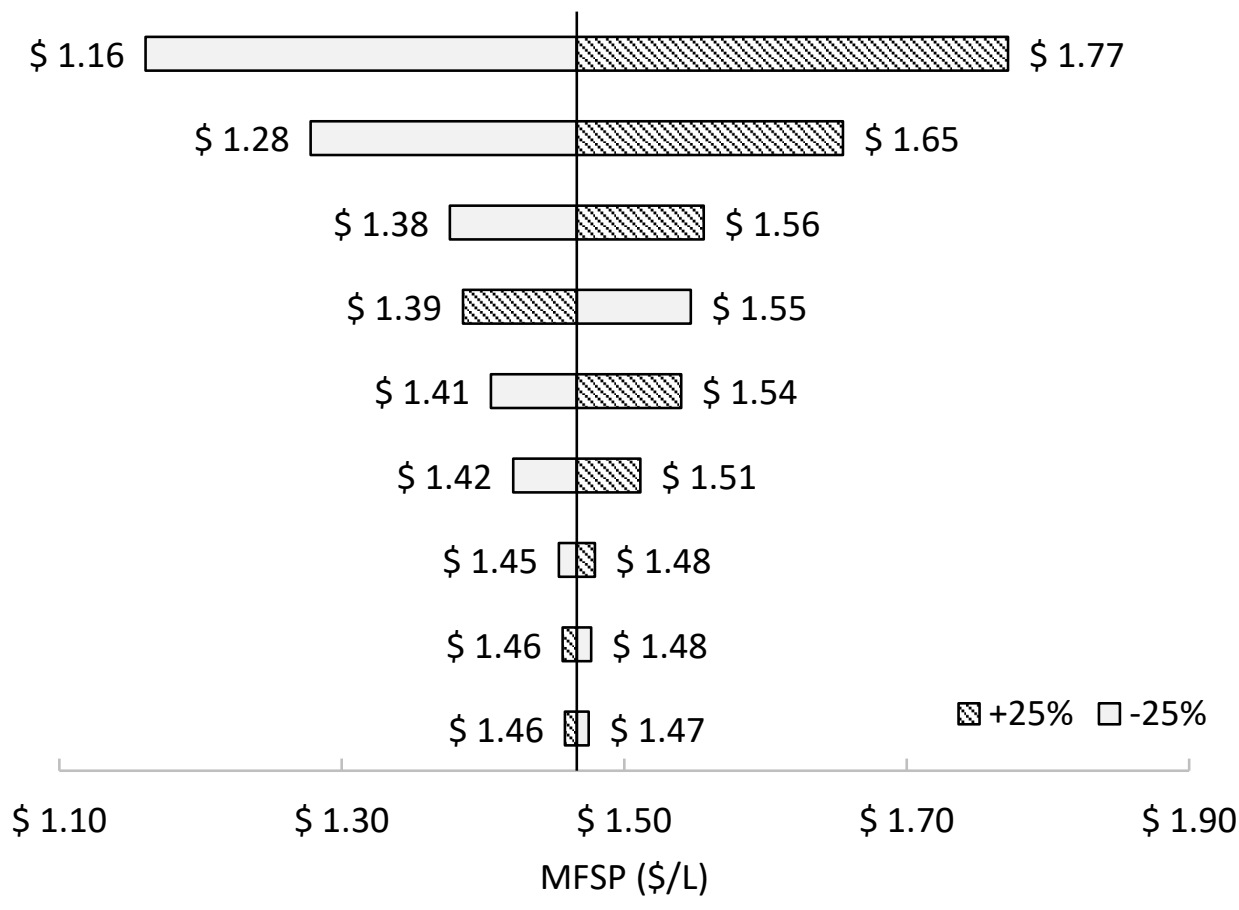

Figure 32: Sensitivity analysis (MSP in \$/L) for biorefinery scenario C-200 
Fixed Capital Investment

Biochar Selling Price

Total Operating Cost

Income Tax Rate

Biomass Cost Price

Working Capital

Electricity Selling Price
$\$ 3.46$
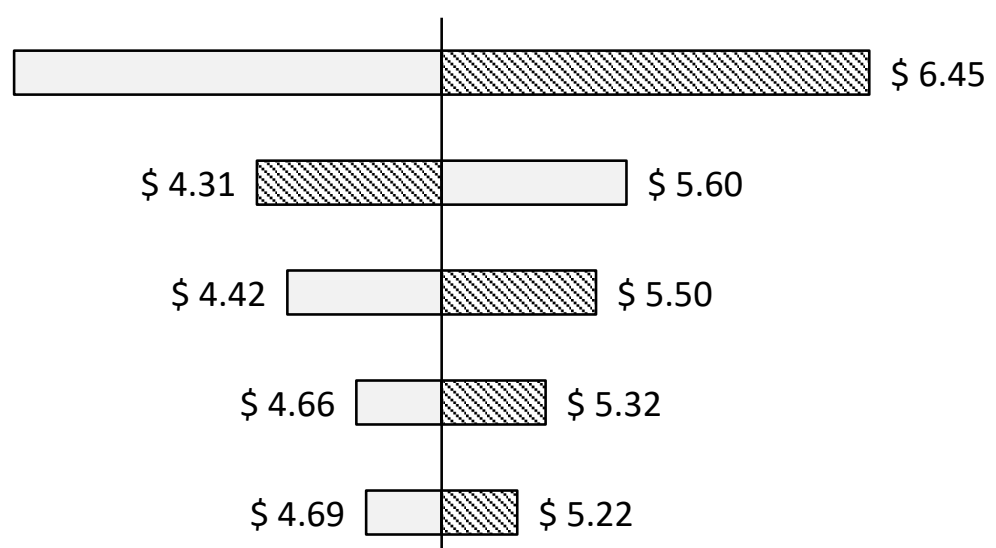

$\$ 4.89$ \$ $\$ 5.02$

$\$ 4.94 \$ 4.97 \quad$ 政 $+25 \% \quad \square-25 \%$

$\$ 3.00 \quad \begin{array}{ccc}\$ 5.00 & \$ 5.00 & \text { MSP }(\$ / G G E)\end{array}$

Figure 33: Sensitivity analysis (MSP in \$/GGE) for biorefinery scenario NC-200

Fixed Capital Investment

Total Operating Cost

Catalyst cost price

Biochar selling price Income tax rate

Biomass cost price

Working capital

Agri-lime selling price

Electricity selling price

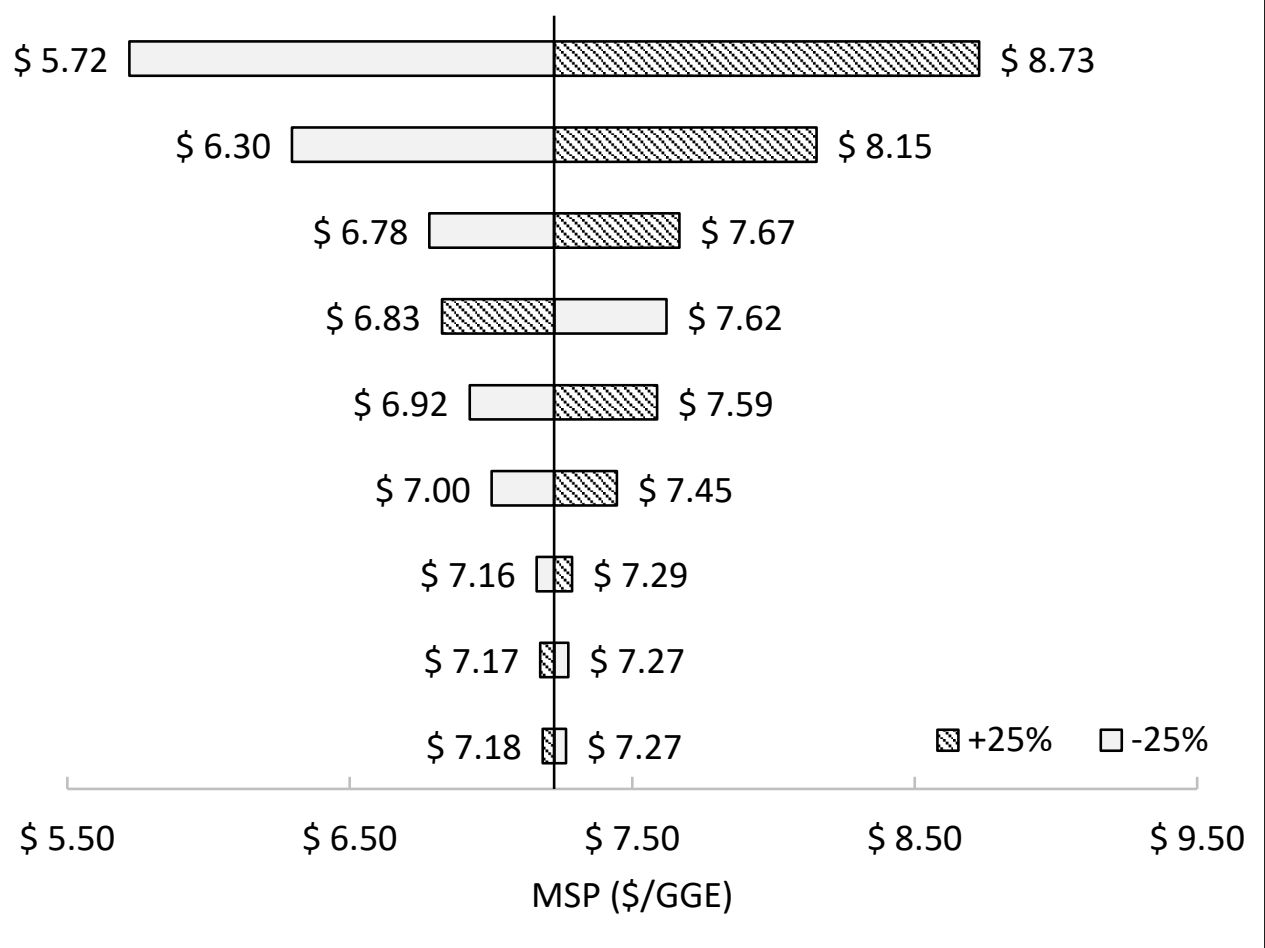

Figure 34: Sensitivity analysis (MSP in \$/GGE) for biorefinery scenario C-200 
Installed equipment costs and employee salaries for the non-catalytic and catalytic pyrolysis biorefinery scenarios in this study are in-line with studies conducted for the United States and not South Africa, which may overestimate the MSP of bio-oil. Therefore, an additional economic sensitivity analysis was conducted to assess how the MSP of bio-oil reacts to a $25 \%$ simultaneous decrease in $\mathrm{FCl}$ and employee salaries. For a $25 \%$ decrease in both $\mathrm{FCl}$ and employee salaries, the MSP of bio-oil for the NC-200 and C-200 biorefinery scenarios was $\$ 0.57 / \mathrm{L}$ (\$3.36/GGE) and $\$ 1.14 / \mathrm{L}$ (\$5.63/GGE), respectively. This change in the MSP of bio-oil for the NC-200 and C-200 biorefinery scenarios corresponds to a 32.3 and $22.1 \%$ decrease. Furthermore, employee salaries alone only slightly decreased the MSP of bio-oil for the NC-200 and C-200 biorefinery scenarios by 2.2 and $1.2 \%$, respectively.

\subsubsection{Process sensitivity analysis}

The products recovered from pilot plant experiments amounted to approximately $89 \mathrm{wt}$ \% of the biomass feed therefore, several assumptions were made to close the mass balance for process simulation development as discussed in Section 4.4.1. The MSP of bio-oil for each biorefinery scenario was conservatively estimated based on unreconciled bio-oil and non-condensable gas yields for non-catalytic and catalytic pyrolysis processes as previously reported in Table 28. However, more efficient product recovery at industrial-scale may improve these yields. Therefore, a process sensitivity analysis was also conducted to assess the effect of an 89.0, 94.5 and 100.0 wt. \% mass balance closure on the MSP of bio-oil at the desired $22 \%$ IRR for the NC-200 and C-200 biorefinery scenarios. The results are presented in Table 36. The MSP (\$/L) of bio-oil for the NC-200 and C-200 biorefinery scenarios decreased by 16.3 and $14.5 \%$ for a 100 wt. \% mass balance closure, respectively. The MSP of bio-oil decreased mostly because more bio-oil is produced. In addition, the energy demand for the non-catalytic biorefinery scenarios was met by combusting $21.5 \mathrm{wt}$. \% of the char and all of the unreconciled non-condensable gases produced. However, improved non-condensable gas yields reduces the amount of char required for combustion to 18.0 and $14.5 \mathrm{wt}$ \% for a 94.5 and $100.0 \mathrm{wt}$. $\%$ mass balance closure, respectively. Therefore, more char is available for sale. The improved noncondensable gas yields increases the amount of surplus electricity produced in the catalytic biorefinery scenarios since the energy demand for the process was already met by only combusting the unreconciled non-condensable gases produced. The biochar selling price though exceeds the electricity selling price therefore, the MSP of crude bio-oil improved slightly more than the MSP of upgraded bio-oil as product recovery increased. 
Table 36: Sensitivity analysis for mass balance reconciliation

\begin{tabular}{|lcccc|}
\hline \multirow{2}{*}{ Mass Balance Closure (\%) } & \multicolumn{2}{c}{ NC-200 } & \multicolumn{2}{c|}{ C-200 } \\
& MSP (\$/L) & MSP (\$/GGE) & MSP (\$/L) & MSP (\$/GGE) \\
\hline 100.0 & 0.71 & 4.15 & 1.25 & 6.17 \\
94.5 & 0.77 & 4.53 & 1.34 & 6.62 \\
89.0 & 0.85 & 4.96 & 1.47 & 7.22 \\
\hline
\end{tabular}

\subsection{Environmental impact results}

The Life Cycle Impact Assessment (LCIA) was conducted using the CML-IA baseline method to characterise the environmental impact of bio-oil production via non-catalytic and catalytic pyrolysis processes based on the developed process simulations. Two scenarios are defined for the LCIA: Scenario 1 assesses the environmental impact of valorising $1 \mathrm{~kg}$ of dry forest residues by producing bio-oil via non-catalytic or catalytic pyrolysis instead of disposing of forest residues by in-field burning, and Scenario 2 evaluates the environmental impact of producing $1 \mathrm{MJ}$ of bio-oil via non-catalytic or catalytic pyrolysis instead of producing $1 \mathrm{MJ}$ of crude-oil or $1 \mathrm{MJ}$ of diesel. Crude-oil and diesel are chosen for Scenario 2 to estimate the environmental impact of producing $1 \mathrm{MJ}$ of the VGO intermediate. The LCIA results for abiotic depletion (ADP) of fossil fuels, acidification (AP), eutrophication (EP), global warming potential over 100 years (GWP), and ozone layer depletion (ODP) for Scenario 1 and Scenario 2 are given in Figure 35 and Figure 36, respectively.

In Scenario 1, the combustion of forest residues resulted in the highest environmental impact for $\mathrm{AP}$ and $\mathrm{EP}$ due to higher $\mathrm{SO}_{2}$ and $\mathrm{NO}_{2}$ emissions than the pyrolysis processes, where nitrogen and sulphur compounds from the biomass were stored in the biochar. Furthermore, catalytic pyrolysis produced the highest environmental impact for ADP of fossil fuels and ODP mostly because of the CaO catalyst, whereas other contributors for both non-catalytic and catalytic pyrolysis were related to biomass collection and transport. 


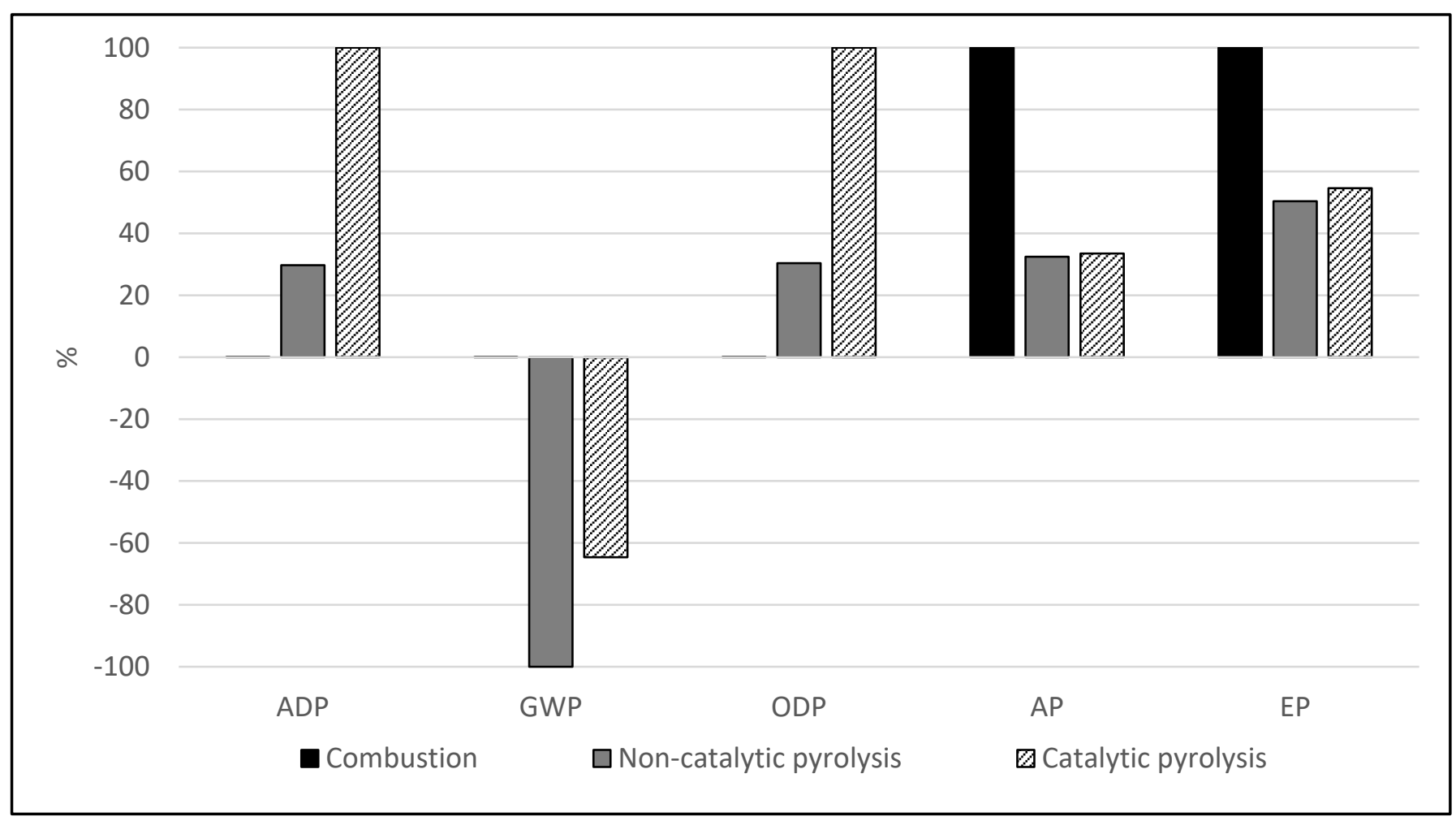

Figure 35: LCIA results for Scenario 1 (valorisation compared to in-field burning of forest residues)

In Scenario 2, crude-oil and diesel production had unsurprisingly the highest environmental impact for ADP of fossil fuels and ODP. Biomass collection and transport, biochar transport to agricultural areas and bio-oil transport to the oil refinery gate contributed to ADP of fossil fuels and ODP for both bio-oil production via non-catalytic and catalytic pyrolysis processes. Non-catalytic pyrolysis, on the other hand, had the highest environmental impact for AP and EP as a result of some biochar combustion to provide heat for the process.

The GWPs for crude and upgraded bio-oil production in both Scenario 1 and Scenario 2 are significantly negative. Non-catalytic pyrolysis also has the lowest GWP overall because more biochar was produced for carbon sequestration than catalytic pyrolysis, and no $\mathrm{CaO}$ catalyst was consumed in the process. The net GWPs for combustion, non-catalytic pyrolysis and catalytic pyrolysis in Scenario 1 are $0.00018,-1.13$ and $-0.73 \mathrm{~kg} \mathrm{CO} 2 \mathrm{eq} / \mathrm{kg}$ of forest residues, respectively. These results indicate that valorising forest residues by producing crude and upgraded bio-oils is far better in terms of $\mathrm{CO}_{2}$ emissions than in-field burning. Therefore, paper and pulp industries in South Africa could successfully reduce their carbon emissions through both non-catalytic and catalytic pyrolysis of the forest residues left behind after pulpwood production. The net GWPs for crude bio-oil, upgraded bio-oil, crude-oil and diesel production in Scenario 2 are $-0.30,-0.14,0.0052$ and $0.013 \mathrm{~kg} \mathrm{CO} 2 \mathrm{eq} / \mathrm{MJ}$ of fuel, respectively. The results for Scenario 2 substantiate that crude or upgraded bio-oil production has a considerably lower environmental impact in terms of $\mathrm{CO}_{2}$ equivalent emissions than both crude-oil and diesel production. 


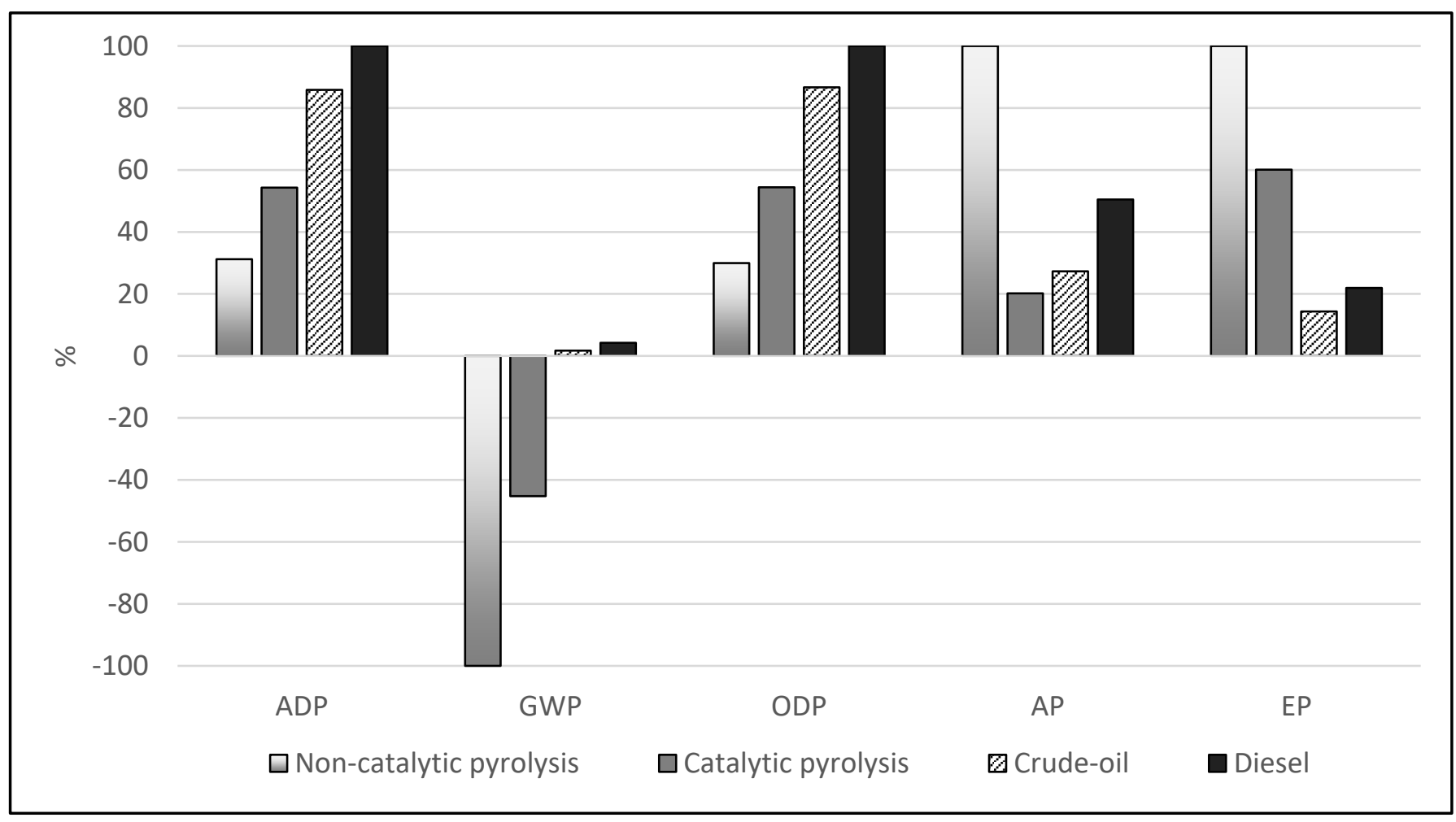

Figure 36: LCIA results for Scenario 2 (producing $1 \mathrm{MJ}$ of bio-oil compared to $1 \mathrm{MJ}$ of crude-oil or $1 \mathrm{MJ}$ of diesel)

The contributors to the net GWP for crude and upgraded bio-oil production via non-catalytic and catalytic pyrolysis in Scenario 2 are shown in Figure 37 and Figure 38, respectively. The contributions to GWP are divided into positive and negative contributions. Positive GWP contributions for bio-oil production via non-catalytic pyrolysis come from forest residue (FR) collection, chipping and transport, pyrolysis, biochar transport and bio-oil transport. Bio-oil production via catalytic pyrolysis had the same positive GWP contributors with the addition of the $\mathrm{CaO}$ catalyst, agri-lime transport and agri-lime application. Total positive GWP was 0.13 and $0.20 \mathrm{~kg} \mathrm{CO} \mathrm{CO}_{2}$ eq/MJ for non-catalytic and catalytic pyrolysis, respectively. The $\mathrm{CaO}$ catalyst contributed the most to the total positive GWP for catalytic pyrolysis with $0.094 \mathrm{~kg} \mathrm{CO} 2 \mathrm{eq} / \mathrm{MJ}$. Negative GWP contributions for bio-oil production via noncatalytic and catalytic pyrolysis came from biomass $\mathrm{CO}_{2}$ absorption and biochar carbon sequestration. Total negative GWP was -0.43 and $-0.34 \mathrm{~kg} \mathrm{CO}_{2} \mathrm{eq} / \mathrm{MJ}$ for non-catalytic and catalytic pyrolysis, respectively.

The GWP reported by Iribarren, Peters and Dufour (2012) was $-0.051 \mathrm{~kg} \mathrm{CO} 2$ eq/MJ of liquid fuel produced (Iribarren et al., 2012). The researchers applied a "cradle-to-gate" LCA approach for the production of gasoline and diesel-quality fuels from short-rotation poplar wood chips via fast pyrolysis and hydrotreating. The GWP for the biomass alone was $-0.120 \mathrm{~kg} \mathrm{CO}$ eq/MJ of liquid fuel produced and included biomass cultivation, harvesting and $\mathrm{CO}_{2}$ absorption. In comparison, the GWP for the biomass was $-0.287 \mathrm{~kg} \mathrm{CO}$ eq/MJ of upgraded bio-oil produced in this study, which was much lower 
because the environmental impact associated with biomass cultivation and harvesting were allocated to stem wood production only, and not to the forest residues. All of the char produced in the reported study was also combusted to provide sufficient heat for the pyrolysis reactor. Therefore, the overall GWP for the reported study was $62.7 \%$ higher than the overall GWP for upgraded bio-oil production in this study. Furthermore, producing both bio-oil and biochar as main products is an environmental advantage of operating at intermediate pyrolysis conditions. Biochar clearly had a significant influence on the GWP of bio-oil production through carbon sequestration. 


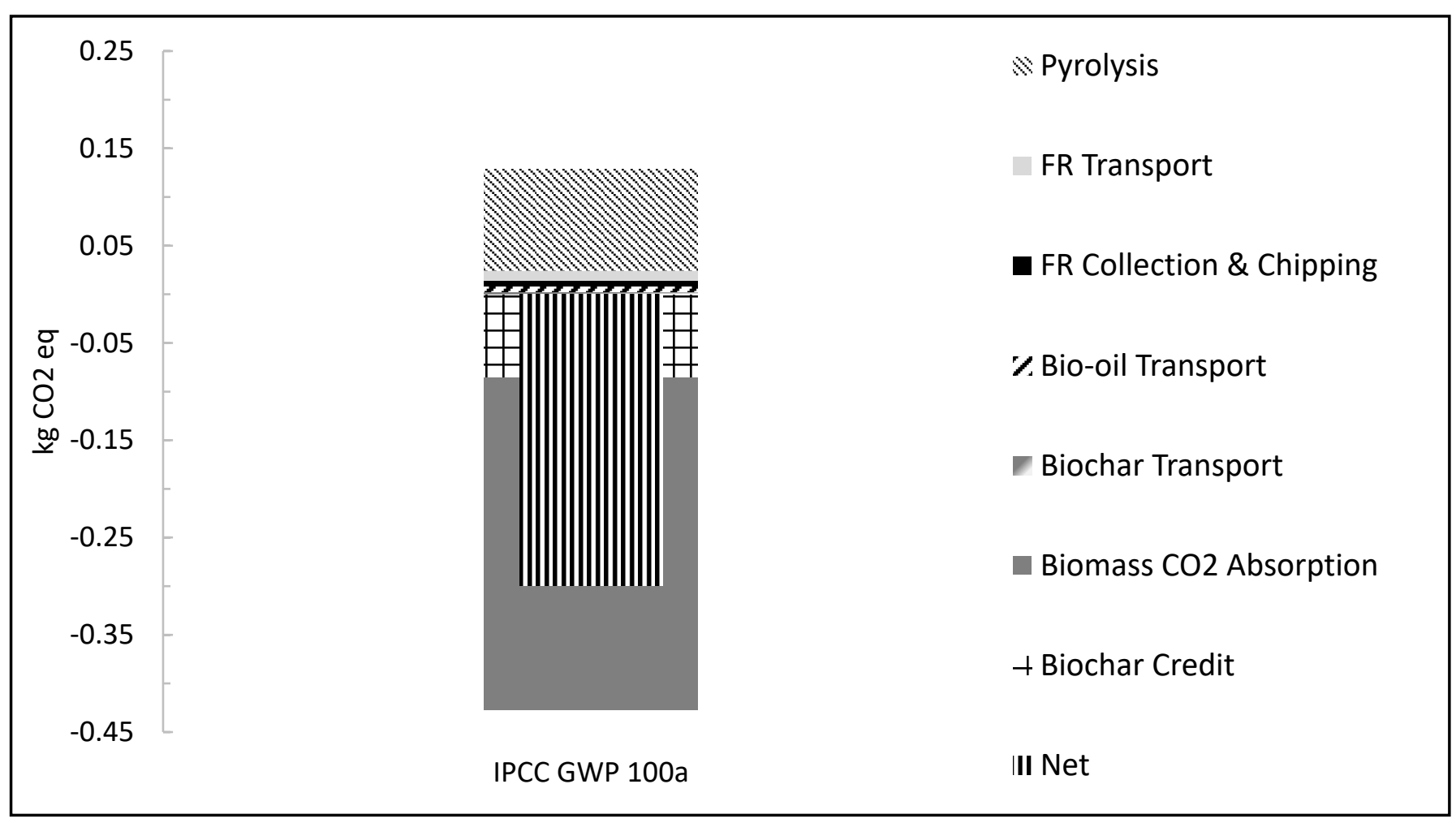

Figure 37: GWP contributions for bio-oil production via non-catalytic pyrolysis in Scenario 2

\begin{tabular}{|c|c|c|}
\hline 0.25 & & - Calcium Oxide \\
\hline \multirow[t]{2}{*}{0.15} & & \&Pyrolysis \\
\hline & & X. Agri-lime Application \\
\hline \multirow{4}{*}{ 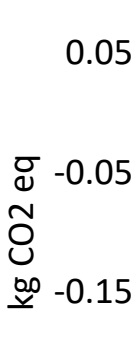 } & 0000 & \\
\hline & 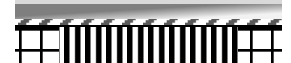 & FR Transport \\
\hline & & Biochar \& Agri-lime Transport \\
\hline & & "Bio-oil Transport \\
\hline \multirow[t]{2}{*}{-0.25} & & aR Collection \& Chipping \\
\hline & & Biomass CO2 Absorption \\
\hline-0.35 & & † Biochar Credit \\
\hline \multirow[t]{2}{*}{-0.45} & & \\
\hline & IPCC GWP 100a & III Net \\
\hline
\end{tabular}

Figure 38: GWP contributions for bio-oil production via catalytic pyrolysis in Scenario 2 
The net GWPs on a mass basis for crude bio-oil, upgraded bio-oil, crude-oil and diesel production in Scenario 2 are $-6.15,-3.50,0.24$ and $0.57 \mathrm{~kg} \mathrm{CO} 2 \mathrm{eq} / \mathrm{kg}$ of fuel, respectively. Consequently, co-processing crude or upgraded bio-oil has the potential to significantly decrease the GWP of the FCC feed. The blend of crude or upgraded bio-oil and VGO that can be co-processed at the Natref, Enref and Sapref oil refineries was previously reported in Table 17 in Section 4.2. The GWP of VGO is between the GWP of crude-oil and the GWP of diesel. The GWP of the FCC feed (crude bio-oil with crude-oil or upgraded bio-oil with crude-oil or crude bio-oil with diesel or upgraded bio-oil with diesel) is measured against the GWP of pure crude-oil or pure diesel to yield the reduction in GWP for each biorefinery scenario.

The average price of Brent Crude in 2017 was \$0.34/L (Macrotrends, 2019), and the average price (specifically, the BFP) of diesel in 2017 was $\$ 0.41 / L$ (Department of Energy, 2019). The MSP (22 $\%$ IRR) of crude or upgraded bio-oil presented in Table 34 is measured against these crude-oil and diesel prices to determine the price premium of either crude or upgraded bio-oil for each biorefinery scenario.

The reduction in GWP is subsequently plotted against the price premium of crude or upgraded bio-oil for each biorefinery scenario in Figure 39. The shaded areas seen in Figure 39 represent the range for the reduction in GWP and price premium of co-processing crude bio-oil and VGO (light grey) or upgraded bio-oil and VGO (dark grey). The reduction in GWP increases for co-processing crude biooil and crude-oil from 55.8 to $351.0 \%$, and for crude bio-oil and diesel from 24.4 to $153.7 \%$ as the biomass collection distance increases up to a $300 \mathrm{~km}$ radius of the biorefinery. Simultaneously, the price premium decreases for co-processing crude bio-oil and crude-oil from 77.2 to $53.9 \%$, and for crude bio-oil and diesel from 72.7 to $44.8 \%$ as the biomass collection distance increases up to a 300 $\mathrm{km}$ radius of the biorefinery. The same trend is seen for upgraded bio-oil, however, the change is less significant. The reduction in GWP increases for co-processing upgraded bio-oil and crude-oil from 31.0 to $226.3 \%$, and for upgraded bio-oil and diesel from 14.1 to $102.6 \%$ as the biomass collection distance increases up to a $300 \mathrm{~km}$ radius of the biorefinery. At the same time, the price premium decreases for co-processing upgraded bio-oil and crude-oil from 84.4 to $74.5 \%$, and for upgraded bio-oil and diesel from 81.4 to $69.4 \%$ as the biomass collection distance increases up to a $300 \mathrm{~km}$ radius of the biorefinery.

At a $300 \mathrm{~km}$ radius of the biorefinery, and overall, co-processing crude bio-oil reduces the GWP of the FCC feed far more for a lower price premium than co-processing upgraded bio-oil. However, the reduction in GWP for co-processing 5 wt. \% crude bio-oil (Scenario NC-5) is between 134.3 (crude-oil) and 58.8 (diesel) \%, whereas the reduction in GWP for co-processing 10 wt. \% upgraded bio-oil (Scenario C-10) is between 157.0 (crude-oil) and 71.2 (diesel) \%. Therefore, the potential to co-process more upgraded bio-oil than crude bio-oil significantly decreases the GWP of the FCC feed at the Natref oil refinery alone. The 8.0 (crude-oil) to 13.1 (diesel) \% difference in price premium for co-processing 
$5 \mathrm{wt} . \%$ crude bio-oil or $10 \mathrm{wt} . \%$ upgraded bio-oil also has the potential to decrease if the additional costs (process equipment modifications, changes in FCC product distribution etc.) for co-processing at the Natref oil refinery are considered.

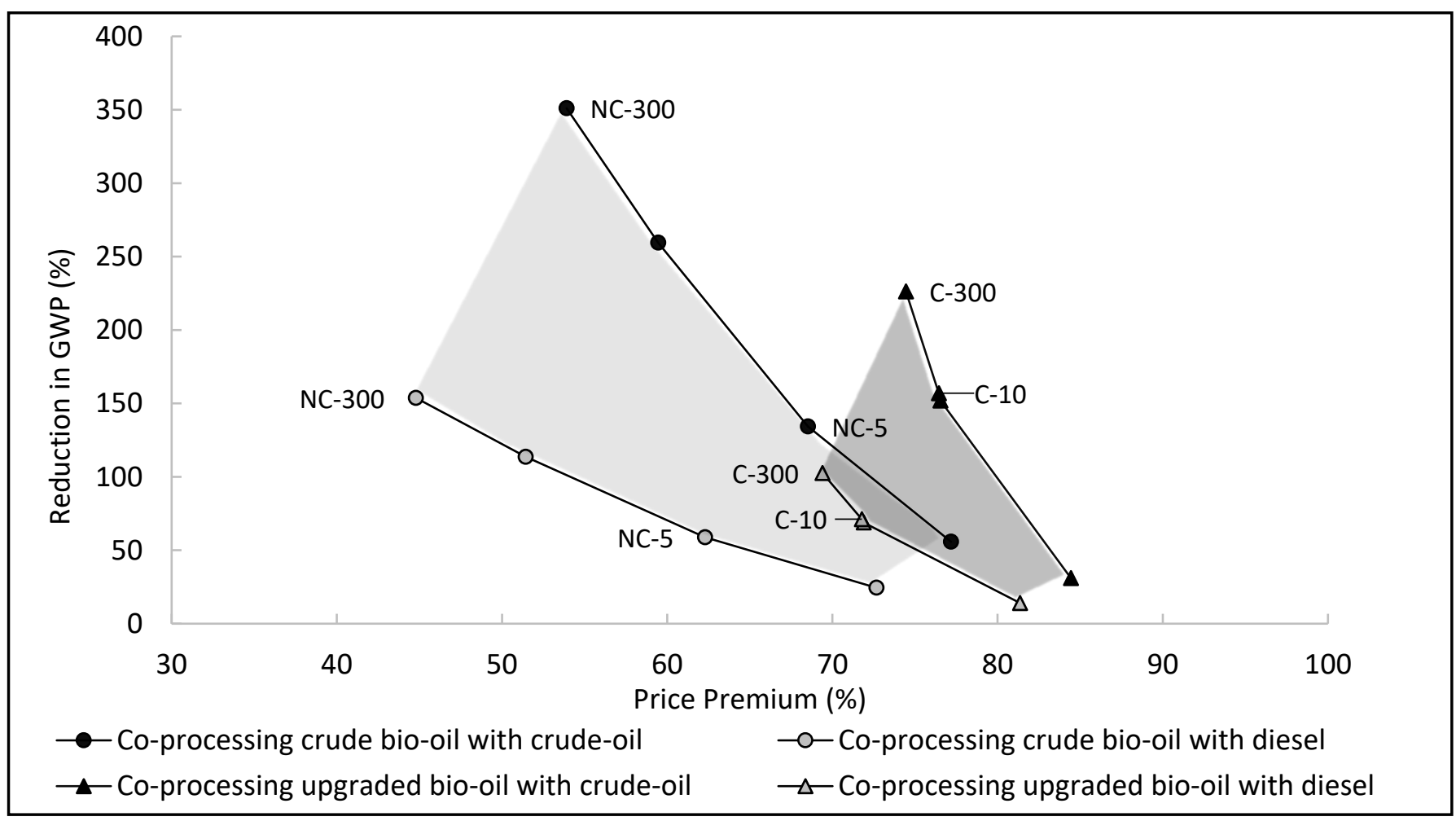

Figure 39: Reduction in GWP for price premium of crude and upgraded bio-oils - Non-catalytic (NC) and catalytic (C) pyrolysis for biomass collection within a 100, 200 and $300 \mathrm{~km}$ radius of the biorefinery, and NC and C at the required biorefinery capacity to co-process 5 and $10 \mathrm{wt}$. \% bio-oil, respectively 


\section{CHAPTER 6}

\section{Conclusions and Recommendations}

The overall aim of this project was to determine whether or not the production of crude and upgraded bio-oils via non-catalytic and catalytic pyrolysis of forest residues for co-processing in an oil refinery is economically and environmentally feasible. This chapter gives an overview of the objectives for the project, answers key research questions and provides recommendations for further research.

\subsection{Addressing the objectives}

The objectives for this project were developed to address the gaps in literature on the technoeconomic analysis of upgraded bio-oil production via catalytic pyrolysis with a basic metal oxide catalyst, and the environmental benefit of biochar as a co-product of pyrolysis.

\subsubsection{Develop process simulations in Aspen Plus ${ }^{\mathrm{TM}}$ for non-catalytic and catalytic pyrolysis biorefinery scenarios based on pilot plant data}

Non-catalytic pyrolysis of E. grandis forest residues (8.28 wt. \% moisture) yielded 22.6 wt. \% biochar and 19.8 wt. \% crude bio-oil available for sale, while catalytic pyrolysis yielded $16.5 \mathrm{wt}$. \% biochar and 18.4 wt. \% upgraded bio-oil available for sale.

Both non-catalytic and catalytic biorefinery scenarios were designed to be entirely energy selfsufficient by combusting the non-condensable gas and $21.5 \mathrm{wt}$. \% of the char (for non-catalytic pyrolysis biorefinery scenarios only) products. Consequently, the total energy supplied to the noncatalytic and catalytic pyrolysis biorefinery scenarios for heating, cooling and power was 25.0 and 25.9 $\%$ of biomass HHV, respectively. Furthermore, the total energy recovered in bio-oil and biochar products was 61.9 and $53.0 \%$ of the biomass HHV for non-catalytic and catalytic pyrolysis biorefinery scenarios, respectively.

\subsubsection{Develop economic analyses for non-catalytic and catalytic pyrolysis biorefinery scenarios based on process simulations}

The non-catalytic (NC-100, NC-200, NC-300 and NC-5) and catalytic (C-100, C-200, C-300 and C-10) pyrolysis biorefinery scenarios were chosen based on the biomass collection distance from the biorefinery (100, 200 and $300 \mathrm{~km}$ radius), and the amount of crude and upgraded bio-oil required to co-process 5 and $10 \mathrm{wt}$. \% at the Natref oil refinery, respectively.

There was a clear economy-of-scale benefit for the MSP of both crude and upgraded bio-oils as the biomass collection distance increased up to a $300 \mathrm{~km}$ radius of the biorefinery. The MSP of upgraded bio-oil though was always higher than the MSP of crude bio-oil for the same IRR and biomass 
collection distance. The most economically viable biorefinery scenario (Scenario NC-300) and the lowest MSP of crude bio-oil at a nominal $10 \%$ IRR was $\$ 0.27 / \mathrm{L}$, which fell below the estimated VGO market price of $\$ 0.35 / \mathrm{L}$. The MSP of upgraded bio-oil at a nominal $10 \%$ IRR for the corresponding catalytic pyrolysis biorefinery scenario (Scenario C-300) was $\$ 0.77 / \mathrm{L}$, which was considerably higher than the MSP of crude bio-oil. However, the quality of upgraded bio-oil was superior to crude bio-oil for co-processing in an oil refinery.

Co-processing up to $10 \mathrm{wt}$. \% crude bio-oil with VGO compared to upgraded bio-oil with VGO in an industrial-scale FCC unit will likely decrease gasoline yields and produce more $\mathrm{CO}, \mathrm{CO}_{2}$ and $\mathrm{H}_{2} \mathrm{O}$ gaseous products as a result of deoxygenation reactions. Co-processing up to $5 \mathrm{wt}$. \% crude bio-oil with VGO will be more reasonable. However, a significantly lower renewable carbon content present in the bio-derived fuels produced, as well as the process equipment and FCC catalyst modifications required to accommodate co-processing crude bio-oil in an oil refinery could make co-processing upgraded biooil more economically feasible. Nevertheless, investors will look for higher returns on innovative projects associated with high financial risk.

An oil refinery such as Natref could co-process $5 \mathrm{wt}$. \% crude bio-oil for $\$ 1.09 / \mathrm{L}$ (Scenario NC5) or 10 wt. \% upgraded bio-oil for $\$ 1.46 /$ L (Scenario C-10) at the desired $22 \%$ IRR. Alternatively, oil refineries such as Enref and Sapref could collaborate with Natref to benefit from economy-of-scale by co-processing crude and upgraded bio-oils at the lowest price of \$0.75/L (NC-300) and \$1.35/L (C-300) for a desired $22 \%$ IRR, respectively. The most economically viable biorefinery scenarios was still NC300 , however, the MSP on a volume basis did not account for the difference in energy value of the crude and upgraded bio-oils.

The MSP of crude and upgraded bio-oils were compared on a gasoline gallon equivalent (GGE) basis. The MSP of crude bio-oil on a GGE basis remained lower than the MSP of upgraded bio-oil overall. However, the MSP of upgraded bio-oil (\$6.64/GGE) was slightly closer to the MSP of crude biooil (\$4.36/GGE) for a desired $22 \%$ IRR at a $300 \mathrm{~km}$ radius of the biorefinery, which showed that upgraded bio-oil was in fact more competitive with crude bio-oil.

An economic sensitivity analysis showed that the MSP of crude bio-oil was most sensitive to a $25 \%$ change in $\mathrm{FCl}$, biochar selling price and total operating cost, while the MSP of upgraded bio-oil was most sensitive to a $25 \%$ change in $\mathrm{FCl}$, total operating cost (catalyst cost included) and catalyst cost. Therefore, the catalyst cost was a substantial contributor to the difference in MSP of crude and upgraded bio-oils.

The price premium for crude and upgraded bio-oils, however, have to be substantiated by a significant environmental benefit over VGO for oil refineries to recover costs through potential carbon tax rebates and potential government subsidisation. 


\subsubsection{Measure and compare the environmental impact of producing crude and upgraded bio-oils to crude-oil and diesel using SimaPro ${ }^{\mathrm{TM}}$}

Scenario 1 assessed the environmental impact of valorising $1 \mathrm{~kg}$ of dry forest residues by producing bio-oil via non-catalytic or catalytic pyrolysis instead of disposing of forest residues by in-field burning, and Scenario 2 evaluated the environmental impact of producing $1 \mathrm{MJ}$ of bio-oil via non-catalytic or catalytic pyrolysis instead of producing $1 \mathrm{MJ}$ of crude-oil or $1 \mathrm{MJ}$ of diesel.

The GWP for crude and upgraded bio-oil production in both Scenario 1 and Scenario 2 was significantly negative. Intermediate pyrolysis conditions had the advantage of producing both bio-oil and biochar as main products. Therefore, biochar had a substantial influence on the GWP for bio-oil production through carbon sequestration. The net GWP for combustion, non-catalytic pyrolysis and catalytic pyrolysis in Scenario 1 was $0.00018,-1.13$ and $-0.73 \mathrm{~kg} \mathrm{CO}{ }_{2} \mathrm{eq} / \mathrm{kg}$ of forest residues, respectively. Forest residue valorisation into crude or upgraded bio-oil was considerably better than in-field burning. The net GWP for crude bio-oil, upgraded bio-oil, crude-oil and diesel in Scenario 2 was $-0.30,-0.14,0.0052$ and $0.013 \mathrm{~kg} \mathrm{CO}_{2}$ eq/MJ of fuel, respectively. The GWP for VGO production was in the region between the GWP for crude-oil production and the GWP for diesel production. Crude and upgraded bio-oil production had a significantly lower GWP compared to crude-oil and diesel production. Furthermore, the GWP for crude bio-oil production was superior to upgraded bio-oil production because of the negative environmental impact associated with the $\mathrm{CaO}$ catalyst.

The reduction in GWP of the FCC feed for each biorefinery scenario was measured against the price premium of crude or upgraded bio-oil. At a $300 \mathrm{~km}$ radius of the biorefinery, co-processing crude bio-oil reduced the GWP of the FCC feed by between 153.7 (diesel) and 351.0 (crude-oil) \%, while coprocessing upgraded bio-oil reduced the GWP of the FCC feed by between 102.6 (diesel) and 226.3 (crude-oil) \%. Simultaneously, the price premium for co-processing crude bio-oil ranged from 44.8 (diesel) to 53.9 (crude-oil) \%, whereas the price premium for co-processing upgraded bio-oil ranged from 69.4 (diesel) to 74.5 (crude-oil) \%.

However, the reduction in GWP for co-processing 5 wt. \% crude bio-oil (Scenario NC-5) was between 58.8 (diesel) and 134.3 (crude-oil) \%, whereas the reduction in GWP for co-processing 10 wt. \% upgraded bio-oil (Scenario C-10) was between 71.2 (diesel) and 157.0 (crude-oil) \%. Therefore, the GWP of the FCC feed for a single oil refinery decreased considerably by co-processing more upgraded bio-oil than crude bio-oil. The difference in price premium for co-processing $5 \mathrm{wt}$. \% crude bio-oil or 10 wt. \% upgraded bio-oil was between 13.1 (diesel) and 8.0 (crude-oil) \%. Furthermore, considering the possible costs to the oil refinery for co-processing crude or (less so) upgraded bio-oil, this difference in price premium will likely decrease. 


\subsection{Recommendations for further research}

Recommendations are made for future experimental work that will expand the scope of this project, and provide further insight into the economic feasibility of commercial bio-oil production for coprocessing in an oil refinery:

- Biomass collection (currently forest residues only) could be expanded to include invasive alien plants, which are problematic for conservation throughout South Africa, but especially in KZN and Mpumalanga. A decrease in biomass transport distance to the biorefinery will also be favourable for the process economics, while maintaining bio-oil production and supply (i.e. economy-of-scale) to oil refineries as described in this study.

- The biomass grinder consumed up to $51 \%$ of the power required by the biorefinery therefore, further pilot-plant experiments followed by an update of the techno-economic analysis developed in this study could be conducted to assess the technical and economic feasibility of processing larger biomass particles at industrial-scale. Industrial-scale pyrolysis reactors operating at intermediate pyrolysis conditions may not require grinding biomass particles down from $2 \mathrm{~cm}$ to $2 \mathrm{~mm}$.

- The power demand of the biorefinery could be supplied from the grid (mostly coal-fired power) instead of recovering heat from the process to produce steam for the installed steam turbines. Consequently, the production of crude and upgraded bio-oils has the potential to be more economically feasible, however, the environmental impact of the biorefinery could significantly change.

- Recovery of the $\mathrm{CaO}$ catalyst without compromising the biochar (usually by combustion) could be investigated since the cost and GWP of the catalyst significantly influenced the MSP of upgraded bio-oil and the environmental impact of upgraded bio-oil production in this study, respectively. One potential method, depending on the biochar particle size distribution, involves entraining biochar particles using a process known as blow through. Another physical separation method involves sieving the biochar and catalyst particles.

- Alternative upgrading methods (to in situ catalytic pyrolysis with $\mathrm{CaO}$ catalyst) could be considered to potentially reduce the MSP of upgraded bio-oil and improve the GWP of upgraded bio-oil production; such as hydrotreating with hydrogen produced via water electrolysis powered by solar PV panels. Various hydrogen production methods (natural gas steam reforming, biomass/biochar steam gasification, bio-oil reforming etc.) could also be compared both economically and environmentally.

- Co-processing crude and upgraded bio-oils at lab and pilot-scale could be investigated to evaluate the correlation between blending ratio, distribution of FCC products (specifically coke, gasoline and (CO) and the extent of deoxygenation reactions that produce the 
undesirable $\mathrm{H}_{2} \mathrm{O}, \mathrm{CO}$ and $\mathrm{CO}_{2}$ gaseous product. Co-processing up to $20 \mathrm{wt}$. $\%$ crude bio-oil at demonstration-scale is technically feasible therefore, co-processing more than $20 \mathrm{wt}$ \% upgraded bio-oil could be investigated. However, biomass availability and the long-term implications for an oil refinery should also be considered. Furthermore, these experiments could be used to evaluate the susceptibility of FCC construction materials to the corrosivity of bio-oil, as well as the damage caused to FCC catalysts by the high water content of bio-oil.

- The scope of this project could be expanded to include a techno-economic analysis for coprocessing crude and upgraded bio-oils at an oil refinery using co-processing data (FCC product yields, reaction conditions etc.) preferably generated from lab or pilot-scale experiments or available in literature (upgraded bio-oil co-processing data is limited to upgraded bio-oil produced via hydrotreating or catalytic pyrolysis with zeolite catalysts). The additional capital and operating costs incurred by the oil refinery could then be included in the profitability analysis developed for this project to better compare the MSP of crude and upgraded bio-oils. Subsequently, the environmental impact of co-processing crude and upgraded bio-oils could be investigated to expand the GWP analysis from crude and upgraded bio-oil production to bio-derived fuel production.

- A techno-economic analysis to compare crude bio-oil deoxygenation during FCC co-processing to upgrading bio-oil followed by FCC co-processing could be investigated to determine whether or not it is necessary and economically feasible to upgrade bio-oil before FCC coprocessing. Furthermore, the techno-economic analysis could compare upgrading bio-oil through catalytic pyrolysis to upgrading bio-oil through hydrotreating at the oil refinery, where hydrogen is readily available. The latter could benefit from a significant improvement in the process economics, however, the environmental benefit and renewable carbon content of the FCC products should be considered. 


\section{References}

Ackerman, P., Ham, C., Dovey, S., Toit, B., Wet, J. De, Kunneke, A. \& Seifert, T. 2013. State of the art use of forest residues for bioenergy in southern Africa. Institute for Commercial Forestry Research.

Activated Carbon Innovations. 2019. Our Products. [Online], Available: http://activatedcarbon.co.za/our-products/ [2019, May 14].

Agegnehu, G., Srivastava, A.K. \& Bird, M.I. 2017. The role of biochar and biochar-compost in improving soil quality and crop performance: A review. Applied Soil Ecology. 119:156-170.

Akhtar, J. \& Amin, N.S. 2012. A review on operating parameters for optimum liquid oil yield in biomass pyrolysis. Renewable and Sustainable Energy Reviews. 16(7):5101-5109.

Ali Mandegari, M., Farzad, S. \& Görgens, J.F. 2017. Economic and environmental assessment of cellulosic ethanol production scenarios annexed to a typical sugar mill. Bioresource Technology. 224:314-326.

Amos, W. a. 1998. Report on Biomass Drying Technology. National Renewable Energy Laboratory.

Anex, R.P., Aden, A., Kazi, F.K., Fortman, J., Swanson, R.M., Wright, M.M., Satrio, J.A., Brown, R.C., et al. 2010. Techno-economic comparison of biomass-to-transportation fuels via pyrolysis, gasification, and biochemical pathways. Fuel. 89:S29-S35.

AspenTech. 2013. Aspen Plus - Getting Started Modeling Processes with Solids. Aspen Technology Inc. Azeez, A.M., Meier, D., Odermatt, J. \& Willner, T. 2010. Fast pyrolysis of African and European lignocellulosic biomasses using $\mathrm{Py}-\mathrm{GC} / \mathrm{MS}$ and fluidized bed reactor. Energy and Fuels. 24(3):2078-2085.

Balat, M., Balat, M., Kirtay, E. \& Balat, H. 2009. Main routes for the thermo-conversion of biomass into fuels and chemicals. Part 1: Pyrolysis systems. Energy Conversion and Management. 50(12):3147-3157.

Bergsten, B. 2009. Evaporative Cooling Tower and Chilled Beams. Design Aspects for Cooling in Office Buildings in Northern Europe. Chalmers University of Technology.

Bezergianni, S., Dimitriadis, A., Kikhtyanin, O. \& Kubička, D. 2018. Refinery co-processing of renewable feeds. Progress in Energy and Combustion Science. 68:29-64.

Bridgwater, A. V. 2012a. Review of fast pyrolysis of biomass and product upgrading. Biomass and Bioenergy. 38:68-94.

Bridgwater, A. V. 2012b. Upgrading Biomass Fast Pyrolysis Liquids. Environmental Progress \& Sustainable Energy. 31(2):261-268.

Bridgwater, A. V, Toft, A.J. \& Brammer, J.G. 2002. A techno-economic comparison of power production by biomass fast pyrolysis with gasification and combustion. Renewable and Sustainable Energy Reviews. 6:181-248. 
Brown, T.R. \& Brown, R.C. 2013. Techno-economics of advanced biofuels pathways. RSC Advances. 3(17):5758-5764.

Brown, D., Rowe, A. \& Wild, P. 2013. A techno-economic analysis of using mobile distributed pyrolysis facilities to deliver a forest residue resource. Bioresource Technology. 150:367-376.

Bru, K., Blin, J., Julbe, A. \& Volle, G. 2007. Pyrolysis of metal impregnated biomass: An innovative catalytic way to produce gas fuel. Journal of Analytical and Applied Pyrolysis. 78(2):291-300.

Bu, Q., Lei, H., Zacher, A.H., Wang, L., Ren, S., Liang, J., Wei, Y., Liu, Y., et al. 2012. A review of catalytic hydrodeoxygenation of lignin-derived phenols from biomass pyrolysis. Bioresource Technology. 124:470-477.

Burger, M.D. 2018. Evaluating different value adding processing systems for bamboo developments. Stellenbosch University.

Cao, X., Ma, L., Gao, B. \& Harris, W. 2009. Dairy-manure derived biochar effectively sorbs lead and atrazine. Environmental Science \& Technology. 43(9):3285-3291.

Carey, P., Ketterings, Q. \& Hunter, M. 2006. Liming materials. [Online], Available: http://cceonondaga.org/resources/liming-materials [2019, May 09].

Carlson, T.R., Tompsett, G.A., Conner, W.C. \& Huber, G.W. 2009. Aromatic production from catalytic fast pyrolysis of biomass-derived feedstocks. Topics in Catalysis. 52(3):241-252.

Carpenter, D., Westover, T.L., Czernik, S. \& Jablonski, W. 2014. Biomass feedstocks for renewable fuel production: a review of the impacts of feedstock and pretreatment on the yield and product distribution of fast pyrolysis bio-oils and vapors. Green Chemistry. 16(2):384-406.

Carrasco, J.L., Gunukula, S., Boateng, A.A., Mullen, C.A., DeSisto, W.J. \& Wheeler, M.C. 2017. Pyrolysis of forest residues: An approach to techno-economics for bio-fuel production. Fuel. 193:477-484.

Channiwala, S.A. \& Parikh, P.P. 2002. A unified correlation for estimating HHV of solid, liquid and gaseous fuels. Fuel. 81(8):1051-1063.

Chireshe, F. 2019. Production of an upgraded bio-oil by catalytic pyrolysis of forest residues. Stellenbosch University.

Collard, F.-X. \& Blin, J. 2014. A review on pyrolysis of biomass constituents: Mechanisms and composition of the products obtained from the conversion of cellulose, hemicelluloses and lignin. Renewable and Sustainable Energy Reviews. 38:594-608.

Collard, F.-X., Blin, J., Bensakhria, A. \& Valette, J. 2012. Influence of impregnated metal on the pyrolysis conversion of biomass constituents. Journal of Analytical and Applied Pyrolysis. 95:213-226.

Couhert, C., Commandre, J.M. \& Salvador, S. 2009. Is it possible to predict gas yields of any biomass after rapid pyrolysis at high temperature from its composition in cellulose, hemicellulose and lignin? Fuel. 88(3):408-417.

Czernik, S. \& Bridgwater, A. V. 2004. Overview of applications of biomass fast pyrolysis oil. Energy and Fuels. 18(2):590-598. 
Daugaard, D.E. \& Brown, R.C. 2003. Enthalpy for Pyrolysis for Several Types of Biomass. Energy and Fuels. 17:934-939.

Dayton, D.C., Carpenter, J.R., Kataria, A., Peters, J.E., Barbee, D., Mante, O.D. \& Gupta, R. 2015. Design and operation of a pilot-scale catalytic biomass pyrolysis unit. Green Chemistry. 17(9):4680-4689.

Demirbas, A. 2016. Calculation of higher heating values of fatty acids. Energy Sources, Part A: Recovery, Utilization and Environmental Effects. 38(18):2693-2697.

Demirbas, M.F. \& Balat, M. 2006. Recent advances on the production and utilization trends of biofuels: A global perspective. Energy Conversion and Management. 47(15-16):2371-2381.

Department of Agriculture Forestry and Fisheries. 2018. Guide to Machinery Costs 2015-2016. [Online], Available: https://www.daff.gov.za/daffweb3/Home/Crop-Estimates/Economic [2018, June 08].

Department of Energy. 2019. Petrol Price Archive. [Online], Available: http://www.energy.gov.za/files/esources/petroleum/petroleum_arch.html [2019, May 13].

Department of Environmental Affairs. 2015. South Africa's Intended Nationally Determined Contribution. [Online], Available: https://www.environment.gov.za [2019, September 05].

Department of Environmental Affairs. 2016. South Africa joins Nations of the World in ratifying the Paris Agreement on Climate Change. [Online], Available: https://www.environment.gov.za/mediarelease/southafrica_ratifies_parisagreement [2017, November 12].

Dhyani, V. \& Bhaskar, T. 2018. A comprehensive review on the pyrolysis of lignocellulosic biomass. Renewable Energy. 129:695-716.

Dickerson, T. \& Soria, J. 2013. Catalytic fast pyrolysis: A review. Energies. 6(1):514-538.

Do, T.X. \& Lim, Y. II. 2016. Techno-economic comparison of three energy conversion pathways from empty fruit bunches. Renewable Energy. 90:307-318.

Dovey, S.B. 2009. Estimating biomass and macronutrient content of some commercially important plantation species in South Africa. Southern Forests. 71(3):245-251.

Du, S., Valla, J.A. \& Bollas, G.M. 2013. Characteristics and origin of char and coke from fast and slow, catalytic and thermal pyrolysis of biomass and relevant model compounds. Green Chemistry. 15(11):3214.

Dutta, A., Sahir, A., Tan, E., Humbird, D., Snowden-swan, L.J., Meyer, P., Ross, J., Sexton, D., et al. 2015. Process Design and Economics for the Conversion of Lignocellulosic Biomass to Hydrocarbon Fuels: Thermochemical Research Pathways with In Situ and Ex Situ Upgrading of Fast Pyrolysis Vapors. National Renewable Energy Laboratory.

van Dyk, S., Su, J., McMillan, J.D. \& Saddler, J. 2019. Potential synergies of drop-in biofuel production with further co-processing at oil refineries. Biofuels, Bioproducts and Biorefining. 13(3):760-775.

Eskom. 2019. Integrated Report. [Online], Available: http://www.eskom.co.za/IR2018/Pages/default.aspx [2019, August 30]. 
Farzad, S., Mandegari, M.A., Guo, M., Haigh, K.F., Shah, N. \& Görgens, J.F. 2017. Multi-product biorefineries from lignocelluloses: a pathway to revitalisation of the sugar industry? Biotechnology for Biofuels. 10(1):87.

Farzad, S., Mandegari, M.A. \& Görgens, J.F. 2017. Integrated techno-economic and environmental analysis of butadiene production from biomass. Bioresource Technology. 239:37-48.

Federal Reserve Economic Data. 2019. Producer Price Index by Commodity for Chemicals and Allied Products. [Online], Available: https://fred.stlouisfed.org/series/WPU06\#0 [2019, July 02].

Fogassy, G., Thegarid, N., Schuurman, Y. \& Mirodatos, C. 2012. The fate of bio-carbon in FCC coprocessing products. Green Chemistry. 14(5):1367-1371.

Forestry Economics Services. 2017. Commercial Timber Resources and Primary Roundwood Processing in South Africa 2015/2016. Pretoria: Department of Agriculture, Forestry and Fisheries.

Galadima, A. \& Muraza, O. 2015. In situ fast pyrolysis of biomass with zeolite catalysts for bioaromatics/gasoline production: A review. Energy Conversion and Management. 105:338-354.

Garcia-Pérez, M., Chaala, A., Pakdel, H., Kretschmer, D. \& Roy, C. 2007. Vacuum pyrolysis of softwood and hardwood biomass. Comparison between product yields and bio-oil properties. Journal of Analytical and Applied Pyrolysis. 78(1):104-116.

Gollakota, A.R.K., Reddy, M., Subramanyam, M.D. \& Kishore, N. 2016. A review on the upgradation techniques of pyrolysis oil. Renewable and Sustainable Energy Reviews. 58:1543-1568.

Gonçalves, J.L.M., Wichert, M.C.P., Gava, J.L., Masetto, A.V., Junior, A.J.C., Serrano, M.I.P. \& Mello, S.L.M. 2007. Soil Fertility and Growth of Eucalyptus grandis in Brazil under Different Residue Management Practices. Southern Hemisphere Forestry Journal. 69(2):95-102.

Gorgens, J.F., Mandegari, M., Farzad, S., Daful, A. \& Haigh, K. 2016. A biorefinery approach to improve the sustainability of the South African sugar industry: Assessment of selected scenarios. Department of Environmental Affairs.

Grain SA. 2019. Fertilizer/Agro-chemical Report - October 2018. [Online], Available: https://www.grainsa.co.za/ [2019, May 07].

Han, J., Elgowainy, A., Dunn, J.B. \& Wang, M.Q. 2013. Life cycle analysis of fuel production from fast pyrolysis of biomass. Bioresource Technology. 133:421-428.

Hill, D. 2011. North Dakota Refining Capacity Study. United States Department of Energy.

Hsu, D.D. 2012. Life cycle assessment of gasoline and diesel produced via fast pyrolysis and hydroprocessing. Biomass and Bioenergy. 45:41-47.

Hugo, W. 2016. Bioenergy Atlas for South Africa. Department of Science and Technology.

Humbird, D., Davis, R., Tao, L., Kinchin, C., Hsu, D., Aden, A., Schoen, P., Lukas, J., et al. 2011. Process Design and Economics for Biochemical Conversion of Lignocellulosic Biomass to Ethanol. National Renewable Energy Laboratory. 
Ibarra, Á., Veloso, A., Bilbao, J., Arandes, J.M. \& Castaño, P. 2016. Dual coke deactivation pathways during the catalytic cracking of raw bio-oil and vacuum gasoil in FCC conditions. Applied Catalysis B: Environmental. 182:336-346.

IEA Renewable Energy Division. 2010. Sustainable production of second-generation biofuels: Potential and perspectives in major economies and developing countries. Paris: International Energy Agency.

IEA Renewable Energy Division. 2011. Technology Roadmap: Biofuels for Transport. Paris: International Energy Agency.

Iribarren, D., Peters, J.F. \& Dufour, J. 2012. Life cycle assessment of transportation fuels from biomass pyrolysis. Fuel. 97:812-821.

Isahak, W.N.R.W., Hisham, M.W.M., Yarmo, M.A. \& Yun Hin, T. 2012. A review on bio-oil production from biomass by using pyrolysis method. Renewable and Sustainable Energy Reviews. 16(8):5910-5923.

Jacobson, J.J., Roni, M.S., Lamers, P. \& Cafferty, K.G. 2014. Biomass Feedstock Supply System Design and Analysis. Idaho National Laboratory.

Jechura, J. 2016. Refinery Feedstocks \& Products: Properties \& Specifications. Colorado School of Mines.

Jindo, K., Mizumoto, H., Sawada, Y., Sanchez-Monedero, M.A. \& Sonoki, T. 2014. Physical and chemical characterization of biochars derived from different agricultural residues. Biogeosciences. 11(23):6613-6621.

Jones, S., Meyer, P., Snowden-Swan, L., Asanga, P., Eric, T., Abhijit, D., Jacob, J. \& Cafferty, K. 2013. Process design and economics for the conversion of lignocellulosic biomass to hydrocarbon fuels: Fast pyrolysis and hydrotreating bio-oil pathway. Pacific Northwest National Laboratory.

Kalkor. 2019. Price List. [Online], Available: http://www.kalkor.co.za/site/content/id/price-list [2019, May 26].

De Kam, M.J., Morey, R.V. \& Tiffany, D.G. 2009. Biomass Integrated Gasification Combined Cycle for heat and power at ethanol plants. Energy Conversion and Management. 50(7):1682-1690.

Kan, T., Strezov, V. \& Evans, T.J. 2016. Lignocellulosic biomass pyrolysis: A review of product properties and effects of pyrolysis parameters. Renewable and Sustainable Energy Reviews. 57:126-1140.

Kauffman, N., Hayes, D. \& Brown, R. 2011. A life cycle assessment of advanced biofuel production from a hectare of corn. Fuel. 90(11):3306-3314.

Kim, K.H., Kim, T.S., Lee, S.M., Choi, D., Yeo, H., Choi, I.G. \& Choi, J.W. 2013. Comparison of physicochemical features of biooils and biochars produced from various woody biomasses by fast pyrolysis. Renewable Energy. 50:188-195.

Konz, J., Cohen, B. \& van der Merwe, A. 2015. Assessment of the potential to produce biochar and its application to South African soils as a mitigation measure. Department of Environmental Affairs. 
Lappas, A.A., Kalogiannis, K.G., Iliopoulou, E.F., Triantafyllidis, K.S. \& Stefanidis, S.D. 2012. Catalytic pyrolysis of biomass for transportation fuels. Wiley Interdisciplinary Reviews: Energy and Environment. 1(3):285-297.

Lee, Y., Park, J., Ryu, C., Gang, K.S., Yang, W., Park, Y.K., Jung, J. \& Hyun, S. 2013. Comparison of biochar properties from biomass residues produced by slow pyrolysis at $500^{\circ} \mathrm{C}$. Bioresource Technology. 148:196-201.

Li, B., Ou, L., Dang, Q., Meyer, P., Jones, S., Brown, R. \& Wright, M. 2015. Techno-economic and uncertainty analysis of in situ and ex situ fast pyrolysis for biofuel production. Bioresource Technology. 196:49-56.

Li, W., Fu, F., Ma, L., Liu, P., Li, Z. \& Dai, Y. 2013. A process-based model for estimating the well-to-tank cost of gasoline and diesel in China. Applied Energy. 102:718-725.

Lin, Y., Zhang, C., Zhang, M. \& Zhang, J. 2010. Deoxygenation of bio-oil during pyrolysis of biomass in the presence of $\mathrm{CaO}$ in a fluidized-bed reactor. Energy and Fuels. 24(10):5686-5695.

Lindfors, C., Paasikallio, V., Kuoppala, E., Reinikainen, M., Oasmaa, A. \& Solantausta, Y. 2015. Coprocessing of dry bio-oil, catalytic pyrolysis oil, and hydrotreated bio-oil in a micro activity test unit. Energy and Fuels. 29(6):3707-3714.

Liu, C., Wang, H., Karim, A.M., Sun, J. \& Wang, Y. 2014. Catalytic fast pyrolysis of lignocellulosic biomass. Chemical Society Reviews. 43(22):7594-7623.

Lu, H.R. \& El Hanandeh, A. 2019. Life cycle perspective of bio-oil and biochar production from hardwood biomass; what is the optimum mix and what to do with it? Journal of Cleaner Production. 212:173-189.

Lu, H., Zhang, W., Yang, Y., Huang, X., Wang, S. \& Qiu, R. 2012. Relative distribution of Pb 2+ sorption mechanisms by sludge-derived biochar. Water Research. 46(3):854-862.

Luo, G., Chandler, D.S., Anjos, L.C.A., Eng, R.J., Jia, P. \& Resende, F.L.P. 2017. Pyrolysis of whole wood chips and rods in a novel ablative reactor. Fuel. 194:229-238.

Macrotrends. 2019. Brent Crude Oil Prices - 10 Year Daily Chart. [Online], Available: https://www.macrotrends.net/2480/brent-crude-oil-price [2019, May 13].

Mandegari, M.A., Farzad, S. \& Gorgens, J.F. 2016. Process Design, Flowsheeting, and Simulation of Bioethanol Production from Lignocelluloses. In R.S. Singh, A. Pandey, \& E. Gnansounou (eds.) Biofuels: Production and Future Perspectives. 255-277.

Meier, D., Oasmaa, A. \& Peacocke, G.V.C. 1997. Properties of Fast Pyrolysis Liquids: Status of Test Methods. In A.V. Bridgwater \& D.G.B. Boocock (eds.). Dordrecht: Springer Developments in Thermochemical Biomass Conversion. 391-408.

Melendez, J., LeBel, L. \& Stuart, P.R. 2013. A Literature Review of Biomass Feedstocks for a Biorefinery. In M.M. El-Halwagi \& P.R. Stuart (eds.) Integrated Biorefineries: Design, Analysis, and Optimization. 433-455. 
de Miguel Mercader, F., Groeneveld, M.J., Kersten, S.R.A., Way, N.W.J., Schaverien, C.J. \& Hogendoorn, J.A. 2010. Production of advanced biofuels: Co-processing of upgraded pyrolysis oil in standard refinery units. Applied Catalysis B: Environmental. 96:57-66.

Mirkouei, A., Haapala, K.R., Sessions, J. \& Murthy, G.S. 2017. A review and future directions in technoeconomic modeling and optimization of upstream forest biomass to bio-oil supply chains. Renewable and Sustainable Energy Reviews. 67:15-35.

Mitchell, K.A., Parker, N.C., Sharma, B. \& Kaffka, S. 2015. Potential for Biofuel Production from Forest Woody Biomass. California Biomass Collaborative.

Mohan, D., Pittman, C.U. \& Steele, P.H. 2006. Pyrolysis of wood/biomass for bio-oil: A critical review. Energy and Fuels. 20(3):848-889.

Morris, M.A. 2011. Production of bio-oils via catalytic pyrolysis. In First ed. R. Luque, J. Campelo, \& J.H. Clark (eds.). Oxford: Woodhead Publishing Limited Handbook of biofuels production - processes and technologies. 349-389.

Motiang, M. \& Nembahe, R. 2017. South African Energy Price Report. Pretoria: Department of Energy. Mullen, C.A., Strahan, G.D. \& Boateng, A.A. 2009. Characterization of various fast-pyrolysis bio-oils by NMR spectroscopy. Energy and Fuels. 23(5):2707-2718.

Mullen, C.A., Boateng, A.A., Goldberg, N.M., Lima, I.M., Laird, D.A. \& Hicks, K.B. 2010. Bio-oil and biochar production from corn cobs and stover by fast pyrolysis. Biomass and Bioenergy. 34:67-74.

Nambiar, E.K.S. \& Kallio, M.H. 2008. Increasing and Sustaining Productivity in Subtropical and Tropical Plantation forests: Making a Difference through Research Partnership. In Site management and productivity in tropical plantation forests: Proceedings of Workshops in Piracicaba (Brazil) 22-26 November 2004 and Bogor (Indonesia) 6-9 November 2006. 205-227.

Neves, D., Thunman, H., Matos, A., Tarelho, L. \& Gómez-Barea, A. 2011. Characterization and prediction of biomass pyrolysis products. Progress in Energy and Combustion Science. $37(5): 611-630$.

Nieder-Heitmann, M., Haigh, K.F. \& Görgens, J.F. 2018. Process design and economic analysis of a biorefinery co-producing itaconic acid and electricity from sugarcane bagasse and trash lignocelluloses. Bioresource Technology. 262:159-168.

Nikolaidis, P. \& Poullikkas, A. 2017. A comparative overview of hydrogen production processes. Renewable and Sustainable Energy Reviews. 67:597-611.

Nolte, M.W. \& Shanks, B.H. 2017. A Perspective on Catalytic Strategies for Deoxygenation in Biomass Pyrolysis. Energy Technology. 5(1):7-18.

Nsaful, F., Görgens, J.F. \& Knoetze, J.H. 2013. Comparison of combustion and pyrolysis for energy generation in a sugarcane mill. Energy Conversion and Management. 74:524-534.

Oasmaa, A., Kuoppala, E., Gust, S. \& Solantausta, Y. 2003. Fast Pyrolysis of Forestry Residue. 1. Effect of Extractives on Phase Separation of Pyrolysis Liquids. Energy and Fuels. 17(1):1-12. 
Oasmaa, A., Solantausta, Y., Arpiainen, V., Kuoppala, E. \& Sipilä, K. 2010. Fast pyrolysis bio-oils from wood and agricultural residues. Energy and Fuels. 24(2):1380-1388.

Onarheim, K., Solantausta, Y. \& Lehto, J. 2015. Process Simulation Development of Fast Pyrolysis of Wood Using Aspen Plus. Energy and Fuels. 29(1):205-217.

Paasikallio, V., Kalogiannis, K., Lappas, A., Lehto, J. \& Lehtonen, J. 2017. Catalytic Fast Pyrolysis: Influencing Bio-Oil Quality with the Catalyst-to-Biomass Ratio. Energy Technology. 5(1):94-103.

PAMSA. 2019. Paper in Perspective - Industry Report 2016. [Online], Available: https://www.thepaperstory.co.za/brochures-and-publications/ [2019, May 24].

Patel, M., Zhang, X. \& Kumar, A. 2016. Techno-economic and life cycle assessment on lignocellulosic biomass thermochemical conversion technologies: A review. Renewable and Sustainable Energy Reviews. 53:1486-1489.

Perry, R.H., Green, D.W. \& Maloney, J.O. 1997. Perry's Chemical Engineers ' Handbook. Seventh ed. New York: McGraw-Hill.

Peters, J.F., Iribarren, D. \& Dufour, J. 2015. Life cycle assessment of pyrolysis oil applications. Biomass Conversion and Biorefinery. 5:1-19.

Pinho, A. de R., de Almeida, M.B.B., Mendes, F.L., Casavechia, L.C., Talmadge, M.S., Kinchin, C.M. \& Chum, H.L. 2017. Fast pyrolysis oil from pinewood chips co-processing with vacuum gas oil in an FCC unit for second generation fuel production. Fuel. 188:462-473.

Pinho, A.D.R., De Almeida, M.B.B., Mendes, F.L., Ximenes, V.L. \& Casavechia, L.C. 2015. Co-processing raw bio-oil and gasoil in an FCC Unit. Fuel Processing Technology. 131:159-166.

Pisupati, S. V \& Tchapda, A.H. 2015. Thermochemical Processing of Biomass. In P. Ravindra (ed.). Cham: Springer Advances in Bioprocess Technology. 277-314.

Polagye, B.L., Hodgson, K.T. \& Malte, P.C. 2007. An economic analysis of bio-energy options using thinnings from overstocked forests. Biomass and Bioenergy. 31:105-125.

Puy, N., Murillo, R., Navarro, M. V., López, J.M., Rieradevall, J., Fowler, G., Aranguren, I., García, T., et al. 2011. Valorisation of forestry waste by pyrolysis in an auger reactor. Waste Management. 31(6):1339-1349.

Qambrani, N.A., Rahman, M.M., Won, S., Shim, S. \& Ra, C. 2017. Biochar properties and eco-friendly applications for climate change mitigation, waste management, and wastewater treatment: A review. Renewable and Sustainable Energy Reviews. 79:255-273.

Qu, T., Guo, W., Shen, L., Xiao, J. \& Zhao, K. 2011. Experimental study of biomass pyrolysis based on three major components: Hemicellulose, cellulose, and lignin. Industrial and Engineering Chemistry Research. 50(18):10424-10433.

Republic of South Africa. 2019. Carbon Tax Act 15 of 2019. Cape Town: Government Printer. 
Richardson, Y., Blin, J., Volle, G., Motuzas, J. \& Julbe, A. 2010. In situ generation of Ni metal nanoparticles as catalyst for $\mathrm{H} 2$-rich syngas production from biomass gasification. Applied Catalysis A: General. 382(2):220-230.

Ringer, M., Putsche, V. \& Scahill, J. 2006. Large-Scale Pyrolysis Oil Production: A Technology Assessment and Economic Analysis. National Renewable Energy Laboratory.

Roberts, K.G., Gloy, B.A., Joseph, S., Scott, N.R. \& Lehmann, J. 2010. Life Cycle Assessment of Biochar Systems: Estimating the Energetic, Economic, and Climate Change Potential. Environmental Science \& Technology. 44(2):827-833.

Röser, D. 2008. Sustainable use of forest biomass for energy: a synthesis with focus on the Baltic and Nordic region. D. Röser, A. Asikainen, K. Raulund-Rasmussen, \& I. Stupak (eds.). Dordrecht: Springer.

Rowell, R.M., Pettersen, R., Han, J.S., Rowell, J.S. \& Tshabalala, M.A. 2005. Cell Wall Chemistry. In R.M. Rowell (ed.) Handbook of Wood Chemistry and Wood Composites.

Roy, P. \& Dias, G. 2017. Prospects for pyrolysis technologies in the bioenergy sector: A review. Renewable and Sustainable Energy Reviews. 77:59-69.

Sandström, L., Johansson, A.C., Wiinikka, H., Öhrman, O.G.W. \& Marklund, M. 2016. Pyrolysis of Nordic biomass types in a cyclone pilot plant - Mass balances and yields. Fuel Processing Technology. 152:274-284.

Seal Water Tech. 2019. Granular Activated Carbon (GAC) Media. [Online], Available: https://www.sealwatertech.co.za/granular-activated-carbon [2019, May 14].

Serrano-Ruiz, J.-C. \& Dumesic, J.A. 2012. Catalytic production of liquid hydrocarbon transportation fuels. In L. Guczi \& A. Erdohelyi (eds.) Catalysis for Alternative Energy Generation. 29-56.

Shadangi, K.P. \& Mohanty, K. 2014a. Comparison of yield and fuel properties of thermal and catalytic Mahua seed pyrolytic oil. Fuel. 117:372-380.

Shadangi, K.P. \& Mohanty, K. 2014b. Thermal and catalytic pyrolysis of Karanja seed to produce liquid fuel. Fuel. 115:434-442.

Sharifzadeh, M., Sadeqzadeh, M., Guo, M., Borhani, T.N., Murthy, N.V.S.N., Cortada, M., Wang, L., Hallett, J., et al. 2019. The multi-scale challenges of biomass fast pyrolysis and bio-oil upgrading: Review of the state of art and future research directions. Progress in Energy and Combustion Science. 71:1-80.

Shemfe, M., Gu, S. \& Fidalgo, B. 2017. Techno-economic analysis of biofuel production via bio-oil zeolite upgrading: An evaluation of two catalyst regeneration systems. Biomass and Bioenergy. 98:182-193.

South African Petroleum Industry Association. 2017. South African fuel industry. [Online], Available: http://www.sapia.org.za/Overview/Old-fuel-prices [2017, October 20]. 
Statistics South Africa. 2019. Producer Price Index - December 2017. [Online], Available: www.statssa.gov.za [2018, October 29].

Steele, P., Puettmann, M.E., Penmetsa, V.K. \& Cooper, J.E. 2012. Life-Cycle Assessment of Pyrolysis Bio-Oil Production. Forest Products Journal. 62(4):326-334.

Stefanidis, S.D., Kalogiannis, K.G., Iliopoulou, E.F., Lappas, A.A. \& Pilavachi, P.A. 2011. In-situ upgrading of biomass pyrolysis vapors: Catalyst screening on a fixed bed reactor. Bioresource Technology. 102(17):8261-8267.

Stefanidis, S.D., Karakoulia, S.A., Kalogiannis, K.G., Iliopoulou, E.F., Delimitis, A., Yiannoulakis, H., Zampetakis, T., Lappas, A.A., et al. 2016. Natural magnesium oxide (MgO) catalysts: A costeffective sustainable alternative to acid zeolites for the in situ upgrading of biomass fast pyrolysis oil. Applied Catalysis B: Environmental. 196:155-173.

Talmadge, M.S., Baldwin, R.M., Biddy, M.J., Mccormick, R.L., Beckham, G.T., Ferguson, G.A., Czernik, S., Magrini-bair, K.A., et al. 2014. A perspective on oxygenated species in the refinery integration of pyrolysis oil. Green Chemistry. 16:407-453.

Thegarid, N., Fogassy, G., Schuurman, Y., Mirodatos, C., Stefanidis, S., Iliopoulou, E.F., Kalogiannis, K. \& Lappas, A.A. 2014. Second-generation biofuels by co-processing catalytic pyrolysis oil in FCC units. Applied Catalysis B: Environmental. 145:161-166.

Thilakaratne, R., Brown, T., Li, Y., Hu, G. \& Brown, R. 2014. Mild catalytic pyrolysis of biomass for production of transportation fuels: a techno-economic analysis. Green Chemistry. 16:627-636.

Torri, I.D.V., Paasikallio, V., Faccini, C.S., Huff, R., Caramão, E.B., Sacon, V., Oasmaa, A. \& Zini, C.A. 2016. Bio-oil production of softwood and hardwood forest industry residues through fast and intermediate pyrolysis and its chromatographic characterization. Bioresource Technology. 200:680-690.

Tripathi, M., Sahu, J.N. \& Ganesan, P. 2016. Effect of process parameters on production of biochar from biomass waste through pyrolysis: A review. Renewable and Sustainable Energy Reviews. 55:467-481.

Turton, R., Bailie, R.C., Whiting, W.B. \& Shaeiwitz, J.A. 2009. Analysis, synthesis, and design of chemical processes. Third ed. Boston: Pearson Education, Inc.

U.S. Bureau of Labor Statistics. 2019. Employment, Hours, and Earnings from the Current Employment Statistics survey (National). [Online], Available: https://data.bls.gov/pdq/SurveyOutputServlet [2019, July 02].

Van de Velden, M., Baeyens, J., Brems, A., Janssens, B. \& Dewil, R. 2010. Fundamentals, kinetics and endothermicity of the biomass pyrolysis reaction. Renewable Energy. 35:232-242.

Veses, A., Aznar, M., Martinez, I., Martinez, J.D., Lopez, J.M., Navarro, M. V., Callen, M.S., Murillo, R., et al. 2014. Catalytic pyrolysis of wood biomass in an auger reactor using calcium-based catalysts. Bioresource Technology. 162:250-258. 
Veses, A., Aznar, M., López, J.M., Callén, M.S., Murillo, R. \& García, T. 2015. Production of upgraded bio-oils by biomass catalytic pyrolysis in an auger reactor using low cost materials. Fuel. 141:17-22.

Vlysidis, A., Binns, M., Webb, C. \& Theodoropoulos, C. 2011. A techno-economic analysis of biodiesel biorefineries: Assessment of integrated designs for the co-production of fuels and chemicals. Energy. 36(8):4671-4683.

Walas, S.M. 1990. Chemical Process Equipment: Selection and Design. First ed. Boston: ButterworthHeinemann.

Wang, W. \& Jan, J. 2018. From laboratory to pilot: Design concept and techno-economic analyses of the fluidized bed fast pyrolysis of biomass. Energy. 155:139-151.

Wang, C., Li, M. \& Fang, Y. 2016. Coprocessing of Catalytic-Pyrolysis-Derived Bio-Oil with VGO in a PilotScale FCC Riser. Industrial and Engineering Chemistry Research. 55(12):3525-3534.

Wang, C., Venderbosch, R. \& Fang, Y. 2018. Co-processing of crude and hydrotreated pyrolysis liquids and VGO in a pilot scale FCC riser setup. Fuel Processing Technology. 181:157-165.

Wang, K., Dayton, D.C., Peters, J.E. \& Mante, O.D. 2017. Reactive catalytic fast pyrolysis of biomass to produce high-quality bio-crude. Green Chemistry. 19(14):3243-3251.

Wang, S., Dai, G., Yang, H. \& Luo, Z. 2017. Lignocellulosic biomass pyrolysis mechanism: A state-of-theart review. Progress in Energy and Combustion Science. 62:33-86.

Wattle Wood Farm. 2019. Firewood For Sale - Pricelist - Wattle Products. [Online], Available: http://www.wattlewood.co.za/wattlewood-firewood-prices-product-pole-prices.html] [2019, May 13].

Woods, D.R. 2007. Rules of Thumb in Engineering Practice. Weinheim: John Wiley \& Sons.

Wright, L.L., Eaton, L.M., Perlack, R.D. \& Stokes, B.J. 2012. Woody biomass. In A. Sayigh (ed.). Elsevier Comprehensive Renewable Energy. 263-291.

Wright, M.M., Satrio, J. a., Brown, R.C., Daugaard, D.E. \& Hsu, D.D. 2010. Techno-economic analysis of biomass fast pyrolysis to transportation fuels. National Renewable Energy Laboratory.

Yang, C., Li, R. \& Zhang, B. 2016. Biomass harvesting and collection. In J.B. Holm-Nielsen \& E.A. Ehimen (eds.). Elsevier Biomass Supply Chains for Bioenergy and Biorefining. 103-125.

Yang, H., Kudo, S., Kuo, H., Norinaga, K., Mori, A., Ondrej, M. \& Hayashi, J. 2013. Estimation of Enthalpy of Bio-Oil Vapor and Heat Required for Pyrolysis of Biomass. Energy and Fuels. 27:2675-2686.

Yang, Y., Heaven, S., Venetsaneas, N., Banks, C.J. \& Bridgwater, A. V. 2018. Slow pyrolysis of organic fraction of municipal solid waste (OFMSW): Characterisation of products and screening of the aqueous liquid product for anaerobic digestion. Applied Energy. 213:158-168.

Yildiz, G., Ronsse, F., Duren, R. Van \& Prins, W. 2016. Challenges in the design and operation of processes for catalytic fast pyrolysis of woody biomass. Renewable and Sustainable Energy Reviews. 57:1596-1610. 
Zhang, M., Resende, F.L.P. \& Moutsoglou, A. 2014. Catalytic fast pyrolysis of aspen lignin via Py-GC/MS. Fuel. 116:358-369.

Zhang, S., Yan, Y., Li, T. \& Ren, Z. 2005. Upgrading of liquid fuel from the pyrolysis of biomass. Bioresource Technology. 96(5):545-550.

Zhao, B., Zhang, X., Chen, L., Sun, L., Si, H. \& Chen, G. 2014. High quality fuel gas from biomass pyrolysis with calcium oxide. Bioresource Technology. 156:78-83. 


\section{Appendices}

\subsection{Appendix A}

Table A1: Pilot plant results for non-catalytic pyrolysis

\begin{tabular}{|c|c|c|c|c|c|c|c|c|c|}
\hline & & Feed & Char & C1 & C2A & C2O & C3 & C4 & Gas \\
\hline $\begin{array}{l}\text { Yield } \\
\text { (wt. \%) }\end{array}$ & & & 28.71 & 8.34 & 19.96 & 4.92 & 4.13 & 2.42 & 20.62 \\
\hline \multirow{5}{*}{$\begin{array}{l}\text { Elemental } \\
\text { Analysis } \\
\text { (wt. \%, db) }\end{array}$} & C & 48.01 & 83.15 & 44.31 & 42.51 & 71.80 & 67.46 & 74.24 & \\
\hline & $\mathrm{H}$ & 6.36 & 3.40 & 8.02 & 4.98 & 6.67 & 8.74 & 6.91 & \\
\hline & 0 & 45.46 & 13.04 & 47.67 & 52.51 & 21.29 & 23.79 & 18.85 & \\
\hline & $\mathrm{N}$ & 0.12 & 0.34 & 0.00 & 0.00 & 0.23 & 0.00 & 0.00 & \\
\hline & $S$ & 0.06 & 0.08 & 0.00 & 0.00 & 0.00 & 0.00 & 0.00 & \\
\hline \multirow{4}{*}{$\begin{array}{l}\text { Proximate } \\
\text { analysis } \\
\text { (wt. \%) }\end{array}$} & Moisture & 8.28 & 0.00 & 8.73 & 87.17 & 18.00 & 26.09 & 21.39 & \\
\hline & Fixed carbon & 15.06 & 77.42 & & & & & & \\
\hline & Volatile matter & 75.70 & 19.27 & & & & & & \\
\hline & Ash & 0.95 & 3.32 & & & & & & \\
\hline $\begin{array}{l}\text { HHV } \\
(\mathrm{MJ} / \mathrm{kg}, \mathrm{db})\end{array}$ & & 19.33 & & 22.10 & & 29.08 & 30.17 & 32.63 & \\
\hline $\begin{array}{l}\text { Density } \\
\left(\mathrm{kg} / \mathrm{m}^{3}, \mathrm{db}\right)\end{array}$ & & & & 1184 & 1288 & 1041 & 1117 & 1234 & \\
\hline \multirow{8}{*}{$\begin{array}{l}\text { Composition } \\
\text { (wt. \%) }\end{array}$} & $\mathrm{CO}_{2}$ & & & & & & & & 50.34 \\
\hline & $\mathrm{CO}$ & & & & & & & & 33.98 \\
\hline & $\mathrm{CH}_{4}$ & & & & & & & & 8.54 \\
\hline & $\mathrm{H}_{2}$ & & & & & & & & 0.57 \\
\hline & $\mathrm{C}_{2} \mathrm{H}_{6}$ & & & & & & & & 3.74 \\
\hline & $\mathrm{C}_{2} \mathrm{H}_{4}$ & & & & & & & & 1.11 \\
\hline & $\mathrm{C}_{3} \mathrm{H}_{8}$ & & & & & & & & 1.11 \\
\hline & $\mathrm{C}_{4} \mathrm{H}_{6}$ & & & & & & & & 0.61 \\
\hline
\end{tabular}


Table A2: Pilot plant results for catalytic pyrolysis

\begin{tabular}{|c|c|c|c|c|c|c|c|c|c|c|}
\hline & & Feed & Char & $\begin{array}{c}\mathrm{CO}_{2} \\
\left(\mathrm{CaCO}_{3}\right)\end{array}$ & C1 & C2A & C2O & C3 & C4 & Gas \\
\hline $\begin{array}{l}\text { Yield } \\
\text { (wt. \%) }\end{array}$ & & & 16.48 & 20.85 & 10.00 & 15.70 & 3.73 & 2.77 & 1.90 & 17.63 \\
\hline \multirow{5}{*}{$\begin{array}{l}\text { Elemental } \\
\text { Analysis } \\
\text { (wt. \%, db) }\end{array}$} & C & 48.01 & 79.37 & & 79.67 & 28.90 & 80.64 & 60.56 & 82.10 & \\
\hline & $\mathrm{H}$ & 6.36 & 3.37 & & 7.11 & 6.46 & 6.09 & 6.14 & 7.29 & \\
\hline & 0 & 45.46 & 16.58 & & 12.78 & 63.28 & 13.23 & 32.42 & 10.38 & \\
\hline & $\mathrm{N}$ & 0.12 & 0.68 & & 0.44 & 1.36 & 0.05 & 0.88 & 0.22 & \\
\hline & $S$ & 0.06 & 0.00 & & 0.00 & 0.00 & 0.00 & 0.00 & 0.00 & \\
\hline \multirow{4}{*}{$\begin{array}{l}\text { Proximate } \\
\text { analysis } \\
\text { (wt. \%) }\end{array}$} & Moisture & 8.28 & 0.00 & & 22.78 & 86.60 & 13.82 & 58.97 & 17.01 & \\
\hline & Fixed carbon & 15.06 & 56.25 & & & & & & & \\
\hline & Volatile matter & 75.70 & 37.98 & & & & & & & \\
\hline & Ash & 0.95 & 5.77 & & & & & & & \\
\hline $\begin{array}{l}\text { HHV } \\
(\mathrm{MJ} / \mathrm{kg}, \mathrm{db})\end{array}$ & & 19.33 & & & 35.37 & & 34.61 & 25.93 & 37.84 & \\
\hline $\begin{array}{l}\text { Density } \\
\left(\mathrm{kg} / \mathrm{m}^{3}, \mathrm{db}\right)\end{array}$ & & & & & 1152 & 1198 & 1040 & 1031 & 1042 & \\
\hline \multirow{8}{*}{$\begin{array}{l}\text { Composition } \\
\text { (wt. \%) }\end{array}$} & $\mathrm{CO}_{2}$ & & & & & & & & & 22.11 \\
\hline & $\mathrm{CO}$ & & & & & & & & & 40.45 \\
\hline & $\mathrm{CH}_{4}$ & & & & & & & & & 15.32 \\
\hline & $\mathrm{H}_{2}$ & & & & & & & & & 2.29 \\
\hline & $\mathrm{C}_{2} \mathrm{H}_{6}$ & & & & & & & & & 13.57 \\
\hline & $\mathrm{C}_{2} \mathrm{H}_{4}$ & & & & & & & & & 1.93 \\
\hline & $\mathrm{C}_{3} \mathrm{H}_{8}$ & & & & & & & & & 3.41 \\
\hline & $\mathrm{C}_{4} \mathrm{H}_{6}$ & & & & & & & & & 0.92 \\
\hline
\end{tabular}




\subsection{Appendix B}

Table B1: Stream Table for Biorefinery Scenario NC-100

\begin{tabular}{|c|c|c|c|c|c|c|c|c|c|c|}
\hline Stream & & 홍 & ิㅗㅇ & m̊ & ষ্ণ & ํㅗㅇ & ஜ̊ & ఫิ & ஜ̊ㅇ & ஜㅇ \\
\hline Temperature & C & 25 & 58 & 130 & 131 & 51 & 51 & 100 & 100 & 100 \\
\hline Pressure & BAR & 1.01 & 1.01 & 1.29 & 1.3 & 1.01 & 1.01 & 1.01 & 1.01 & 1.01 \\
\hline Mass Flow & KG/H & 9384.5 & 9384.5 & 28658.8 & 28658.8 & 29847 & 8196.3 & 8196.3 & 6926.2 & 1270.1 \\
\hline \multicolumn{11}{|c|}{ Component Mass Flow } \\
\hline $\mathrm{CO} 2$ & KG/H & 0 & 0 & 7664.2 & 7664.2 & 7656.5 & 7.7 & 7.7 & 7.7 & 0 \\
\hline N2 & KG/H & 0 & 0 & 18924 & 18924 & 18918.9 & 5.2 & 5.2 & 5.1 & 0 \\
\hline $\mathrm{O} 2$ & KG/H & 0 & 0 & 957.5 & 957.5 & 957.1 & 0.4 & 0.4 & 0.4 & 0 \\
\hline $\mathrm{H} 2 \mathrm{O}$ & KG/H & 9384.5 & 9384.5 & 1113.1 & 1113.1 & 2314.5 & 8183.1 & 8183.1 & 6913.1 & 1270 \\
\hline Mass Enthalpy & $\mathrm{MJ} / \mathrm{KG}$ & -15.9 & -15.7 & -2.8 & -2.8 & -3.3 & -15.7 & -13.6 & -13.3 & -15.5 \\
\hline \multicolumn{11}{|c|}{ Substream: NCPSD } \\
\hline \multicolumn{11}{|c|}{ Component Mass Flow } \\
\hline EGRANDIS & KG/H & 14076.7 & 14076.7 & 0 & 0 & 0 & 14076.7 & 14076.7 & 0 & 14076.7 \\
\hline
\end{tabular}

Table B1: Stream Table for Biorefinery Scenario NC-100 (continued...)

\begin{tabular}{|c|c|c|c|c|c|c|c|c|c|c|}
\hline Stream & & ণ্் & ర్తి & 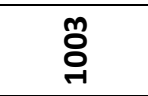 & ఫ্] & 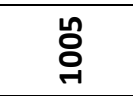 & ঃ & ڤ్తి & $\stackrel{\infty}{\circ}$ & 음 \\
\hline Temperature & C & 0 & 25 & 25 & 25 & 25 & 25 & 25 & 100 & 100 \\
\hline Pressure & BAR & 0 & 1.01 & 1.01 & 1.01 & 1.01 & 1.01 & 1.01 & 1.01 & 1.01 \\
\hline Mass Flow & KG/H & 0 & 9384.5 & 9384.5 & 9384.5 & 9384.5 & 8113.4 & 1271 & 1271 & 1271 \\
\hline \multicolumn{11}{|c|}{ Component Mass Flow } \\
\hline $\mathrm{H} 2 \mathrm{O}$ & KG/H & 0 & 9384.5 & 9384.5 & 9384.5 & 9384.5 & 8113.4 & 1271 & 1271 & 1271 \\
\hline Mass Enthalpy & $\mathrm{MJ} / \mathrm{KG}$ & 0 & -15.9 & -15.9 & -15.9 & -15.9 & -15.9 & -15.9 & -15.5 & -15.5 \\
\hline \multicolumn{11}{|c|}{ Substream: NCPSD } \\
\hline EGRANDIS & KG/H & 14076.7 & 0 & 14076.7 & 14076.7 & 14076.7 & 0 & 14076.7 & 14076.7 & 14076.7 \\
\hline
\end{tabular}


Table B1: Stream Table for Biorefinery Scenario NC-100 (continued...)

\begin{tabular}{|c|c|c|c|c|c|c|c|c|c|c|}
\hline Stream & & 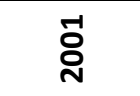 & ণ্ণ & $\stackrel{m}{\text { ஜn }}$ & ర্ & ํํ & ஜ & 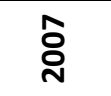 & $\stackrel{\infty}{\stackrel{N}{~}}$ & ষ্ণ \\
\hline Temperature & C & 100 & 500 & 500 & 500 & 500 & 0 & 0 & 0 & 0 \\
\hline Pressure & BAR & 1.01 & 1.01 & 1.01 & 1.01 & 1.01 & 0 & 0 & 0 & 0 \\
\hline Mass Flow & $\mathrm{KG} / \mathrm{H}$ & 1271 & 10904.3 & 10904.3 & 10904 & 10904 & 0 & 0 & 0 & 0 \\
\hline \multicolumn{11}{|c|}{ Component Mass Flow } \\
\hline $\mathrm{CO} 2$ & $\mathrm{KG} / \mathrm{H}$ & 0 & 2342.5 & 2342.5 & 2342.5 & 2343 & 0 & 0 & 0 & 0 \\
\hline $\mathrm{CO}$ & $\mathrm{KG} / \mathrm{H}$ & 0 & 1326.5 & 1326.5 & 1326.5 & 1327 & 0 & 0 & 0 & 0 \\
\hline $\mathrm{H} 2$ & $\mathrm{KG} / \mathrm{H}$ & 0 & 206.9 & 206.9 & 206.9 & 206.9 & 0 & 0 & 0 & 0 \\
\hline $\mathrm{CH} 4$ & $\mathrm{KG} / \mathrm{H}$ & 0 & 58.6 & 58.6 & 58.6 & 58.6 & 0 & 0 & 0 & 0 \\
\hline ETHYLENE & $\mathrm{KG} / \mathrm{H}$ & 0 & 31.6 & 31.6 & 31.6 & 31.6 & 0 & 0 & 0 & 0 \\
\hline ETHANE & $\mathrm{KG} / \mathrm{H}$ & 0 & 22.2 & 22.2 & 22.2 & 22.2 & 0 & 0 & 0 & 0 \\
\hline BUTANE & $\mathrm{KG} / \mathrm{H}$ & 0 & 5 & 5 & 5 & 5 & 0 & 0 & 0 & 0 \\
\hline PROPANE & $\mathrm{KG} / \mathrm{H}$ & 0 & 5 & 5 & 5 & 5 & 0 & 0 & 0 & 0 \\
\hline CROTONIC & KG/H & 0 & 105.2 & 105.2 & 105.2 & 105.2 & 0 & 0 & 0 & 0 \\
\hline 3-METHOX & $\mathrm{KG} / \mathrm{H}$ & 0 & 37 & 37 & 37 & 37 & 0 & 0 & 0 & 0 \\
\hline $\mathrm{H} 2 \mathrm{O}$ & KG/H & 1271 & 3594.7 & 3594.7 & 3594.7 & 3595 & 0 & 0 & 0 & 0 \\
\hline LIGNINA & KG/H & 0 & 56.3 & 56.3 & 56.3 & 56.3 & 0 & 0 & 0 & 0 \\
\hline BENZDIOL & $\mathrm{KG} / \mathrm{H}$ & 0 & 155.3 & 155.3 & 155.3 & 155.3 & 0 & 0 & 0 & 0 \\
\hline ACETOL & $\mathrm{KG} / \mathrm{H}$ & 0 & 625.7 & 625.7 & 625.7 & 625.7 & 0 & 0 & 0 & 0 \\
\hline ISOEUGEN & $\mathrm{KG} / \mathrm{H}$ & 0 & 40.3 & 40.3 & 40.3 & 40.3 & 0 & 0 & 0 & 0 \\
\hline LEVOG-01 & $\mathrm{KG} / \mathrm{H}$ & 0 & 214.8 & 214.8 & 214.8 & 214.8 & 0 & 0 & 0 & 0 \\
\hline FURAN & KG/H & 0 & 250.5 & 250.5 & 250.5 & 250.5 & 0 & 0 & 0 & 0 \\
\hline CELLO-01 & $\mathrm{KG} / \mathrm{H}$ & 0 & 399.8 & 399.8 & 399.8 & 399.8 & 0 & 0 & 0 & 0 \\
\hline DIMETHOX & $\mathrm{KG} / \mathrm{H}$ & 0 & 102.9 & 102.9 & 102.9 & 102.9 & 0 & 0 & 0 & 0 \\
\hline ABIETIC & $\mathrm{KG} / \mathrm{H}$ & 0 & 125.5 & 125.5 & 125.5 & 125.5 & 0 & 0 & 0 & 0 \\
\hline LIGNINB & $\mathrm{KG} / \mathrm{H}$ & 0 & 55.8 & 55.8 & 55.8 & 55.8 & 0 & 0 & 0 & 0 \\
\hline ACETIC & KG/H & 0 & 529.1 & 529.1 & 529.1 & 529.1 & 0 & 0 & 0 & 0 \\
\hline GUAIA-01 & $\mathrm{KG} / \mathrm{H}$ & 0 & 34.9 & 34.9 & 34.9 & 34.9 & 0 & 0 & 0 & 0 \\
\hline SYRIN-01 & $\mathrm{KG} / \mathrm{H}$ & 0 & 40.3 & 40.3 & 40.3 & 40.3 & 0 & 0 & 0 & 0 \\
\hline FORMI-01 & $\mathrm{KG} / \mathrm{H}$ & 0 & 175.6 & 175.6 & 175.6 & 175.6 & 0 & 0 & 0 & 0 \\
\hline N-PRO-01 & $\mathrm{KG} / \mathrm{H}$ & 0 & 41.2 & 41.2 & 41.2 & 41.2 & 0 & 0 & 0 & 0 \\
\hline PHENO-01 & $\mathrm{KG} / \mathrm{H}$ & 0 & 97.6 & 97.6 & 97.6 & 97.6 & 0 & 0 & 0 & 0 \\
\hline TOLUE-01 & $\mathrm{KG} / \mathrm{H}$ & 0 & 33.8 & 33.8 & 33.8 & 33.8 & 0 & 0 & 0 & 0 \\
\hline FURFU-01 & $\mathrm{KG} / \mathrm{H}$ & 0 & 80.4 & 80.4 & 80.4 & 80.4 & 0 & 0 & 0 & 0 \\
\hline BENZE-01 & $\mathrm{KG} / \mathrm{H}$ & 0 & 109.1 & 109.1 & 109.1 & 109.1 & 0 & 0 & 0 & 0 \\
\hline Mass Enthalpy & $\mathrm{MJ} / \mathrm{KG}$ & -15.5 & -7.3 & -7.3 & -7.3 & -7.3 & 0 & 0 & 0 & 0 \\
\hline \multicolumn{11}{|c|}{ Substream: NCPSD } \\
\hline \multicolumn{11}{|c|}{ Component Mass Flow } \\
\hline CHAR & $\mathrm{KG} / \mathrm{H}$ & 0 & 4412.9 & 4412.9 & 4412.9 & 0 & 4412.9 & 948.8 & 3464.1 & 3464.1 \\
\hline EGRANDIS & $\mathrm{KG} / \mathrm{H}$ & 14076.7 & 0 & 0 & 0 & 0 & 0 & 0 & 0 & 0 \\
\hline BALANCE & $\mathrm{KG} / \mathrm{H}$ & 0 & 30.6 & 30.6 & 30.6 & 0 & 30.6 & 6.6 & 24 & 24 \\
\hline
\end{tabular}


Table B1: Stream Table for Biorefinery Scenario NC-100 (continued...)

\begin{tabular}{|c|c|c|c|c|c|c|c|c|c|c|c|}
\hline Stream & & ర్తి & 용 & ஜ̊ & ষ্ণ & 옹 & ஜீ & 옹 & $\stackrel{\infty}{\circ}$ & 용 & 움 \\
\hline Temperature & $\mathrm{C}$ & 500 & 260 & 210 & 80 & 80 & 80 & 60 & 60 & 60 & 60 \\
\hline Pressure & BAR & 1.01 & 1.01 & 1.01 & 1.01 & 1.01 & 1.01 & 1.01 & 1.01 & 1.01 & 1.01 \\
\hline Mass Flow & $\mathrm{KG} / \mathrm{H}$ & 10904.3 & 10904.3 & 10904 & 10904 & 1681.3 & 9223 & 9223 & 4189.6 & 765.8 & 3423.8 \\
\hline \multicolumn{12}{|c|}{ Component Mass Flow } \\
\hline $\mathrm{CO} 2$ & KG/H & 2342.5 & 2342.5 & 2342.5 & 2342.5 & 0 & 2342.5 & 2343 & 0 & 0 & 0 \\
\hline $\mathrm{CO}$ & $\mathrm{KG} / \mathrm{H}$ & 1326.5 & 1326.5 & 1326.5 & 1326.5 & 0 & 1326.5 & 1327 & 0 & 0 & 0 \\
\hline $\mathrm{H} 2$ & $\mathrm{KG} / \mathrm{H}$ & 206.9 & 206.9 & 206.9 & 206.9 & 0 & 206.9 & 206.9 & 0 & 0 & 0 \\
\hline $\mathrm{CH} 4$ & $\mathrm{KG} / \mathrm{H}$ & 58.6 & 58.6 & 58.6 & 58.6 & 0 & 58.6 & 58.6 & 0 & 0 & 0 \\
\hline ETHYLENE & $\mathrm{KG} / \mathrm{H}$ & 31.6 & 31.6 & 31.6 & 31.6 & 0 & 31.6 & 31.6 & 0 & 0 & 0 \\
\hline ETHANE & $\mathrm{KG} / \mathrm{H}$ & 22.2 & 22.2 & 22.2 & 22.2 & 0 & 22.2 & 22.2 & 0 & 0 & 0 \\
\hline BUTANE & $\mathrm{KG} / \mathrm{H}$ & 5 & 5 & 5 & 5 & 0 & 5 & 5 & 0 & 0 & 0 \\
\hline PROPANE & $\mathrm{KG} / \mathrm{H}$ & 5 & 5 & 5 & 5 & 0 & 5 & 5 & 0 & 0 & 0 \\
\hline CROTONIC & $\mathrm{KG} / \mathrm{H}$ & 105.2 & 105.2 & 105.2 & 105.2 & 79.2 & 26.1 & 26.1 & 26.1 & 26.1 & 0 \\
\hline 3-METHOX & $\mathrm{KG} / \mathrm{H}$ & 37 & 37 & 37 & 37 & 34.5 & 2.5 & 2.5 & 2.4 & 2.3 & 0.2 \\
\hline $\mathrm{H} 2 \mathrm{O}$ & $\mathrm{KG} / \mathrm{H}$ & 3594.7 & 3594.7 & 3594.7 & 3594.7 & 127 & 3467.7 & 3468 & 3189.2 & 154.4 & 3034.7 \\
\hline LIGNINA & $\mathrm{KG} / \mathrm{H}$ & 56.3 & 56.3 & 56.3 & 56.3 & 0 & 56.3 & 56.3 & 56.3 & 56.3 & 0 \\
\hline BENZDIOL & $\mathrm{KG} / \mathrm{H}$ & 155.3 & 155.3 & 155.3 & 155.3 & 0 & 155.3 & 155.3 & 155.2 & 155.1 & 0.1 \\
\hline ACETOL & $\mathrm{KG} / \mathrm{H}$ & 625.7 & 625.7 & 625.7 & 625.7 & 527.5 & 98.3 & 98.3 & 2.3 & 2.3 & 0 \\
\hline ISOEUGEN & $\mathrm{KG} / \mathrm{H}$ & 40.3 & 40.3 & 40.3 & 40.3 & 0 & 40.3 & 40.3 & 40.2 & 40.2 & 0 \\
\hline LEVOG-01 & $\mathrm{KG} / \mathrm{H}$ & 214.8 & 214.8 & 214.8 & 214.8 & 102.7 & 112.1 & 112.1 & 112 & 2.4 & 109.6 \\
\hline FURAN & $\mathrm{KG} / \mathrm{H}$ & 250.5 & 250.5 & 250.5 & 250.5 & 0 & 250.5 & 250.5 & 249.3 & 228.2 & 21.2 \\
\hline CELLO-01 & $\mathrm{KG} / \mathrm{H}$ & 399.8 & 399.8 & 399.8 & 399.8 & 267.5 & 132.2 & 132.2 & 28.1 & 2.5 & 25.6 \\
\hline DIMETHOX & $\mathrm{KG} / \mathrm{H}$ & 102.9 & 102.9 & 102.9 & 102.9 & 0 & 102.9 & 102.9 & 10.8 & 10.6 & 0.3 \\
\hline ABIETIC & $\mathrm{KG} / \mathrm{H}$ & 125.5 & 125.5 & 125.5 & 125.5 & 0 & 125.5 & 125.5 & 1.5 & 1.3 & 0.3 \\
\hline LIGNINB & $\mathrm{KG} / \mathrm{H}$ & 55.8 & 55.8 & 55.8 & 55.8 & 0 & 55.8 & 55.8 & 1.9 & 1.9 & 0 \\
\hline ACETIC & $\mathrm{KG} / \mathrm{H}$ & 529.1 & 529.1 & 529.1 & 529.1 & 525.9 & 3.2 & 3.2 & 3.1 & 3.1 & 0 \\
\hline GUAIA-01 & $\mathrm{KG} / \mathrm{H}$ & 34.9 & 34.9 & 34.9 & 34.9 & 0 & 34.9 & 34.9 & 2 & 2 & 0 \\
\hline SYRIN-01 & $\mathrm{KG} / \mathrm{H}$ & 40.3 & 40.3 & 40.3 & 40.3 & 0 & 40.3 & 40.3 & 40.2 & 40.2 & 0 \\
\hline FORMI-01 & $\mathrm{KG} / \mathrm{H}$ & 175.6 & 175.6 & 175.6 & 175.6 & 17 & 158.6 & 158.6 & 158.5 & 4.4 & 154.1 \\
\hline N-PRO-01 & $\mathrm{KG} / \mathrm{H}$ & 41.2 & 41.2 & 41.2 & 41.2 & 0 & 41.2 & 41.2 & 21.1 & 21.1 & 0 \\
\hline PHENO-01 & $\mathrm{KG} / \mathrm{H}$ & 97.6 & 97.6 & 97.6 & 97.6 & 0 & 97.6 & 97.6 & 1.7 & 1.7 & 0 \\
\hline TOLUE-01 & $\mathrm{KG} / \mathrm{H}$ & 33.8 & 33.8 & 33.8 & 33.8 & 0 & 33.8 & 33.8 & 6.5 & 6.5 & 0 \\
\hline FURFU-01 & $\mathrm{KG} / \mathrm{H}$ & 80.4 & 80.4 & 80.4 & 80.4 & 0 & 80.4 & 80.4 & 80 & 2.3 & 77.8 \\
\hline BENZE-01 & $\mathrm{KG} / \mathrm{H}$ & 109.1 & 109.1 & 109.1 & 109.1 & 0 & 109.1 & 109.1 & 1.1 & 1.1 & 0 \\
\hline Mass Enthalpy & $\mathrm{MJ} / \mathrm{KG}$ & -7.3 & -7.8 & -7.9 & -8.4 & -7.1 & -8.5 & -9.1 & -12.8 & -4.8 & -14.6 \\
\hline
\end{tabular}


Table B1: Stream Table for Biorefinery Scenario NC-100 (continued...)

\begin{tabular}{|c|c|c|c|c|c|c|c|c|c|c|c|c|}
\hline Stream & & 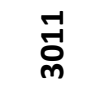 & 궁 & $\underset{m}{\stackrel{m}{8}}$ & $\underset{\text { 峁 }}{+}$ & $\stackrel{n}{\stackrel{n}{\circ}}$ & $\begin{array}{l}0 \\
-1 \\
\end{array}$ & 공 & $\underset{\text { D্ }}{\infty}$ & ్ㅗㅇ & ్ㅗㅇ & స్తి \\
\hline Temperature & $\mathrm{C}$ & 60 & 40 & 40 & 40 & 20 & 20 & 45 & 20 & 65 & 65 & 65 \\
\hline Pressure & BAR & 1.01 & 1.01 & 1.01 & 1.01 & 1.01 & 1.01 & 1.3 & 1.01 & 1.01 & 2 & 2 \\
\hline Mass Flow & $\mathrm{KG} / \mathrm{H}$ & 5034 & 5033.5 & 652.4 & 4381.1 & 4381.1 & 3998 & 3998.4 & 382.7 & 3482.1 & 3482 & 3482.1 \\
\hline \multicolumn{13}{|c|}{ Component Mass Flow } \\
\hline $\mathrm{CO} 2$ & $\mathrm{KG} / \mathrm{H}$ & 2343 & 2342.5 & 0 & 2342.5 & 2342.5 & 2343 & 2342.5 & 0 & 0 & 0 & 0 \\
\hline $\mathrm{CO}$ & $\mathrm{KG} / \mathrm{H}$ & 1327 & 1326.5 & 0 & 1326.5 & 1326.5 & 1327 & 1326.5 & 0 & 0 & 0 & 0 \\
\hline $\mathrm{H} 2$ & $\mathrm{KG} / \mathrm{H}$ & 206.9 & 206.9 & 0 & 206.9 & 206.9 & 206.9 & 206.9 & 0 & 0 & 0 & 0 \\
\hline $\mathrm{CH} 4$ & $\mathrm{KG} / \mathrm{H}$ & 58.6 & 58.6 & 0 & 58.6 & 58.6 & 58.6 & 58.6 & 0 & 0 & 0 & 0 \\
\hline ETHYLENE & $\mathrm{KG} / \mathrm{H}$ & 31.6 & 31.6 & 0 & 31.6 & 31.6 & 31.6 & 31.6 & 0 & 0 & 0 & 0 \\
\hline ETHANE & $\mathrm{KG} / \mathrm{H}$ & 22.2 & 22.2 & 0 & 22.2 & 22.2 & 22.2 & 22.2 & 0 & 0 & 0 & 0 \\
\hline BUTANE & $\mathrm{KG} / \mathrm{H}$ & 5 & 5 & 0 & 5 & 5 & 5 & 5 & 0 & 0 & 0 & 0 \\
\hline PROPANE & $\mathrm{KG} / \mathrm{H}$ & 5 & 5 & 0 & 5 & 5 & 5 & 5 & 0 & 0 & 0 & 0 \\
\hline CROTONIC & $\mathrm{KG} / \mathrm{H}$ & 0 & 0 & 0 & 0 & 0 & 0 & 0 & 0 & 105.2 & 105.2 & 105.2 \\
\hline 3-METHOX & $\mathrm{KG} / \mathrm{H}$ & 0.1 & 0.1 & 0 & 0.1 & 0.1 & 0 & 0 & 0.1 & 36.8 & 36.8 & 36.8 \\
\hline $\mathrm{H} 2 \mathrm{O}$ & $\mathrm{KG} / \mathrm{H}$ & 278.6 & 278.6 & 188.1 & 90.4 & 90.4 & 0 & 0 & 90.4 & 560 & 560 & 560 \\
\hline LIGNINA & $\mathrm{KG} / \mathrm{H}$ & 0 & 0 & 0 & 0 & 0 & 0 & 0 & 0 & 56.3 & 56.3 & 56.3 \\
\hline BENZDIOL & $\mathrm{KG} / \mathrm{H}$ & 0.2 & 0.2 & 0 & 0.2 & 0.2 & 0 & 0 & 0.2 & 155.2 & 155.2 & 155.2 \\
\hline ACETOL & $\mathrm{KG} / \mathrm{H}$ & 95.9 & 95.9 & 95.9 & 0 & 0 & 0 & 0 & 0 & 625.7 & 625.7 & 625.7 \\
\hline ISOEUGEN & $\mathrm{KG} / \mathrm{H}$ & 0.1 & 0.1 & 0 & 0.1 & 0.1 & 0 & 0 & 0.1 & 40.3 & 40.3 & 40.3 \\
\hline LEVOG-01 & $\mathrm{KG} / \mathrm{H}$ & 0 & 0 & 0 & 0 & 0 & 0 & 0 & 0 & 105.2 & 105.2 & 105.2 \\
\hline FURAN & $\mathrm{KG} / \mathrm{H}$ & 1.1 & 1.1 & 0 & 1.1 & 1.1 & 0 & 0 & 1.1 & 229.3 & 229.3 & 229.3 \\
\hline CELLO-01 & $\mathrm{KG} / \mathrm{H}$ & 104.1 & 104.1 & 48.1 & 56.1 & 56.1 & 0 & 0 & 56.1 & 374.2 & 374.2 & 374.2 \\
\hline DIMETHOX & $\mathrm{KG} / \mathrm{H}$ & 92 & 92 & 91.9 & 0.1 & 0.1 & 0 & 0 & 0.1 & 102.6 & 102.6 & 102.6 \\
\hline ABIETIC & $\mathrm{KG} / \mathrm{H}$ & 124 & 124 & 124 & 0.1 & 0.1 & 0 & 0 & 0.1 & 125.3 & 125.3 & 125.3 \\
\hline LIGNINB & $\mathrm{KG} / \mathrm{H}$ & 54 & 54 & 24.1 & 29.8 & 29.8 & 0 & 0 & 29.8 & 55.8 & 55.8 & 55.8 \\
\hline ACETIC & $\mathrm{KG} / \mathrm{H}$ & 0.1 & 0.1 & 0 & 0.1 & 0.1 & 0 & 0 & 0.1 & 529.1 & 529.1 & 529.1 \\
\hline GUAIA-01 & $\mathrm{KG} / \mathrm{H}$ & 32.9 & 32.9 & 32.9 & 0 & 0 & 0 & 0 & 0 & 34.9 & 34.9 & 34.9 \\
\hline SYRIN-01 & $\mathrm{KG} / \mathrm{H}$ & 0.1 & 0.1 & 0 & 0.1 & 0.1 & 0 & 0 & 0.1 & 40.3 & 40.3 & 40.3 \\
\hline FORMI-01 & $\mathrm{KG} / \mathrm{H}$ & 0.1 & 0.1 & 0 & 0.1 & 0.1 & 0 & 0 & 0.1 & 21.5 & 21.5 & 21.5 \\
\hline N-PRO-01 & $\mathrm{KG} / \mathrm{H}$ & 20.1 & 20.1 & 20.1 & 0 & 0 & 0 & 0 & 0 & 41.2 & 41.2 & 41.2 \\
\hline PHENO-01 & $\mathrm{KG} / \mathrm{H}$ & 95.9 & 95.9 & 0 & 95.9 & 95.9 & 0 & 0 & 95.9 & 97.6 & 97.6 & 97.6 \\
\hline TOLUE-01 & $\mathrm{KG} / \mathrm{H}$ & 27.2 & 27.2 & 27.2 & 0 & 0 & 0 & 0 & 0 & 33.8 & 33.8 & 33.8 \\
\hline FURFU-01 & $\mathrm{KG} / \mathrm{H}$ & 0.4 & 0.4 & 0 & 0.4 & 0.4 & 0 & 0 & 0.4 & 2.7 & 2.7 & 2.7 \\
\hline BENZE-01 & $\mathrm{KG} / \mathrm{H}$ & 108 & 108 & 0 & 108 & 108 & 0 & 0 & 108 & 109.1 & 109.1 & 109.1 \\
\hline $\begin{array}{l}\text { Mass } \\
\text { Enthalpy }\end{array}$ & $\mathrm{MJ} / \mathrm{KG}$ & -6.3 & -6.4 & -6.6 & -6.4 & -6.5 & -6.6 & -6.6 & -5.3 & -6.3 & -6.3 & -6.3 \\
\hline
\end{tabular}


Table B1: Stream Table for Biorefinery Scenario NC-100 (continued...)

\begin{tabular}{|c|c|c|c|c|c|c|c|c|c|c|c|}
\hline Stream & & ర্口 & ర్ & mo & ষ্ণ & 옹 & ஜ̊ & )े & : & ষ্ণ & 웅 \\
\hline Temperature & C & 500 & 56 & 25 & 52 & 259 & 865 & 800 & 300 & 130 & 130 \\
\hline Pressure & BAR & 1.01 & 1.3 & 1.01 & 1.3 & 1.3 & 1.3 & 1.3 & 1.29 & 1.29 & 1.29 \\
\hline Mass Flow & $\mathrm{KG} / \mathrm{H}$ & 824.3 & 3164.4 & 24670.1 & 24670.1 & 24670.1 & 28658.8 & 28658.8 & 28658.8 & 28658.8 & 28659 \\
\hline \multicolumn{12}{|c|}{ Component Mass Flow } \\
\hline $\mathrm{CO} 2$ & $\mathrm{KG} / \mathrm{H}$ & 0 & 1593.1 & 0 & 0 & 0 & 7664.2 & 7664.2 & 7664.2 & 7664 & 7664.2 \\
\hline $\mathrm{CO}$ & $\mathrm{KG} / \mathrm{H}$ & 0 & 1075.2 & 0 & 0 & 0 & 0 & 0 & 0 & 0 & 0 \\
\hline $\mathrm{H} 2$ & KG/H & 0 & 18 & 0 & 0 & 0 & 0 & 0 & 0 & 0 & 0 \\
\hline $\mathrm{CH} 4$ & $\mathrm{KG} / \mathrm{H}$ & 0 & 270.2 & 0 & 0 & 0 & 0 & 0 & 0 & 0 & 0 \\
\hline ETHYLENE & $\mathrm{KG} / \mathrm{H}$ & 0 & 35.2 & 0 & 0 & 0 & 0 & 0 & 0 & 0 & 0 \\
\hline ETHANE & $\mathrm{KG} / \mathrm{H}$ & 0 & 118.4 & 0 & 0 & 0 & 0 & 0 & 0 & 0 & 0 \\
\hline BUTANE & $\mathrm{KG} / \mathrm{H}$ & 0 & 19.3 & 0 & 0 & 0 & 0 & 0 & 0 & 0 & 0 \\
\hline PROPANE & KG/H & 0 & 35 & 0 & 0 & 0 & 0 & 0 & 0 & 0 & 0 \\
\hline N2 & KG/H & 0 & 0 & 18924 & 18924 & 18924 & 18924 & 18924 & 18924 & 18924 & 18924 \\
\hline $\mathrm{O} 2$ & $\mathrm{KG} / \mathrm{H}$ & 0 & 0 & 5746.1 & 5746.1 & 5746.1 & 957.5 & 957.5 & 957.5 & 958 & 957.5 \\
\hline $\mathrm{H} 2 \mathrm{O}$ & $\mathrm{KG} / \mathrm{H}$ & 0 & 0 & 0 & 0 & 0 & 1113.1 & 1113.1 & 1113.1 & 1113 & 1113.1 \\
\hline CARBON & $\mathrm{KG} / \mathrm{H}$ & 824.3 & 0 & 0 & 0 & 0 & 0 & 0 & 0 & 0 & 0 \\
\hline $\begin{array}{l}\text { Mass } \\
\text { Enthalpy }\end{array}$ & $\mathrm{MJ} / \mathrm{KG}$ & 0.6 & -6.3 & 0 & 0 & 0.2 & -2 & -2 & -2.6 & -2.8 & -2.8 \\
\hline
\end{tabular}

Table B1: Stream Table for Biorefinery Scenario NC-100 (continued...)

\begin{tabular}{|c|c|c|c|c|c|c|c|c|c|c|}
\hline Stream & & $\overline{8}$ & రิ & \%ั & ठ্ & น̊ㅇํ & \&ั & ì & $\begin{array}{l}\infty \\
\text { ơ }\end{array}$ & \%े \\
\hline Temperature & C & 100 & 102 & 128 & 228 & 234 & 35 & 234 & 234 & 361 \\
\hline Pressure & BAR & 1.45 & 30 & 30 & 30 & 30 & 1.01 & 29.99 & 29.99 & 29.99 \\
\hline Mass Flow & KG/H & 9482.7 & 9482.7 & 9482.7 & 9483 & 9483 & 284.5 & 284.5 & 9198.2 & 9198.2 \\
\hline \multicolumn{11}{|c|}{ Component Mass Flow } \\
\hline $\mathrm{H} 2 \mathrm{O}$ & $\mathrm{KG} / \mathrm{H}$ & 9482.7 & 9482.7 & 9482.7 & 9483 & 9483 & 284.5 & 284.5 & 9198.2 & 9198.2 \\
\hline Mass Enthalpy & $\mathrm{MJ} / \mathrm{KG}$ & -15.5 & -15.5 & -15.4 & -14.9 & -13.1 & -15.8 & -14.8 & -13 & -12.8 \\
\hline
\end{tabular}

Table B1: Stream Table for Biorefinery Scenario NC-100 (continued...)

\begin{tabular}{|c|c|c|c|c|c|c|c|c|c|c|c|}
\hline Stream & & 옹 & $\vec{g}$ & İ & $\stackrel{m}{9}$ & 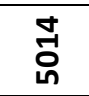 & 年 & 年 & $\begin{array}{l}\infty \\
\stackrel{1}{0} \\
\text { hn }\end{array}$ & 궁 & $\begin{array}{l}\text { ్ㅠ } \\
\text { in }\end{array}$ \\
\hline Temperature & C & 168 & 168 & 60 & 50 & 168 & 110 & 102 & 25 & 25 & 100 \\
\hline Pressure & BAR & 4.5 & 4.5 & 0.2 & 0.2 & 4.5 & 1.43 & 1.45 & 1.01 & 2 & 1.45 \\
\hline Mass Flow & KG/H & 9198.2 & 1230.9 & 1230.9 & 1230.9 & 7967 & 7967.3 & 9198 & 284.5 & 284.5 & 9482.7 \\
\hline \multicolumn{12}{|c|}{ Component Mass Flow } \\
\hline $\mathrm{H} 2 \mathrm{O}$ & $\mathrm{KG} / \mathrm{H}$ & 9198.2 & 1230.9 & 1230.9 & 1230.9 & 7967 & 7967.3 & 9198 & 284.5 & 284.5 & 9482.7 \\
\hline Mass Enthalpy & $\mathrm{MJ} / \mathrm{KG}$ & -13.2 & -13.2 & -13.6 & -15.8 & -13 & -15.5 & -15.5 & -15.9 & -15.9 & -15.5 \\
\hline
\end{tabular}


Table B2: Stream Table for Biorefinery Scenario C-100

\begin{tabular}{|c|c|c|c|c|c|c|c|c|c|c|}
\hline Stream & & চे & ণั & \%̊ & ষ & นn & ஜ & ¿े & \&̊ㅇ & : \\
\hline Temperature & C & 25 & 100 & 130 & 131 & 58 & 58 & 100 & 100 & 100 \\
\hline Pressure & BAR & 1.01 & 1.01 & 1.29 & 1.3 & 1.01 & 1.01 & 1.01 & 1.01 & 1.01 \\
\hline Mass Flow & $\mathrm{KG} / \mathrm{H}$ & 9384.5 & 9384.5 & 40327.6 & 40327.6 & 42960.9 & 6751.1 & 6751.1 & 5480 & 1271.1 \\
\hline \multicolumn{11}{|c|}{ Component Mass Flow } \\
\hline $\mathrm{CO} 2$ & $\mathrm{KG} / \mathrm{H}$ & 0 & 0 & 5047.6 & 5047.6 & 5045.2 & 2.4 & 2.4 & 2.4 & 0 \\
\hline N2 & KG/H & 0 & 0 & 28859.1 & 28859.1 & 28855.2 & 4 & 4 & 4 & 0 \\
\hline $\mathrm{O} 2$ & KG/H & 0 & 0 & 4026 & 4026 & 4025.2 & 0.8 & 0.8 & 0.8 & 0 \\
\hline $\mathrm{H} 2 \mathrm{O}$ & $\mathrm{KG} / \mathrm{H}$ & 9384.5 & 9384.5 & 2394.9 & 2394.9 & 5035.4 & 6744 & 6744 & 5472.9 & 1271.1 \\
\hline Mass Enthalpy & $\mathrm{MJ} / \mathrm{KG}$ & -15.9 & -15.5 & -1.8 & -1.8 & -2.6 & -15.7 & -13.7 & -13.3 & -15.5 \\
\hline \multicolumn{11}{|c|}{ Substream: NCPSD } \\
\hline \multicolumn{11}{|c|}{ Component Mass Flow } \\
\hline EGRANDIS & $K G / H$ & 14076.7 & 14076.7 & 0 & 0 & 0 & 14076.7 & 14076.7 & 0 & 14076.7 \\
\hline
\end{tabular}

Table B2: Stream Table for Biorefinery Scenario C-100 (continued...)

\begin{tabular}{|c|c|c|c|c|c|c|c|c|c|c|c|}
\hline Stream & & $\underset{-}{0}$ & ণ్రి & $\stackrel{m}{0}$ & $\underset{్}{\text { ¿ }}$ & ํㅗㅇ & ஜ & 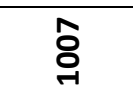 & 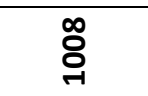 & $\underset{8}{8}$ & 옹 \\
\hline Temperature & C & 0 & 25 & 25 & 25 & 25 & 25 & 25 & 100 & 0 & 89 \\
\hline Pressure & BAR & 0 & 1.01 & 1.01 & 1.01 & 1.01 & 1.01 & 1.01 & 1.01 & 0 & 1.01 \\
\hline Mass Flow & KG/H & 0 & 9384.5 & 9384.5 & 9384.5 & 9384.5 & 8113.4 & 1271 & 1271 & 0 & 1271 \\
\hline \multicolumn{12}{|c|}{ Component Mass Flow } \\
\hline $\mathrm{H} 2 \mathrm{O}$ & KG/H & 0 & 9384.5 & 9384.5 & 9384.5 & 9384.5 & 8113.4 & 1271 & 1271 & 0 & 1271 \\
\hline $\begin{array}{l}\text { Mass } \\
\text { Enthalpy }\end{array}$ & $\mathrm{MJ} / \mathrm{KG}$ & 0 & -15.9 & -15.9 & -15.9 & -15.9 & -15.9 & -15.9 & -15.5 & 0 & -15.6 \\
\hline \multicolumn{12}{|c|}{ Substream: NCPSD } \\
\hline \multicolumn{12}{|c|}{ Component Mass Flow } \\
\hline EGRANDIS & $\mathrm{KG} / \mathrm{H}$ & 14076.7 & 0 & 14076.7 & 14076.7 & 14076.7 & 0 & 14076.7 & 14076.7 & 0 & 14076.7 \\
\hline \multicolumn{12}{|c|}{ Substream: CISOLID } \\
\hline CAO & $\mathrm{KG} / \mathrm{H}$ & 0 & 0 & 0 & 0 & 0 & 0 & 0 & 0 & 6575 & 6575 \\
\hline
\end{tabular}


Table B2: Stream Table for Biorefinery Scenario C-100 (continued...)

\begin{tabular}{|c|c|c|c|c|c|c|c|c|c|c|}
\hline Stream & & ఫ્ઠ & ్ㅜㅇ & 용 & ষ্ণ & 옹 & ஜ̊̊ & ఫ్రి & 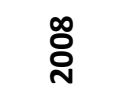 & 옹 \\
\hline Temperature & $\mathrm{C}$ & 89 & 500 & 500 & 500 & 500 & 0 & 0 & 0 & 0 \\
\hline Pressure & BAR & 1.01 & 1.01 & 1.01 & 1.01 & 1.01 & 0 & 0 & 0 & 0 \\
\hline Mass Flow & $\mathrm{KG} / \mathrm{H}$ & 1271 & 12791 & 9598.6 & 9598.6 & 9598.6 & 0 & 0 & 0 & 0 \\
\hline \multicolumn{11}{|c|}{ Component Mass Flow } \\
\hline $\mathrm{CO} 2$ & $\mathrm{KG} / \mathrm{H}$ & 0 & 4905.6 & 1713.2 & 1713.2 & 1713.2 & 0 & 0 & 0 & 0 \\
\hline $\mathrm{CO}$ & $\mathrm{KG} / \mathrm{H}$ & 0 & 79.2 & 79.2 & 79.2 & 79.2 & 0 & 0 & 0 & 0 \\
\hline $\mathrm{H} 2$ & $\mathrm{KG} / \mathrm{H}$ & 0 & 35.9 & 35.9 & 35.9 & 35.9 & 0 & 0 & 0 & 0 \\
\hline $\mathrm{CH} 4$ & $\mathrm{KG} / \mathrm{H}$ & 0 & 629.9 & 629.9 & 629.9 & 629.9 & 0 & 0 & 0 & 0 \\
\hline ETHYLENE & $\mathrm{KG} / \mathrm{H}$ & 0 & 124.1 & 124.1 & 124.1 & 124.1 & 0 & 0 & 0 & 0 \\
\hline ETHANE & $\mathrm{KG} / \mathrm{H}$ & 0 & 31.9 & 31.9 & 31.9 & 31.9 & 0 & 0 & 0 & 0 \\
\hline BUTANE & $\mathrm{KG} / \mathrm{H}$ & 0 & 43.5 & 43.5 & 43.5 & 43.5 & 0 & 0 & 0 & 0 \\
\hline PROPANE & $\mathrm{KG} / \mathrm{H}$ & 0 & 897.4 & 897.4 & 897.4 & 897.4 & 0 & 0 & 0 & 0 \\
\hline CROTONIC & $\mathrm{KG} / \mathrm{H}$ & 0 & 46.9 & 46.9 & 46.9 & 46.9 & 0 & 0 & 0 & 0 \\
\hline 3-METHOX & $\mathrm{KG} / \mathrm{H}$ & 0 & 36.8 & 36.8 & 36.8 & 36.8 & 0 & 0 & 0 & 0 \\
\hline $\mathrm{H} 2 \mathrm{O}$ & $\mathrm{KG} / \mathrm{H}$ & 1271 & 3267.9 & 3267.9 & 3267.9 & 3267.9 & 0 & 0 & 0 & 0 \\
\hline LIGNINA & $\mathrm{KG} / \mathrm{H}$ & 0 & 34.8 & 34.8 & 34.8 & 34.8 & 0 & 0 & 0 & 0 \\
\hline BENZDIOL & $\mathrm{KG} / \mathrm{H}$ & 0 & 34.7 & 34.7 & 34.7 & 34.7 & 0 & 0 & 0 & 0 \\
\hline ACETOL & $\mathrm{KG} / \mathrm{H}$ & 0 & 41 & 41 & 41 & 41 & 0 & 0 & 0 & 0 \\
\hline ISOEUGEN & $\mathrm{KG} / \mathrm{H}$ & 0 & 77 & 77 & 77 & 77 & 0 & 0 & 0 & 0 \\
\hline LEVOG-01 & $\mathrm{KG} / \mathrm{H}$ & 0 & 80.2 & 80.2 & 80.2 & 80.2 & 0 & 0 & 0 & 0 \\
\hline FURAN & $\mathrm{KG} / \mathrm{H}$ & 0 & 482.4 & 482.4 & 482.4 & 482.4 & 0 & 0 & 0 & 0 \\
\hline CELLO-01 & $\mathrm{KG} / \mathrm{H}$ & 0 & 49.5 & 49.5 & 49.5 & 49.5 & 0 & 0 & 0 & 0 \\
\hline DIMETHOX & $\mathrm{KG} / \mathrm{H}$ & 0 & 566 & 566 & 566 & 566 & 0 & 0 & 0 & 0 \\
\hline ABIETIC & $\mathrm{KG} / \mathrm{H}$ & 0 & 49.5 & 49.5 & 49.5 & 49.5 & 0 & 0 & 0 & 0 \\
\hline LIGNINB & $\mathrm{KG} / \mathrm{H}$ & 0 & 44.4 & 44.4 & 44.4 & 44.4 & 0 & 0 & 0 & 0 \\
\hline ACETIC & $\mathrm{KG} / \mathrm{H}$ & 0 & 42.6 & 42.6 & 42.6 & 42.6 & 0 & 0 & 0 & 0 \\
\hline GUAIA-01 & $\mathrm{KG} / \mathrm{H}$ & 0 & 32.1 & 32.1 & 32.1 & 32.1 & 0 & 0 & 0 & 0 \\
\hline SYRIN-01 & $\mathrm{KG} / \mathrm{H}$ & 0 & 35.5 & 35.5 & 35.5 & 35.5 & 0 & 0 & 0 & 0 \\
\hline FORMI-01 & $\mathrm{KG} / \mathrm{H}$ & 0 & 276.6 & 276.6 & 276.6 & 276.6 & 0 & 0 & 0 & 0 \\
\hline N-PRO-01 & $\mathrm{KG} / \mathrm{H}$ & 0 & 42.3 & 42.3 & 42.3 & 42.3 & 0 & 0 & 0 & 0 \\
\hline PHENO-01 & $\mathrm{KG} / \mathrm{H}$ & 0 & 35.9 & 35.9 & 35.9 & 35.9 & 0 & 0 & 0 & 0 \\
\hline TOLUE-01 & $\mathrm{KG} / \mathrm{H}$ & 0 & 541.7 & 541.7 & 541.7 & 541.7 & 0 & 0 & 0 & 0 \\
\hline FURFU-01 & $\mathrm{KG} / \mathrm{H}$ & 0 & 36.9 & 36.9 & 36.9 & 36.9 & 0 & 0 & 0 & 0 \\
\hline BENZE-01 & $\mathrm{KG} / \mathrm{H}$ & 0 & 188.6 & 188.6 & 188.6 & 188.6 & 0 & 0 & 0 & 0 \\
\hline Mass Enthalpy & $\mathrm{MJ} / \mathrm{KG}$ & -15.6 & -6.8 & -6.2 & -6.2 & -6.2 & 0 & 0 & 0 & 0 \\
\hline \multicolumn{11}{|c|}{ Substream: NCPSD } \\
\hline \multicolumn{11}{|c|}{ Component Mass Flow } \\
\hline CHAR & $\mathrm{KG} / \mathrm{H}$ & 0 & 2537.4 & 2537.4 & 2537.4 & 0 & 2537.4 & 0 & 2537.4 & 2537.4 \\
\hline EGRANDIS & $\mathrm{KG} / \mathrm{H}$ & 14076.7 & 0 & 0 & 0 & 0 & 0 & 0 & 0 & 0 \\
\hline BALANCE & $\mathrm{KG} / \mathrm{H}$ & 0 & 19.3 & 19.3 & 19.3 & 0 & 19.3 & 0 & 19.3 & 19.3 \\
\hline \multicolumn{11}{|c|}{ Substream: CISOLID } \\
\hline \multicolumn{11}{|c|}{ Component Mass Flow } \\
\hline CAO & $\mathrm{KG} / \mathrm{H}$ & 6575 & 6575 & 2507.3 & 2507.3 & 0 & 2507.3 & 0 & 2507.3 & 2507.3 \\
\hline СACO3 & $\mathrm{KG} / \mathrm{H}$ & 0 & 0 & 7260.1 & 7260.1 & 0 & 7260.1 & 0 & 7260.1 & 7260.1 \\
\hline
\end{tabular}


Table B2: Stream Table for Biorefinery Scenario C-100 (continued...)

\begin{tabular}{|c|c|c|c|c|c|c|c|c|c|c|c|}
\hline Stream & & ণ্ণ & ్ㅇㅇ & ஜ̊ & ষ্ঠ & 농 & ஜ̊ & 옹 & : & 일 & 옴 \\
\hline Temperature & $\mathrm{C}$ & 500 & 260 & 210 & 80 & 80 & 80 & 60 & 60 & 60 & 60 \\
\hline Pressure & BAR & 1.01 & 1.01 & 1.01 & 1.01 & 1.01 & 1.01 & 1.01 & 1.01 & 1.01 & 1.01 \\
\hline Mass Flow & $\mathrm{KG} / \mathrm{H}$ & 9598.6 & 9598.6 & 9598.6 & 9598.6 & 1969.7 & 7628.9 & 7628.9 & 3314.4 & 580.2 & 2734.1 \\
\hline \multicolumn{12}{|c|}{ Component Mass Flow } \\
\hline $\mathrm{CO} 2$ & $\mathrm{KG} / \mathrm{H}$ & 1713.2 & 1713.2 & 1713.2 & 1713.2 & 0 & 1713.2 & 1713.2 & 0 & 0 & 0 \\
\hline $\mathrm{CO}$ & $\mathrm{KG} / \mathrm{H}$ & 79.2 & 79.2 & 79.2 & 79.2 & 0 & 79.2 & 79.2 & 0 & 0 & 0 \\
\hline $\mathrm{H} 2$ & $\mathrm{KG} / \mathrm{H}$ & 35.9 & 35.9 & 35.9 & 35.9 & 0 & 35.9 & 35.9 & 0 & 0 & 0 \\
\hline $\mathrm{CH} 4$ & $\mathrm{KG} / \mathrm{H}$ & 629.9 & 629.9 & 629.9 & 629.9 & 0 & 629.9 & 629.9 & 0 & 0 & 0 \\
\hline ETHYLENE & $\mathrm{KG} / \mathrm{H}$ & 124.1 & 124.1 & 124.1 & 124.1 & 0 & 124.1 & 124.1 & 0 & 0 & 0 \\
\hline ETHANE & $\mathrm{KG} / \mathrm{H}$ & 31.9 & 31.9 & 31.9 & 31.9 & 0 & 31.9 & 31.9 & 0 & 0 & 0 \\
\hline BUTANE & $\mathrm{KG} / \mathrm{H}$ & 43.5 & 43.5 & 43.5 & 43.5 & 0 & 43.5 & 43.5 & 0 & 0 & 0 \\
\hline PROPANE & $\mathrm{KG} / \mathrm{H}$ & 897.4 & 897.4 & 897.4 & 897.4 & 0 & 897.4 & 897.4 & 0 & 0 & 0 \\
\hline CROTONIC & $\mathrm{KG} / \mathrm{H}$ & 46.9 & 46.9 & 46.9 & 46.9 & 0.8 & 46.1 & 46.1 & 25.3 & 25.3 & 0 \\
\hline 3-METHOX & $\mathrm{KG} / \mathrm{H}$ & 36.8 & 36.8 & 36.8 & 36.8 & 8.1 & 28.7 & 28.7 & 28.7 & 28.7 & 0 \\
\hline $\mathrm{H} 2 \mathrm{O}$ & $\mathrm{KG} / \mathrm{H}$ & 3267.9 & 3267.9 & 3267.9 & 3267.9 & 405.9 & 2862.1 & 2862.1 & 2513.9 & 91.9 & 2422 \\
\hline LIGNINA & $\mathrm{KG} / \mathrm{H}$ & 34.8 & 34.8 & 34.8 & 34.8 & 34.8 & 0 & 0 & 0 & 0 & 0 \\
\hline BENZDIOL & $\mathrm{KG} / \mathrm{H}$ & 34.7 & 34.7 & 34.7 & 34.7 & 34.7 & 0 & 0 & 0 & 0 & 0 \\
\hline ACETOL & $\mathrm{KG} / \mathrm{H}$ & 41 & 41 & 41 & 41 & 6.8 & 34.2 & 34.2 & 34.2 & 25.7 & 8.5 \\
\hline ISOEUGEN & $\mathrm{KG} / \mathrm{H}$ & 77 & 77 & 77 & 77 & 32.2 & 44.8 & 44.8 & 9.3 & 9.3 & 0 \\
\hline LEVOG-01 & $\mathrm{KG} / \mathrm{H}$ & 80.2 & 80.2 & 80.2 & 80.2 & 16.6 & 63.5 & 63.5 & 34.9 & 15.4 & 19.5 \\
\hline FURAN & $\mathrm{KG} / \mathrm{H}$ & 482.4 & 482.4 & 482.4 & 482.4 & 192.1 & 290.3 & 290.3 & 262.7 & 262.7 & 0 \\
\hline CELLO-01 & $\mathrm{KG} / \mathrm{H}$ & 49.5 & 49.5 & 49.5 & 49.5 & 36.8 & 12.8 & 12.8 & 2.8 & 0 & 2.8 \\
\hline DIMETHOX & $\mathrm{KG} / \mathrm{H}$ & 566 & 566 & 566 & 566 & 546.6 & 19.4 & 19.4 & 19.4 & 9.9 & 9.5 \\
\hline ABIETIC & $\mathrm{KG} / \mathrm{H}$ & 49.5 & 49.5 & 49.5 & 49.5 & 49.5 & 0 & 0 & 0 & 0 & 0 \\
\hline LIGNINB & $\mathrm{KG} / \mathrm{H}$ & 44.4 & 44.4 & 44.4 & 44.4 & 44.4 & 0 & 0 & 0 & 0 & 0 \\
\hline ACETIC & $\mathrm{KG} / \mathrm{H}$ & 42.6 & 42.6 & 42.6 & 42.6 & 1.8 & 40.8 & 40.8 & 5.3 & 0 & 5.3 \\
\hline GUAIA-01 & $\mathrm{KG} / \mathrm{H}$ & 32.1 & 32.1 & 32.1 & 32.1 & 32.1 & 0 & 0 & 0 & 0 & 0 \\
\hline SYRIN-01 & $\mathrm{KG} / \mathrm{H}$ & 35.5 & 35.5 & 35.5 & 35.5 & 1.7 & 33.8 & 33.8 & 0 & 0 & 0 \\
\hline FORMI-01 & $\mathrm{KG} / \mathrm{H}$ & 276.6 & 276.6 & 276.6 & 276.6 & 0.1 & 276.6 & 276.6 & 266.6 & 0 & 266.6 \\
\hline N-PRO-01 & $\mathrm{KG} / \mathrm{H}$ & 42.3 & 42.3 & 42.3 & 42.3 & 42.3 & 0 & 0 & 0 & 0 & 0 \\
\hline PHENO-01 & $\mathrm{KG} / \mathrm{H}$ & 35.9 & 35.9 & 35.9 & 35.9 & 35.9 & 0 & 0 & 0 & 0 & 0 \\
\hline TOLUE-01 & $\mathrm{KG} / \mathrm{H}$ & 541.7 & 541.7 & 541.7 & 541.7 & 430.3 & 111.4 & 111.4 & 111.4 & 111.4 & 0 \\
\hline FURFU-01 & $\mathrm{KG} / \mathrm{H}$ & 36.9 & 36.9 & 36.9 & 36.9 & 16.1 & 20.8 & 20.8 & 0 & 0 & 0 \\
\hline BENZE-01 & $\mathrm{KG} / \mathrm{H}$ & 188.6 & 188.6 & 188.6 & 188.6 & 0 & 188.6 & 188.6 & 0 & 0 & 0 \\
\hline CARBON & $\mathrm{KG} / \mathrm{H}$ & 0 & 0 & 0 & 0 & 0 & 0 & 0 & 0 & 0 & 0 \\
\hline $\begin{array}{l}\text { Mass } \\
\text { Enthalpy }\end{array}$ & $\mathrm{MJ} / \mathrm{KG}$ & -6.2 & -6.8 & -6.9 & -7.4 & -3.9 & -8.4 & -8.9 & -12.8 & -3.3 & -14.9 \\
\hline
\end{tabular}


Table B2: Stream Table for Biorefinery Scenario C-100 (continued...)

\begin{tabular}{|c|c|c|c|c|c|c|c|c|c|c|c|c|}
\hline Stream & & $\vec{g}$ & $\underset{n}{\sim}$ & 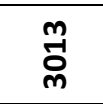 & $\underset{n}{\stackrel{D}{0}}$ & ח. & $\begin{array}{l}0 \\
-1 \\
0\end{array}$ & ने & $\stackrel{\infty}{-1}$ & ণ্: & 유 & స్ \\
\hline Temperature & C & 60 & 40 & 40 & 40 & 20 & 20 & 38 & 20 & 64 & 64 & 64 \\
\hline Pressure & BAR & 1.01 & 1.01 & 1.01 & 1.01 & 1.01 & 1.01 & 1.3 & 1.01 & 1.01 & 2 & 2 \\
\hline Mass Flow & $\mathrm{KG} / \mathrm{H}$ & 4314.5 & 4314.5 & 461.5 & 3853 & 3853 & 3555.2 & 3555.2 & 297.8 & 3309.3 & 3309.3 & 3309.3 \\
\hline \multicolumn{13}{|c|}{ Component Mass Flow } \\
\hline $\mathrm{CO} 2$ & KG/H & 1713.2 & 1713.2 & 0 & 1713.2 & 1713.2 & 1713.2 & 1713.2 & 0 & 0 & 0 & 0 \\
\hline $\mathrm{CO}$ & $\mathrm{KG} / \mathrm{H}$ & 79.2 & 79.2 & 0 & 79.2 & 79.2 & 79.2 & 79.2 & 0 & 0 & 0 & 0 \\
\hline $\mathrm{H} 2$ & $K G / H$ & 35.9 & 35.9 & 0 & 35.9 & 35.9 & 35.9 & 35.9 & 0 & 0 & 0 & 0 \\
\hline $\mathrm{CH} 4$ & $\mathrm{KG} / \mathrm{H}$ & 629.9 & 629.9 & 0 & 629.9 & 629.9 & 629.9 & 629.9 & 0 & 0 & 0 & 0 \\
\hline ETHYLENE & KG/H & 124.1 & 124.1 & 0 & 124.1 & 124.1 & 124.1 & 124.1 & 0 & 0 & 0 & 0 \\
\hline ETHANE & $K G / H$ & 31.9 & 31.9 & 0 & 31.9 & 31.9 & 31.9 & 31.9 & 0 & 0 & 0 & 0 \\
\hline BUTANE & $\mathrm{KG} / \mathrm{H}$ & 43.5 & 43.5 & 0 & 43.5 & 43.5 & 43.5 & 43.5 & 0 & 0 & 0 & 0 \\
\hline PROPANE & KG/H & 897.4 & 897.4 & 0 & 897.4 & 897.4 & 897.4 & 897.4 & 0 & 0 & 0 & 0 \\
\hline CROTONIC & $\mathrm{KG} / \mathrm{H}$ & 20.8 & 20.8 & 7.7 & 13.1 & 13.1 & 0 & 0 & 13.1 & 46.9 & 46.9 & 46.9 \\
\hline 3-METHOX & $\mathrm{KG} / \mathrm{H}$ & 0 & 0 & 0 & 0 & 0 & 0 & 0 & 0 & 36.8 & 36.8 & 36.8 \\
\hline $\mathrm{H} 2 \mathrm{O}$ & KG/H & 348.2 & 348.2 & 290.6 & 57.6 & 57.6 & 0 & 0 & 57.6 & 846 & 846 & 846 \\
\hline LIGNINA & $\mathrm{KG} / \mathrm{H}$ & 0 & 0 & 0 & 0 & 0 & 0 & 0 & 0 & 34.8 & 34.8 & 34.8 \\
\hline BENZDIOL & $K G / H$ & 0 & 0 & 0 & 0 & 0 & 0 & 0 & 0 & 34.7 & 34.7 & 34.7 \\
\hline ACETOL & $\mathrm{KG} / \mathrm{H}$ & 0 & 0 & 0 & 0 & 0 & 0 & 0 & 0 & 32.5 & 32.5 & 32.5 \\
\hline ISOEUGEN & $\mathrm{KG} / \mathrm{H}$ & 35.5 & 35.5 & 35.5 & 0 & 0 & 0 & 0 & 0 & 77 & 77 & 77 \\
\hline LEVOG-01 & $\mathrm{KG} / \mathrm{H}$ & 28.6 & 28.6 & 0 & 28.6 & 28.6 & 0 & 0 & 28.6 & 60.7 & 60.7 & 60.7 \\
\hline FURAN & $\mathrm{KG} / \mathrm{H}$ & 27.5 & 27.5 & 17 & 10.5 & 10.5 & 0 & 0 & 10.5 & 482.4 & 482.4 & 482.4 \\
\hline CELLO-01 & $\mathrm{KG} / \mathrm{H}$ & 10 & 10 & 0 & 10 & 10 & 0 & 0 & 10 & 46.8 & 46.8 & 46.8 \\
\hline DIMETHOX & $\mathrm{KG} / \mathrm{H}$ & 0 & 0 & 0 & 0 & 0 & 0 & 0 & 0 & 556.5 & 556.5 & 556.5 \\
\hline ABIETIC & $\mathrm{KG} / \mathrm{H}$ & 0 & 0 & 0 & 0 & 0 & 0 & 0 & 0 & 49.5 & 49.5 & 49.5 \\
\hline LIGNINB & KG/H & 0 & 0 & 0 & 0 & 0 & 0 & 0 & 0 & 44.4 & 44.4 & 44.4 \\
\hline ACETIC & $\mathrm{KG} / \mathrm{H}$ & 35.5 & 35.5 & 35.5 & 0 & 0 & 0 & 0 & 0 & 37.4 & 37.4 & 37.4 \\
\hline GUAIA-01 & $\mathrm{KG} / \mathrm{H}$ & 0 & 0 & 0 & 0 & 0 & 0 & 0 & 0 & 32.1 & 32.1 & 32.1 \\
\hline SYRIN-01 & $\mathrm{KG} / \mathrm{H}$ & 33.8 & 33.8 & 33.8 & 0 & 0 & 0 & 0 & 0 & 35.5 & 35.5 & 35.5 \\
\hline FORMI-01 & $\mathrm{KG} / \mathrm{H}$ & 10 & 10 & 10 & 0 & 0 & 0 & 0 & 0 & 10.1 & 10.1 & 10.1 \\
\hline N-PRO-01 & $\mathrm{KG} / \mathrm{H}$ & 0 & 0 & 0 & 0 & 0 & 0 & 0 & 0 & 42.3 & 42.3 & 42.3 \\
\hline PHENO-01 & $\mathrm{KG} / \mathrm{H}$ & 0 & 0 & 0 & 0 & 0 & 0 & 0 & 0 & 35.9 & 35.9 & 35.9 \\
\hline TOLUE-01 & KG/H & 0 & 0 & 0 & 0 & 0 & 0 & 0 & 0 & 541.7 & 541.7 & 541.7 \\
\hline FURFU-01 & $\mathrm{KG} / \mathrm{H}$ & 20.8 & 20.8 & 20.8 & 0 & 0 & 0 & 0 & 0 & 36.9 & 36.9 & 36.9 \\
\hline BENZE-01 & $\mathrm{KG} / \mathrm{H}$ & 188.6 & 188.6 & 10.5 & 178 & 178 & 0 & 0 & 178 & 188.6 & 188.6 & 188.6 \\
\hline CARBON & KG/H & 0 & 0 & 0 & 0 & 0 & 0 & 0 & 0 & 0 & 0 & 0 \\
\hline $\begin{array}{l}\text { Mass } \\
\text { Enthalpy }\end{array}$ & $\mathrm{MJ} / \mathrm{KG}$ & -6 & -6.1 & -11.3 & -5.6 & -5.6 & -5.8 & -5.8 & -3.8 & -4.8 & -4.8 & -4.8 \\
\hline
\end{tabular}


Table B2: Stream Table for Biorefinery Scenario C-100 (continued...)

\begin{tabular}{|c|c|c|c|c|c|c|c|c|c|c|c|}
\hline Stream & & 홍 & ญ̊ & ஜ & ষ্ণ & 옹 & ஜ̊ & 용 & 号 & g & 옹 \\
\hline Temperature & $\mathrm{C}$ & 500 & 56 & 25 & 52 & 247 & 1048 & 975 & 300 & 130 & 130 \\
\hline Pressure & BAR & 1.01 & 1.3 & 1.01 & 1.3 & 1.3 & 1.3 & 1.3 & 1.29 & 1.29 & 1.29 \\
\hline Mass Flow & $\mathrm{KG} / \mathrm{H}$ & 0 & 2705.7 & 37621.9 & 37621.9 & 37621.9 & 40327.6 & 40327.6 & 40327.6 & 40327.6 & 40327.6 \\
\hline \multicolumn{12}{|c|}{ Component Mass Flow } \\
\hline $\mathrm{CO} 2$ & KG/H & 0 & 598.3 & 0 & 0 & 0 & 5047.6 & 5047.6 & 5047.6 & 5047.6 & 5047.6 \\
\hline $\mathrm{CO}$ & $\mathrm{KG} / \mathrm{H}$ & 0 & 1094.4 & 0 & 0 & 0 & 0 & 0 & 0 & 0 & 0 \\
\hline $\mathrm{H} 2$ & $\mathrm{KG} / \mathrm{H}$ & 0 & 61.9 & 0 & 0 & 0 & 0 & 0 & 0 & 0 & 0 \\
\hline $\mathrm{CH} 4$ & $\mathrm{KG} / \mathrm{H}$ & 0 & 414.4 & 0 & 0 & 0 & 0 & 0 & 0 & 0 & 0 \\
\hline ETHYLENE & $\mathrm{KG} / \mathrm{H}$ & 0 & 52.2 & 0 & 0 & 0 & 0 & 0 & 0 & 0 & 0 \\
\hline ETHANE & $\mathrm{KG} / \mathrm{H}$ & 0 & 367.1 & 0 & 0 & 0 & 0 & 0 & 0 & 0 & 0 \\
\hline BUTANE & $\mathrm{KG} / \mathrm{H}$ & 0 & 92.3 & 0 & 0 & 0 & 0 & 0 & 0 & 0 & 0 \\
\hline PROPANE & $\mathrm{KG} / \mathrm{H}$ & 0 & 25 & 0 & 0 & 0 & 0 & 0 & 0 & 0 & 0 \\
\hline N2 & $\mathrm{KG} / \mathrm{H}$ & 0 & 0 & 28859.1 & 28859.1 & 28859.1 & 28859.1 & 28859.1 & 28859.1 & 28859.1 & 28859.1 \\
\hline $\mathrm{O} 2$ & $\mathrm{KG} / \mathrm{H}$ & 0 & 0 & 8762.8 & 8762.8 & 8762.8 & 4026 & 4026 & 4026 & 4026 & 4026 \\
\hline $\mathrm{H} 2 \mathrm{O}$ & $\mathrm{KG} / \mathrm{H}$ & 0 & 0 & 0 & 0 & 0 & 2394.9 & 2394.9 & 2394.9 & 2394.9 & 2394.9 \\
\hline $\begin{array}{l}\text { Mass } \\
\text { Enthalpy }\end{array}$ & $\mathrm{MJ} / \mathrm{KG}$ & 0.6 & -4.7 & 0 & 0 & 0.2 & -0.7 & -0.8 & -1.6 & -1.8 & -1.8 \\
\hline
\end{tabular}

Table B2: Stream Table for Biorefinery Scenario C-100 (continued...)

\begin{tabular}{|c|c|c|c|c|c|c|c|c|c|c|}
\hline Stream & & ర్తి & ర్ & ஜ̊ & ষ্ & 농 & ๕̊ํํ & 옹 & : & : \\
\hline Temperature & C & 75 & 76 & 91 & 159 & 234 & 35 & 234 & 234 & 363 \\
\hline Pressure & BAR & 1.45 & 30 & 30 & 30 & 30 & 1.01 & 29.99 & 29.99 & 29.99 \\
\hline Mass Flow & $\mathrm{KG} / \mathrm{H}$ & 15096.8 & 15096.8 & 15096.8 & 15096.8 & 15096.8 & 452.9 & 452.9 & 14643.9 & 14643.9 \\
\hline \multicolumn{11}{|c|}{ Component Mass Flow } \\
\hline $\mathrm{H} 2 \mathrm{O}$ & $\mathrm{KG} / \mathrm{H}$ & 15096.8 & 15096.8 & 15096.8 & 15096.8 & 15096.8 & 452.9 & 452.9 & 14643.9 & 14643.9 \\
\hline Mass Enthalpy & $\mathrm{MJ} / \mathrm{KG}$ & -15.7 & -15.6 & -15.6 & -15.3 & -13.1 & -15.8 & -14.8 & -13 & -12.8 \\
\hline
\end{tabular}

Table B2: Stream Table for Biorefinery Scenario C-100 (continued...)

\begin{tabular}{|c|c|c|c|c|c|c|c|c|c|c|c|}
\hline Stream & & 옹 & 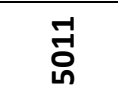 & 공 & $\stackrel{m}{0}$ & 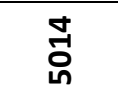 & 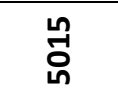 & 今̀ & $\underset{\text { on }}{\infty}$ & 옹 & 유 \\
\hline Temperature & C & 170 & 170 & 60 & 50 & 170 & 110 & 76 & 25 & 25 & 75 \\
\hline Pressure & BAR & 4.5 & 4.5 & 0.2 & 0.2 & 4.5 & 1.43 & 1.45 & 1.01 & 2 & 1.45 \\
\hline Mass Flow & $\mathrm{KG} / \mathrm{H}$ & 14643.9 & 8374.3 & 8374.3 & 8374.3 & 6269.6 & 6269.6 & 14643.9 & 452.9 & 452.9 & 15096.8 \\
\hline \multicolumn{12}{|c|}{ Component Mass Flow } \\
\hline $\mathrm{H} 2 \mathrm{O}$ & $\mathrm{KG} / \mathrm{H}$ & 14643.9 & 8374.3 & 8374.3 & 8374.3 & 6269.6 & 6269.6 & 14643.9 & 452.9 & 452.9 & 15096.8 \\
\hline Mass Enthalpy & $\mathrm{MJ} / \mathrm{KG}$ & -13.1 & -13.1 & -13.6 & -15.8 & -13.1 & -15.5 & -15.6 & -15.9 & -15.9 & -15.7 \\
\hline
\end{tabular}


8.3 Appendix C

Table C1: Purchased equipment costs, installations factors and scaling factors

\begin{tabular}{|c|c|c|c|c|c|c|c|c|}
\hline Equipment & Equipment ID & Base Scale & Unit & Base Purchased Equipment Cost & $\begin{array}{l}\text { Base Year } \\
\text { (CEPCI) }\end{array}$ & Scaling Factor & Installation Factor & Reference* \\
\hline \multicolumn{9}{|l|}{ A000/A11000: Pre-treatment } \\
\hline Hammer Grinder & MILL & 2857 & MT/DAY & $\$ 4081875$ & 2015 & 0.8 & 1.7 & [1] \\
\hline Bale Transport Conveyor & & 2857 & MT/DAY & $\$ 1388963$ & 2015 & 0.8 & 1.7 & [1] \\
\hline Bale Unwrapping Conveyor & & 2857 & MT/DAY & $\$ 521187$ & 2015 & 0.8 & 1.7 & [1] \\
\hline Discharge Conveyor & & 2857 & MT/DAY & $\$ 87299$ & 2015 & 0.8 & 1.7 & [1] \\
\hline Truck Scales & & 2857 & MT/DAY & $\$ 58634$ & 2015 & 0.8 & 1.7 & [1] \\
\hline Truck Unloading Forklift & & 2857 & MT/DAY & $\$ 125085$ & 2015 & 0.8 & 1.7 & [1] \\
\hline Bale Moving Forklift & & 2857 & MT/DAY & $\$ 125085$ & 2015 & 0.8 & 1.7 & [1] \\
\hline Concrete Storage Slab & & 2857 & MT/DAY & $\$ 781780$ & 2015 & 0.8 & 1.7 & [1] \\
\hline Flue Gas Blower & FAN0001 & 204 & $\mathrm{HP}$ & $\$ 59300$ & 2013 & 0.78 & 1.94 & [2] \\
\hline Biomass Preheater & HX0001 & 10 & SQM & $\$ 132000$ & $(1000)$ & 1.04 & 2.4 & [4] \\
\hline Direct Dryer & DR0001 & 7600 & $\mathrm{KG} / \mathrm{H}$ & $\$ 323000$ & 1984 & 0.88 & 1 & [3] \\
\hline Indirect Dryer & HX0002/DR0002 & 100 & SQM & $\$ 155000$ & $(1000)$ & 0.75 & 3 & [4] \\
\hline Biomass/Catalyst Mixer & MIX1001 & 3 & CUM & $\$ 66000$ & $(1000)$ & 0.6 & 2.25 & [4] \\
\hline \multicolumn{9}{|l|}{ A2000: Pyrolysis } \\
\hline Biomass/Catalyst Feeding Bin & & 2222 & MT/DAY & $\$ 395054$ & 2015 & 0.8 & 1.7 & {$[1]$} \\
\hline Pyrolysis Reactor (Incl. Piston Feeder and Furnace) & PYRO & 24 & MT/DAY & $\$ 1016000$ & 2017 & 0.7 & 3 & Quote from supplier \\
\hline Char Cyclone & CY2001 & 2222 & MT/DAY & $\$ 3944673$ & 2015 & 0.8 & 1 & [1] \\
\hline \multicolumn{9}{|l|}{ A3000: Product Recovery } \\
\hline Process Heat Exchanger & $\begin{array}{l}\text { HX3001 } \\
\text { HX3002 }\end{array}$ & 100 & SQM & $\$ 70000$ & $(1000)$ & 0.71 & 5.6 & [4] \\
\hline \multirow{3}{*}{ Condenser } & CON3001 & \multirow{3}{*}{100} & \multirow{3}{*}{ SQM } & \multirow{3}{*}{$\$ 70000$} & \multirow{3}{*}{$(1000)$} & \multirow{3}{*}{0.71} & \multirow{3}{*}{5.6} & \multirow{3}{*}{ [4] } \\
\hline & $\begin{array}{l}\text { CON3002 } \\
\text { CON3003 }\end{array}$ & & & & & & & \\
\hline & CON3004 & & & & & & & \\
\hline \multirow{4}{*}{ Vapour/Liquid Separator } & S3001 & \multirow{4}{*}{20.0} & \multirow{4}{*}{ CUM } & \multirow{4}{*}{$\$ 100000$} & \multirow{4}{*}{$(1000)$} & \multirow{4}{*}{0.52} & \multirow{4}{*}{6.325} & \multirow{4}{*}{ [4] } \\
\hline & S3002A & & & & & & & \\
\hline & S3003 & & & & & & & \\
\hline & S3004 & & & & & & & \\
\hline
\end{tabular}


Stellenbosch University https://scholar.sun.ac.za

Table C1: Purchased equipment costs, installations factors and scaling factors (continued...)

\begin{tabular}{|c|c|c|c|c|c|c|c|c|}
\hline Equipment & Equipment ID & Base Scale & Unit & Base Purchased Equipment Cost & $\begin{array}{c}\text { Base Year } \\
\text { (CEPCI) }\end{array}$ & Scaling Factor & Installation Factor & Reference* \\
\hline Decanter & S3002B & 1013050 & $\mathrm{LB} / \mathrm{H}$ & $\$ 294700$ & 2013 & 0.7 & 1.82 & [2] \\
\hline Aqueous Phase Filter & & 182 & GPM & $\$ 26500$ & 2013 & 0.8 & 1.77 & [2] \\
\hline Aqueous Filter Charge Pump & & 182 & GPM & $\$ 7500$ & 2013 & 0.8 & 4.2 & [2] \\
\hline Bio-oil Pump & P3001 & 23 & KW & $\$ 9500$ & $(1000)$ & 0.79 & 2.793 & [4] \\
\hline Non-condensable Gas Blower & FAN3001 & 10 & CUM/S & $\$ 27750$ & $(1000)$ & 0.93 & 1.7 & [4] \\
\hline \multicolumn{9}{|l|}{ A4000: Heat Recovery } \\
\hline Char Feeding Bin & & 2222 & MT/DAY & $\$ 395054$ & 2015 & 0.8 & 1 & [1] \\
\hline Air Blower & FAN4001 & 10 & $\mathrm{CUM} / \mathrm{s}$ & $\$ 27750$ & $(1000)$ & 0.93 & 1.7 & [4] \\
\hline Air Preheater & $\mathrm{HX} 4002$ & 100 & SQM & $\$ 70000$ & $(1000)$ & 0.71 & 5.6 & [4] \\
\hline Process Heat Exchanger & $\begin{array}{l}\text { HX4001 } \\
\text { HX4003 }\end{array}$ & 100 & SQM & $\$ 70000$ & $(1000)$ & 0.71 & 5.6 & [4] \\
\hline Flue Gas Cyclone & CY4001 & 10 & $\mathrm{CUM} / \mathrm{S}$ & $\$ 35000$ & $(1000)$ & 0.56 & 2.5 & [4] \\
\hline \multicolumn{9}{|l|}{ A5000: Steam and Power Production } \\
\hline BFW Pump & P5001 & 494622 & LB/H & $\$ 304578$ & 2007 & 0.3 & 1.35 & [2] \\
\hline Steam Drum & STEAM & 494622 & $\mathrm{LB} / \mathrm{H}$ & $\$ 104100$ & 2007 & 0.65 & 2.28 & [2] \\
\hline Blowdown Cooler & CON5002 & 381671 & $\mathrm{BTU} / \mathrm{H}$ & $\$ 16780$ & 2007 & 0.65 & 4.32 & [2] \\
\hline Blowdown Flash Drum & & 9892 & $\mathrm{LB} / \mathrm{H}$ & $\$ 47205$ & 2007 & 0.65 & 3.41 & [2] \\
\hline Steam Turbine Generator & $\begin{array}{l}\text { C5001 } \\
\text { C5002 }\end{array}$ & -40418 & HP & $\$ 7700000$ & 2010 & 0.7 & 1.8 & [2] \\
\hline Low Pressure Steam Condenser & CON5001 & 100 & SQM & $\$ 70000$ & $(1000)$ & 0.71 & 2.8 & [4] \\
\hline Low Pressure Steam Condensate Tank & & 500400 & $\mathrm{LB} / \mathrm{H}$ & $\$ 28505$ & 2007 & 0.65 & 6.83 & [2] \\
\hline Low Pressure Steam Condensate Pump & & 247010 & $\mathrm{LB} / \mathrm{H}$ & $\$ 9810$ & 2007 & 0.3 & 4.61 & [2] \\
\hline Condensate Collection Pump & & 247010 & $\mathrm{LB} / \mathrm{H}$ & $\$ 9810$ & 2007 & 0.3 & 4.61 & [2] \\
\hline Condensate Collection Tank & S5002 & 500400 & $\mathrm{LB} / \mathrm{H}$ & $\$ 28505$ & 2007 & 0.65 & 6.83 & [2] \\
\hline BFW EDI and Polishing & & 300000 & $\mathrm{LB} / \mathrm{H}$ & $\$ 1325000$ & 2010 & 0.6 & 2 & [2] \\
\hline EDI Pump & & 247010 & $\mathrm{LB} / \mathrm{H}$ & $\$ 9810$ & 2007 & 0.3 & 4.61 & [2] \\
\hline Condensate Surge Tank & & 500400 & $\mathrm{LB} / \mathrm{H}$ & $\$ 27704$ & 2007 & 0.65 & 6.51 & [2] \\
\hline Deaerator & & 494619 & $\mathrm{LB} / \mathrm{H}$ & $\$ 53299$ & 2007 & 0.65 & 5.07 & [2] \\
\hline Deaerator Packed Column & & 494619 & $\mathrm{LB} / \mathrm{H}$ & $\$ 18405$ & 2007 & 0.65 & 5.18 & [2] \\
\hline BFW Makeup Pump & P5002 & 80411 & $\mathrm{LB} / \mathrm{H}$ & $\$ 6528$ & 2007 & 0.3 & 4.72 & [2] \\
\hline Start-up Boiler & & 204131 & LB/H & $\$ 275500$ & 2013 & 0.6 & 1.69 & [2] \\
\hline
\end{tabular}


Stellenbosch University https://scholar.sun.ac.za

Table C1: Purchased equipment costs, installations factors and scaling factors (continued...)

\begin{tabular}{|c|c|c|c|c|c|c|c|c|}
\hline Equipment & Equipment ID & Base Scale & Unit & Base Purchased Equipment Cost & $\begin{array}{l}\text { Base Year } \\
\text { (CEPCI) }\end{array}$ & Scaling Factor & Installation Factor & Reference* \\
\hline \multicolumn{9}{|l|}{ A6000: Wastewater Treatment } \\
\hline Aerobic Digestion System & & 1000 & MT/DAY & $\$ 1554000$ & 2004 & 0.65 & 3 & [5] \\
\hline \multicolumn{9}{|l|}{ A7000: Utilities } \\
\hline Cooling Tower System & & 7506000 & $\mathrm{LB} / \mathrm{H}$ & $\$ 260852$ & 2010 & 0.78 & 2.47 & [2] \\
\hline Chilled Water System & & 28200000 & BTU/H & $\$ 637500$ & 2011 & 0.6 & 1.8 & [2] \\
\hline Flue Gas Scrubber & & 489600 & $\mathrm{LB} / \mathrm{H}$ & $\$ 436250$ & 2010 & 0.65 & 2.47 & [2] \\
\hline Flue Gas Scrubber Circulation Pump & & 489600 & $L B / H$ & $\$ 12510$ & 2007 & 0.3 & 4.12 & [2] \\
\hline Flue Gas Stack & & 939119 & $L B / H$ & $\$ 169187$ & 2007 & 0.65 & 1.3 & [2] \\
\hline BFW Chemical Pump & & 262454 & $\mathrm{LB} / \mathrm{H}$ & $\$ 3842$ & 2007 & 0.3 & 5.21 & [2] \\
\hline BFW Chemical Storage Tank & & 262454 & $\mathrm{LB} / \mathrm{H}$ & $\$ 22004$ & 2007 & 0.65 & 6.7 & [2] \\
\hline Firewater Pump & & 262454 & $\mathrm{LB} / \mathrm{H}$ & $\$ 23043$ & 2007 & 0.3 & 3.7 & [2] \\
\hline Firewater Storage Tank & & 262454 & $\mathrm{LB} / \mathrm{H}$ & $\$ 229900$ & 2007 & 0.65 & 1.46 & [2] \\
\hline Cooling Water Pump & & 7001377 & $\mathrm{LB} / \mathrm{H}$ & $\$ 239375$ & 2007 & 0.3 & 2.14 & [2] \\
\hline Plant Air Compressor & & 262454 & $\mathrm{LB} / \mathrm{H}$ & $\$ 87922$ & 2007 & 0.3 & 1.57 & [2] \\
\hline Plant Air Receiver & & 262454 & $\mathrm{LB} / \mathrm{H}$ & $\$ 21005$ & 2007 & 0.65 & 5.44 & [2] \\
\hline Instrument Air Dryer & & 262454 & $\mathrm{LB} / \mathrm{H}$ & $\$ 8349$ & 2002 & 0.6 & 2.47 & [2] \\
\hline Ammonia Pump & & 262454 & $\mathrm{LB} / \mathrm{H}$ & $\$ 3842$ & 2007 & 0.3 & 5.21 & [2] \\
\hline Ammonia Storage Tank & & 262454 & $\mathrm{LB} / \mathrm{H}$ & $\$ 15704$ & 2007 & 0.65 & 5.39 & [2] \\
\hline Caustic Pump & & 262454 & $\mathrm{LB} / \mathrm{H}$ & $\$ 4906$ & 2007 & 0.3 & 4.3 & [2] \\
\hline Caustic Storage Tank & & 262454 & $\mathrm{LB} / \mathrm{H}$ & $\$ 16005$ & 2007 & 0.65 & 3.01 & [2] \\
\hline Hydraulic Truck Dump With Scale & & 367437 & $\mathrm{LB} / \mathrm{H}$ & $\$ 80000$ & 1998 & 0.6 & 2.47 & [2] \\
\hline Product Loading Rack & & 262454 & $\mathrm{LB} / \mathrm{H}$ & $\$ 25000$ & 2011 & 1 & 2.47 & [2] \\
\hline \multicolumn{9}{|l|}{ Storage } \\
\hline Bio-oil Storage Tank & T3001 & 50 & GPM & $\$ 442700$ & 2013 & 0.7 & 1.75 & [2] \\
\hline Char/Agri-lime Storage Bin & & 350 & CUM & $\$ 350000$ & $(1000)$ & 0.65 & 2.5 & [4] \\
\hline Biomass Storage Bin & & 350 & CUM & $\$ 350000$ & $(1000)$ & 0.65 & 2.5 & [4] \\
\hline Catalyst Storage Bin & & 350 & CUM & $\$ 350000$ & $(1000)$ & 0.65 & 2.5 & [4] \\
\hline
\end{tabular}

*[1] (Carrasco et al., 2017) [4] (Woods, 2007)

[2] (Dutta et al., 2015) [5] (Jones et al., 2013)

[3] (Amos, 1998) 
Table C2: Installed equipment costs, direct costs, indirect costs, $\mathrm{FCl}$ and TCI for each biorefinery scenario

\begin{tabular}{|c|c|c|c|c|c|c|c|c|c|c|}
\hline Scenario & & & NC-100 & NC-5 & NC-200 & NC-300 & C-100 & C-200 & C-10 & C-300 \\
\hline \multirow{8}{*}{ Installed Equipment Costs } & A1000: Pre-treatment & & $\$ 8843217$ & $\$ 18154051$ & $\$ 32634788$ & $\$ 46689452$ & $\$ 9923272$ & $\$ 38498702$ & $\$ 39591973$ & $\$ 55972836$ \\
\hline & A2000: Pyrolysis & & $\$ 21735295$ & $\$ 40380087$ & $\$ 66691067$ & $\$ 90457375$ & $\$ 27949296$ & $\$ 85783539$ & $\$ 87769462$ & $\$ 116364134$ \\
\hline & A3000: Product Recovery & & $\$ 9339216$ & $\$ 15037968$ & $\$ 22167870$ & $\$ 28091412$ & $\$ 7455856$ & $\$ 17696000$ & $\$ 18012826$ & $\$ 22423916$ \\
\hline & A4000: Heat Recovery & & $\$ 1149868$ & $\$ 2150398$ & $\$ 3574696$ & $\$ 4870134$ & $\$ 1442124$ & $\$ 4475224$ & $\$ 4580111$ & $\$ 6093991$ \\
\hline & $\begin{array}{l}\text { A5000: Steam and Power } \\
\text { Production }\end{array}$ & & $\$ 3085883$ & $\$ 5307565$ & $\$ 8312771$ & $\$ 10954591$ & $\$ 5089947$ & $\$ 14221583$ & $\$ 14527393$ & $\$ 18895397$ \\
\hline & A6000: Wastewater Treatment & & $\$ 2943191$ & $\$ 5208439$ & $\$ 8267751$ & $\$ 10945789$ & $\$ 2943191$ & $\$ 8267751$ & $\$ 8443764$ & $\$ 10945789$ \\
\hline & A7000: Utilities & & $\$ 2024817$ & $\$ 3112018$ & $\$ 4496489$ & $\$ 5670515$ & $\$ 2354721$ & $\$ 5312593$ & $\$ 5407232$ & $\$ 6732019$ \\
\hline & A8000: Storage & & $\$ 5531320$ & $\$ 9839313$ & $\$ 15686582$ & $\$ 20823851$ & $\$ 7150068$ & $\$ 20236577$ & $\$ 20670675$ & $\$ 26848693$ \\
\hline Total Inside-Battery-Limits (ISBL) & & & $\$ 41067597$ & $\$ 75722504$ & $\$ 125068421$ & $\$ 170108373$ & $\$ 46770548$ & $\$ 146453465$ & $\$ 149954373$ & $\$ 200854877$ \\
\hline Total Installed Equipment Cost & & & $\$ 54652808$ & $\$ 99189839$ & $\$ 161832014$ & $\$ 218503120$ & $\$ 64308476$ & $\$ 194491970$ & $\$ 199003436$ & $\$ 264276776$ \\
\hline \multirow{3}{*}{ Direct Costs } & Warehouse & $4 \% I S B L$ & $\$ 1642704$ & $\$ 3028900$ & $\$ 5002737$ & $\$ 6804335$ & $\$ 1870822$ & $\$ 5858139$ & $\$ 5998175$ & $\$ 8034195$ \\
\hline & Site Development & $9 \%$ ISBL & $\$ 3696084$ & $\$ 6815025$ & $\$ 11256158$ & $\$ 15309754$ & $\$ 4209349$ & $\$ 13180812$ & $\$ 13495894$ & $\$ 18076939$ \\
\hline & Additional Piping & $4.5 \% \mathrm{ISBL}$ & $\$ 1848042$ & $\$ 3407513$ & $\$ 5628079$ & $\$ 7654877$ & $\$ 2104675$ & $\$ 6590406$ & $\$ 6747947$ & $\$ 9038469$ \\
\hline Total Direct Cost (TDC) & & & $\$ 61839637$ & $\$ 112441277$ & $\$ 183718987$ & $\$ 248272085$ & $\$ 72493322$ & $\$ 220121326$ & $\$ 225245451$ & $\$ 299426380$ \\
\hline \multirow{5}{*}{ Indirect Costs } & Prorateable costs & $10 \%$ TDC & $\$ 6183964$ & $\$ 11244128$ & $\$ 18371899$ & $\$ 24827209$ & $\$ 7249332$ & $\$ 22012133$ & $\$ 22524545$ & $\$ 29942638$ \\
\hline & Field Expenses & $10 \%$ TDC & $\$ 6183964$ & $\$ 11244128$ & $\$ 18371899$ & $\$ 24827209$ & $\$ 7249332$ & $\$ 22012133$ & $\$ 22524545$ & $\$ 29942638$ \\
\hline & Home Office and Construction Fees & $20 \%$ TDC & $\$ 12367927$ & $\$ 22488255$ & $\$ 36743797$ & $\$ 49654417$ & $\$ 14498664$ & $\$ 44024265$ & $\$ 45049090$ & $\$ 59885276$ \\
\hline & Project Contingency & $10 \%$ TDC & $\$ 6183964$ & $\$ 11244128$ & $\$ 18371899$ & $\$ 24827209$ & $\$ 7249332$ & $\$ 22012133$ & $\$ 22524545$ & $\$ 29942638$ \\
\hline & Other Costs & $10 \%$ TDC & $\$ 6183964$ & $\$ 11244128$ & $\$ 18371899$ & $\$ 24827209$ & $\$ 7249332$ & $\$ 22012133$ & $\$ 22524545$ & $\$ 29942638$ \\
\hline Total Indirect Cost & & & $\$ 37103782$ & $\$ 67464766$ & $\$ 110231392$ & $\$ 148963251$ & $\$ 43495993$ & $\$ 132072796$ & $\$ 135147271$ & $\$ 179655828$ \\
\hline Fixed Capital Investment (FCl) & & & $\$ 98943420$ & $\$ 179906043$ & $\$ 293950380$ & $\$ 397235337$ & $\$ 115989315$ & $\$ 352194122$ & $\$ 360392722$ & $\$ 479082208$ \\
\hline Working Capital & & $5 \% \mathrm{FCl}$ & $\$ 4947171$ & $\$ 8995302$ & $\$ 14697519$ & $\$ 19861767$ & $\$ 5799466$ & $\$ 17609706$ & $\$ 18019636$ & $\$ 23954110$ \\
\hline Land & & & $\$ 531399$ & $\$ 1278758$ & $\$ 2603314$ & $\$ 4008696$ & $\$ 531399$ & $\$ 2603314$ & $\$ 2689066$ & $\$ 4008696$ \\
\hline Total Capital Investment (TCl) & & & $\$ 104421989$ & $\$ 190180104$ & $\$ 311251213$ & $\$ 421105799$ & $\$ 122320179$ & $\$ 372407143$ & $\$ 381101425$ & $\$ 507045014$ \\
\hline
\end{tabular}


Stellenbosch University https://scholar.sun.ac.za

Table C3: Fixed operating costs, variable operating costs and total operating costs for each biorefinery scenario

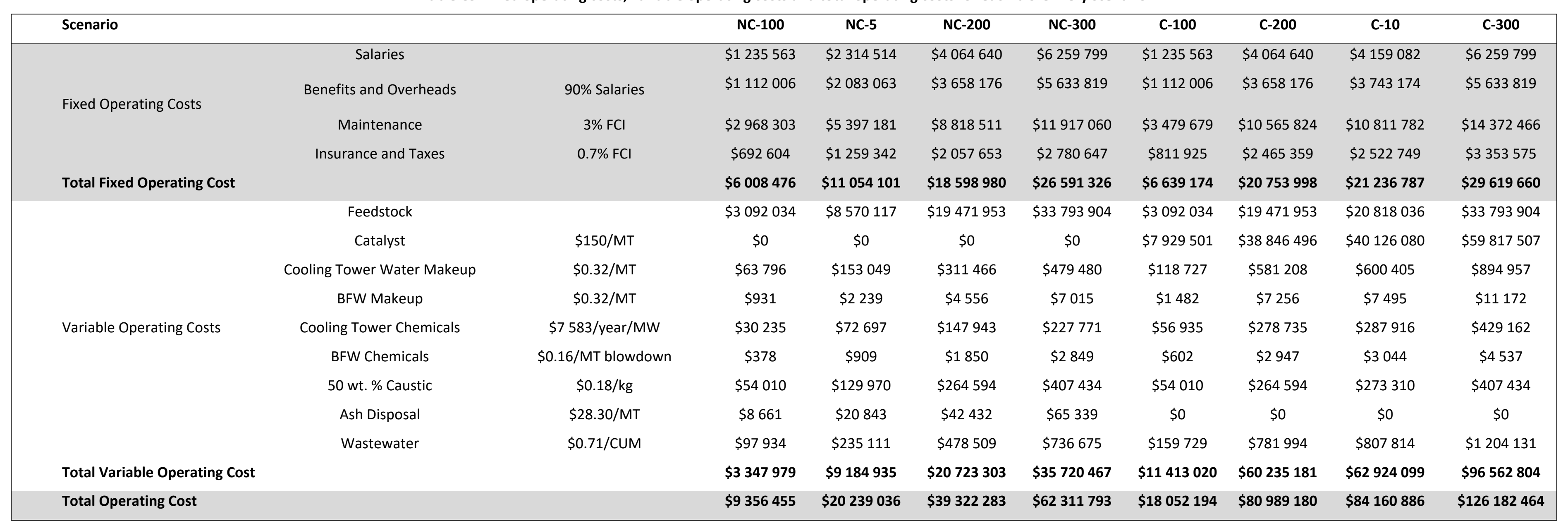




\subsection{Appendix D}

Table D1: LCl for non-catalytic pyrolysis of $1 \mathrm{~kg}$ of dry forest residues in Scenario 1

\begin{tabular}{|lccc|}
\hline Product & Amount & Unit & Alloc. \\
\hline Bio-oil & 0.24737 & $\mathrm{~kg}$ & $50.76 \%$ \\
Biochar & 0.23792 & $\mathrm{~kg}$ & $48.82 \%$ \\
Electricity & 0.05862 & $\mathrm{MJ}$ & $0.41 \%$ \\
\hline Input & Amount & Unit \\
\hline Air & 1.75801 & $\mathrm{~kg}$ \\
Water, unspecified natural origin, ZA & 1.45042 & $\mathrm{~L}$ \\
Transport, tractor and trailer, agricultural \{GLO\}| market for | APOS, S & 1.00000 & $\mathrm{kgkm}$ \\
Wood chipping, chipper, mobile, diesel, at forest road \{GLO\}| market for | APOS, S & 0.00008 & $\mathrm{hr}$ \\
Transport, freight, lorry >32 metric ton, EURO3 \{GLO\}| market for | APOS, S & 596.67 & $\mathrm{kgkm}$ \\
\hline Output & Amount & Unit \\
\hline Carbon dioxide, to soil or biomass stock & 1.74071 & $\mathrm{~kg}$ \\
Carbon dioxide & 0.52813 & $\mathrm{~kg}$ \\
Water & 1.19139 & $\mathrm{~kg}$ \\
Oxygen & 0.06823 & $\mathrm{~kg}$ \\
Nitrogen dioxide & 0.00083 & $\mathrm{~kg}$ \\
Nitrogen, atmospheric & 1.34854 & $\mathrm{~kg}$ \\
Sulphur dioxide & 0.00025 & $\mathrm{~kg}$ \\
Wood ash mixture, pure \{RoW\}| market for wood ash mixture, pure | APOS, S & 0.01040 & $\mathrm{~kg}$ \\
Wastewater, unpolluted \{RoW\}| treatment of, capacity 5E9|/year | APOS, S & 1.18879 & $\mathrm{~L}$ \\
\hline
\end{tabular}


Table D2: LCl for catalytic pyrolysis of $1 \mathrm{~kg}$ of dry forest residues in Scenario 1

\begin{tabular}{|lccc|}
\hline Product & Amount & Unit & Alloc. \\
\hline Bio-oil & 0.23509 & $\mathrm{~kg}$ & $21.13 \%$ \\
Biochar & 0.18026 & $\mathrm{~kg}$ & $15.25 \%$ \\
Agri-lime & 0.69387 & $\mathrm{~kg}$ & $62.31 \%$ \\
Electricity & 0.34429 & $\mathrm{MJ}$ & $1.31 \%$ \\
\hline Input & Amount & Unit \\
\hline Quicklime, milled, packed \{GLO\}| market for | APOS, S & 0.46709 & $\mathrm{~kg}$ \\
Air & 2.67273 & $\mathrm{~kg}$ \\
Water, unspecified natural origin, ZA & 2.66133 & $\mathrm{~L}$ & \\
Transport, tractor and trailer, agricultural \{GLO\}| market for | APOS, S & 1.00000 & $\mathrm{kgkm}$ \\
Wood chipping, chipper, mobile, diesel, at forest road \{GLO\}| market for | APOS, S & 0.00008 & $\mathrm{hr}$ \\
Transport, freight, lorry $>32$ metric ton, EURO3 \{GLO\}| market for | APOS, S & 596.67 & $\mathrm{kgkm}$ \\
\hline Output & Amount & Unit \\
\hline Carbon dioxide, to soil or biomass stock & 1.74071 & $\mathrm{~kg}$ & \\
Carbon dioxide & 0.35859 & $\mathrm{~kg}$ \\
Water & 1.68902 & $\mathrm{~kg}$ \\
Oxygen & 0.28601 & $\mathrm{~kg}$ \\
Nitrogen dioxide & 0.00000 & $\mathrm{~kg}$ \\
Nitrogen, atmospheric & 2.05020 & $\mathrm{~kg}$ \\
Sulphur dioxide & 0.00000 & $\mathrm{~kg}$ \\
Wood ash mixture, pure \{RoW\}| market for wood ash mixture, pure | APOS, S & 0.01040 & $\mathrm{~kg}$ \\
Wastewater, unpolluted \{RoW\}| treatment of, capacity 5E9I/year | APOS, S & 1.92458 & $\mathrm{~L}$ \\
\hline
\end{tabular}


Table D3: LCl for combustion of $1 \mathrm{~kg}$ of dry forest residues in Scenario 1

\begin{tabular}{|lcc|}
\hline Input & Amount & Unit \\
\hline Air & 5.65926 & $\mathrm{~kg}$ \\
\hline Output & Amount & Unit \\
\hline Carbon dioxide, to soil or biomass stock & 1.74071 & $\mathrm{~kg}$ \\
Carbon dioxide & 1.74071 & $\mathrm{~kg}$ \\
Water & 1.22869 & $\mathrm{~kg}$ \\
Oxygen & 0.00000 & $\mathrm{~kg}$ \\
Nitrogen dioxide & 0.00385 & $\mathrm{~kg}$ \\
Nitrogen, atmospheric & 4.34112 & $\mathrm{~kg}$ \\
Sulphur dioxide & 0.00115 & $\mathrm{~kg}$ \\
Wood ash mixture, pure \{RoW\}| market for wood ash mixture, pure | APOS, S & 0.01040 & $\mathrm{~kg}$ \\
\hline
\end{tabular}


Table D4: LCl for producing $1 \mathrm{MJ}$ of crude bio-oil in Scenario 2

\begin{tabular}{|lccc|}
\hline Product & Amount & Unit & Alloc. \\
\hline Bio-oil & 0.0486 & $\mathrm{~kg}$ & $49.93 \%$ \\
Biochar & 0.04834 & $\mathrm{~kg}$ & $49.67 \%$ \\
Electricity & 0.0115 & $\mathrm{MJ}$ & $0.41 \%$ \\
\hline Input & Amount & Unit \\
\hline Air & 0.34535 & $\mathrm{~kg}$ \\
Water, unspecified natural origin, ZA & 0.28487 & $\mathrm{~L}$ \\
Transport, tractor and trailer, agricultural \{GLO\}| market for | APOS, S & 0.19645 & $\mathrm{kgkm}$ \\
Wood chipping, chipper, mobile, diesel, at forest road \{GLO\}| market for | APOS, S & 0.00002 & $\mathrm{hr}$ & \\
Transport, freight, lorry >32 metric ton, EURO3 \{GLO\}| market for | APOS, S & 117.22 & $\mathrm{kgkm}$ \\
\hline Output & Amount & Unit \\
\hline Carbon dioxide, to soil or biomass stock & 0.34196 & $\mathrm{~kg}$ \\
Carbon dioxide & 0.10375 & $\mathrm{~kg}$ \\
Water & 0.23402 & $\mathrm{~kg}$ \\
Oxygen & 0.01340 & $\mathrm{~kg}$ \\
Nitrogen dioxide & 0.00016 & $\mathrm{~kg}$ \\
Nitrogen, atmospheric & 0.26491 & $\mathrm{~kg}$ \\
Sulphur dioxide & 0.00005 & $\mathrm{~kg}$ \\
Wood ash mixture, pure \{RoW\}| market for wood ash mixture, pure | APOS, S & 0.00204 & $\mathrm{~kg}$ \\
Wastewater, unpolluted \{RoW\}| treatment of, capacity 5E9I/year | APOS, S & 0.23350 & $\mathrm{~L}$ \\
\hline
\end{tabular}

Table D5: LCl for transporting 1 MJ of crude bio-oil in Scenario 2

\begin{tabular}{|lcc|}
\hline Input & Amount & Unit \\
\hline Bio-oil & 0.04860 & $\mathrm{~kg}$ \\
Transport, freight, lorry 16-32 metric ton, EURO3 \{GLO\}| market for | APOS, S & 31.587 & $\mathrm{kgkm}$ \\
\hline
\end{tabular}

Table D6: LCI for transporting and applying non-catalytic biochar in Scenario 2

\begin{tabular}{|lcc|}
\hline Input & Amount & Unit \\
\hline Biochar & 0.04834 & $\mathrm{~kg}$ \\
Transport, freight, lorry $>32$ metric ton, EURO3 $\{\mathrm{GLO}\} \mid$ market for | APOS, S & 29.007 & $\mathrm{kgkm}$ \\
\hline Output & Amount & Unit \\
\hline Carbon dioxide & 0.02843 & $\mathrm{~kg}$ \\
Fertiliser, applied (N component) & 0.00018 & $\mathrm{~kg}$ \\
Carbon dioxide, to soil or biomass stock & 0.11374 & $\mathrm{~kg}$ \\
\hline
\end{tabular}


Table D7: $\mathrm{LCl}$ for producing $1 \mathrm{MJ}$ of upgraded bio-oil in Scenario 2

\begin{tabular}{|lccc|}
\hline Product & Amount & Unit & Alloc. \\
\hline Bio-oil & 0.03870 & $\mathrm{~kg}$ & $21.13 \%$ \\
Biochar & 0.02967 & $\mathrm{~kg}$ & $15.25 \%$ \\
Agri-lime & 0.11421 & $\mathrm{~kg}$ & $62.31 \%$ \\
Electricity & 0.05677 & $\mathrm{MJ}$ & $1.31 \%$ \\
\hline Input & Amount & Unit \\
\hline Quicklime, milled, packed \{GLO\}| market for | APOS, S & 0.07688 & $\mathrm{~kg}$ \\
Air & 0.43921 & $\mathrm{~kg}$ \\
Water, unspecified natural origin, ZA & 0.43783 & $\mathrm{~L}$ \\
Transport, tractor and trailer, agricultural \{GLO\}| market for | APOS, S & 0.16460 & $\mathrm{kgkm}$ \\
Wood chipping, chipper, mobile, diesel, at forest road \{GLO\}| market for | APOS, S & 0.00001 & $\mathrm{hr}$ \\
Transport, freight, lorry >32 metric ton, EURO3 \{GLO\}| market for | APOS, S & 98.21 & $\mathrm{kgkm}$ \\
\hline Output & Amount & Unit \\
\hline Carbon dioxide, to soil or biomass stock & 0.28653 & $\mathrm{~kg}$ & \\
Carbon dioxide & 0.05902 & $\mathrm{~kg}$ \\
Water & 0.27793 & $\mathrm{~kg}$ \\
Oxygen & 0.04691 & $\mathrm{~kg}$ \\
Nitrogen dioxide & 0.00000 & $\mathrm{~kg}$ \\
Nitrogen, atmospheric & 0.33691 & $\mathrm{~kg}$ \\
Sulphur dioxide & 0.00000 & $\mathrm{~kg}$ \\
Wood ash mixture, pure \{RoW\}| market for wood ash mixture, pure | APOS, S & 0.00171 & $\mathrm{~kg}$ \\
Wastewater, unpolluted \{RoW\}| treatment of, capacity 5E9|/year | APOS, S & 0.31664 & $\mathrm{~L}$ \\
\hline
\end{tabular}


Table D8: LCl for transporting $1 \mathrm{MJ}$ of upgraded bio-oil in Scenario 2

\begin{tabular}{|lcc|}
\hline Input & Amount & Unit \\
\hline Bio-oil & 0.03870 & $\mathrm{~kg}$ \\
Transport, freight, lorry 16-32 metric ton, EURO3 \{GLO\}| market for | APOS, S & 25.152 & $\mathrm{kgkm}$ \\
\hline
\end{tabular}

Table D9: LCl for transporting and applying catalytic biochar in Scenario 2

\begin{tabular}{|lcc|}
\hline Input & Amount & Unit \\
\hline Biochar & 0.02967 & $\mathrm{~kg}$ \\
Transport, freight, lorry >32 metric ton, EURO3 \{GLO\}| market for | APOS, S & 17.805 & $\mathrm{kgkm}$ \\
\hline Output & Amount & Unit \\
\hline Carbon dioxide & 0.01620 & $\mathrm{~kg}$ \\
Fertiliser, applied (N component) & 0.00019 & $\mathrm{~kg}$ \\
Carbon dioxide, to soil or biomass stock & 0.06482 & $\mathrm{~kg}$ \\
\hline
\end{tabular}

Table D10: LCI for transporting and applying agri-lime in Scenario 2

\begin{tabular}{|lcc|}
\hline Avoided Product & Amount & Unit \\
\hline Soil pH raising agent, as $\mathrm{CaCO}\{$ GLO\}| market for | APOS, S & 0.13738 & $\mathrm{~kg}$ \\
\hline Input & Amount & Unit \\
\hline Agri-lime & 0.11421 & $\mathrm{~kg}$ \\
Transport, freight, lorry $>32$ metric ton, EURO3 $\{\mathrm{GLO}\} \mid$ market for | APOS, S & 68.526 & $\mathrm{kgkm}$ \\
\hline Output & Amount & Unit \\
\hline Carbon dioxide & 0.03735 & $\mathrm{~kg}$ \\
Water & 0.02471 & $\mathrm{~kg}$ \\
Calcium & 0.05490 & $\mathrm{~kg}$ \\
\hline
\end{tabular}

